\title{
The Role of Khatami's Belief System in Changing Iranian Foreign Policy from 1997 to 2005
}

\author{
By
}

\section{AZADEH MOMENI}

A thesis submitted to the Faculty of Graduate and Postdoctoral Affairs in partial fulfillment of the requirements for the degree of

Doctor of Philosophy

in

Political Science

Carleton University

Ottawa, Ontario

@2021 Azadeh Momeni 



\begin{abstract}
This dissertation maps Khatami's belief system and introduce a number of factors that shaped Iranian foreign policy during his presidency from 1997 to 2005. Khatami's intellectual world reflected on Iran's foreign policy and shifted it from a confrontational to a peaceful approach toward both domestic and international communities. The main question of this dissertation is as follows: "what are the underlying reasons for the change of approach in foreign policy under Khatami's presidency and how has this shift been manifested in Iranian foreign policy?" I will argue that the cornerstone of this fundamental change rests on Khatami's intellectual world, and in order to capture the content of his belief system, I will apply the Operational Code analysis.

I have applied Operational Code analysis as the theoretical framework to my research since this approach examines how the decision-maker perceives world politics - whether as conflictual or harmonious - and then decides what strategy he/she would adopt to achieve their goals. As this dissertation shows, Khatami believed that conflict was not a permanent feature of the international system; therefore, he followed a cooperative approach on the foreign policy front. The outcome of this new approach was Dialogue among Civilizations, instead of Clash of Civilizations. Based on this worldview, Iran, under Khatami, experienced the most peaceful relations with the international community since the inception of the Islamic Revolution in 1979.
\end{abstract}




\section{Acknowledgements}

I express my deep gratitude to Prof. Farhang Rajaee, my supervisor, for his valuable supervision. I am also grateful to Prof. Hans-Martin Jaeger, and Prof. Mira Sucharov, the committee members, for their very insightful and constructive guidance. Last but not least, I am thankful to my husband, Dr. Hamed Layssi, for his endless love and encouragement.

This dissertation is dedicated to my mother, Shahnaz Khorrami, and my father, Siamak Momeni. 


\section{Table of Contents}

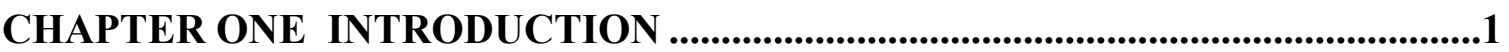

Khatami's Approach to Foreign Policy ………………….................................... 3

Iranian Foreign Policy and International Relations Theories .................................... 4

1. Classical Realism and Iran's Foreign policy ............................................... 4

2. Structural Realism and Iran's Foreign Policy …………………...................... 9

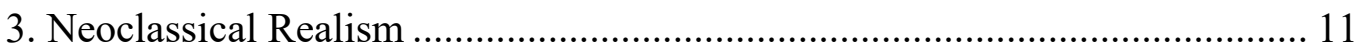

3. Discursive Analysis, Constructivism, and Iran's Foreign Policy .................... 11

4. Domestic Politics and Iran's Foreign Policy ................................................. 16

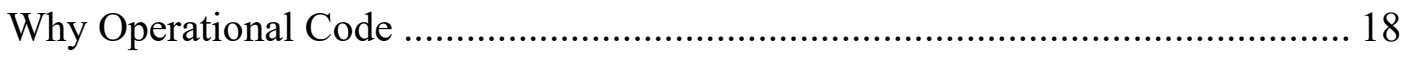

International Politics and Foreign Policy Analysis................................................ 20

Operational Code as The Theoretical Framework ………...................................... 25

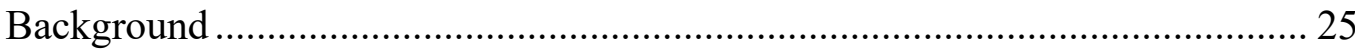

The Operational Code Quantified ..................................................................... 26

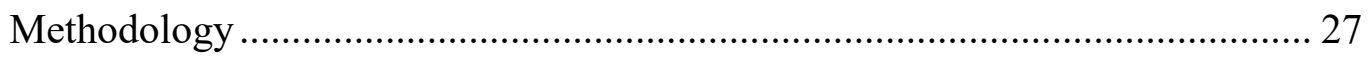

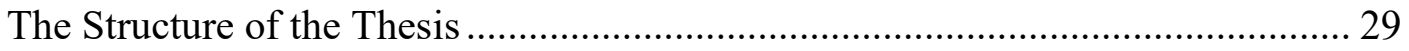

CHAPTER TWO POST-REVOLUTIONARY IRANIAN FOREIGN POLICY.....32

The Political System in Iran, with the Focus of Relationship Between the Supreme

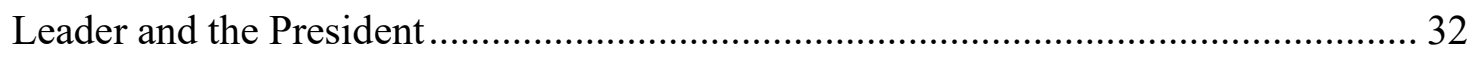


Iranian Foreign Policy Under Khomeini (1979-1989)........................................ 40

Iranian Foreign Policy Under Rafsanjani (1989-1997) ........................................ 44

Iranian Foreign Policy Under the Khatami Presidency (1997-2005) .................. 51

Iranian Foreign Policy Under Ahmadinejad (2005-2013) ................................. 54

Iranian Foreign Policy Under Rouhani (2013-present) ...................................... 59

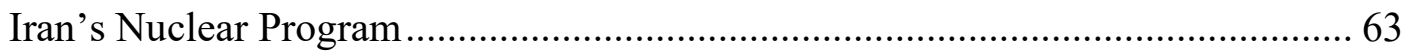

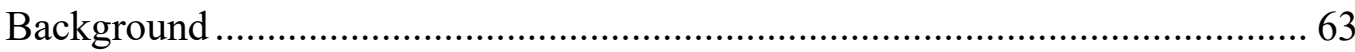

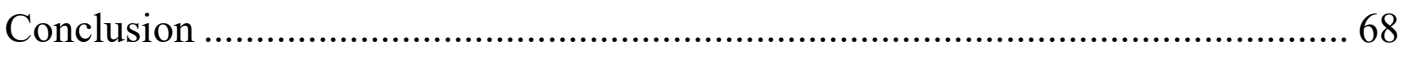

CHAPTER THREE OPERATIONAL CODE ANALYSIS ..........................................70

Historical Background ................................................................................. 70

Actors, Structures, and Foreign Policy Analysis ...................................................... 71

Role of Actors and Structures in "Process" Approaches to Foreign Policy ....... 72

Role of Actors and Structure in "Policy" Approaches to Foreign Policy ............ 73

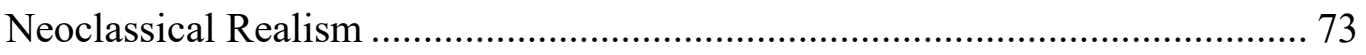

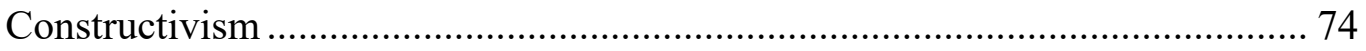

Approaches from an Actor-Based Perspective ...................................................... 77

Traditional Approaches to Foreign Policy Analysis (FPA) and its Criticism .... 78

Foreign Policy Analysis and Behavioural International Relations ......................... 82

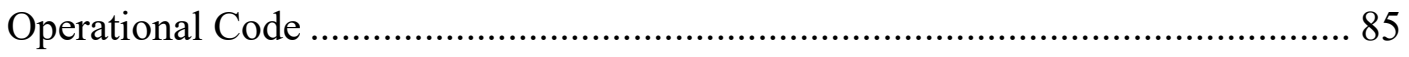

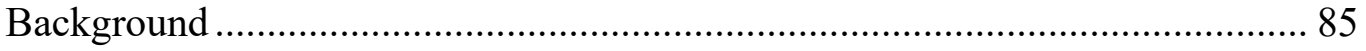


What Are Beliefs? 87

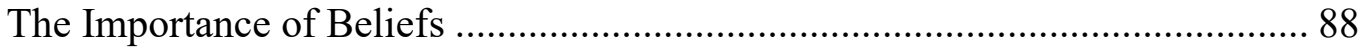

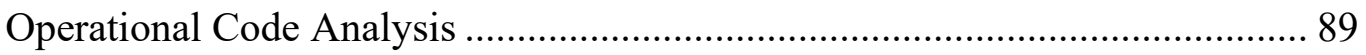

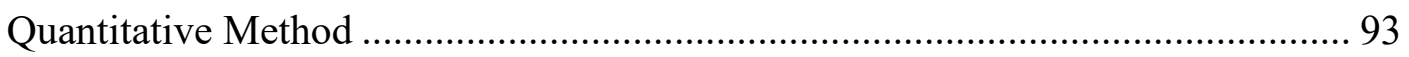

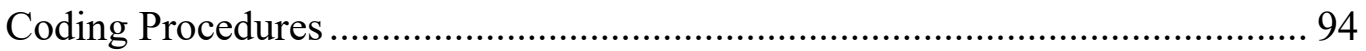

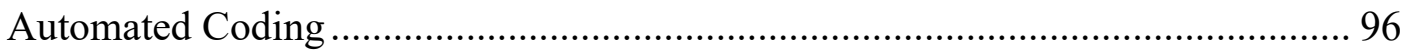

Operational Code Analysis at Distance: The Verbs In Context System (VICS) .... 96

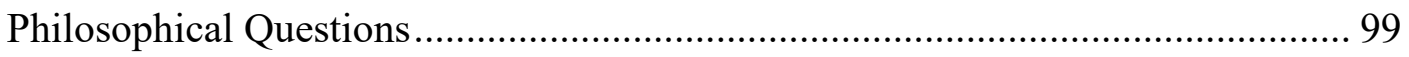

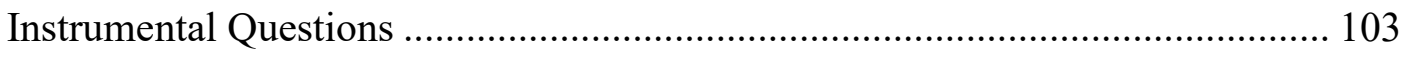

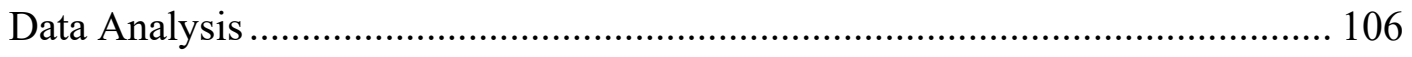

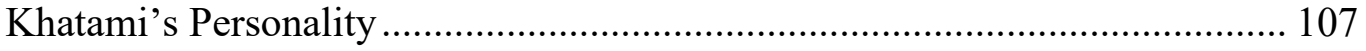

Analysis of Khatami's Operational Code ................................................. 108

Comparison Between Ahmadinejad's Operational Code and Khatami's

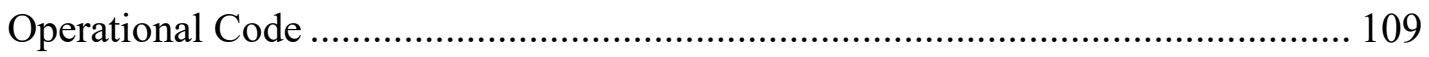

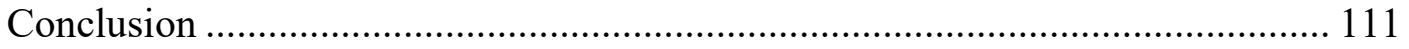

\section{CHAPTER FOUR DIALOGUE AMONG CIVILIZATIONS ..................................113}

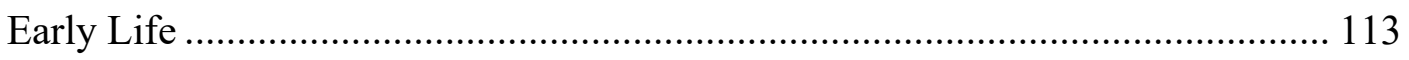

Iran's 1997 Presidential Election ............................................................... 117

Khatami's Thoughts and Worldview ......................................................... 123

How Khatami Views the West: Enemy or Counterpart? ................................. 125 
"Self" and "Other" in Khatami's Worldview

Post Cold War International Order Theses ......................................................... 133

Huntington and Khatami: Similarities and Differences....................................... 135

Criticism of Huntington's Civilizational-Based Approach.................................... 137

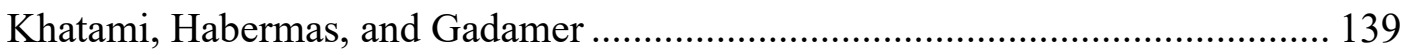

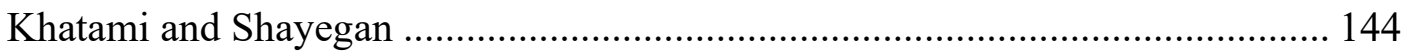

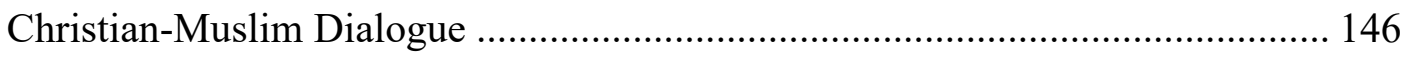

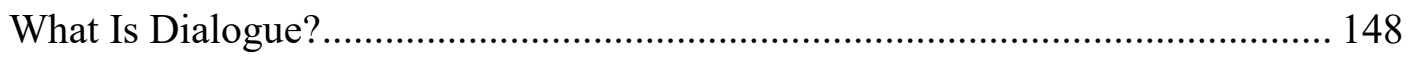

How A Dialogue Among Civilizations Can Be Achieved.................................... 152

Khatami's Discourse of Dialogue Among Civilizations ....................................... 153

General Principles of Dialogue Among Civilizations ........................................... 162

The United Nations and the Year of Dialogue Among Civilizations .................... 164

The Role of International Organizations........................................................... 165

Berlin International Symposium on Dialogue among Civilizations and Cultures 168

Tunis Appeal on Dialogue Among Civilizations .................................................... 169

Damascus Declaration on Dialogue Among Civilizations for Coexistence ……. 170

Tehran Declaration on Dialogue Among Civilizations ........................................ 170

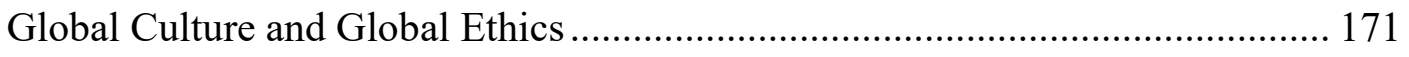

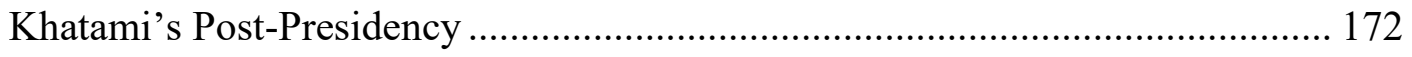

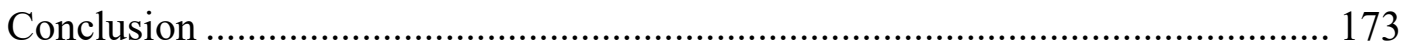




\section{CHAPTER FIVE IRANIAN FOREIGN POLICY UNDER KHATAMI

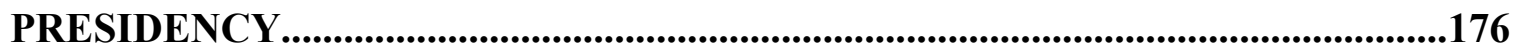

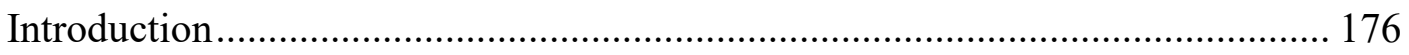

Iranian Foreign Policy Under Khatami’s Presidency (1997-2005) ....................... 176

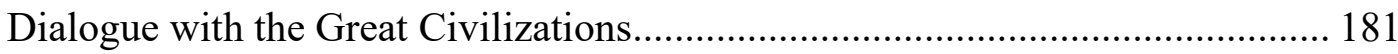

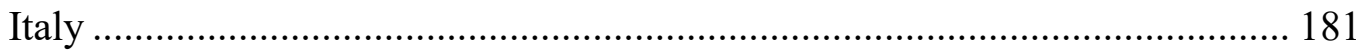

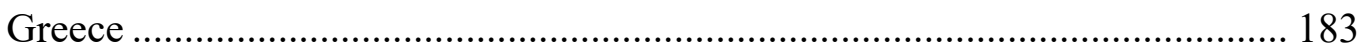

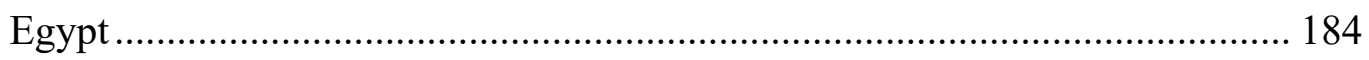

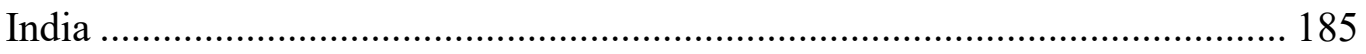

Organization of Islamic Conference (OIC) …………........................................ 186

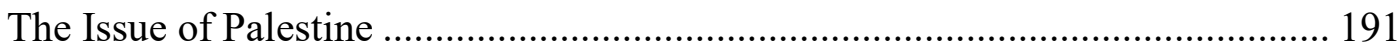

Relations with Persian Gulf Arab States.............................................................. 192

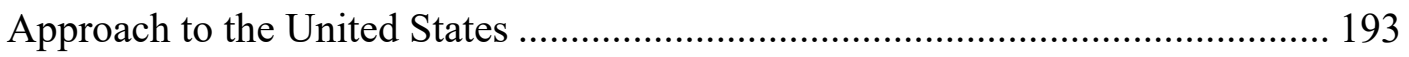

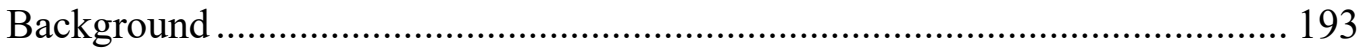

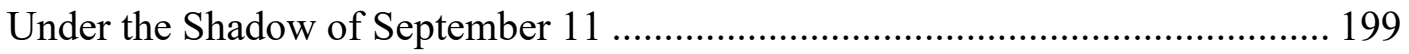

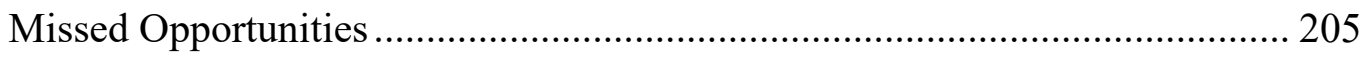

Relations with the European Union .................................................................. 208

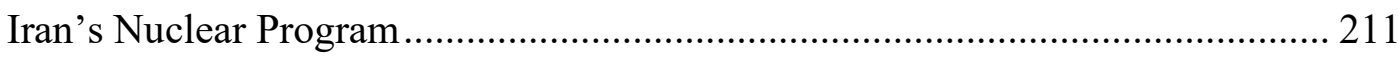

Iraqi Invasion of Kuwait in 2003 and Iran's Approach ...................................... 212

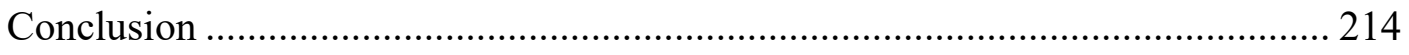




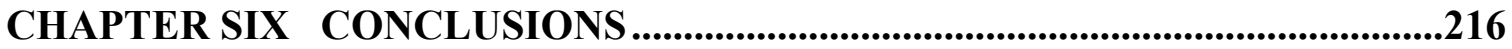

REFERENCES

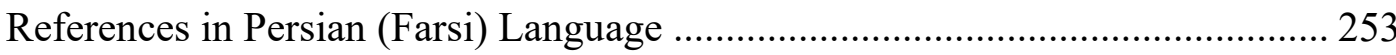

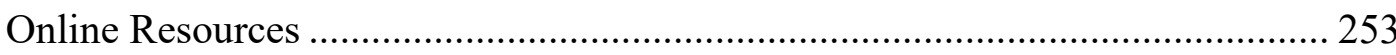

Appendix 1 Khatami's Operational Code Analysis ...........................................................A1

Appendix 2 Text Analysis................................................................................................ B1

Appendix 3 Documents on International Meetings and Conferences...........................C1 


\section{CHAPTER ONE}

\section{INTRODUCTION}

This dissertation maps Khatami's belief system and introduce a number of factors that shaped Iranian foreign policy during his presidency from 1997 to 2005. Khatami's intellectual world reflected on Iran's foreign policy and shifted it from a confrontational to a peaceful approach toward both domestic and international communities. The main question of this dissertation is as follows: "what are the underlying reasons for the change of approach in foreign policy under Khatami's presidency and how has this shift been manifested in Iranian foreign policy?" I will argue that the cornerstone of this fundamental change rests on Khatami's intellectual world, and in order to capture the content of his belief system, I will apply the Operational Code analysis.

Some scholars suggest that the main principles of Iran's foreign policy during the last four decades have remained the same, and that the few changes in Iran's behaviour are mostly tactical, not strategic (Dehshiri, 2001; Haji Yousefi, 2008; Ehteshami, 1995, 2014). According to this perspective, these tactical changes can be attributed to factors like the socialization of the decision-makers, internal pressures on the government, economic sanctions, and the need for change in order to ensure the survival of the current regime. Furthermore, scholars who share this perspective hold that the Iranian supreme leader is the final arbiter in Iran's foreign policy decision-making process and as such Iran continues to act and make decisions based on the ideologies of the Islamic Revolution (Hunter, 2010; Ramazani, 1989). 
Other analysts primarily base their explanations of Iranian foreign policy on the assumption that Iran is a rational actor, which means that its survival has been the most important determining element in shaping its foreign policy. In other words, Iranian leaders have had an important role in foreign policy decision-making purely from a cost-benefit calculation. According to this view, the foreign policy of Iran has gone through strategic shifts during the last few decades. For instance, Iran's acceptance of the Security Council Resolution 598 regarding the termination of the Iran-Iraq war, the foreign policy of dialogue and cooperation proposed by President Khatami, the foreign policy of confrontation and conflict carried out by Ahmadinejad, and the moderate foreign policy supported by Rouhani are a few examples of the broad changes that have occurred in Iranian foreign policy (Kazemzadeh, 2007; Abedin, 2011).

Although I agree with the second group that Iranian foreign policy has gone through shifts during different periods, I go further by arguing that under Khatami, such changes led to positive and constructive foreign relations. Specifically, compared to its predecessors and successors, the Iranian regime under Khatami experienced more peaceful relations with the international community. I suggest that the main reason for this paradigm shift lies in Khatami's belief system and worldview rather than in the realist explanation based on seeking power and survival, or the neorealist explanation of distribution of power across the international system. In other words, I claim that the main determining elements in shaping Iranian foreign policy depend on how Iranian presidents and their supporters view themselves and others and what strategy they pursue in order to achieve their goals according to that view. Ahmadinejad, for instance, viewed the world as a conflictual environment, which convinced him to pursue assertive and aggressive foreign policy. In 
contrast, Khatami viewed the political world as harmonious. He believed that with dialogue and meaningful relations, Iran could achieve coexistence with all the international community members, even the United States, which has been called The Great Satan since the Islamic Revolution. Like Khatami, Rouhani suggests that in order to solve the country's problem with the rest of the world, Iran must revise its foreign policy direction. Indeed, by introducing moderation in foreign policy, Rouhani has been pursuing constructive conversations with other countries. In fact, Rouhani has followed Khatami's approach regarding Iran's foreign behaviour. In sum, I argue that the Iranian decision-makers' belief systems can best explain the different approaches in post-revolutionary foreign policy.

\section{Khatami's Approach to Foreign Policy}

When Khatami assumed office, Iran had been isolated in the international community. He attempted to put an end to this isolation, having to move quickly to tear down "the wall of mutual distrust," as he called it, with other nations. A fragile relationship with the European Union, and apparent suspicion by Sunni Muslim countries regarding the Islamic Republic's propagation of Shi'ism in the region (e.g., Lebanon, Bahrain, Saudi Arabia) were some of the challenges to his foreign policy agenda (Amuzegar, 2006, p. 67). To remove these challenges, Khatami emphasized the importance of Iran to adopt a pragmatic, cooperative and responsible foreign policy that was respectful of international norms. He stressed the right of nations to self-determination and insisted that Iran did not seek to

dominate neighbouring states. He advocated the breaking down of Iran's isolation by introducing the discourse of "Dialogue among Civilizations". 
Khatami made rapid early progress in reorienting Iranian foreign policy. He insisted that his policies were based on détente, mutual respect, and dialogue, and that his government would avoid any conflict with Iran's neighbours. In 1999, Khatami visited Riyadh. By seeking détente with Saudi Arabia and pursuing a good neighbour policy, he also hoped to normalize relations with the Persian Arab states. Far from the harsh rhetoric of his predecessors and successors he emphasized that "cultivating confidence is the first and most appropriate strategic approach to ensuring regional security by regional powers themselves" (quoted in Jones, 2009).

\section{Iranian Foreign Policy and International Relations Theories}

Iran's post-revolutionary foreign policy has been studied from different perspectives, including realism, structural realism, discourse analysis, and constructivism. In addition, some scholars suggest that in the formulation of Iran's foreign policy, ideology and domestic structure have a more important role compared to the other elements. I will discuss the main arguments of each perspective in the following paragraphs.

\section{Classical Realism and Iran's Foreign policy}

According to realism, states are the main actors in the international system. States must pursue power to survive since in a hostile and threatening environment, they can only rely on themselves. For realists, however, the survival of the state can never be guaranteed because the use of force is a legitimate instrument among all states. Power is central to realist thought and traditionally has been narrowly defined in military-strategic terms. Yet, regardless of how much power a state may possess, the core national interests of all states must be survival (Schmidt, 2005, p. 164). 
Realists are skeptical of the idea that universal moral principles exist and, therefore, warn state leaders against sacrificing their own self-interest to some notion of ethical conduct. Indeed, realists argue that the need for survival requires state leaders to distance themselves from traditional morality, which attaches a positive value to caution, piety, and the greater good for humankind as a whole (Schmidt, 2005, p. 163). The subordination of morality to power is often presented as a descriptive statement of the fact of international political life. "The actions of states are determined not only by moral principles and legal commitments but by considerations of interest and power" (Morgenthau 2005, p. 382).

Among realist thinkers who analyze Iranian foreign policy, R. Ramazani (2004, 1966, 1975, 1986) posits that the balance between ideology and pragmatism has been one of the more complicated and difficult issues in Iranian foreign policy. He maintains that from the creation of the Iranian state to the present time, pragmatism rather than ideology has dominated in foreign policy decision making. In this context, acts of pragmatism are defined as those which are employed to ensure Iran a beneficial outcome (Barnelkow Rasmussen, 2009, p. 2).

Ramazani gives different examples ranging from the era of Cyrus the Great to the period of the Sasanid dynasty (224 AD-651AD) and that of the Safavids (1500-1736 AD) to the First and Second Pahlavi regimes (1925-1979). The continuing dominance of pragmatism over ideological influence, according to him, can be traced even after the revolution; and the most outstanding example of this trend was the secret purchase of arms from the United States, "he Great Satan" and Israel, "the lesser Satan" during the Iran-Iraq war (Ramezani, 2004, pp. 549-559). 
In a similar line of argument, Perthes (2010) argues that Iran has been a pragmatic actor in relations with its Arab neighbours, as well as with the states of Central Asia, Iraq, Afghanistan, Pakistan, Russia, and China. For instance, Iran did not support the anti-regime movement in the states of Central Asia, Russia's Caucasus republics, or among China's Muslim minorities. Iranian policymakers have repeatedly stressed that Iran's national interests demand stability on its borders, good relations with neighbouring states, and, in fragmented societies such as Iraq, that involves good relations with all constituent groups, not just the Shia majority. Transborder threats to stability such as drug trafficking from Afghanistan are of particular concern and certainly leave no place for ideology (97-8).

Like Ramazani and Perthes, Tarock (1999) suggests that in the 1990s, pragmatism under the Rafsanjani administration became dominant compared to the early years of the revolution. He argues that although Iranian foreign policy makers may sometimes express their policy in religious terms, in practice their actions are based more on Iran's national interests. To support his claim, he refers to the conflict between Christian Armenia and the Muslim Republic of Azerbaijan, in which Tehran took the former's side to neutralize Turkey's influence in Central Asia. Moreover, Iran remained neutral in the war between Russia and Muslim Chechnya because the former's friendship was deemed better to serve Iran's interests (37-38). One could argue that it might also be because Chechnya has a predominantly Sunni Muslim population. The Iranian government has indeed supported Shia movements, but in this case, because of the friendship/benefits of Russia-Iran relations, Iran remained neutral. Therefore, interests were more important than Shia/Sunni contradiction. 
Some realist thinkers suggest that geography has played a key part in the formation of Iran's foreign policy for centuries, which has had two consequences. On the one hand, "it has facilitated the spread of Persian influences in Asia, on the other, it has exposed Iran to great power rivalries and the diplomatic machinations of out-of-area states" (Ehteshami 2002, p. 283; Amir-Arjomand, 2007; Barzegar 2010).

This focus on geography as the major influence in determining Iran's foreign policy follows from the fact that Iran largely shares its borders with politically unstable neighbouring countries. To its east, Iran must contend with Pakistan and Afghanistan, two increasingly volatile states; to its west, Iran has to cope with the bankrupt state of Iraq; to its north lie the unpredictable former Soviet states and to its south lie the totalitarian, security-reliant Persian Gulf states, all of which are likely to go through political and social changes at any given time. Barzegar insists that this highly insecure environment could most likely lead to the proliferation of local rivalries, military conflict, and possibly the presence of foreign powers in the region (2010, p. 180). Middle Eastern instability, the Israeli-Palestinian conflict, and Persian Gulf security largely influence Iran's foreign policy (Perthes, 2010, p. 95). Thus, Iran's geographical location presents unique geostrategic concerns. These concerns are further exacerbated by the fact that Iran's former sole regional partner, Syria, has been struggling with civil war since 2011. It follows that the preservation of Iran's territorial integrity, as well as the military capabilities to do so constitute one of Iran's top priorities (Sahimi, 2013).

In addition to geography, another key element influencing foreign policy has been nationalism. Historically, fears and perceptions of foreign interference have formed the basis of Iranian nationalism. Nationalism has for generations been intertwined with 
ensuring Iran's territorial integrity, which, in turn, has created what Fuller calls "an intensely Irano-centric" view of the world (1991, p. 2). Geopolitics, therefore, has had-and continues to have-a special place in the shaping of Iran's foreign policy.

Takeyh maintains that Iranians have been influenced by a unique sense of their history, civilization, and empires. For instance, the Achaemenid Empire of the sixth century B.C. was the first global power, governing land spanning from Greece to India. Sassanians and Safavids ruled over vast domains as well. According to Takeyh, a sense of superiority over their Arab and Turk neighbours would define the core of the Persian cosmology. Although the Persian empire shrank over centuries with the arrival of western powers, a selfperception based on an exaggerated view of Iran remained largely intact. He further argues that western powers proved to be the most challenging to Iran. "These states could neither be absorbed as the Arabs were, nor did they necessarily defer to Persians for the management of their realm". In a sense, Iran became a victim of the "Great Game", played by the British and the Russians for the domination of Central Asia, and later the Cold War rivalry between America and the Soviet Union. Although it was true that Iran was never formally colonized, it was still dominated by imperial actors. Furthermore, the humiliating conquest by Mongols and Arabs has left Iran profoundly suspicious of its neighbours' intentions and motives (2006, pp. 60-62). Such emotions linked to historical events, combined with Iran's geopolitics as an element of realism, have played a crucial role in forming Iran's approach to the nuclear program, which I will develop in this dissertation.

From a similar perspective, Perthes maintains that the U.S.-supported Iranian coup in 1953, which replaced a popular prime minister with an unpopular Shah, and the support of Iraq by the United States and most of the Arab states during the eight-year war with Iran, 
have created a feeling of constant victimization. The result of this victim narrative has strengthened the belief that Iran has to defend its independence at all costs and has to resist oppressive forces in the world (2010, p. 96-97). In other words, two concepts of realism, namely, survival and self-help can be traced here. The experience led Iran to the conclusion that, to maintain its security and survival, it needed to achieve and use all means available without relying on other countries.

\section{Structural Realism and Iran's Foreign Policy}

This form of realism is most associated with Waltz's Theory of International Politics, which defines the structure of the international system in terms of three elements: organizing principle, differentiation of units, and distribution of capabilities. Waltz identified two distinct organizing principles: anarchy, which corresponds to the decentralized reality of international politics, and hierarchy, which is the basis of the domestic order. Anarchy, as Waltz claims, largely eliminates functional differentiation between the units, which means that differences between states "are of capability, not of function" $(1979$, p. 96). There is a difference between domestic politics and international politics, according to Waltz. The former consists of differentiated units performing specified functions, while the latter involves like units engaging in the same activities (1979, p. 97). As structural realism considers the units of the international system as functionally similar sovereign states, unit-level variation is irrelevant in explaining international outcomes. Therefore, the third principle, namely the distribution of capabilities across units, is the key element to understanding international politics along with anarchy. 
Offensive realism assumes that security is scarce, and states try to achieve it by maximizing their relative gains. From that perspective, states' pursuit of security might lead to conflict among them. For offensive realists, domestic differences between states are relatively unimportant, because pressures from the international system are assumed to make similarly situated states behave alike, regardless of their internal characteristics. Therefore, to understand a state's foreign policy, one should examine its relative capabilities and its external environment (Rose, 1998, p. 149). Defensive realism, in contrast, assumes that security is often plentiful rather than scarce. Thus, states only respond to external threats, which are rare. Even then, such states respond to these threats by balancing against them, which deters the threatener and hinders the need for actual conflict (Rose,1998, p. 150).

Defensive realism evaluates Iran's from its threat perception. Iran is located in a region where Israel and Saudi Arabia possess much greater military capabilities. Moreover, the U.S. invasion of Iraq and Afghanistan led to Iran feeling encircled by hostile forces. Thus, according to defensive realism, Iran would seek to maximize its security by counterbalancing through internal and external means. Internal balancing is performed by aggressively pursuing the development of asymmetric military capabilities and by progressing with its nuclear program, while external balancing is pursued by developing ties with allies such as Hezbollah and Hamas and other groups in Iraq (Juneau, 2015).

From a security-seeking perspective, Iran's position in a region surrounded by U.S.backed adversaries stocked with advanced weapons, and the belief that the U.S.'s ultimate objective is to weaken and isolate the country intensifies its sense of vulnerability. This 
situation leads to a security dilemma which results in Iran's attempts to build up its own capabilities (Tabatabai and Tracy, 2017, p. 152-7).

\section{Neoclassical Realism}

Neoclassical realism incorporates two elements of domestic politics and the nature of the international system to explain the state's foreign policy. In this regard, Ripsman (2017) argues that according to neoclassical realism states respond primarily to constraints and opportunities coming from the international system when they conduct their foreign policies; however, those responses are shaped by unit-level factors, such as state-society relations, the nature of their political regime, strategic culture, and leader perceptions.

Thomas Juneau, from the neoclassical realist perspective, argues for what he calls a "strategic analysis variant." He maintains that the distribution of capabilities produces constraints and opportunities for states. These constraints and opportunities are permissive causes that, in certain alignments, create windows of opportunity. Juneau claims that states should use these windows to achieve their goals (2015, pp. 12-13). In the case of Iran, he explains that how "Iran aspires to a certain status but how status is ascribed to it by other actors, primary the United States, resulting in discrepancy and therefore a foreign policy of revisionism" (2015, p. 43).

\section{Discursive Analysis, Constructivism, and Iran's Foreign Policy}

Discourse analysis and constructivism have been very popular among Iranian scholars. There is a considerable amount of work dedicated to analyzing Iran's foreign policy from discourse analysis and a constructivist point of view. 
Discourses are systems of signification that construct social reality. They are "structured largely in terms of binary oppositions," which "establish a relation of power." Discourses produce and define "subjects authorized to speak," "knowledgeable practices," the audience, as well as the common sense of the audience (Milliken 1999, p. 229).

Larsen (1997) argues that political actors are bound by the values and rules of discourse. Discourses delimit their actions and constrain the range of possibilities. They make certain actors, policies, actions, and interactions legitimate while de-legitimizing others. Foreign policy discourses define the self, its interests, preferences, enemies, friends, and in general, its identity. Then, based on that identity, it determines the range of possibilities for the state's action. Political discourses may act as a constraint or enablement that shapes the foreign policy of a state: they are like "a kind of framework within which the foreign policy of a particular country can take place" (Larsen 1997, p. 21).

Moshirzadeh (2007) argues that three discourses have shaped Iran's foreign policy: 1) the discourse of hyper-independence which involves a) refusing foreign dominance, hegemonic power influence, and cultural, political, and economic dependence, and b) seeking to realize self-definition, and self-reliance; 2) the discourse of justice; and 3) the discourse of Resistance, meaning the necessity of resistance against foreign forces that might jeopardize Iran's sovereignty and independence (pp. 521-539)

Mohammad Ni (2012) argues that, based on discourse analysis, all social practices, such as political phenomena, are contextual and relational, depending on the social context in which they take place. Discourse creates a shared way in which people make sense of social reality within a given culture. According to Mohammad Nia, there are four core 
discourses upon which Iranian foreign policy rests, namely, the discourses of Responsibility, Resistance, Counter-hegemony, and Expediency:

A) Responsibility vs Consequentiality: one of the main principles of Iranian foreign policy is the responsibility towards the Muslim world. The Iranian anti-Zionist policy and its support of Islamic resistance movements in Lebanon and Palestine can be interpreted within the logic of responsibility.

B) Resistance: the discourse of resistance is an inseparable part of Iranian identity. According to the Islamic rule of Nafy-e Sabil or no dominance over Muslims, the Islamic Republic of Iran in its foreign relations should behave in such a way that safeguards the country from any foreign domination.

C) Counter-hegemony: this discourse attempts to challenge the monopolizing cores of oppressive powers in international relations and looks for complete elimination of all kinds of colonialism and imperialism. In fact, Iran's anti-western and antiAmerican policies can be understood in the context of these objectives and motivations.

D) Expediency: Expediency (Maslahat-e Nezam) is one of the basic principles of Iranian foreign policy that originates from the capacity of Shia political jurisprudence. The discourse of Expediency elevates the survival of the Islamic Republic to a supreme religious value, which means that when an incompatibility arises, political considerations (survival of the Islamic Republic) take precedence over religious considerations (2012, pp. 29-64).

Islamic ideology and Third Worldism are two other discourses that have shaped Iranian foreign policy, according to Dehghani Firouzabadi. First, the Islamic ideology is based on 
two key concepts: Dar-ol-Islam (the abode of Islam) and Dar-ol-Kofr (the abode of infidels). The Dar-ol-Islam is a territory where Muslims reside, rule, and constitute a united Umma. The Dar-ol-Kofr embodies all territories outside the Islamic and Muslim sovereignty. Therefore, the existing international order, which is incompatible with Islamic ideas, is not favoured and should be changed to the Islamic world system.

Second, Third Worldism has an anti-colonialist, anti-imperialist, and anti-hegemonic nature. This is an idea that opposes the present international political-economic order and advocates amending and adjusting it to promote the interests of the Third World or developing countries. The most important goals of Third Worldism are international justice, economic development, independence and freedom, positive international cooperation, respect for national sovereignty and territorial integrity of countries, and noninterference in the internal affairs of countries (Firouzabadi 2012: 44-56).

Similar to this line of thought, Adib-Moghadam (2005) suggests that the revolution created a new identity in which "anti-imperialism emerged as a central institution of Iran's foreign policy culture" and that "the Iranian republic adheres to certain grand strategic preferences that transcend the fault lines of day-to-day politics". From this perspective, challenging the status quo and the United States' dominant position is the main element of Iranian revolutionary culture. Other themes, such as solidarity with the oppressed, especially Muslims, also continue to resonate culturally (pp. 284-285).

Proceeding from a constructivist perspective, Hossein Salimi (2012) tries to answer the question "what is the cause of the emergence of the revolutionary foreign policy of Iran?" by arguing that theoretically, some socially constructed ideas such as the "illegitimate approach to international order and legitimacy of the use of violence" (pp. 131-132) are the 
main reasons behind revolutionary foreign policy. He believes that the most important common political trends in Iranian foreign policy are the criticism of the world order, U.S. policies, and the conditions of Muslim people in the Middle East (pp. 139-149).

W.A. Rivera (2016) believes that the twin discourse of national and religious identity plays an important role in shaping Iranian foreign policy. Indeed, national identity has generally built on the dual pillars of Persian greatness in military prowess, poetry, art, philosophy, and language on the one hand, and fear and suspicion of foreign powers on the other. Religion, thus, had to be used to unite a people made up of various ethnic backgrounds. What the Iranian revolution did most effectively, therefore, was to unite these two strains through the discourse of the velayat-e faqih (literally, the Guardianship of the Juris consult, but here for clarity, the person who occupied this role is known as "the Supreme Leader"). Moreover, from its inception, the Islamic Republic of Iran avoided a provincial sense of nationalism in favour of a broader Muslim identity- the Umma (p. 395416).

Among constructivist scholars, Farhang Rajaee (2013) explains Iranian foreign policy from a different perspective. He argues that Iranian foreign policy mainly rests on the country's reactive tendency towards domestic and international events rather than on the tendency of being an active agent of change. Rajaee argues that revolutionaries had intended to be idealist and attempted to save what they perceived as justice; as a result, Iran has allowed for events to dictate its course of action, rather than being an active agent of change. 


\section{Domestic Politics and Iran's Foreign Policy}

Some scholars maintain that factionalism plays a more important role in shaping Iran's foreign policy than the factors mentioned above. Fred Halliday (2001), for instance, posits that there is no single center for the making of foreign policy in Iran. Within the government of the Islamic Republic, the main decision-making body is the National Security Council, attended both by the president and the Supreme Leader. However, other bodies, including security services, semi-independent foundations and the Majlis (Parliament), have their own priorities. Thus, because of the multiplicity of power centers and vigorous debates among the factions, foreign policy is not formulated in one clear manner.

With regards to domestic policies, Kazemzadeh (2017), identifies three main factions in the Iranian domestic structure: Expedients, Reformists, and Hard-Liners. The Expedient faction, led by Rafsanjani, proposed a détente with the United States and opposed policies that could provoke a war. The Reformist faction came to power during the presidency of Khatami. Their primary aims were avoiding wars, stabilizing domestic politics, and pursuing economic prosperity. To accomplish these goals, they argued that the regime should abandon ideologically driven foreign policy and instead pursue national interests. Finally, the Hard-Liners, led by the Supreme Leader, believe that the departure from early ideas and policies of the Revolution under the presidency of Rafsanjani and Khatami are the main causes of the crisis. With the change in the balance of power among these factions, Kazemzadeh argues we should expect a change in Iran's foreign policy (p. 198-214).

Along with these scholars, some observers will argue that the ideology of Shiism is a crucial element in shaping Iranian foreign policy. Shiism in Iran has been intertwined with 
both domestic politics and foreign policy. In Shiism, the source of political behaviour is God's will; therefore, people's satisfaction and welfare become secondary to obedience to the Almighty. Although diplomacy based on rationality is the most common tool used in the implementation of foreign policy, in Shiism, jurisprudence replaces rationality (Mirbagheri, 2004; Hunter,1990).

Dehghani Firooz-Abadi (2012), for example, argues that it is Islamic values that form Iran's worldview, not supremacist ambitions. To the Islamic republic, "the present international order that dominates and the international system that goes with it is not suitable and should be revised. For this reason, [Iran] is considered a revisionist country and, contrary to the status quo countries, is trying to bring about revision and gradual changes in the existing international order and system.” (p. 43).

Ideology is the other main factor driving Iranian foreign policy (Barzegar, 2010, p. 177). Iran perceives itself as competent enough to be a leader of both the Middle East and the Persian Gulf region, given its complex geography, history, and religious standing. In fact, Iran has effectively assumed a role as a defender of the Islamic faith, as evidenced by its use of Islam as a guiding principle in its conduct of foreign policy (Ehteshami, 2002, p. 288). Iran has managed to construct an identity and role which it has moulded into an ideology which it uses to shape and determine its foreign policy. Iranian ideology is mainly anti-imperialistic, which has become part of its identity. In fact, it has become a core value of its foreign policy (Kaarbo, et al., 2012, p. 14).

Other scholars suggest that Iranian foreign policy is also shaped by its cultural values; for example, Rubin (2013) suggests that in Iran, nationalism has meshed with the belief that Iran ought to defend Shi'ites and ethnic Persians. Iran has, in the past, supported 
Islamic movements in the Philippines and Bosnia (Ehteshami, 2002, p. 306). Iranian strategic goals are determined by an eclectic mix of Iranian nationalism, rationality, and the Supreme Leader's vision (Rubin, 2013).

Some argue that Iranian national interests are formed in terms of both Khomeini's revolutionary objectives and Iran's material interests. In fact, Iran's post-revolutionary foreign policy has maintained a consistent revolutionary identity with changing means, which have both served and defined its strategic goals since 1979. These goals, which derived from Khomeini's ideology and the 1979 Constitution, have four central components: first, social justice with economic growth and development (material interests often described in terms of the revolutionary objective of social justice); second, preserving national sovereignty and territorial integrity (strategic material interest); third, defending the rights of Muslims and supporting liberation movement (oppressed people); and fourth, the establishment of an Islamic polity based on Shi'a principles (revolutionary objective). Therefore, there has been mutual reinforcement between revolutionary aspirations and strategic interests in the Iranian foreign policy (Afrasiabi, 1994; Perthes, 2010).

\section{Why Operational Code}

The main question of this research is to examine the key reason for Iranian foreign policy Under Khatami's presidency. The above review shows that, for realists, states are rational actors and security, and interests are the determining factors that shape foreign policy. Realist scholars, claim that from the 1979 revolution until the present, Iranian foreign policy has remained the same. A neorealist perspective would argue that there is no change in a state's foreign policy unless the distribution of capabilities within the 
international system changes. In other words, neorealists view states as "billiard balls", meaning that all states share the same behaviour under anarchy, either security-seeking or power-seeking. In the case of Iran, neorealists have explained the continuation of Iranian foreign policy rather than its change.

A focus on domestic politics does not explain changes in Iranian foreign policy either. From this perspective, ideology and revolutionary aspirations have been determining components in shaping Iranian foreign policy. Considering that since the 1979 revolution, these two factors have remained unchanged, I would argue that the domestic-level approach could not explain any alterations.

Constructivists suggest that ideas shape the state's identity and, consequently, its foreign policy. As Kowert (2012) argues, some constructivists study norms and others study identities; they may define the terms in relation to each other, but they rarely study both. He quoted from Katzenstein who argues that sometimes norms have constitutive effects in that they operate as rules and define the identity of an actor. In other words, norms operate as standards that specify the proper behaviour of an actor. Therefore, norms define or constitute identities or regulate behaviour (p. 219). Nevertheless, although some disagreement appears to exist about whether identity constitutes a subset of social norms or the reverse, constructivists have reached a broad consensus that the two constructs are closely related (2012, p. 20). However, although constructivism emphasizes "widely shared or intersubjective beliefs", these are not "reducible to individuals" (Finnemore and Sikkink, 2001, p. 393).

I argue that Iranian foreign policy experienced a paradigm shift under Khatami's presidency and this change rests on Khatami's belief system, that is, on how he understood 
the nature of the political world, and how he defined the relationship between self and other to achieve his goals. For this reason, I choose the Operational Code as the theoretical framework of my research. It is worth mentioning that the decision maker's belief system is not the only factor explaining a state's foreign policy. Other factors such as the external environment are in play. However, I argue that the decision maker's belief system is one of the most important elements. Before explaining the key elements of the Operational Code approach, it would be helpful to explore how and why a decision-maker's belief system is significant in analyzing a state's foreign policy.

\section{International Politics and Foreign Policy Analysis}

Some scholars tend to describe international phenomena from the perspective of the state or/and the international system. One of the predominant paradigms in Foreign Policy Analysis has been realism. Realists define power, survival, security, and national interests, as the key components that drive a state's foreign policy (Morgenthau, 2005; Mearsheimer, 2001). Neorealists, however, view foreign policy as a result of the international system. In other words, the distribution of capabilities (Waltz, 1979) across the international system shapes a state's foreign behaviour. Proponents of this approach suggest that the lack of a governing body above states fosters an environment of constant preparation for conflict within the international system, and, consequently, states are expected to pursue economic and military security. These systemic conditions are thought to explain a considerable range of state behaviour (Waltz, 1979). The neorealist theory rejects individuals as a unit of analysis (Waltz, 1979, p. 65). Indeed, the individual is ignored because the differences in their characteristics (much like the differences among states) are not relevant. In other 
words, international phenomena are being prescribed upon the behaviour of the state, not the individual leader (Lavikainen, 2016, p. 6).

The bipolar system and the relationship between the United States and the Soviet Union during the Cold War reinforced these structural explanations of foreign-policy behaviours. Some of these theories predicted alliance formations to balance against threats (Walt, 1987), the ability of hegemonic powers to maintain superiority (Gilpin, 1981), and the effect of the security dilemma on state behaviour (Jervis, 1978).

In the 1950s and 1960s, leading scholars in Foreign Policy Analysis such as Snyder, Bruck and Sapin (1963), Rosenau (1966), and Sprouts (1956) advocated a different approach. They rejected the assumption that states are exogenously determined and act as unified entities. Instead, they gave weight to the decision-making process in relation to the actor's perception of the environment in which they are functioning (George, 2014). Some scholars based on rational actor models argue that individuals act within the constraints of rationality (Allison and Zelikow, 1971; and Neack, 2008) which is bounded by uncertainty, which means that an actor's subjective beliefs are an important element of foreign policy decisions (Bueno de Mesquita, 1997; Hudson, 2005). As Bueno de Mesquita argued the "expected utility" model assumes that individual leaders base their decisions on their preference and appetite for taking risks. This is done through the analysis of all options available to them and subsequently acting upon the choice with best serves their interests (quoted in Ritcher, 2016, p. 241)

Within this camp, Hermann et al. (2001) challenged the notion that individuals have the same characteristics and that they approach international politics in the same way. The researchers distinguished between different leadership typologies by linking certain 
characteristics with certain leadership styles. They argued that a different leadership style causes different foreign policy directions. Hermann and Hermann (1989) emphasize that merely studying structures and states would not give us a full explanation of international politics. Therefore, they suggest incorporating the "ultimate decision unit" into international relations research (p. 362). The configuration of the individual decision unit partially shapes foreign policy and therefore, makes the relevance of beliefs more convincing (Hermann and Hermann, 1989, p. 384).

Similarly, Young and Schafer (1998), argue that assumptions of leaders' rationality are misguided because the perception of power and interest are not the same from the state and the individual's viewpoint. They maintain that "neither power nor interest is objective; rather, each emerges from the beliefs individuals hold about these concepts" (p. 64).

Renshon (2008) also has a similar view when he argues that those who study international politics and foreign policy decision-making would realize that the beliefs of leaders are critical to understanding their foreign policy decisions since they suggest frameworks for analyzing the situation. Additionally, they are significant because of the influence they have on different levels of international politics, ranging from how leaders understand and respond to public opinion to what type of international system is constituted by mutually reinforcing beliefs of world leaders (p. 820).

Operational Code has been a theoretical framework that examines a decision-maker's belief system, upon which Self and Other is defined; then based on this perception, the best strategies would be adopted to fulfill the goals.

One could wonder about the effect of constraints or changes in the international environment on a leader's belief system. While some researchers argue that changes in the 
international environment have had an effect on a leader's belief system, others claim that this is not the case. For instance, Edgar (1993) examined Reagan's operational code before and after the collapse of the Soviet Union. She argued that Reagan's image of the Soviet Union had not changed, even with the new international system. From Reagan's perspective, "in 1989 the Soviet Union was still a threat, albeit not as menacing as it was in 1981.” (p. 68). Lavikainen (2016) maintained that Vladimir Putin's beliefs remained unchanged during the Ukrainian crisis in 2014, despite the threat of Western involvement and sanctions. And Renshon (2008) in his article Stability and Change in Belief Systems: The Operational Code of George W. Bush suggested that the individuals' belief system is not as interdependent as has often been assumed. The results show the overall temporal consistency; however, belief systems can and do experience major changes. According to him, the results on "durability of many beliefs over time, perhaps providing some confirmation that beliefs are, overall, relatively stable.” (p. 841).

It might be a question of applicability of the Operational Code approach to non-Western countries, sometimes called non-democratic states. In order to address this question, Brummer and Hudson (2017) in their article The Boundedness of Foreign Policy Analysis Theory? posed the question of the necessity for an entirely new or different analytical approach for the areas outside of North America. In other words, they asked if "there is a 'North American-ness' to the theoretical framework for Foreign Policy Analysis. To answer that question, they asked scholars from different regions outside North America if they have had to challenge or transcend the originality of "North American-ness" of the conceptual frameworks and empirical methodologies they have used, including the Operational Code approach, to analyze their region's foreign policymaking. The regions 
surveyed included the Middle East, Europe, Asia, and Latin America. According to the authors, their research revealed that the explanation of foreign policymaking beyond North America does not necessitate new theoretical frameworks. The authors also maintain that Foreign Policy Analysis theories can be sharpened and further specified based on insights from non-Western countries. They argue that although the Operational Code approach has most often been used to examine U.S. foreign policy, the approach has also been used to explain a number of non-U.S. cases, for instance with respect to Russia, the United Kingdom, China, and North Korea (p. 160). In addition, the Operational Code approach has been applied to analyze Middle Eastern and North African Islamic leaders (Ozdamer, 2017).

It is worth mentioning that the Operational Code is not the only approach to examining the belief system of a state leader. Larson (1994) suggested that like belief systems, schemas contain general information about the world. A schema is defined as a cognitive structure that represents knowledge about a concept or type of stimulus, including its attributes and the relations among those attributes. She stated that "belief systems and schemas have many similarities: both are structured, simplify information, and vary with expertise and involvement" (p. 19), and schema resembles the operational code belief about whether political life is conflictual or harmonious (p. 20). The efficiency of schemas, according to her, "originates in inherent human cognitive limitations. Schema theory is closely tied to the notion that limits on the capacity of short-term memory affect how knowledge is organized and used. Belief system theorists did not speculate on how knowledge was structured and ordered in memory, whether via associative links or templates, but instead concentrated on belief stability and change" (p. 20). As the aim of 
the present dissertation is focused on examining Iranian foreign policy, I believe that the Operational Code, as a theory that examines belief system and its role on foreign policy, is more applicable than the Scheme theory, which mainly explores the structure of knowledge in memory.

\section{Operational Code as The Theoretical Framework}

\section{Background}

The concept of the operational code has a relatively long history in the social sciences. The term was coined by Nathan Leites in his two works, The Operational Code of the Politburo (1951), and A Study of Bolshevism (1953). Leites developed a set of "response repertoires" and common sayings among Soviet Politburo members and posited that these responses and beliefs constituted the world view through which they made decisions. Furthermore, he examined the motivational foundations of this Bolshevik belief system by examining the personalities of leaders like Lenin and Stalin. Leites' work was novel in the sense that it incorporated both cognitive and character-based traits to determine Soviet decision-making (Walker,1990, pp. 403-4). The concept of operational code languished for a decade and a half until Alexander George (1969) revived it in his seminal article, The Operational Code: A Neglected Approach to the Study of Political Leaders and DecisionMaking (Renshon, 824).

The operational code does not encompass all the beliefs that influence the behaviour of a given individual. It rather consists of a subset of political beliefs that are especially relevant in the context of political decision-making. George divided these beliefs into philosophical beliefs (general assumptions regarding the fundamental nature of politics, 
conflict, and the individual) and instrumental beliefs (more specific beliefs concerning the methods leaders should use to attain the ends they desire). Then, Schafer and Walker conceptualized both the first Philosophical and Instrumental beliefs as master beliefs, meaning that, based upon theories of cognitive consistency, the other beliefs within each category should emerge from and be theoretically and empirically linked with them (p. 33). An individual's operational code is composed of his or her answers to these questions (Walker, 2011, p. 56).

George suggests that the operational code may help to operationalize the general beliefs and values of an ideology in real-world situations. The operational code would then mediate the impact of ideology on foreign policy behaviour. Philosophical beliefs identify the enemy and predict the prospects for achieving a preferred political order, while the instrumental beliefs of the operational code prescribe strategies and tactics for achieving ideological values. Instrumental beliefs are affected by experience, learning, and political socialization (Larson, 1997, p. 21). The operational code has been further legitimized by widespread usage and with this usage came new styles of analysis. This development is well-documented by Walker in an article titled The Evolution of Operational Code Analysis (1990).

\section{The Operational Code Quantified}

The Operational Code was a qualitative approach until Walker, Schafer, and Young (1998) introduced the quantitative version of it. Using George's ten questions, Walker et al. developed indicators for each question based on the subject's verbal or written material. The verbs within the sample were examined using the Verbs In Context System (VICS) to identify power relationships between self and other. The Verbs In Context "is the systemic, 
at-a-distance method that has been developed for quantitative operational code analysis." (p. 26). This method was created to overcome the problem of access. Most major leaders are unavailable for the major psychological evaluations and extensive interviews that this type of search would demand. Therefore, researchers, of necessity, turn their analysis to the next best things: their public verbal communications (Schafer and Walker, 2006, p. 27).

\section{Methodology}

The VICS method is a content analysis and the link between someone's verbal behaviour and beliefs. The key to this content system is that it connects a leader's behaviour with the way she/he says something about international politics (Schafer and Walker, 2006, p. 30). It gives weight to specific words and identifies the tense and category of verbs. VICS concentrates on the direction and intensity of coded verbs (Schafer and Walker, 2006, p. 31). By direction and intensity, the authors mean the two grammatical factors: subject and verb. When a political leader is making a statement in a speech or other public appearance, she/he either talks about herself/himself or others as the subject. The other factor, the verb, is saying something about the intensity of the political action. Verbs can be placed in different categories, ranged by intensity from very conflictual to very cooperative actions.

VICS analysis consists of two steps. In the first stage, "utterances" (sentences that contain verbs) are coded for directionality ( + for cooperative or - for conflictual) and then for intensity (as either deeds or words). Deeds indicate the exercise of power in a relationship. Words represent the promises or threats to use power, or the support of or opposition to an Other (Schafer and Walker, 2006, p. 31). Intensity is scaled from - 
3 (punish) to +3 (reward). The second stage of VICS coding is the attribution of the verbs. Sentences in which the subject (or an in-group) refers to himself or herself represent his or her beliefs with respect to the exercise of power (or in other words, his or her instrumental beliefs). Sentences that refer to an Other represent beliefs about how others exercise power in the international system and are indicative of the subject's philosophical beliefs (Schafer and Walker, 2006, p. 32). A guide to verbal descriptors for VICS' numerical scores will be discussed in more detail in chapter three. To briefly illustrate the coding system, consider the following sample sentence: "Russian military forces have invaded India." The subject of this sentence is "Russian military forces," which would be coded as referring to an Other. The verb phrase "have invaded" is in the past tense, and the directionality is negative and high in intensity. Thus, this verb phrase would be coded as "punish" (-3).

The resulting score is calculated based on the number of attributions the speaker makes to self or/and others. Several years ago, Social Science Automation (www.socialscienceautomation.com) developed an automated, full-language parser software program for personal computers (profiler plus), which was intended particularly for at-a-distance, psychological assessments of subjects, and generously provided by Dr. Michael Young. VICS coding via software is the most common method of operational code analysis because it produces results that are significantly more reliable than hand-coding while being extremely time-efficient.

I studied and examined Khatami's books, and articles both in Farsi and English, as well as his speeches and lectures at various universities and institutions across the world-from Harvard University in Boston to the University of Florence, the University of St. Andrew in Scotland, where he inaugurated the Institute of Iranian Studies, to the British think-tank 
Chatham House. I also explored his speeches, such as addresses to the United Nations General Assembly, UNICEF, UNESCO, Organization of Islamic Conference (OIC), and Islamic Educational, Scientific and Cultural Organization (IESCO). I also examined his meetings with counterparts, as well as interviews with Iranian and international media on both domestic and international issues.

\section{The Structure of the Thesis}

Chapter two examines the different periods of post-revolutionary Iranian foreign policy to illustrate the distinction between Khatami's presidency and his predecessors' and successors'. The Islamic Revolution in 1979 fundamentally changed Iranian foreign policy, mainly because of Khomeini's belief system, which viewed the world as divided into two camps: oppressors (superpowers) and oppressed (Third World countries). Khomeini believed that the oppressed should follow the Islamic Revolution; therefore, he called for the Export of the Revolution, which made the Persian Gulf Arab states feel threatened.

The next era began with the presidency of Rafsanjani, who brought a pragmatic approach to Iranian foreign policy. Reconstruction of the country after the 8-year war with Iraq was the main priority of his administration. In order to receive foreign investments, Rafsanjani attempted to normalize relations with other countries, as well as integration into the world economy.

Khatami followed the pragmatic approach of Rafsanjani and stressed that Iran would be respectful of international norms and would not pursue revisionist foreign policy. He went further by introducing the discourse of Dialogue among Civilizations upon which 
Iran attempted to have peaceful relations with the international community. He succeeded to reorient Iranian foreign policy from confrontation to cooperation.

The neoconservative president, Ahmadinejad, deliberately distanced himself from Khatami's approach to foreign policy issues. His rhetorically aggressive approach caused real tension between Iran and almost all international community members. Rouhani, as the next president, adopted a moderate approach towards foreign policy. However, the reaction of the United States regarding Iran's nuclear program strained relations between Iran and the United States and gradually with the rest of the international community.

Chapter three provides a comparison between structure-oriented perspectives and actor-oriented ones in the field of foreign policy, and the need for cognitive approaches. It examines how and why decision makers' beliefs became significant in analyzing foreign policy. Following this, it explores the Operational Code as the theoretical framework, and how it became a quantitative method (Verbs in Context System and Profiler Plus). Finally, the results of the operational code analyses of Khatami are provided.

Chapter four begins with a brief study of Khatami's life from childhood to being elected as president. Then the main elements of Khatami's worldview, such as the role of freedom, the concept of civil society, relations between Self and Other, perceiving the West as the possible counterpart, not the enemy, will be examined. It will also discuss the key elements of Khatami's discourse of Dialogue among Civilizations as the main foundation of his foreign policy approach.

In chapter five, I will examine the impact of Khatami's belief system in shaping Iranian foreign policy. By adopting a peaceful approach towards foreign policy based on dialogue and constructive relations, Khatami could reassure the international community that Iran, 
as a proactive actor, would follow international norms and pursue a cooperative approach with the rest of the world.

The conclusion provides a summary of the main arguments about how and why Iranian foreign policy under the Khatami presidency has gone through a paradigm shift from confrontation to a peaceful approach. 


\section{CHAPTER TWO}

\section{POST-REVOLUTIONARY IRANIAN FOREIGN POLICY}

Some scholars believe post-revolutionary Iranian foreign policy, to some extent, has remained the same, since the revolutionary aspiration, anti-imperialism, resistance, and challenging the international order have been the main features of foreign policy since the revolution. However, I argue that Iran under Khatami's presidency experienced a significant change because of his beliefs. To this end, I will examine Iranian foreign policy and how Khatami's beliefs caused a change of course. I will also examine the political decision structure in Iran with a focus on the relations between the Supreme Leader and the president. Before examining different periods of Iran's foreign policy, it will be helpful to start by exploring the political system in Iran.

\section{The Political System in Iran, with the Focus of Relationship Between the Supreme Leader and the President}

The Islamic Republic of Iran is often described by Western observers as a monolithic dictatorship with totalitarian tendencies, ruled by the Islamic clergy. Such a simplified characterization, as Butcha (2000) argues, fails to recognize the complex structure of the Iranian political system. In fact, Iranian policy is determined by a multitude of often loosely connected and fiercely competitive power centers. Some of these power centers are rooted in the constitution and codified regulations; others are informal and grouped either around 
religious-political associations of the Iranian leadership elite or around revolutionary foundations and security forces (p. 2)

Although, according to the constitution, the Supreme Leader is the strongest power center in the Islamic Republic, without cooperation between the president and the Supreme Leader, the stability of the Islamic Republic could not be maintained. For this reason, "the two incumbents have thus far cooperated tolerably, despite their personal differences and rivalries." (Butcha, 2000, p. XI).

The president is elected by the people and represents the second strongest power center. As the head of the state executive, he is responsible for the country's policy, both foreign and domestic. The presidency in its current form is the result of the constitutional revision implemented in July 1989, following the death of Khomeini. According to the 1979 constitution, the executive branch was divided between the president and the prime minister. The head of the executive was the president, who was popularly elected for a four-year term and could run for re-election only once. The president had more ceremonial power than real. It was the prime minister who had actual power. Although the prime minister was appointed by the president, he acted independently (Butcha, 2000, p. 26).

Within this framework of executive power, tension sometimes was unavoidable, especially when the president and the prime minister belonged to different factions. This was the case for the tenures of the presidents Bani-Sadr (1980-81) and Khamenei (198189). Khamenei, who was part of the combined traditional right and the technocratic camp had to work with a prime minister who opposed him, namely Mir-Hosein Musavi. The result was the conflict between the two over numerous domestic and foreign issues, a conflict kept in check only through Khomeini's arbitration (Butcha, 2000, p. 22). 
In order to resolve the tension and conflict between those two branches of the executive, Khomeini established the Constitutional Reform Committee in late April 1989. As a result, the office of the prime minister was abolished, and his responsibilities were assumed by the president. At the head of the government, the president appoints and dismisses ministers, whom the parliament must confirm, and he controls the Sazeman-e Barname va Bujeh (Planning and Budget Organizations), which is extraordinarily important in the drafting of economic policy. Moreover, two new bodies were created: the Expediency Council and the Supreme National Security Council (SNSC). The Expediency Council was intended to resolve disputes between the Parliament and the Council of Guardians (a twelve-member body that reviews the decisions of the parliament for compatibility with Sharia and the constitution) on domestic issues (Kazemzadeh, 2017, p. 21). The president acts as chairman of the Supreme National Security Council, an influential committee that coordinates all governmental activities related to issues involving defence, the intelligence service, and foreign policy. The president also wields considerable influence in the personnel composition of the Supreme Council of the Islamic Cultural Revolution, which is responsible for cultural and educational issues. The president and his ministers can be removed only through a two-thirds majority no-confidence vote by the Parliament (Butcha, 2000, p. 23).

According to the constitution, the Supreme Leader has ultimate authority on foreign policy, national security, war and peace. However, certain instances show that negotiation or cooperation between the Supreme Leader and the President determined the ultimate decision. For instance, during the presidency of Rafsanjani between 1989 and 1997 the president made almost all the major decisions on foreign policy (Kazemzadeh, 2017; 
Nialooee \& Ejazee, 2015; Sarmadi \& Badri, 2017). Furthermore, Rouhi and Snow (2019) in their article Decision-Making in the Revolutionary States: Beyond the Whims of the Charismatic Leaders examined case studies of Iran during the Iran-Iraq war, of Russia after the 1917 revolution (Lenin and Communism), of Sudan after the 1989 revolution (al-Bashir and Islam), and Afghanistan after the 1996 revolution (Mullah Omar's Taliban and Islam) to show that the process in these states involved input and considerations from various actors and therefore cannot be understood by simply looking at the desires of the charismatic leaders.

In the case of Iran, the continuation of the Iran-Iraq war after the 1982 liberation of Khorramshahr was examined. In September 1980, one year after the revolution, Iraq attacked Iran. The Iranian leadership was in the process of establishing a new government, and the war necessitated major defensive operations. One of the critical regions that was captured by the Iraqis in the early months of the fighting was the port city of Khorramshahr. It had strategic significance as a port, as well as symbolic importance as a section of Iranian territory occupied by an invader. Two years into the war, Iran finally blocked the Iraqi advances into its territory and liberated Khorramshahr. This was when the international community began calling for a cession of hostility and end to the war between the two countries $^{1}$. However, Iran decided to continue the war.

Rouhi and Snow (2019) stated that "this decision was wrongly perceived by many leaders around the world as simply a manifestation of Khomeini's personal preferences for

${ }^{1}$ As I also argued in my Master's thesis, the liberation of Khorramshahr could be seen as "the Nash Equilibrium" point in which the costs of the actors would be minimum according to the Game Theory approach. 
the expansion of the Iranian revolution across the region" (p. 453). According to them, it was shaped by political and military officials who convinced Khomeini to pursue this policy. In fact, there was extensive debate and controversy over the decision to pursue this strategy and to then secure Khomeini's approval, since the final decision went against his original desires and impulses.

Khomeini had a fundamental belief in the power of the Islamic message to bring change throughout the region. He viewed Iraqis as fellow Muslims but Saddam Hussein as an infidel who suppressed the religious uprising and prevented regime change in Iraq. He believed that change in Iraq would take place through Iraqi citizens albeit with the support of Iran. Therefore, he emphasized that Iranian forces had not advanced into Iraqi territory to not undermine that goal. On the other hand, there were some different perspectives from Khomeini's which led to continuing the war.

On May 27, 1982, three days after the liberation of Khorramshahr, a meeting of the Higher Defense Council was held in Khomeini's residence. At that historic meeting, two main strategies were considered. Some military commanders believed that military means would lead to the overthrow of the Iraqi government, while others favoured a political resolution. In order to resolve the disagreement, Khomeini decided to delegate the authority for solving these disputes to then-president Rafsanjani. The strategy that the two camps finally agreed on - capturing a portion of Iraqi territory for leverage purposes in subsequent negotiations - represented an approach that was not the Supreme Leader's choice (Rouhi \& Snow, 2019, p. 453).

After Khomeini's death in January 1989, Khamenei became the Supreme Leader. There was a difference between Khomeini's theological status and Khamenei's. Butcha (2000) 
argued that Khamenei, unlike his predecessor Khomeini, cannot extend his influence easily because he has a theological Achilles' heel. Khamenei possesses neither Khomeini's charisma and authority nor his theological qualifications. Part of the Shi'a religious doctrine requires that adherents pick a living grand ayatollah, whom they consider a Marjae Taqlid (source of emulation), as their paramount instance, whom they follow in matters of religious behaviour and social interactions. Khomeini was the Marja-e Taqlid for millions of Iranians; his religious instructions and fatwas accordingly had authoritative character. Khamenei was the favourite of the Assembly of Experts, which was responsible for naming a successor, but until the time of Khomeini's death, Khamenei had held only the title of hojatoleslam, a mid-level theological rank. He was not a faqih or ayatollah. In a political act, therefore, the Assembly raised Khamenei's theological rank to the level of an ayatollah, making him a faqih and granting him authority to issue fatwas. The non-political majority of the Shi'a clergy in Iran still doubts that Khamenei is a veritable scholar; however, there are probably not many believers who ask Khamenei to issue a fatwa for them. Moreover, Khamenei still does not possess the title of ayatollah ozma (grand ayatollah). Therefore, he cannot rightfully claim to be both the highest political authority in Iran and the highest religious authority in the Shi'a world (pp. 52-53).

In sum, despite the power that the Iranian Constitution assigned to the Supreme Leader as the ultimate authority, there are some examples that the decisions have been made through negotiations between the Supreme Leader and other actors including the president. One could argue that during Khatami's presidency, Khamenei's relatively weak theological status helped the former to advance his idea of a peaceful relationship with the international community. For instance, because of the Salman Rushdie Fatwa (1989) and 
the Mykonos incident (1992), European states recalled their ambassadors from Iran and suspended all ministerial contacts. As a result, Iran became isolated within the international system. However, after extensive negotiation with Khamenei, Khatami convinced him that Iran had to solve those issues to break the isolation. With the approval of Khamenei, Khatami managed to secure the return of the European ambassadors to Tehran, which was a significant achievement in Iranian foreign policy during his presidency. This will be discussed in more detail in the following chapters.

\section{Post-Revolutionary Iranian Foreign Policy}

Post-revolutionary Iranian Foreign policy has gone through five phases: first, the years immediately following the revolution until the death of Khomeini (1979-1989); second, the period identified with the presidency of Rafsanjani (1989-1997); third, the years associated with the presidency of Khatami (1997-2005); fourth, the era recognized with the presidency of Ahmadinejad (2005-2013); and fifth, the period which started with the presidency of Rouhani in 2013.

In February 1979, the triumph of the revolutionary forces ended a 2,500-year tradition of monarchy in Iran. Khomeini, as a leader of the Revolution, during the early 1970s when he was in exile in Najaf, spent most of his time preparing and giving lectures. In fact, he was thinking about a fundamentally different Iran. In his 1941 work, Secrets Revealed, Khomeini had talked about the merits of a morally guided religious government. He developed his ideas further through the 1960s and 70s and published them under the title Islamic Government (1971). Khomeini believed that a religious government was a 
necessity. He explained his ideas in a series of lectures that were attended mostly by young students (Malici and Walker, 2017, p. 120).

In Islamic Government, Khomeini developed his doctrines. The most significant departure from tradition was his idea of velayat-e faqih, which can be understood as "the vice regency of the theologian," "the governance of the jurist," or "the guardianship of the jurisconsult" (Moin, 2000, p. 153). Although this idea had already been advanced in the early $19^{\text {th }}$ century, what Khomeini argued was unprecedented in the history of a Shi'a Iran: the faqih would hold ultimate authority not only in religious matters but in all matters, including foreign affairs (Shakibi, 2010, p. 90).

Moin (2000) argues that although Iranians accepted Khomeini as the uncontested leader of the Revolution, they were not prepared for a "Khomeini-style theology." He added that most Iranians, regardless of their level of education, had never heard of "[velayat-e fagih] as an option for the political system that would replace the monarchy" (p. 218). Nevertheless, as revolutionary enthusiasm continued, Khomeini and his supporters were able to further consolidate their authority. Now velayat-e faqih was publicized across the country, and Khomeini openly aimed for a theocratic constitution. Not surprisingly, many on the Iranian left, as well as nationalists and also senior clerics opposed it. However, they would not manage to unite in an effective opposition (Malici and Walker, 2017, p. 142). After the students captured the US embassy, Khomeini moved closer to his goal (Kinzer 2010; Hunter 1990; Cottam 1988).

On November 4, 1979, a group of young students calling themselves the "Students Following the Line of Imam" captured the American Embassy and took more than 60 diplomats and staffers hostage. The articulated demands of the students were the return of 
the Shah to Iran for trial, a US apology for the 1953 coup, and the release of Iran's frozen assets in the US (Bowden, 2006, pp. 548-51). Very soon after the takeover, they stated:

The Islamic Republic of Iran represents a new achievement in the ongoing struggle between the people and the oppressive superpowers... Iran's revolution has undermined the political, economic and strategic hegemony of America in the region... We Muslim students, followers of Ayatollah Khomeini, have occupied the espionage embassy of America in protest against the ploys of the imperialists and Zionists. We announced our protest to the world; a protest against America for granting asylum and employing the criminal Shah, $[\ldots]$ for creating a malignant atmosphere of biased and monopolized propaganda, and for supporting and recruiting counterrevolutionary agents against the Islamic Revolution of Iran... and finally, for its undermining and destructive role in the face of the struggle of the peoples for freedom from the chains of imperialism (Ebtekar 2001, p. 69-70).

These students continued to hold the Americans hostage. A few were soon released, but 52 Americans were held for 444 days until 20 January 1981. On December 3, 1979, a new constitution was passed, which assigned Khomeini as the first valy-e faqih. A new autocracy emerged while Iran-U.S. relations continued to deteriorate.

\section{Iranian Foreign Policy Under Khomeini (1979-1989)}

Before the 1979 revolution and in response to the political landscape of the Cold War, the last Iranian monarch, Mohammad Reza Shah, had adopted a "positive equilibrium" policy, meaning that although Iran was militarily close to the West, it also recognized the significance of improving relations with the Soviet Union. The 1979 revolution, however, had replaced this policy with Khomeini's idea of "neither East nor West." In fact, Khomeini fundamentally changed the nature of Iranian foreign policy. 
The first phase was marked by the "gradual entrenchment of the clerics in power and a rejection of the status quo in the Middle East" (Ehteshami 2002, p. 297). The key goal of this phase was to develop an "Islamic" foreign policy for Iran, and possibly the elimination of Western and Communist-backed alliances in the Middle East.

The revolutionaries highlighted the new principles of Iran's foreign policy in the new Constitution. These principles are as follows: 1) prevention of the foreigners' domination of Iran; 2) non-alignment towards the dominant and great powers; 3) establishment of relations with peace-seeker states; 4) rejection of seeking dominance by Iran over other countries; 5) preservation of Iran's independence in all aspects, 6) Islamic-Worldism; and 7) Third-Worldism (Islamic Republic of Iran's constitution of 1979, constituteproject.org). According to Khomeini, the world is divided into two camps: those countries and peoples who have power and use it to dominate and exploit others, namely, the arrogant or oppressors and those who lack power and are exploited, namely, the downtrodden or the oppressed. In the realm of foreign policy, this idea translated as follows: 1) the oppressorarrogant camp, which consists of the two superpowers and a few other great powers; 2) the camp of the oppressed-downtrodden, which includes the Muslim countries and most of the Third World (Hunter, 1990). Moreover, Khomeini believed that there are two main groups in the world: those who follow the corrupt path, the path of Satan and disbelief, and those who follow the path of God. This worldview stemmed from the traditional Islamic view, with its division of the world into Dar-al-Islam, the realm of peace and belief, and Dar-al Harb, the realm of war and disbelief (Hunter,1990, p. 37). According to Khomeini, the "Islamic revolution was a struggle between Good and Evil; a battle waged for moral redemption and genuine emancipation from the cultural and political tentacles of the 
profane and iniquitous West" (Takeyh, 2006, p. 62). Consequently, since the revolution, a religious dimension has been integrated into Iranian foreign policy. Consequently, Iran has been engaged with so-called Islamic issues, which has affected Iran's relations with the international community. As a result of this idea, most of the armed groups that received support from Iran during the 1980s were Shi'i organizations in opposition to Saddam Hussein in Iraq, or to other rulers in the Persian Gulf region, or active in Lebanon, Afghanistan, and Pakistan (Ehteshami, 1995; Roy, 1999, p. 101). In the 1990s, Iran also supported Sunni groups such as the Islamic Salvation Front (FIS) in Algeria, the National Islamic Movement in Sudan, Hamas and Islamic Jihad in Palestine, the Muslim Brotherhood in Jordan, the al-Nahda Party in Tunisia and the Jihad Group in Egypt (Ehteshami, 1997, p. 30). Keddie and Matthee (2002) argue that the Iranian leadership's call for Islamic uprising might have found sympathy in the Muslim societies in the 1980s, but it also reinforced suspicion among Arab elites of Iran's intentions and encouraged them to contain Iran's influence. The proof was the comprehensive support of almost all the countries, especially the Arab states, for Iraq during the 8-year war between Iran and Iraq.

For Khomeini, the Islamic Revolution was not limited to Iran but extended to the wider region. It was to be a "revolution without borders," extending to pro-western monarchies of the Middle East, which Khomeini saw as corrupt and morally bankrupt regimes. Khomeini's Iran was to be "a vanguard state leading the subjugated masses towards freedom and justice" (Takeyh, 2009, p. 2). Khomeini believed in the emancipatory feature of the Islamic Revolution that had to be followed by other Muslim states. Therefore, Iran's revolutionary actions challenged the regional status quo as well as the "political integrity of Arab neighbours." In particular, the idea of the export of the revolution caused real 
tension between Iran and the regional Arab states especially in the countries with Shi'a majority such as Iraq and Bahrain (Hinnebusch \& Ehteshami, 2014).

According to Khomeini, the Islamic Revolution transcended Iran and would be a crucial step toward establishing a regional order. In his words: "Islam is a sacred trust from God to us, and the Iranian nation must grow in power and resolution until it has vouchsafed Islam to the entire world" (Takeyh, 2006, p. 18). In other words, Khomeini's ideological conception rejected the concept of the nation-state and an international system with its arbitrary territorial democracies.

Furthermore, Khomeini believed that monarchy is the source of oppression and tyranny. He argued that "monarchy is one of the most shameful and disgraceful reactionary manifestations" (Marschall, 2003, p. 62). This announcement caused the relations between Iran and Saudi Arabia to deteriorate. Additionally, In July 1987, during Hajj season, when the Saudi police reacted violently and killed over 400 Iranian pilgrims, all relations were broken until Rafsanjani reopened Iran's embassy in Riyadh on the last day of March 1991 and announced shortly thereafter that the Saudi government had agreed to increase the quota for Iranian pilgrims to Mecca from 45,000 to 100,000. After that, the Saudi Foreign Minister visited Tehran in June 1991 — the first visit by a senior Saudi official to Iran since the revolution (Amir-Arjomand, 2009, p. 142).

The tension between Iran and the Arab states did not subside until the end of the 1980s, due to several key domestic and regional developments taking place in a very short period of time (1988-1991), namely, the end of the Iran-Iraq war, Khomeini's death, the rise of a more pragmatic leadership in Iran, the Kuwait crisis, and “Iran's bridge-building regional 
strategy in the aftermath of the collapse of the Soviet Union" (Ehteshami, 2007, pp. 268269).

\section{Iranian Foreign Policy Under Rafsanjani (1989-1997)}

The second phase of Iranian foreign policy started when Rafsanjani came to power in 1989. Rafsanjani, one of the key figures among the revolutionary elite, became Iran's first president in 1989 , winning 13.5 million out of the 14.2 million vote cast in that year's presidential election. Despite the customary level of "horse-trading in appointments to senior posts," Rafsanjani's cabinet, to a large degree, reflected his main objective: reconstruction of the shattered country. To this end, he assembled his administration of Western-educated technocrats and social reformers, and he called it "the cabinet for reconstruction," with Khatami as one of its key social reformers as the Minister of Culture and Islamic Guidance (Ehteshami and Zweiri, 2007, p. 3).

By the time of Khomeini's death in 1989, the Islamic Republic's attempt to export its revolution had not only failed but had led the Persian Gulf states to solidify against Iran. As a result, the Arab monarchies came together in the Gulf Cooperation Council (GCC), an organization largely devoted to containing Iranian influence. Along these lines, the Arab sheikhdoms increased "their security ties to the United States and generously supported Saddam Hussein's military in his war with Iran" (Takeyh, 2006, p. 65).

Soon after Khomeini's death, Rafsanjani and his technocrats began to assert their identity and political platform. They had risen to critical positions in the professional associations, the modern business community, and state bureaucracies. For Rafsanjani, Iran could best preserve its revolution only "under the aegis of the rational and logical polity." (Hamshahri, February 17, 1996). 
The unstable circumstances following the revolution could be one of the main reasons for the Iraqi invasion in 1980. The fear of the Export of the Revolution and Iran's influence in the Middle East united almost all Arab states in supporting Iraq logistically and financially, though formally they had declared themselves neutral (Pakei, 2007, p. 169). Furthermore, Western counties and the Soviet Union gave Iraq political and military support. They hoped that Saddam Hussein would be able to save the world from the fundamentalists in Iran (Tarock, 1999, p. 43).

As the war ended, the main concern was the reconstruction of the shattered economy and a recovery plan for the years of inefficient central planning and the restrictive war economy. It was in 1986 that Iran for the first time, started to debate the issue of privatization, borrowing money from international financial institutions and liberalization of economic activity, but these debates did not make much legislative progress at the time. This was so until the end of the war and the rise of the Rafsanjani administration in 1989. This period is known as reconstruction proved that Iran was suffering not only from a collapsed economy but also from profound international isolation. The eight years of war and the image of Iran as a country trying to export its ideology and exerting its influence in the Middle East created a real challenge for foreign policy decision-makers. To overcome these problems, Iran dramatically needed assistance from the international community. In this regard, the sixth Organization of Islamic Conference (OIC) summit in 1991 was a valuable opportunity for Iran. Rafsanjani, as the Iranian president, participated in this conference and in negotiating with Islamic leaders. The result was effective since more than ten Islamic countries decided to renew their diplomatic relations with Iran. 
However, the rapprochement towards the West was very slow and dominated by suspicion (Juneau, 2015).

Ehteshami (1995) argues that the essence of Rafsanjani's foreign policy had been the restoration of stability to the Persian Gulf region, and further and faster reintegration into the world capitalist system. Rafsanjani specifically named South Korea and Turkey as the successful examples of the Third World and possible models for Iran to follow in the postwar period (Keyhan Havai, 13 December 1989), and in terms of greater participation in regional and global organizations such as the Islamic Conference Organization (ICO).

Rafsanjani believed that the normalization of Iran's international relations was a precondition of economic restoration and reconstruction of the country which suffered tremendous damage as a result of the eight-year war with Iraq. Therefore, economic factors were a crucial component of Rafsanjani's efforts to redesign Iran's international relations in a less confrontational manner. He stated that "reconstructing Iran's economy required achieving three primary goals: 1) developing "normal" diplomatic relations with the outside world; 2) improving Iran's access to Western technology, particularly in oil infrastructure; and 3) integration of Iran into the world economy to increase Iran's socioeconomic development" (Rafsanjani, 1995, p. 30).

The security of the Persian Gulf became a top priority of Rafsanjani's foreign policy, as Iran required the Persian Gulf countries to assure the free flow of oil. Iran depends on Persian Gulf stability for its international trade, an area where more than 90 percent of its international trade, including oil export, has taken place (Amirahmadi 1993, p. 100; Milani 1994, p. 93). Rafsanjani also hoped that good relations with Persian Gulf neighbours would increase investments from Arab countries and open up Arab markets for Iranian products. 
In fact, after the ceasefire, Iran was able to substantially improve its trade relations with its smaller Gulf neighbours and create a free zone on its islands of Kish and Qeshm to attract Foreign Direct Investment (FDI) (Milani, 2001). In this regard, Rafsanjani argued that the stability of the Persian Gulf region would be ensured by the local regimes, not external powers. He emphasized that instead of "promoting Shi'a uprisings and encouraging other countries to emulate Iran's revolutionary model," Iran had to pursue economic and security cooperation. The success of this idea required the withdrawal of American forces from the Persian Gulf region. However, as Takeyh argues, the Iraqi invasion of Kuwait revealed that the local regimes could not rely on themselves for their security. Although relations between Iran and the Persian Gulf states did improve in terms of the establishment of formal diplomatic ties and volume of trade, the level of defence cooperation between these countries and the United States significantly increased, with "American enforcing the containment of Iran and the no-fly zones from military bases in Saudi Arabia and Kuwait" (2006, pp. 66-7). The improved relations between Iran and Persian Gulf countries were evident during the Gulf Cooperation Council (GCC) in December 1990 summit in Qatar, where the organization declared that it would welcome future cooperation with Iran and the country's participation in regional security arrangements (Ramazani, 1992).

Trade relations between Iran and regional Arab countries, especially Saudi Arabia, expanded during Rafsanjani's presidency since Iran proved that it no longer sought to export its revolution and challenge the regional status quo. Furthermore, Iraq's invasion of Kuwait made Saudi Arabia realize that "Iran was the only country in the region that could contain Saddam's regional ambitions" (Monshipour and Dorraj, 2013, p. 142). However, distrust and ideological competition have complicated the relationship between Iran and 
Saudi Arabia since then. Among these complicating factors, "mutual threat" has been significant. Iranian leaders view the Saudi government as responsible for the U.S. presence in the region and as being complicit in imposing sanctions on Iran. For its part, Saudi Arabia has been opposed to any deal between Iran and the U.S. because it believes that any improvement in Iran-U.S. relations may lead to Iran becoming a more powerful actor in the Persian Gulf region (Monshipour and Dorraj, 2013).

In addition to Persian Gulf countries, Rafsanjani hoped to establish cordial relations with European countries. However, two incidents: Mykonos and the Rushdie Fatwa, defeated his attempts. The assassination of Kurdish dissidents at the Mykonos restaurant in Berlin in 1992 led German courts to conclude that key Iranian figures had been involved (Reuters, 10 April 1997). Subsequently, the EU recalled its ambassadors from Iran in protest and suspended all ministerial contact. The trial verdict was passed the month before Khatami's election. However, ambassadors returned six months later, following extensive negotiations between Khatami and Khamenei. Furthermore, the Fatwa that Khomeini issued against Salman Rushdie, the author of Satanic Verses, in February 1989 resulted in the withdrawal of European ambassadors from Iran. The Rushdie affair complicated relations between Iran and European countries even after the death of Khomeini (Rakel, 2008, p. 169).

It is worth mentioning that one of the main goals of Rafsanjani's administration was a stable society that would fulfill the Iranians' economic needs. Along these lines, pragmatists would seek to transcend Khomeini's populist policies by emphasizing private sectors and attracting foreign investments. This would entail borrowing from the World Bank and agreeing to partial foreign ownership of domestic industries (Takeyh, 2006, pp. 
40-1). To this end, his administration decided to join the World Trade Organization (WTO). In 1995 Iran submitted a request for WTO observer status, but the WTO ignored Iran's request due to United States pressures (Salehi, 2014, pp. 192-200). President Clinton accused Iran of supporting terrorism, opposing the Arab-Israeli peace process, and pursuing weapons of mass destruction. He issued Executive Order 12957 in March 1995. In addition to cancelling the Conoco contract, this order banned American companies from participating in oil development projects in Iran. Two months later, he issued Executive Order 12959, which imposed a comprehensive embargo on all American trade and investment in Iran. Thereafter, the U.S. Congress passed, and Clinton signed, the IranLibya Sanctions Act (ILSA) in 1996 (Ejazee and Niakooee, 2014, pp. 194-5).

Meanwhile, in December 1992, the European Council adopted a policy of critical dialogue towards the Islamic Republic. This policy was based on four principles: 1) the violation of human rights, 2) the Fatwa against Salman Rushdie, 3) weapons procurement, and 4) Iran's skepticism towards the Palestine-Israel peace process (Sabet-Saeidi 2008, p. 58). These initiatives by both sides led to some tangible results. The Rafsanjani administration stressed its readiness to reconcile with Iran's Arab neighbours and the West (Struwe, 1998). European countries considered Iran, with a population of 60 million, to be a suitable country for investment. By doing so, Europeans would benefit from Iran's influence in the Shiite community in Lebanon and surmount major obstacles for the release of Western hostages in Lebanon. In this period, Iran's foreign trade relations improved, particularly with Germany, France, Britain, and Italy (Dadandish, 2012, p. 64). It must be taken into account that the European countries were the main buyer of Iran's oil and 
adopted a different position toward the Islamic Republic compared to the U.S. (Samoudi and Hatamzadeh, 2012, p. 152).

The Critical Dialogue, however, was harshly criticized by the U.S. and Israel. From the U.S. perspective, the Critical Dialogue was not a serious policy strategy and would be unable to bring about any significant changes in Iran's behaviour. At the same time, it undermined U.S. efforts on sanctions and gave European firms a competitive advantage over their American counterparts (Indyk, 1993, p. 7).

In order to overcome these challenges, Rafsanjani attempted to separate political issues from economic ones, which might have enabled Iran to trade with the U.S. regardless of the absence of diplomatic relationships between these two countries. He believed that Iran could not trust the United States to resume political relations because it did not intend to treat Iran based on mutual respect. Therefore, he emphasized economic cooperation between U.S. companies and their Iranian counterparts. As a result, the Islamic Republic signed a $\$ 1$ billion contract with The Conoco Companies in the oil and gas industry. Despite his moderate foreign policy, Clinton, as noted above, terminated the contract on 11 March 1995 (Ejazee and Niakooee, 2014, pp. 190-191).

In summary, after the end of the Iran-Iraq war in 1988 and the Cold War in 1991, it can be argued that coalition-making became the dominant strategy in Iranian foreign policy. The policy required Iran to accept the current order of the international system, to respect international norms and principles, to attempt peaceful coexistence with other countries, particularly cooperation with the neighbours and European countries to solve economic problems and crises resulting from the revolution as well as the Iran-Iraq war. In other words, during this time, as Haji-Yousefi (2016) argues, “Iran's foreign policy moved from 
a domestic-oriented and isolationist policy towards external-oriented and cooperations one" (p. 6).

\section{Iranian Foreign Policy Under the Khatami Presidency (1997-2005)}

Since the Iranian foreign policy under Khatami will be discussed in depth in chapter four, here I only briefly highlight the key elements which resulted in a paradigm shift in Iran's external behaviour.

Until 1997, the foundations of Iranian foreign relations had been deeply shaped by Islamic ideology and revolutionary aspirations. Such discourse dramatically changed after 1997 by the victory of Khatami with a new social, political, and economic agenda, as well as a new approach in foreign policy. In domestic politics, Khatami supported political and cultural openness by emphasizing civil society and the rule of law, protected human rights, increased opportunities for women's social and political participation, and the growth of NGOs (Amuzegar, 2006). On the foreign policy front, he pursued an inclusive global discourse through his Dialogue Among Civilizations discourse, a kind of antidote to Samuel Huntington's Clash of Civilizations thesis. Tolerance, peace, and understanding were the cornerstone of Khatami's rapprochement to the international community (Tazmini, 2009).

Khatami's worldview and personality were the crucial elements of his success. Even his appearance, as a tall, elegant, good looking and smiling clergyman, substituting Gucci shoes for the traditional na'alayn (strapless clerical footwear), and dressing up for different occasions, presented a great contrast to his old-fashioned and unattractive rival, NateqNouri. He was a mild-mannered man with a reputation for good humour, even temper, tolerance for opposing views, and a preference for discussion and debates over fights and 
quarrels. Ideologically, he was, judging from his published writings, considered an openminded liberal (Amuzegar, 2006, p. 60).

He emphasized that Iran had to adopt a pragmatic and moderate foreign policy that was respectful of international norms. He stressed the right of nations to self-determination and insisted that Iran did not seek to dominate neighbouring states. Early in his presidency, by introducing the idea of Dialogue Among Civilizations, Khatami declared that "we must try and establish a dialogue...this way we can bring about coexistence without enmity" (quoted in Jones, 2009).

Khatami had a different perspective towards foreign policy. He suggested that in foreign affairs, a state should utilize all international means to persuade others. In other words, Khatami suggested that Iran had to avoid rhetorically or practically hostile behaviour to maintain national interests. He also expressed Iran's willingness to establish good relations with all nations that respect its independence, dignity, and interests. He added that Iran "would not interfere in the affairs of others," nor would it allow any power to interfere in its domestic affairs (Khatami, 1997). These beliefs became crucial components of his discourse of Dialogue Among Civilizations. During his visit to the General Assembly of the United Nations in September 2000, Khatami proposed to call 2001 the Year of the Dialogue of Civilizations, which was accepted by the General Assembly. Having developed the idea of Dialogue Among Civilizations, Khatami began to establish meaningful and constructive relations with the international community, including the great world civilizations such as Greece, Italy, India, and Egypt. Iran has had relations with Greece, Italy, and India for centuries; however, relations between Iran and Egypt had deteriorated since the Islamic Revolution. Khatami expressed his willingness to 
remove the tension between these two countries. The normalization was significant for Iran since Egypt as the largest Arab state has been an active participant in the Middle East diplomacy (Wastnidge, 2016). Khatami focused on common grounds, and gradually, he was successful in improving Egypt-Iran relations. In addition, Khatami's achievement in normalizing relations with Persian Gulf Arab states was considerable. Regarding the relation with the European Union, Khatami insisted that his government would not carry out the Fatwa against Rushdie; and after extensive negotiation with Khamenei, Khatami managed to secure the return of European ambassadors to Tehran, which was a significant shift in Iranian foreign policy (Tazmini, 2009, p. 85). In sum, Khatami's belief system and worldview, which was based on détente, and dialogue instead of confrontation, enabled him to prove to the international community that Iran, as an active member of the latter, could play a constructive role to create a peaceful environment from which all international actors could benefit.

Khatami's achievements, however, were undermined by Bush's announcement of the "Axis of Evil," which resulted in increased pressure from Iranian neo-conservatives who criticized Khatami for overlooking Iran's economic problems. For them, the priority was the improvement of the living standards of the people; therefore, the promotion of political reforms was a violation of revolutionary goals. The neo-conservatives found a new concept: economic justice. With the election of Ahmadinejad in 2005, foreign policy dramatically shifted from a pragmatic approach under Rafsanjani and peaceful coexistence under Khatami to a rhetorically more hostile attitude, especially towards the West and Israel. The situation even worsened due to the nuclear program, which will be discussed later. 


\section{Iranian Foreign Policy Under Ahmadinejad (2005-2013)}

Ahmadinejad represents a group of younger ideologues closely connected to the revolutionary and military forces such as the Islamic Revolutionary Guard Corps (IRGC), and the Basiji militia. Most members of Ahmadinejad's cabinet had careers in the IRGC and security forces. These appointments were controversial even in Iran, where personal loyalty often takes precedence over qualifications or competence. A former deputy foreign minister noted that his ministry was humiliated by unparalleled interventions and pressures from outside and that experts were replaced by ideologues (Thaler et al., 2010, p. 86).

The worldview of these neoconservatives was dominated by the events of 1979 and the argument that Iranian society had been unsuccessful in realizing the revolutionary Islamic principles. Social groups associated with the revolution were adversely affected by the reform policies of Khatami and felt that their hard-fought-for revolutionary aims had been undermined by Khatami's reformist policies. According to them, the reform movement was more focused on political change than the role of these social groups in establishing the Islamic state. They felt that they had been betrayed and that the regime had been "kidnapped" by liberals, intellectuals, and unreligious people (Ehteshami and Zweiri, pp, 70-72). During his electoral campaign, he accused his two predecessors of having failed to establish a "true Islamic state" in Iran (Pakel, 2008, p. 122).

During Ahmadinejad's presidency, because of the emphasis on security as opposed to Khatami's diplomacy approach, the IRGC gained more weight in policy debate. For instance, the IRGC was more concentrated on its role in the resistance and exporting the revolution through the success of the Qods Force in Lebanon and Iraq. As a result, the IRGC would benefit from this increased visibility by gaining more resources and increasing 
its prestige. Moreover, the government, as the reaction to the perceived threat posed by the U.S., reinforced the IRGC's emphasis on protecting the revolution (Thaler, 2010, p. 92; Kazemzadeh, 2007).

In Ahmadinejad's belief system, the nation-state is defined in the framework of Islamic-Shi'a ideology and worldview; this means government is not of a secular nature and is completely religious. Iran's national identity has an essential element that is the priority of the Islamic revolution and ideals and values resulting from it; this identity is the product of Islamic identity, Islamic revolution, and Iran in which Islam and the Islamic revolution have priority over Iran. Translated into the realm of foreign policy, this worldview would result in two assumptions: 1) The Islamic Revolution is not considered a national and limited revolution; instead, it is extra-national and extraterritorial, based on the belief that its ideology is religious and universal; 2) The goal of foreign policy is to expand the values related to the sovereignty of Islam in order to establish an international Islamic community. As a result, Iran would reject the existing international order since it is not compatible with Islamic values (Eivazi, 2008, p. 209-219).

In his first few months in office, Ahmadinejad adopted an aggressive approach in foreign policy. Firstly, he rejected the two-state solution to the Israel-Palestine conflict accepted by Khatami. In October 2005, he affirmed: “As the Imam [Khomeini] said, Israel must be wiped off the map." Secondly, his denial of the Holocaust and declaring the "Holocaust as a myth fabricated for the creation of Israel" escalated the tension between Iran and the West (Amir- Arjomand, p. 197). In fact, Ahmadinejad's foreign policy rested upon two pillars: confrontation with the West, and interaction with the rest. Although he hoped for a closer relationship with the Muslim world, his approach brought the reverse. 
For instance, for countries such as Turkey, Pakistan, Tunisia, Morocco, Bahrain, Qatar, Kuwait and Oman, which have attempted to build links with Israel, Ahmadinejad's call for the destruction of Israel not only led them to unify in support of against Israel but caused the Arab world collective condemnation of Ahmadinejad's message (Ehteshami and Zweiri, 2007, p. 119).

Vakil (2006) argues that in 2005 Ahmadinejad's announcement to "look to the East" became the main direction in Iran's foreign policy to balance the West. It seemed that Ahmadinejad attempted to distance his government from the previous governments, which he regarded as his political antithesis. Ahmadinejad and his administration believed that Iran's Islamic nature had been problematic for the West, not its policies and foreign behaviours, while Khatami had believed that Iran's foreign policy caused distrust between Iran and the international community. Therefore, Khatami had proposed Dialogue Among Civilizations with the aim of confidence-building and détente. On the other hand, Ahmadinejad regarded the West, particularly the U.S. hostility towards Iran, as a deeper phenomenon, and believed that the U.S. threat to Iran is an existential one. He argued that if Iran moderated its policy and behaviour towards the West, just and constructive relations would not form but, as the nuclear negotiation under Khatami proved, they would enhance their expectations (Molana, 2009; Mohammadi, 2009).

But why did Ahmadinejad decide to subvert Khatami's achievements of improving Iran's image by adopting a radical, even violent, discourse against the West and Israel? According to Taheri (2006), there are two main reasons for Ahmadinejad's decision: firstly, he desired to portray his opponents, especially Khatami and Rafsanjani, as "weaklings" motivated by personal interests in exchange for prestige and business deals. 
He believed that the goals of the Islamic Republic were compromised by the newly rich mullahs, so the goals needed to be regenerated by the new generation of non-mullahs who had grown up with the revolution; the second reason for Ahmadinejad's provocative moves concerned his belief that international politics was nothing but the surface manifestation of a deeper Clash of Civilizations (p. 100). In other words, Rafsanjani and Khatami were Others to Ahmadinejad, whom he attempted to be distinct from. Ahmadinejad criticized Rafsanjani's construction policy, maintaining that development was an American plan to restore U.S. domination in Iranian culture, politics, and economy. He also criticized Khatami and his administration as U.S.-dependent intellectual and political puppets who had undermined the basis of the Islamic Republic and religious beliefs (Rajabi, 2007, p. 26).

Moreover, according to Ahmadinejad, Khatami's foreign policy was passive, defensive, and based on compromise. They believed that while Khatami's government cooperated with the West over different issues such as crises in Iraq and Afghanistan, and compromised on Iran's nuclear issue, it was nonetheless placed in the Axis of Evil and condemned by the West. Additionally, it was argued that the reformists never achieved any advantage from the West in exchange for suspending uranium enrichment as they expected; thus, their attitude towards the West was simplistic and mistaken. Therefore, it was necessary for Iran to adopt a new approach towards the West, which was mainly aggressive and offensive (Mohammadi, 2008, pp. 81-89; Molana and Mohammadi, 2009).

Reformists and pragmatists opposed Ahmadinejad's foreign policy. They believed that Ahmadinejad's approach was too provocative. Moreover, they argued that international politics could be a non-zero-sum game, while Ahmadinejad viewed it as a zero-sum game. 
Reformists and pragmatists criticized Ahmadinejad's approach for "confronting the dominant rules of the game" in diplomacy and seeking to establish "relations with nations rather than governments" and, by inference, export the revolution (Al-Hoseyni, 2008). In contrast, during the reformist period under Khatami, Iran both considered downgrading its ties with Hezbollah to help Tehran reconcile with Washington and sought détente with the Persian Gulf Arab states (Rajaee, 1999; Yektafar, 2008; Hashim, 2008).

The divergence between these two approaches towards foreign policy is clear. When Khatami emphasized détente and dialogue with the other international actors, it implied that he accepted the international order and the rules of the game and maintained that Iran would be willing to have constructive relations with the rest of the world, including the West. However, he suggested a better paradigm in order to establish more peaceful relations among the states. Contrary to Khatami, Ahmadinejad challenged the international order and refused to interact with the West; instead, he developed relations with "likeminded" countries such as African and Latin American ones (Arghavani Pirsalami, 2013, pp. 95-96).

Under Khatami's presidency and his Good Neighbours policy, Iran had peaceful relations with the Persian Gulf states (for more detail, see chapter four), whereas during Ahmadinejad's rule, as a result of previously mentioned factors, relations with the regional states were not favourable. For this reason, Iranian foreign policy shifted towards "noncontiguous regions" (Haji-Yousefi, 2010). However, regarding Central Asia and the Caucasus, despite some similarities such as cultural, historical and linguistic factors, Iran was not able to play an active role for various reasons: 1) a difference in the nature of political systems; 2) different political ideologies; 3) the strong and effective presence of 
other non-regional actors; 4) a major difference in interpreting security and concepts such as terrorism and religious fundamentalism; and, 5) not paying enough attention to regional economic problems by Iran despite the existence of economic cooperation potentials (Hunter, 2010, p. 169-173; Haji-Yousefi, 2005, p. 110).

Some scholars suggest that Ahmadinejad used foreign policy to improve his government's legitimacy and to cover the domestic crisis of not being as legitimate as previous presidents. In other words, when Ahmadinejad's government's ability to fulfill domestic expectations dramatically decreased, its incentive to shift the attention from domestic politics to foreign policy increased. For example, in the 2008 Parliamentary elections, the Ahmadinejad government pointed to the brave resistance against perceived external threats. He again used this tactic during the campaign for the June 2009 presidential election (Thaler et al., 2010, p. 77; Kazemzadeh, 2007).

\section{Iranian Foreign Policy Under Rouhani (2013-present)}

Rouhani was deputy speaker of the fourth and fifth terms of the Parliament of Iran, Secretary of the Supreme National Security Council from 1989 to 2005, and chief nuclear negotiator under Khatami's presidency. In June 2013, he became the president of Iran.

Rouhani believed that the country's main problems were rooted in its foreign policy. Therefore, his foreign policy agenda focuses on resolving both the nuclear issue and easing tensions with the outside world, especially Iran's Arab neighbours, and the West. Along these lines, during his presidential campaign, he maintained Iran should engage in serious negotiations with Western countries, reduce regional conflict through constructive engagement with its immediate neighbourhood, and concentrate on its economic recovery and the general prosperity of Iranian society (Afkar News, 24 September 2005). He added 
that the well-being of Iranians should take priority over its nuclear program (Monshipour and Dorraj, 2013, p. 133).

In order to achieve these goals, Rouhani assigned Mohammad Javad Zarif, a career diplomat who had been the chief negotiator in some of Iran's international negotiations such as Resolution 598 negotiations, as the minister of foreign affairs (Iranian Diplomacy, August 12, 2013). In addition, Rouhani decided to bring back the Iranian nuclear dossier from the National Security Council to the Ministry of Foreign Affairs (Haji-Yousefi, 2018, p. 235). In this regard, Ahmadinejad's discourse of resistance was replaced by a conciliatory approach that focused on incremental steps and reciprocity.

Zarif (2014) set the stage for this conciliatory approach to international relations by mentioning that the global system has changed significantly concerning the way nations conduct foreign policy, something made necessary by globalization. In contrast to discussions of foreign policy by Khamenei, Zarif avoids any mention of religion or an ideological approach to foreign policy. The current foreign policy of Iran, according to Zarif (2014) was to enhance its regional and global stature; to promote its ideals, including Islamic democracy; to expand its bilateral and multilateral relations, particularly with neighbouring Muslim-majority countries and nonaligned states; to reduce tensions and manage disagreements with other states; to foster peace and security at both the regional and the international levels through positive engagement, and to promote international understanding through dialogue and cultural interaction.

The divergence between Ahmadinejad and Rouhani's worldviews originates from different perspectives on whether Iran should be guided by diplomacy or provocation. Rouhani, by using Iran's nuclear program, distinguished between these two approaches. 
He maintained that, on the one hand, there were moderates who believed that the nuclear controversy could continue to cause Iran serious problems, so they proposed discussion and flexibility as a possible solution. On the other hand, there were neoconservatives who saw a weakened United States as an opportunity to use Iran's new regional influence (Rouhani, 2007b). Thus, the first group sought to reassure the international community about Iran's aims and reduce the possibility of isolation and sanctions, whereas the other welcomed confrontation in an assertive foreign policy, which rejected its predecessors' passive diplomacy.

Additionally, he maintained that the Iranian government "still have not reached an agreement on many problems, on how to conduct our foreign policy, on how to deal with our interlocutors, on how to present our policies to the world opinion" and "are still debating whether we should place development or justice at the center of our focus-i.e., whether to behave as a state or as a revolution" (Rouhani, 2008a). Considering national interests as the most important elements led him to argue that sustainable development required security and self-confidence and, therefore, a moderate foreign policy (Nahavandian, 2008).

By introducing a discourse of moderation, Rouhani sought to redesign Iranian foreign policy. Unlike his predecessor, who made the nuclear program a crucial and identityrelated topic, Rouhani hoped for a fair and peaceful dissolution of the dispute with the West over Iran's nuclear program. Similar to Khatami, he attempted to improve Iran's position in the international system through constructive interaction with the world. Therefore, constructive interaction became one of the key concepts in his moderate foreign policy. Rouhani maintained that easing tension, creating mutual trust, and interacting 
constructively was the path that his administration would adopt and explicitly asserted that Iran never wanted war with the world.

On the other hand, he added that Iran could never be forced to submit through embargos or never be threatened into war; rather, the only way to interact with Iran was by way of conversation between equals, mutual trust-building and bilateral respect, and reducing hostile approaches (Jafari and Emamjomehzadeh, 2018, p. 149). Rouhani respected Khatami's achievements of Dialogue Among Civilizations discourse and announced that he intended to continue his policies. One could argue that Rouhani's belief system was close and similar to Khatami's since both employed common themes in order to explain their foreign policy. Rouhani, like Khatami, emphasized conversation, mutual respect, understanding, and constructive relations with the aim of coexistence with other countries.

Immediately after Rouhani's election, the White House released the following statement: "the U.S. remains ready to engage the Iranian government directly in order to reach a diplomatic solution that will fully address the international community's concerns about Iran's nuclear program.” (www.whitehouse.gov/the-pressoffice/2013/06/15/statement -press-secretary-election-Iran)

Rouhani's first public appearance on the world stage as the new Iranian president was at the UN in New York in September 2013. He was preceded by President Obama who had offered Iran a new relationship. When Rouhani took to the podium, he said: "I listened carefully to the statement made by President Obama today at the General Assembly. Commensurate with the political will of the leadership in the United States and hoping that they will refrain from following the short-sighted interest of warmongering pressure groups, we can arrive at a framework to manage our differences." 
(http://gadebate.un.org/sites/default/files/gastatements/68/IR_en.pdf). Shortly afterwards, Rouhani had a telephone conversation with Obama. This was remarkable because, since 1979, there had been no direct exchange between the leaders of the two countries. Once again, there seemed to be hope for the betterment of U.S.-Iranian relations (Malici and Walker, 2017, p. 174).

\section{Iran's Nuclear Program}

\section{Background}

Iran's nuclear program began with the support of the United States during the First Pahlavi era. Iran began its first nuclear program in 1957, with the signing of the Atoms for Peace Program between Iran and the U.S. (Bowen and Kidd, 2004, p. 263).

In 1967, the first nuclear facility was established at Tehran University, and the U.S. and West Germany sent the research reactors. In 1968, Iran signed the Non-Proliferation Treaty (NPT), according to which Iran had the right to develop research, production and use of nuclear energy for peaceful purposes, and to have access to equipment, materials, and scientific and technological information (Rakel, 2008, p. 201)

Construction of the Bushehr plant began in 1974 by the West German Siemens Company and subsidiary Kraftwerke Union. Iran intended to have built 20 nuclear plants by the beginning of the 1990s (Cottrell,1978, p. 428). The Islamic Revolution, however, fundamentally changed the expectation since it caused the Western countries to be skeptical about completing the nuclear program. This skepticism escalated during the IranIraq war. After the end of the Iran-Iraq war in 1988, the nuclear program was restarted with Russian and Pakistani assistance (Bowen and Kidd, 2004, p. 263). 
In 1992, the Iran-Iraq Arms Non-Proliferation Act was implemented by the U.S. which banned the transfer of "goods or technologies that led Iran and Iraq to obtain chemical, biological, nuclear or destabilizing numbers and types of advanced conventional weapons" (Aghazadeh,2013, pp. 140-2). Since France, the United Kingdom, and Germany were not willingly engaging in multilateral sanctions against Iran, the U.S. created the Iran and Libya Sanctions Act (ILSA) in 1996, which placed an embargo on individuals and foreign companies who exported petroleum from Iran or participated in oil and gas development projects. This Act was extended by George W. Bush in 2001 and later modified to the Iran Sanctions Act (ISA) in 2006 (Ritcher, 2016, pp. 162-3).

During Ahmadinejad's presidency, after the International Atomic Energy Agency (IAEA) reported Iran to the United Nations Security Council for not giving full access to nuclear facilities, the Security Council adopted Resolution 1696 in July 2006, marking the beginning of broad multilateral sanctions against Iran (Aghazadeh, 2013, p. 148). The resolution called for Iran to suspend the enrichment and development of the nuclear program until the IAEA was able to conduct investigations about the intent of Iran's program. Iran responded by announcing that it would not stop the program, insisting it was for peaceful purposes. The Security Council, in turn, responded with Resolution 1737 banning countries from any technical or financial assistance or the sale of any equipment or materials which could conceivably be used for Iran's enrichment program. These sanctions tightened further with Resolutions 1747 (2007), 1803 and 1835 (2008) and 1929 (2010), in addition to strict sanctions imposed by the European Union (Aghazadeh, 2013, pp. 149-55). 
In the following, I highlight the different approaches to Iran's nuclear program from both sides: Iran, and the United States. From the Iranian perspective, I will explain Khatami's approach, Ahmadinejad's, and Rouhani's, followed by the American point of view.

In Khatami's era (mid-2002) when disclosure about undeclared sites at Natanz became public, it was a great probability that the IAEA Board of Governors would refer the issue to the UN Security Council, where the issue would become political rather than technical. Less than a year after the al-Qaeda attacks on the U.S., Iran was cautious not to provoke the U.S. into military action. At the same time, increased U.S. presence in the region made Iran feel that the U.S. might find an excuse to attack Iran after the Iraqi invasion. Iran may have interpreted the disclosure as a direct threat against its government. To manage the situation, Khamenei assigned then-Secretary of the Supreme National Security Council (SNSC) Hassan Rouhani (now Iran's president) as the chief of the negotiations team. Rouhani's main goal was to prevent the issue from being sent to the UN Security Council. To this end, Iran had to reassure the international community of its peaceful intentions. Therefore, Iran agreed, in the Sa'dabad Declaration in Autumn 2003, to subject its program to the Additional Protocol to the Nuclear Non-Proliferation Treaty (NPT), a set of inspections more intrusive than those previously in force, and to suspend its enrichment activities. A year later, in Paris, Iran and three principal European Union states known as the EU3 (Great Britain, France, and Germany) made a similar agreement. Iran emphasized that the suspension was temporary and voluntary and that Iran itself would terminate it (Thaler, 2010, pp. 92-95). 
In order to portray Iran as a flexible actor who pursues confidence-building with the international community, Rouhani stated that acceptance of the suspension was necessary to remove any excuses that America might have to attack Iran. He went further by arguing that since the suspension was voluntary, it would not prevent us from achieving our peaceful nuclear program (Rouhani, 2008). However, the new 2004 neoconservative Parliament members criticized the mentioned agreements; and by Ahmadinejad's election as president in 2005, Iran's negotiations with the EU3 were postponed.

Some scholars maintain that Iran's nuclear program had two functions during Ahmadinejad's presidency. Domestically, it became a matter of factional rivalry and state legitimacy. In other words, it allowed the government to criticize reformists whose achievements went against the interests of the Islamic Republic. With this line, Ahmadinejad, in more than 30 trips to different provinces, argued for Iran's nuclear rights and against the West's attempt to deny these. He called his predecessors traitors and accused them of giving comfort to the enemy through their dissent and their exaggeration of the dangers of sanctions (Mardom Salary, 28 November 2007). At the same time, he claimed that the nuclear issue had enhanced national unity and increased Iran's prestige (Jomhury-e Eslami, 20 August 2006).

Internationally, Ahmadinejad's administration believed that diplomacy was a losing game in favour of the U.S. As a result, resistance, determination to fight bullies and securing Iran's rights became the main pillars of their approach to the nuclear issue. Thus, they rejected the limits agreed upon by Khatami's administration and determined to restart the enrichment and centrifuge programs. In fact, Ahmadinejad's government did not take the threat of the IAEA referral to the UN Security Council as seriously as its reformist 
predecessors had, and thus found itself in that chamber by the end of 2006 (Green et al., 2009, pp. 52-65; Chubin 2006; Thaler et. al., 2010, pp. 95-98).

From the American perspective, excepting the Obama Administration, all U.S. governments since 1979 have employed some policy of containment when dealing with Iran. Containment was articulated by George Kennan during the Cold War, aiming at decreasing Soviet Union influence. After the 1991 dissolution of the Soviet Union, this policy was perceived as a successful model to be used against other threatening states that did not seek peaceful relations with the U.S., including post-revolutionary Iran. Different U.S. administrations have applied more passive or active forms of containment against Iran in forms of sanctions, diplomatic efforts at isolation, covert actions, and military deployments to the Persian Gulf to pressure Tehran (Pollack, 2010).

After the Revolution, the Carter Administration settled on a policy of containment to prevent the impact of the Iranian Revolution from spreading beyond Iran's borders. This policy was perpetuated under the Reagan Administration despite the Iran-Contra negotiations. George W. Bush, despite the initial interest in engagement with Tehran, was never able to translate this initial interest into a tangible policy shift. The Clinton administration, however, more strictly implemented a dual containment policy towards both Iran and Iraq, resulting in the imposition of tough Congressional sanctions against Tehran and pressuring international companies against investing in Iran. Despite tentative cooperation between the George W. Bush administration and Iran after the 9/11 attacks, containment was again employed. In 2002, revelations regarding Iran's nuclear sites convinced the U.S. to adopt a new policy beyond containment. George Bush employed a 
"carrot and stick" approach to pressure Iran to change its behaviour (Vakili, 2017, pp. 813).

Obama's approach was relatively different in the sense that he called for engagement with Iran based on mutual respect (Obama, 2009). He sought to find a diplomatic solution for one of the most sensitive issues between the two countries. Moreover, he believed that trust and communication between Tehran and Washington would reduce tensions on a number of Middle East issues. To this end, secret negotiations mediated through the Omani government began in 2013, which led to a more open discussion on the issue with relatively greater trust and confidence emerging between the US and Iranian counterparts. In the same year, the victory of Rouhani as the president paved the way for more constructive engagement. The result of the negotiations was a first agreement known as the Joint Plan of Action (JPA) signed in November 2013, followed by a Framework Agreement concluded in April 2015. The final JPA was concluded in July 2015, concluding over three years of negotiations (Vakili, 2017).

Nonetheless, criticism of this agreement mounted on both sides. In the U.S., opponents argued the deal would reinforce Iran's regional influence. Similarly, Saudi Arabia and Israel stated that the deal would legitimize the Islamic Republic and bolster Tehran's authority in the Middle East. Under this circumstance, the Trump Administration's shift in policy revoking the nuclear agreement was not surprising (Malici and Walker, 2017).

\section{Conclusion}

Although some scholars argue that Iranian foreign policy since the 1979 revolution has remained largely unchanged over time, examination of the different periods reveals that 
under Khatami's presidency, Iran's foreign policy went through a paradigm shift. The dominant revolutionary paradigm consisted of Anti-Colonialism, Third Worldism, and Islamic Worldism. This paradigm gradually began to change with Rafsanjani's presidency. However, domestic issues and international pressures prevented Iran from improving its relations with the international community. It was under Khatami's presidency that Iran was able to establish peaceful relations with the rest of the world. Nonetheless, Ahmadinejad's aggressive approach dramatically undermined Khatami's achievements, and again Iran was viewed as a revisionist actor who challenged the regional and international order. 


\section{CHAPTER THREE}

\section{OPERATIONAL CODE ANALYSIS}

In this chapter, I first examine the different approaches to foreign policy based on actorstructure relations, followed by the emergence of the cognitive approach to foreign policy analysis. I then explore the Operational Code as a theoretical framework that examines the role of the leader's belief system on foreign policy decision making, through answering five philosophical and five instrumental questions. In the last section, data analysis will be provided.

\section{Historical Background}

Foreign policy as an empirical subject matter transcends the boundary between the internal and external spheres of a state; therefore, its substance originates from issues of both domestic and international politics. This has complicated the analysis of foreign policy since the beginning of this field of study. It has also added to the difficulties of assessing the role of actors and structures in foreign policy analysis (Carlsnaes, 2012, p. 113).

Foreign policy was first established as an academic field shortly after the Second World War: about the same time Hans Morgenthau introduced realism, a doctrine that became the dominant paradigm of foreign policy during the Cold War. By linking the concept of power to national interests, Morgenthau believed that he could provide a universal explanation for the external behaviour of all sovereign states. During this period, a new school of thought known as behaviouralism emerged, proclaiming that social sciences should be 
more scientific by emulating the methodology of the natural sciences. This new scientific approach had an impact on the realist approach to foreign policy (Carlsnaes, 2012, pp. 115$6)$.

By encouraging researchers to look "below the nation-state level of analysis to the players involved," Snyder, Bruck and Sapin provided a method with which scholars would be able to combine the domestic and international considerations which influenced the foreign policy decisions of individuals (Hudson, 2007, p. 15). Snyder, Bruck and Sapin's 1954 work altered the focus of foreign policy study from the usual emphasis on outcomes, and instead gave prominence to decision making (Hudson, 2005, p. 16). Rosenau argued that identifying the internal and external contributors to foreign policy decisions was insufficient and a middle-range theory could serve to bridge the gap between "grand principles and the complexity of reality" by utilizing several levels of analysis to provide "multilevel and multicausal" explanations of foreign policy decisions (quoted in Hudson, 2005, p. 16). Harold and Margaret Sprout (1956) advocated the study of the "psychomilieu" of individuals and groups making foreign policy. In other words, the Sprouts were recommending that scholars look at how policymakers interpret the international and operational environment in which they are making their decisions.

\section{Actors, Structures, and Foreign Policy Analysis}

Actors and structures are two crucial components of Foreign Policy Analysis, whose interaction results in the development of both. As Hill puts it: "foreign policymaking is a complex process of interaction between many actors, differentially embedded in a wide range of different structures. Their interaction is a dynamic process leading to the constant 
evolution of both actors and structures" (2003, p. 28). In what follows, I will examine the role of actors and structures in different approaches to foreign policy analysis.

\section{Role of Actors and Structures in "Process" Approaches to Foreign Policy}

Under the category of "process" approach to foreign policy, the focus is on the question of "what foreign policy decision-makers are thinking and doing," that is to say, what is their purposive behaviour in the dynamic and complex process of making foreign policy decisions on behalf of the state. Therefore, what needs to be examined and explained is the process rather than policy. Carlsnaes argues that the focus of this approach is "human decisional behaviour" (2012, p. 115). Since the aim of this approach is the process of foreign policy decision-making, rather than policy, scholars of this camp sometimes use the Foreign Policy Decision Making (FPDM) to describe the focus of their study. As summarized by Hudson, foreign policy is "centred on foreign policy decision making (FPDM) as it is performed by a human being." (2007, p. 165).

This process has a certain consequence for the role assigned to actors and structures. A central question here is what function the state plays in the approaches that focus on the decision-making process. The answer would be different depending on the two different perspectives-whether viewing the state from a realist point of view as the main and independent actor on foreign policy or considering foreign policy actors in terms of the domestic functioning of a state in which decisions are made by a number of decisionmakers acting on behalf of the state. Carlsnaes argues that the answer is clear: states are not conceived as unitary actors but rather as an institutional structure within which individual decision-makers act (2012, pp. 116-7). 


\section{Role of Actors and Structure in "Policy" Approaches to Foreign Policy}

This approach concentrates on explaining specific policy rather that the decisionmaking process. In other words, in this approach, foreign policy action has been distinguished from the decision-making preceding it. Therefore, policies are viewed as resulting from such a process rather than being part of it. Charles Hermann maintains that what is significant here is the purposeful action that results from the individual's or group of individuals' decisions; therefore, "it is not the decision, but a product of the decision" (1978, p. 34).

Carlsnaes argues that contrary to the process-oriented approach, this perspective does not prioritize either actors or structures in a particular way since the focus is on policy undertaking and not the behaviour of any particular entity within a specific structural environment (such as decision-making). Therefore, this perspective can apply to a number of different and not necessarily compatible analytical approaches.

In what follows, I will address two approaches that emphasize both actor and structure, namely neoclassical realism, and constructivism.

\section{Neoclassical Realism}

One of the main focuses of realism is the use of a state's power in an anarchical international system. Waltz (1979) has merged realism with system-level theory to find patterns of behaviour in states who pursue the same policies to maintain their security. For

Waltz, the structure of the international system is the decisive force, and not the internal characteristics of the states $(1979$, p. 80). Rose (1998) introduced neoclassical realism to incorporate external and internal variables. He argues that the scope of a state's foreign policy is driven by its place in the international system as well as its relative material 
capabilities; however, the impact of such power capabilities must be translated through intervening variables at the unit level (1998, p. 146).

According to neoclassical realists, a theory of foreign policy limited to systemic factors alone is misguided. They suggest that to understand the way states interpret and respond to their environment, one must analyze how systemic pressures are translated through unitlevel such as decision-maker's perceptions and domestic state structures. For neoclassical realists, leaders can be constrained by both international and domestic politics. Furthermore, "anarchy is neither Hobbesian nor benign but rather murky and difficult to read." (Rose, 1998, p. 152). Therefore, neoclassical realism occupies a middle ground between structural theories and constructivism. The former implicitly accept a clear and direct link between systemic constraints and unit-level behaviour, and the latter denies that any objective systemic constraints exist, arguing instead that international reality is socially constructed and, in Wendt's words, "anarchy is what the state makes of it." (Rose, 1998, p. 152).

\section{Constructivism}

Constructivism was first introduced to International Relations theory in 1989 by Nicholas Greenwood Onuf. In his book World of Our Making, Onuf maintained that states exist in a world where many entities such as social facts are made by human action, as opposed to brute facts which are independent of human action. To clarify the difference between social facts and brute facts, Houghton suggests that some aspects of our surroundings are naturally given and do not depend upon our ideational beliefs about them. For instance, if I play golf in a storm and get hit by lightning, I will be electrocuted whether I believe in the existence of electricity or not. This is a brute fact. Other aspects of our 
surroundings are social facts, which do depend for their existence on what we believe about them, and indeed whether we believe in them at all. Money is a classic example of such a social construction (2007, p. 28).

Constructivist thinkers highlight the significance of the social construction of world politics as opposed to realist and neorealist scholars who believe that international relations are shaped by rational behaviours of actors who pursue their interests and maintain their security based on cost-benefit calculations. While realism and neorealism understand international relations as driven by the states' security and material interests which mostly translated in terms of power, constructivism emphasizes that international relations are shaped by the interaction of the actors' identities and preferences, and how they view themselves in relation to other actors in the international community (Griffiths et.al., 2008, p. 52).

One of the main differences between constructivism and neorealism relies on their perception of the nature of the international system. Whereas neorealists maintain that the structure of the international system is anarchic and is created by "distribution of capabilities" (Waltz, 1979), constructivists suggest that its structure is also made of "social relationships" and constructed by the three elements of "shared knowledge, material resources and practices" (Wendt, 1998, pp. 416-18). In other words, while for neorealists anarchy might generate competition and conflict and lead to a more conflictual than the peaceful international environment, for constructivists anarchy is not the only determining element, since under anarchy different social structures define actors' identities, and accordingly, their national interests and the way they secure them. In Wendt's words "anarchy is what states make of it" (2013). 
Furthermore, where realists and liberalists see international actors as inherently presocial "atomistic egoists" whose interests are formed "prior to social interaction" and who initiate such interaction solely for material gains and "strategic purposes," for constructivists actors are intrinsically "social" beings whose identities and interests are "the products of inter-subjective social structures." (Reus-Smit, 2005, p. 193).

Constructivism has been categorized into three different forms: systemic, unit-level, and holistic. Systemic constructivism represented by Alexander Wendt follows the Waltzian neorealist "third-image" level of analysis, focussing on the interaction between unitary state actors rather than internal or domestic factors. In other words, this trend of constructivism de-emphasizes states' domestic politics and its role in forming their identities and interests. Unit-level constructivism concentrates on the relationship between domestic social and legal norms and identities and interests of states. Finally, holistic constructivism aims to bridge the gap between "the international and the domestic" by explaining how states' identities and interests are constituted. In other words, holistic constructivism integrates both domestic and international identities into a unified analytical perspective that treats these as two faces of a single social and political order (Reus-Smit: 2005, pp. 194-201).

In sum, one could argue that, from a constructivist perspective, foreign policy is a product of discursive factors and socio-cultural constructions. The basis of foreign policy is the state's identity which is created through the interaction in collective "meaning structure" (Wendt,1992, p. 397). This argument, however, does not undermine the importance of the material factors of international relations. States are not exogenous entities whose interactions are defined based on their interests. States are endogenous 
entities whose identities are socially constructed through interaction with the other actors. In other words, it is the states' constructed identities, based on shared understanding and socio-political situation in the broader international system, which determine the states' foreign policy.

\section{Approaches from an Actor-Based Perspective}

One of the most important contributions of Foreign Policy Analysis, according to Hudson (2005), is to identify the point of theoretical intersection between the primary determinants of state behaviour, namely the material and ideational factors. Hudson argues that the point of intersection between these two factors is not the state, but human decisionmakers. According to her, states are not agents because states are an abstraction and therefore have no agency. Only human beings can be true agents, and their agency is the source of all international politics and all changes therein (2005, pp. 2-3). Hudson goes further by arguing that if international relations theories do not include human beings, they portray a world with a lack of change, creativity, persuasion, and accountability. She suggests that including human decision-makers brings some advantages to international relations theories. One of these advantages is the possibility of incorporating the concept of agency, a definite advantage since international relations theories currently provide much more insight into structure than agency. Another major advantage is to move beyond a description of natural law-like generalizations of state behaviour to a more satisfying explanation of state behaviour, which requires the contributions of human beings (2005, pp. 3-5). 


\section{Traditional Approaches to Foreign Policy Analysis (FPA) and its Criticism}

The realist paradigm defines state behaviour as a series of power relations. States pursue national interests based on power and security (Morgenthau, 2005; Mearsheimer, 2001). Realist scholars believe that human nature is selfish, short and self-interested (Doyle, 1997, pp. 42-47) and attach these characteristics to states to analyze their behaviours. This approach was challenged by scholars who tried to understand how beliefs affect foreign policy decision-making. In their article Decision-Making as an Approach to the Study of International Politics, Snyder, Bruck, and Sapin (1962) suggested that "a state is its decision-makers." They provide a framework for focusing on individuals within the state. Scholars in this camp maintain that state behaviour is partly a product of the psychology and personality of the leader. Different leaders have different decision-making tendencies based on their perspectives of the political universe and their leadership style (Herman, 1978). The early foundation of Operational Code analysis was also introduced at this time when Nathan Leites adopted psychoanalytical methods to study the political strategy of the Soviet Politburo.

The notion that beliefs matter in international relations has been challenged by structuralist scholars. Indeed, in his neorealist theory, Kenneth Waltz argues that individuals cannot be a reasonable unit of analysis in international relations since human nature is fixed. He introduces two levels of analysis: unit-level (state) and structure-level (system). Neorealists redefine state relations not in terms of human nature but as a result of the constraints imposed by the structure of the international system (Waltz, 1979). Neorealists view the state as a "black box" or "billiard balls," meaning that regardless of their domestic politics, all states have the same functions which are rooted in the structure 
of the international system. They go further by suggesting that the international system, unlike a sovereign state, lacks the authority to regulate states' behaviour, which leads to the constant possibility of conflict. These circumstances make states rely solely on themselves to maintain their security, and to increase their military capabilities. These systemic conditions explain states' external behaviour (Waltz,1979, pp. 65-66). Constructivists, on the other hand, accept that an anarchical international system guides international politics but suggest that its nature is determined by its culture rather than by the distribution of capabilities (Wendt, 1999).

Tetlock (1998) argues that beliefs as subjective representations of reality matter in the explanation of world politics but are not addressed very well by general international relations theories. For instance, neorealists emphasize the balance of power among states while neoliberals highlight international regimes, and constructivists focus on socially constructed norms that impact foreign policy choices. Katzenstein (1996), however, maintains that leaders can act to change the balance of power, domestic and international institutions, and cultural norms over the long term.

Moreover, the notion that human nature is constant and fixed and that individuals have the same characteristics and approach politics, in the same way, has been challenged as well. Hudson argues that the mind of a foreign policymaker is not a tabula rasa; it contains complex and related information and patterns, such as beliefs, attitudes, values, experiences, emotions, memory, and self-conceptions. Culture, history, geography, economics, political institutions, ideology, demographics, and other factors shape the social context in which the decision-maker operates (2005, p. 10). 
Byman and Pollack (2001) argue that instead of actors with uniform characteristics, a variety of different personalities occupies the highest political offices. Once we accept that human nature is not constant and that different personalities make different decisions, then the argument that individuals matter becomes more convincing. Similarly, Herman et al., (2001) distinguished between different leadership types by linking certain characteristics and certain leadership styles. They argue that leadership style influences foreign policy outcomes. Different leadership styles lead to different governmental decisions. In other words, they believe that studying structures and states alone does not fully explain international politics and decision-making.

Moreover, Foreign Policy Analysts (FPA) do not assume that decision-makers will act in a classically rational fashion. In fact, as Hudson and Vore (1995) argue, FPA is built upon what the social sciences-psychology, economics, sociology, anthropology, geography, etc.--are learning about human decision making. This challenge to the concept of rationality resulted in a new generation of theories called the cognitive revolution. Rational Actor Models (RAM) embody the assumption that actors in the decision-making process - individual leaders, bureaucracies, or regimes — are acting rationally in the "long term and persistent national interests of the country and since the national interests do not change, changes in leadership have little consequences" (according to Neack, as quoted in Richter, 2016).

The cognitive model is based on bounded rationality, meaning that while individuals' actions are based on rationality, their actions are bounded by their environment and their knowledge of the subject at hand. Cognitive theories differ from rational choice models and structural theories regarding the role of beliefs as a causal mechanism. Whereas the 
latter assigns to beliefs the endogenous role of transmission belts (Rose, 1998, p. 147), conveying information about the environment at home and abroad, cognitive theories assume that beliefs have an exogenous role: instead of merely reflecting reality, they direct the decisions of leaders by shaping the leaders' perceptions of reality, acting as mechanisms of cognitive biases that distort, block and recast incoming information from the environment (Schafer and Walker, 2006).

Although Rational Actor Models are quite useful in that they identify foreign policy decision making at the micro-level, if one accepts that any condition can be interpreted in various ways, depending on the historical background, the personalities and experiences of individuals and their social and cultural influences, then all these elements are significant in decision-making. The elements identified can similarly undercut a rational cost/benefit analysis (Schafer and Walker, 2006, pp. 210-212). Hermann and Hermann also posit that among government authorities, there is always the "ultimate decision unit" that is the final arbiter of foreign policy. Besides a predominant leader, it may be a single group of people or a unit of multiple autonomous actors. They suggest that the nature of the decision unit will have important effects on foreign policy (1989, pp. 362-365).

Furthermore, some critics of rational choice like Young and Schafer suggest that assumptions of leaders' rationality are misguided because views on power and interest vary among both states and individuals. They believe that power and interest are not objective but cognitive in nature and emerge from the beliefs that individuals hold about those concepts (1998, p. 64). In other words, the cognitive approach can analyze world politics by examining the leaders' belief system. 
To conclude, there two different approaches to the study of Foreign Policy: one focusing on states-as-actors, whose decision making is influenced by the constraints of the international system, and the other focusing on individuals-as-actors who make decisions under the influence of a broad range of additional constraints and incentives located within states and even within individuals (Walker, 2011, p. 7). Walker and Schafer (2011) claimed that the Operational Code, to some degree, can fill this gap, on the grounds that the conceptualizations of foreign policy behaviour is that it is constituted by the words and deeds carried out on behalf of one state toward other states and informed by the beliefs and preferences of individuals acting alone or in the larger group within the state. These words and deeds display the exercise of power in world politics, as they are designed to establish domination, submission, cooperation or conflict relationships regarding issues between states in the international system. It is desirable to analyze those kinds of behaviour and the consequences of those decisions (pp. 223-224).

\section{Foreign Policy Analysis and Behavioural International Relations}

Although research on the cognitive and psychological characteristics of individual decision-makers has been viewed with considerable skepticism by scholars advancing structural explanations of foreign policy, this trend has been developed over the last decades. Contrary to realist and neorealist scholars, cognitive approach thinkers rejected rational choice and argued that individuals have an important role in making foreign policy decisions since their beliefs and their personality, as well as the way they process information, have a considerable impact (Carlsnaes, 2012, p. 122). 
The behavioural approach in political science in the first half of the $20^{\text {th }}$ century spread to the field of international relations as a reaction to the limitations of "legalisticinstitutional" explanations of political phenomena, which failed to explain political behaviour in the absence of information about the attitudes and beliefs of individuals and groups within institutions and societies (Walker, 2011, p. 22). Some scholars believe that "Behavioural IR" could be an alternative to macro-level analysis (Hudson, 2005; Mintz, 2077; Schafer 2000).

Alex Mintz (2007), in his article Why Behavioural IR? argues that Behavioural IR is an important social-psychological approach to Foreign Policy Analysis and International Relations. He maintains that while a structural perspective focusing on the interactions among states could explain large-scale, long-term, continuity and change in world politics, focusing on individuals and small groups as actors within states could analyze the smallscale, short-term behaviours that produce patterns of continuity and change in larger political systems.

One of the positive aspects of Behavioral IR is its ability to address the issue of preference formation. While the rational choice approach takes preferences as exogenous and then examines the likelihood of outcomes as a product of strategic interaction, Behavioural IR, by providing the ability to examine the origins of the preferences, enables us to increase our understanding of motives as well as explanation of behaviour (James, 2007).

The work of Margaret G. Hermann attempts to categorize leaders with specific reference to foreign policy dispositions. The core of her research is the leaders' personal characteristics $(1970,1978)$. Using a modified operational code framework, in conjunction 
with content analysis, she is able to compare and contrast leaders' beliefs, motivations, decisional styles, and interpersonal styles.

Additionally, political psychology can assist us in understanding foreign policy. Under certain conditions factors such as high stress, high uncertainty, the dominant position of the head of state in Foreign Policy Decision Making (FPDM), and the personal characteristics of the individual become crucial in understanding foreign policy choice. One of the efforts at a systemic study of leader personality effects is the concept of Operational Code, an idea originating with Leites (1951), and refined and extended by one of the most important figures in this area of research: George (1969). George defined the leader's estimation of his or her own power to change events, as well as an exploration of the preferred means and style of pursuing goals (Hudson, 2005, pp. 5-12).

The application of a behavioural approach to individuals as actors in world politics embodies a set of concepts, methods, and heuristic devices as a research program. Walker et al. (1998) identify and present applications of these characteristics of behavioural IR within the context of the operational code research program in Foreign Policy Analysis. Operational Code is a neobehavioural approach because it combines features of two older research programs in the study of foreign policy and international relations. It consists of both the concepts of rationality and power and the concepts of beliefs, emotions, and motivations. This neo-behavioural approach to politics focuses on the explanation of foreign policy decisions and their consequences by reference to two political worlds, namely the external world of events, created by the behaviour of other actors, and the internal world of beliefs, generated by the cognitive process of leaders. A leader's operational code connects these two worlds by "representing the external world of events 
as philosophical beliefs about the nature of the political universe and by prescribing strategies, tactics, and moves based on instrumental beliefs for making decisions about the exercise the power vis-à-vis other actors in the political universe" (Walker, 2011, p. 6).

Walker et al. argue that the operational code approach to the general puzzles of conflict, cooperation, domination, and submission in world politics is to examine them both from the perspective offered by the actors and from the system in which they act. In other words, this "dual approach is unified theoretically by the assumption that actors are systems, too." Leaders are individuals-as-actors with cognitive, emotional, and motivational subsystems that constitute an interior system of psychological relations comparable in complexity to the exterior system of states-as-actors and the social relations in which they participate (2011, p. 4). Moreover, they believe that the dual focus on agents and their relations in world politics bridges the subfield of Foreign Policy Analysis and the field of International Relations. In what follows, I will discuss the origins of the operational code approach.

\section{Operational Code}

\section{Background}

Nathan Leites introduced the operational code into political psychology in his two works, The Operational Code of the Politburo (1951) and A Study of Bolshevism (1953). Leites conceptualized the responses of the Politburo to political decisions as a series of decision-making rules and axioms that constituted their worldview. He then drew on psychoanalytic theory and social psychology to account for this worldview and analyze the primary motives and goals of Soviet Leaders. He first identified the shared responsibility of the Politburo's members as a series of decision-making rules, e.g., "push to the limit" 
(in a conflict situation), an axiom, e.g., "politics is war" that constituted the worldview upon which theses rules were based. Then he accounted for their origins with a psychocultural analysis of the fundamental motivations associated with Bolshevism and their manifestation in varying degrees in the personalities of Lenin and Stalin (Walker, 1990).

Fifteen years later in a review article The Operational Code: A Neglected Approach to the Study of Political Leaders and Decision-Making, Alexander George re-examined Leites' analysis of the elite belief system. He referred to Louis Halle, a former State Department planner, observing that "the foreign policy of a nation addresses itself not to the external world, as is commonly stated, but rather to the 'image of the external world' that is in the minds of those who make foreign policy" (Halle quoted by George, 1969, p. 191).

George (1969) maintained that a close examination of what Leites had in mind indicates that he "was referring to a set of general beliefs about fundamental issues of history and central questions of politics as these bear, in turn, on the problem of action." He suggests that these beliefs provide norms and guidelines that impact the leader's choice of strategy and tactics. Yet, they are not the only variable that shapes decision-making behaviour, although they are some of the most important (p. 191). George (1969) removed the psychological dimension to the Operational Code when he argued that it could be investigated without references to psychoanalytical hypotheses since these beliefs can be inferred or postulated on the basis of the kinds of data, observational opportunities, and other methods available to political scientists (p. 195).

To find the best solution for the problem, according to George, the actor typically engages in a definition of the situation, meaning, a cognitive structuring of the situation 
that will clarify the nature of the problem, related to previous experience, and consider the appropriate problem-solving activities. The actor perceives reality through his cognitive map of politics, which includes his/her belief system (1969, p. 200).

Based on Leites' work, George developed ten questions regarding an individual's philosophical and instrumental beliefs, which have since become the basis for all operational code analyses. He conceptualized a leader's operational code as a political belief system with philosophical beliefs guiding the analysis of the context for self and others, and instrumental beliefs prescribing the most effective strategy and tactics for achieving goals (Walker 1990, p. 405; Walker, et al., 1998). Before explaining the philosophical and instrumental questions, it will be useful to elaborate on what beliefs mean and why it is significant in analyzing foreign policy.

\section{What Are Beliefs?}

Beliefs are what we hold to be true. They may be propositions about causal relationships or fundamental assumptions about the way the world operates. Larson suggests that schemas and belief systems should be distinguished from attitudes. Whereas attitudes include both cognitive and evaluative components, schemas and belief systems are purely cognitive (1994, p. 18).

Rokeach defines a belief system as "the total universe of a person's beliefs about the physical world, the social world, and the self" (1968, p. 123). In the broadest sense, a belief is a subject's association between an object or entity and certain attributes and characteristics. The object can be behaviour or a policy, and the attribute can be a certain outcome. In other words, beliefs are a causal mechanism about what we think is true (Renshon, 2008, p. 822). This is what Renshon calls "a comprehensive, personal, 
philosophy $[\ldots]$ of the universe and of human life" (1986, p. 735). A belief system is a distributive web composed of perceptions and knowledge about the world and him/herself (Holsti, 1962, p. 254). At the core of this web lies the master beliefs about political life. Every other idea is derived from these master beliefs (Rosenberg, 1986).

\section{The Importance of Beliefs}

Beliefs act as a primary filter through which other perceptual processes operate, whether the effect is to maintain stability or not. In the context of political decision-making, leaders react not to an objective reality but to a subjective reality that is filtered through their belief system (Holsti, 1962, p. 244). The reason is that the world where individuals live is inherently complex. It is full of contradictions, ambiguity, and surprises. Because of their relatively limited ability to process vast amounts of information, humans are, by necessity, theory driven. Beliefs provide essential utility for decision-makers and facilitate decision-making by providing ready frameworks for analyzing situations and providing answers to fundamental questions about the way the world works and the sources of human behaviour (Renshon, 2008, pp. 822-3).

Tetlock (1991) suggests that beliefs facilitate foreign policy decision-making by serving as a framework to assess different policy options. Beliefs function as principles to evaluate different outcomes (28). In other words, in decision making, leaders often face various constraints, incomplete and ambiguous information about the situation, and the inability to predict consequences. To deal with these limits, individuals use beliefs as guides for decision-making. Furthermore, Walker, Schafer, and Young highlight that beliefs say something about political characteristics. Beliefs reflect the political personality and the way a leader behaves in a social environment (quoted in Riger, 2017). 
Schafer and Walker (2011) argue that the interactions between the two worlds- the world of beliefs whose elements define the possible "state of mind" and the world of events whose elements define the different "state of behaviour"-is significant because it reduces "the entropy (possible states) in each world by reducing the possible states of mind and behaviour and thereby explaining stability and change in each world” (p. 13).

\section{Operational Code Analysis}

The operational code approach to the study of belief systems asks what the individual knows, feels, and wants, regarding the exercise of power in human affairs: What are his or her beliefs about the distribution of power between self and others? What is the likely exercise of power by others and, the most effective exercise of power by the self? Because the exercise of power is a social phenomenon involving both self and others-as either the subject or the object of the exercise of power-operational code analysis identifies a political belief system about self and others and how they interact with one another (Schafer and Walker, 2006, p. 29). However, as George (1969) argued, the operational code does not include all the beliefs that influence the leader's behaviour, but only those that are relevant in the context of political decision-making. As previously stated, George

divided these beliefs into philosophical beliefs (general assumptions regarding the fundamental nature of politics, conflict, and the Other) and instrumental beliefs (assumptions concerning the methods leaders should apply to achieve their goals). An individual's operational code is composed of his/her answers to certain questions. These questions include the following:

\section{Philosophical Questions:}


1) What is the essential nature of political life? Is the political universe essentially one of harmony or conflict? What is the fundamental character of one's political opponents?

2) What are the prospects for the eventual realization of one's fundamental political values and aspirations? Can one be optimistic, or must one be pessimistic on this score? And in what respect the one and/or the other?

3) Is the political future predictable? In what sense and to what extent?

4) How much control or mastery can one have over historical development?

5) What is the role of chance in human affairs and historical development?

\section{Instrumental Questions:}

1) What is the best approach for selecting goals or objectives for political action?

2) How are the goals of action pursued most effectively?

3) How are the risks of political action calculated, controlled, and accepted?

4) What is the best timing of action to advance one's interest?

5) What is the utility and role of different means for advancing one's interests? (George, 1969, pp. 201-216).

George hypothesized that the first operational code belief about the nature of political life and the "image of the opponent" was central. For example, much of the traditional Bolshevik operational code derived from the belief that the enemy was hostile. And Putnam, in his study of elite belief systems in Italy and Britain, found that the belief about whether politics was conflictual or harmonious was correlated with many other beliefs, including the willingness to compromise with political opponents (quoted in Larson, 1994, p. 19). In the same vein, Ole Holsti (1977) notably developed a typology of belief systems 
using two master beliefs, namely "what are the fundamental sources of conflict?" and "what is the fundamental nature of the political universe?". He maintains that an individual's view of the nature of political life is the prominent factor that influences other elements of the individual's belief system. Holsti focused upon this belief as a point of departure, along with the three levels of analysis developed by Waltz to begin the construction of his typology (Walker, 1983, p. 181). The intersection of answers to these two questions and their resulting typologies are illustrated in Table 1.

Table 1. Holsti, 1977, p.158

\begin{tabular}{|l|c|c|}
\hline $\begin{array}{c}\text { What are the } \\
\text { fundamental sources } \\
\text { of conflict? }\end{array}$ & $\begin{array}{c}\text { Harmonious } \\
\text { (Conflict is } \\
\text { temporary) }\end{array}$ & $\begin{array}{c}\text { Conflictual } \\
\text { (Conflict is } \\
\text { permanent) }\end{array}$ \\
\hline Human Nature & $\mathrm{A}$ & $\mathrm{D}$ \\
\hline Attributes of Nations & $\mathrm{B}$ & $\mathrm{E}$ \\
\hline International System & $\mathrm{C}$ & $\mathrm{F}$ \\
\hline
\end{tabular}

The varying combinations of these two master beliefs led to six possible personality types: Type A (the political universe is harmonious because of human nature), Type B (the political universe is harmonious because of the attributes of nations), Type $\mathrm{C}$ (the political universe is harmonious because of the international system), Type $\mathrm{D}$ (the political universe is conflictual because of human nature), Type E (the political universe is conflictual because of the attributes of nations), Type $\mathrm{F}$ (the political universe is conflictual because of the international system).

Walker revised the Holsti typology. Instead of the six master personality types, he advanced four personality types: Type A, Type B, Type C, and Type DEF. 


\section{Type A}

According to the Philosophical Beliefs of Type A personality, conflict is temporary and rooted in human misunderstanding and miscommunication. Therefore, misperception and impulsive responses can be the main cause of war. From this perspective, opponents are often viewed as nonrational actors; however, they tend to respond to conciliation. This type of personality is optimistic about a leader's ability and willingness to shape historical development, as well as the predictability of the future and control over it. Based on the Instrumental Beliefs, goals should be established and identified within a framework of shared interest, with the pursuit of flexible strategies that control risks and avoid conflict and tension. Negotiations and compromise are always options, as well as avoidance of the early use of force.

\section{Type B}

According to the Philosophical Beliefs of Type B personality, conflict is a temporary phenomenon, caused by a warlike state. Opponents are rational and deterrable. Optimism is warranted regarding the realization of goals. The political future is relatively predictable, and control over historical development is possible. Instrumental Beliefs identify the optimal goals within a comprehensive framework, any tactic and resource may be appropriate, including the use of force when it offers prospects for large gains with limited risk.

\section{Type C}

According to Type $\mathrm{C}$ Philosophical Beliefs, conflict is temporary and caused by the anarchical state system. However, it is possible to restructure the international system. 
Opponents vary in nature, goals, and responses to conciliation and firmness. Since predictability and control over historical development is low under anarchy, pessimism about the goals outweighs optimism. Instrumental Beliefs establish optimal goals vigorously within a comprehensive framework. Pursue shared goals, but control risks by limiting means rather than ends. Other resources than military capabilities are useful.

\section{Type DEF}

According to Type DEF Instrumental Belief, conflict is permanent, caused by human nature (D), nationalism (E), or international anarchy (F). The main reason for war is unbalanced power. Opponents may vary, and responses to conciliation or firmness are uncertain. Optimism declines over the long run and in the short run depends upon the quality of leadership and power equilibrium. Predictability and control over historical development is limited. When it comes to Instrumental Beliefs, limited goals with moderate means are pursued. Depending on the opponent and circumstance, using military force is an option but only as a final resource (Walker, 1983, 1986, 1990).

\section{Quantitative Method}

Stephen G. Walker undoubtedly has had the greatest impact on operational code analysis since the contributions of Holsti. Walker's first study in operational code was a study of Henry Kissinger published in 1977, the same year as Holsti's important article. Walker acknowledged the essential contribution of Holsti's typology; however, he maintained that there was a need to apply quantitative analysis in order to more accurately categorize operational code (Walker, 1990). Therefore, Walker with the collaboration of Mark Schafer and Michael D. Young introduced the Verbs in Context System (VICS). 


\section{Coding Procedures}

It is possible to do VICS coding either by hand or with a computer. Coding by hand is very labour-intensive and time-consuming. Additionally, human error will always be present and perhaps act as a confounding factor in the statistical model. Coding by computer was introduced when Social Science Automation (www.socialscienceautomation.com) developed an automated full-language software program for personal computers (Profiler Plus), which was intended particularly for at-adistance, psychological assessments of subjects (Walker et al., 1998; Schafer and Walker, 2006, p. 38).

\section{Hand Coding}

As Schafer and Walker explain, coding begins with gathering appropriate texts relevant to the research question. The first step is to highlight the verbs in the texts. Then, the researcher should apply the appropriate code to each verb based on the rules specified later in this chapter. This is followed by identifying the subject as Self or Other.

Here is a list of steps of hand-coding:

1- Identify the verb-based utterance.

2- Code the verb.

A. Identify the transitive verb or verb-based phrase.

B. Specify the positive or negative valence of the verb, whether it is cooperative $(+)$ or conflictual (-). If it is neutral, discard the verb and move onto the next one. 
C. Specify if the verb is a word or deed. Deeds are actions that have been done. Words are promises or threats of future actions or symbolic declarations of support or opposition. All future-tense constructions should be coded as words. D. Specify the appropriate final coding category for the verb from the six possibilities: punish (-3), threaten (-2), oppose $(-1)$, support $(+1)$, promise $(+2)$, and reward ( +3$)$. Note that deeds are always -3 or +3 depending on direction and that words always go into the remaining four categories, $-2,-1,+1$, and +2 . A helpful and shorthand way to specify this on a code sheet is by simply using the numeric value for each category.

3- Specify the subject of the verb:

whether the subject is the speaker himself or herself or it is another actor. The final coding values for the subject of the utterance are either Self or Other.

4- Identify any additional information from the context of the utterance or broader parts of the speech act that might be relevant to your specific research question (2006, pp. 39-41).

By way of example, Schafer and Walker mentioned a quote from Carter's address to the nation on January 4, 1980. He said, "massive Soviet military forces have invaded the small, non-aligned, sovereign nation of Afghanistan...". In this sentence, the verb is "have invaded," whose direction is conflictual (-) and is a deed. Conflict deeds are coded as -3 . The subject is "massive Soviet military forces." Since Carter is the speaker and he obviously does not refer to himself or any of his in-group; therefore, the subject is coded as other $(2006$, p. 41$)$. 


\section{Automated Coding}

Specific instructions for automated coding with ProfilerPlus as general software programs are available from Social Science Automation, Inc. There are some procedures specific to The Verbs In Context System (VICS) that will be explained in the following. As with hand-coding, the process begins with collecting speech acts that are appropriate for the research question. To be read by the software program, the texts must be in digital format. Then the ProfilerPlus will be applied. In the following paragraphs, the quantified methods of operational code will be discussed.

\section{Operational Code Analysis at Distance: The Verbs in Context System}

\section{(VICS)}

At-a-distance methodology means that we assess the psychological characteristics of individuals from a distance without having direct access to them. The fundamental logic informing this method is the assumption that we can infer psychological characteristics based upon the subject's verbal behaviour. What an individual says and how he or she says it is significant in revealing his or her state of mind (Schafer and Walker, 2006, p. 26).

At a basic level, VICS operates in two phases. The first phase focuses on sentences containing verbs, determining whether they are positive (cooperative) or negative (conflictual), and assigning them a level of intensity broken up into deeds and words. Whereas deeds are indicative of action and exercising of power, words are a promise or threat of an action, or supporting or opposing statements regarding others. Intensity ranges from -3 (punish) to +3 (reward). The second phase centers on the attribution of verbs. 
Sentences referring to oneself or the in-group are considered to represent a person's instrumental beliefs. Sentences referring to an Other are considered indicative of the subject's philosophical beliefs (Renshon, 2008, pp. 13-14; Schafer and Walker 2006, p. 23).

Two simple sentences illustrate the logic of this approach: 1) State X attacks State Z; and 2) State $\mathrm{W}$ praises State $\mathrm{Y}$. The two verbs, attack, and praise have a different meaning in terms of state action. State X's action is conflictual in direction and has a very high level of intensity as a negative deed, while State W's is cooperative in direction with a relatively modest level of intensity as a positive word. Deeds indicate the exercise of power in the form of positive and negative actions. Words represent the exercise of power in the form of making threats and promises or in the form of invoking authority to support or oppose actions between states or other agents in world politics (Schafer and Walker, 2006, p. 30$31)$.

The VICS concentrates primarily on verbs in speech acts by our research subjects, such as texts of their private or public statements in the form of diaries, letters, speeches, memoirs, interviews, press conferences, and social media (Twitter, Facebook, etc.), and not on verbs attributed to our subjects in secondary resources or in reports of state actions by external observers such as journalists, historians, or commentators (Schafer and Walker, 2006, p. 31).

By coding the direction and scaling the intensity of the verbs, we realize how the leader or actor understands the exercise of power in the political universe by self or other. Some may see it as very hostile; therefore, they use more conflict-oriented verbs, while others may view it as relatively friendly and use more cooperative verbs to express their beliefs 
about the exercise of power. Verbs that bring no information in terms of direction and intensity are neutral and coded as "0" (Schafer and Walker, 2006, p. 31).

What follows is an overview of the logic of VICS. In each part, the calculation of the index and its logic will be discussed. Schafer and Walker suggest that VICS would begin with the philosophical questions which provide information about the subject's belief regarding the nature of politics and other actors in the political universe, followed by the indices for the instrumental beliefs. They are often identified later by their number, for example, P-1 or I-1, which conforms to the corresponding number of the belief in George's philosophical and instrumental beliefs. Moreover, the authors maintain that they "conceptualize both the first Philosophical and Instrumental beliefs as 'master beliefs'," meaning that, based upon theories of cognitive consistency, the other beliefs within each category should flow from and be theoretically and empirically linked with them" (Schafer and Walker, 2006, p. 33). For this reason, ProfilerPlus automatically calculated the first two indices of both the Internal and Philosophical beliefs. However, the calculation of all philosophical and instrumental questions will be examined in the following paragraphs. 
Table 2 - Steps in the verbs in context system for coding verbs:

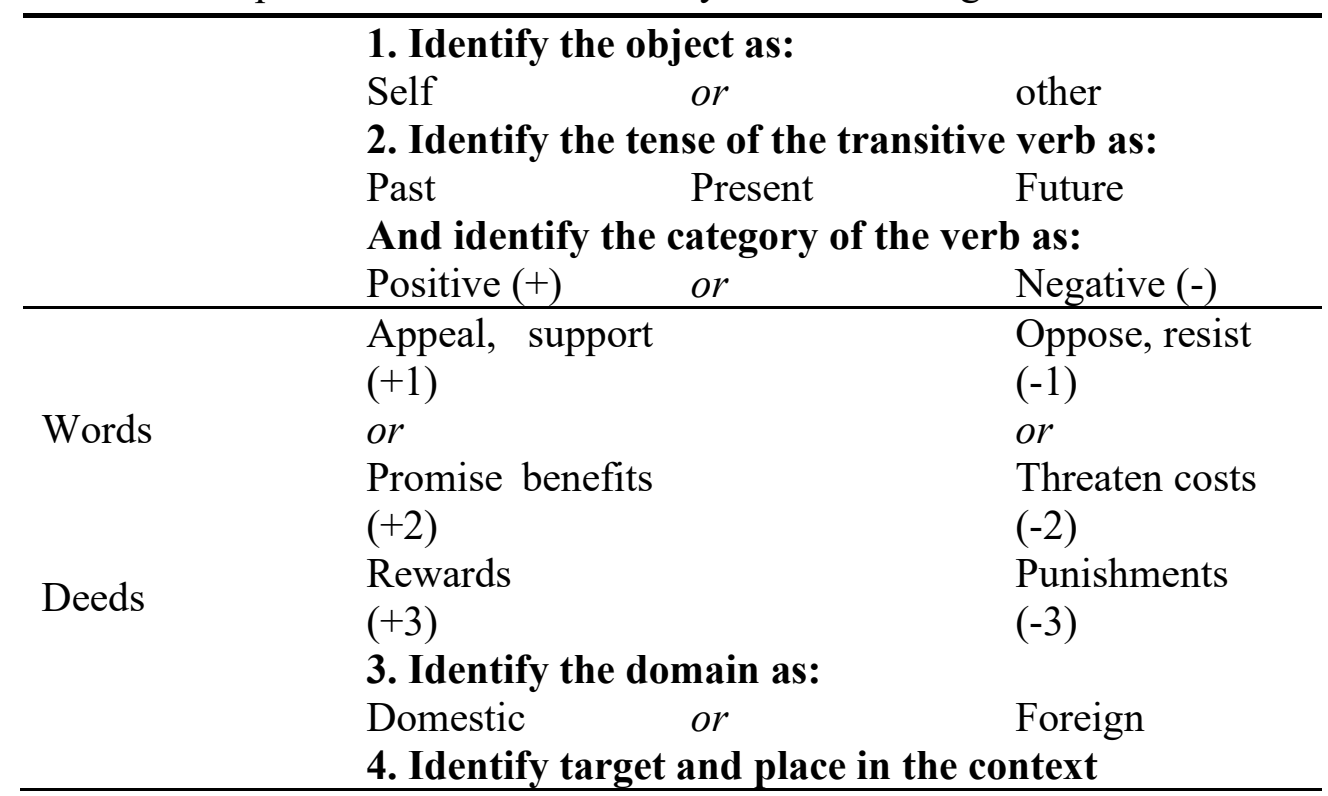

Source: Schafer and Walker, 2006: 32

\section{Philosophical Questions}

NATURE OF POLITICAL UNIVERSE (P-1). This is the "master belief" of the philosophical part of the operational code. Other beliefs are linked to it. Operational code assumes that the leader's images of other actors, their policies, and actions, reflect his or her beliefs about the nature of the political environment. The index calculates the leader's perception about the cooperative or conflictual nature of others. A low score indicates that others are hostile, and a positive one indicates that they are friendly. The index varies between -1 (conflictual) and +1 (cooperative). (Index: \% positive attributions about selfminus \% attributions about others). The $\mathrm{P}-1$ index can be interpreted according to the following scale (Walker et al., 1998, p. 178; Schafer and Walker, 2006, p. 35):

\begin{tabular}{|l|l|l|l|l|l|l|l|l|}
\hline HOSTILE & & & & & & & & FRIENDLY \\
\hline Extremely & Very & Definitely & Somewhat & Mixed & Somewhat & Definitely & Very & Extremely \\
\hline-1.0 & -0.75 & -0.05 & -0.25 & 0.0 & +0.25 & +0.50 & +0.75 & +1.0 \\
\hline
\end{tabular}


REALIZATION OF FUNDAMENTAL VALUES (P-2): Optimism versus Pessimism. This index is based on the leader's perception of the intensity of others' actions. A leader who sees a friendly, positive world is expected to be more optimistic about realizing his fundamental values, and a leader who sees a hostile world of other actors is expected to be more pessimistic. A high number of hostile deeds indicates pessimism, while a high number of friendly deeds indicate an optimistic view about political values. Transitive verbs by others are weighed according to intensity (from -3 to $+3:-3=$ punish, $-2=$ threaten, $-1=$ oppose $/$ resist, $0=$ neutral,$+1=$ appeal $/$ support,$+2=$ promise,$+3=$ reward $)$ and the index varies from -1 to +1 . (Index: Intensity of utterance about others divided by 3). The following continuum shows the possible score for P-1 index (Walker et al., 178, p. Schafer and Walker,33).

\begin{tabular}{|c|c|c|c|c|c|c|c|c|}
\hline \multicolumn{4}{|c|}{ PESSIMISTIC } & \multicolumn{5}{|c|}{ OPTIMISTIC } \\
\hline Extremely & Very & Definitely & Somewhat & Mixed & Somewhat & Definitely & Very & Extremely \\
\hline-1.0 & -0.75 & -0.05 & -0.25 & 0.0 & +0.25 & +0.50 & +0.75 & +1.0 \\
\hline
\end{tabular}

PREDICTABILITY OF POLITICAL UNIVERSE (P-3): This index assesses the extent to which the subject sees others acting in consistent and predictable ways. Schafer and Walker (2006, p. 23) assess predictability by using a dispersion measure that calculates the variation in the distribution of observations across the six verb categories when the subject is talking about the other actors. The logic is that the wider the variety of actions the subject attributes to others, the less predictable are their actions. If the subject sees others engaging primarily in one or two categories of action, then he believes others' actions are more consistent and, therefore, more predictable. The authors maintain that this is not necessarily an assessment of an accurate prediction about others' actions, rather the 
assessment of the subject's belief about predictability. In other words, actors can live in a world where others are pursuing a full variety of cooperative and conflictual actions, but if the actor perceives others as pursuing threats and punishments, then he believes others' next moves are more predictable. The dispersion measure is the Index of Quantitative Variation (IQV), which is a ratio of the number of different pairs of observations in distribution to the maximum possible number of different pairs for a distribution with the same $\mathrm{N}$ [number of cases] and the same number of variable classifications. The formula for the P-3 index is one minus the IQV, which varies between 0 and 1 with lower scores indicating that the subject sees less predictability in the political universe and higher scores indicating perceptions of more predictability.

\begin{tabular}{|l|l|l|l|l|}
\hline \multicolumn{5}{|l|}{ PREDICTABILITY } \\
\hline Very Low & Low & Medium & High & Very High \\
\hline 0 & 0.25 & 0.50 & 0.75 & 1.0 \\
\hline
\end{tabular}

CONTROL OVER HISTORICAL DEVELOPMENT (P-4): The balance between the leader's self-attribution and other-attributions indicates the answers to the fourth philosophical question dealing with the extent to which a leader can control historical developments and political outcomes. This reasoning is based upon inferences from the locus-of-control research dealing with the perception of power in social relationships. If the leader attributes more words and deeds to others, for example, then the locus of control is in others rather than in the self. The greater the leader's control over political outcomes compared to the control by others, the higher the net attributions assigned to the self. (Index: Self utterances divided by the sum of self-utterances plus other utterances. The index varies between 0 and 1 . Low scores indicate that the subject sees the locus of control 
residing more with others, while higher scores indicate that the subject sees self as having more control).

\begin{tabular}{|l|l|l|l|l|}
\hline \multicolumn{5}{|l|}{ CONTROL } \\
\hline Very Low & Low & Medium & High & Very High \\
\hline 0 & 0.25 & 0.50 & 0.75 & 1.0 \\
\hline
\end{tabular}

ROLE OF CHANCE (P-5): The answer to the fifth philosophical question about predicting the future and political outcomes is logically a function of the answers to the third and fourth philosophical questions. That is, the higher the role of chance, the greater the variation in the distribution of acts by others and the lower the leader's net selfattributions. This conclusion is based upon the reasoning that if both the predictability of others and the leader's control over political outcomes are relatively low, then the role of chance is relatively high. (Index: 1 minus [predictability Index(P-3) multiple by the Control Over Historical Development Index(P-4)]. 00 indicates the lowest, and 1.0 indicates the highest role of chance) (Walker and Schafer, pp. 177-9).

\begin{tabular}{|l|l|l|l|l|}
\hline \multicolumn{5}{|l|}{ CHANCE } \\
\hline Very Low & Low & Medium & High & Very High \\
\hline 0 & 0.25 & 0.50 & 0.75 & 1.0 \\
\hline
\end{tabular}

In what follows, I will discuss instrumental beliefs. The first two instrumental beliefs deal with the subject's view on goals, objectives, strategies, and tactics for the self in the political universe. What is important here is not to identify specific goals or objectives for the subject, but the subject's beliefs about the utility of cooperative and conflictual actions as indicated in his or her rhetoric. These will be separated into two broad categories of 
actions, namely strategies and tactics. Strategy varies in direction, while tactics vary in intensity.

\section{Instrumental Questions}

DIRECTION OF STRATEGY (I-1). This index parallels (P-1) by investigating the general balance of cooperative and conflictual utterances the subject makes, except that this index aggregates utterances when the subject is talking about self and the self's ingroup. It represents a leader's strategic approach to political goals and assumes that the more cooperative the leader's strategic approach to political goals, the higher the net frequency of cooperative attributions to the self. This reasoning does not specify how the leader selects goals or what goals she or he selects. However, it does identify the strategic direction the leader adopts in approaching them. (Index: \% positive attributions about self minus $\%$ negative attributions about self. -1.0 indicates conflictual strategy, and +1.0 indicates cooperative strategy) (Walker and Schafer, 2007, p. 758).

\begin{tabular}{|l|l|l|l|l|l|l|l|l|}
\hline \multicolumn{10}{|l|}{ CONFLICT } & \multicolumn{1}{l|}{ COOPERATION } \\
\hline Extremely & Very & Definitely & Somewhat & Mixed & Somewhat & Definitely & Very & Extremely \\
\hline-1.0 & -0.75 & -0.05 & -0.25 & 0.0 & +0.25 & +0.50 & +0.75 & +1.0 \\
\hline
\end{tabular}

INTENSITY OF TACTICS (I-2): Intensity in pursuing a conflictual or cooperative strategy indicates the answer to the second instrumental question. This index represents the tactics of how goals and objectives can be pursued most effectively, and its parallels (P-2). Here again, the verbs will be weighted according to the six-point intensity scale: Punish 3, Threaten -2 , Oppose -1 , Support +1 , Promise +2 , and Reward +3 . By weighting each verb when the subject is talking about self and then dividing by the total number of self- 
utterances, we end up with the average level of cooperative or conflictual intensity the subject demonstrates in his/her rhetoric. The intensity of tactics index ranges from -1 to +1 , with lower scores indicating self's belief about the utility of hostile tactics, and higher scores indicating a belief in the utility of cooperative tactics. The formula of I-2 is the mean intensity of utterances made when talking about self, divided by three (Walker et al., 1998, p. 180).

\begin{tabular}{|l|l|l|l|l|l|l|l|l|}
\hline \multicolumn{10}{|l|}{ CONFLICT } \\
\hline Extremely & Very & Definitely & Somewhat & Mixed & Somewhat & Definitely & Very & Extremely \\
\hline-1.0 & -0.75 & -0.05 & -0.25 & 0.0 & +0.25 & +0.50 & +0.75 & +1.0 \\
\hline
\end{tabular}

RISK ORIENTATION (I-3): Averse to Acceptant. The diversity in the types of acts attributed to the self across several categories indicates the answer to the third instrumental question regarding the leader's approach to calculation, control, and acceptance of the risk of political action. The risks, or undesirable outcomes associated with cooperative and conflictual actions, are the risk of submission associated with a cooperative act in the pursuit of a settlement and the risk of deadlock associated with a conflictual act in the pursuit of domination. This reasoning is based upon the concepts of risk acceptance and risk aversion toward different political outcomes. (Index:1 minus IQV for utterances. 00 indicates Risk Averse (Low Predictability) and 1.0 indicates Risk Acceptance (High Predictability) (Walker et al., 1998, p. 181).

\begin{tabular}{|l|l|l|l|l|}
\hline \multicolumn{2}{|l|}{ RISK AVERSE } & \multicolumn{2}{l|}{ RISK ACCEPTANCE } \\
\hline Very Low & Low & Medium & High & Very High \\
\hline 0 & 0.25 & 0.50 & 0.75 & 1.0 \\
\hline
\end{tabular}


IMPORTANCE OF TIMING OF ACTIONS (I-4): The distinction between conflict versus cooperation indicates answers to the fourth instrumental question regarding the leader's position on the matter of the timing of the action. This index is divided into two. The first one (I-4a) tracks the diversity of leader's tactics based on the distribution of cooperative and conflictual actions. The second one (I-4b) is based on the diversity of words and deeds in the leader's rhetoric. I-4a index: 1 minus absolute value of [\%positive self-attributions minus \% negative self-attributions]. I- $4 \mathrm{~b}$ index: 1 minus Absolute Value of [\%words minus \% Deeds].

\begin{tabular}{|l|l|l|l|l|}
\hline \multicolumn{4}{|l|}{ FLEXIBILITY } \\
\hline Very Low & Low & Medium & High & Very High \\
\hline 0 & 0.25 & 0.50 & 0.75 & 1.0 \\
\hline
\end{tabular}

UTILITY OF MEANS (I-5). The distribution of self-attributions into different categories of cooperative and conflictual acts indicates the answer to the fifth instrumental question regarding the utility and role of different means in the exercise of power. Schafer and Walker conceptualize the exercise of political power as the choice of a control relationship between self and other in which the self seeks or maintains control relationships with others by using different types of words and deeds as positive or negative sanctions.

The Appeal/Support and the Oppose/Resist categories represent positive and negative appeals by self to other's moral values as the means of control. The Promise and Reward categories classify the verbal and physical use of positive sanctions while the Threaten and Punish categories refer to their counterparts in the exercise of negative sanctions as the 
means of control. (Index: for Transitive Verb Categories (Punish, Threaten, Oppose/resist, Appeal/Support, Promise, Reward).

\begin{tabular}{|l|l|l|l|l|}
\hline \multicolumn{5}{|l|}{ UTILITY } \\
\hline Very Low & Low & Medium & High & Very High \\
\hline 0 & 0.08 & 0.16 & 0.24 & 0.32 \\
\hline
\end{tabular}

Source: Interpreting VICS Indices (Walker et al., 2008, pp. 227-231 coding software: profiler plus V.5.8.4 provides by Social science Automation. Inc www.socialsciencesautomation.com

\section{Data Analysis}

In this section, I will first discuss Khatami's personality based on Holsti's typology. Then, I will analyze the data obtained from the application of Profilerplus (Appendix 1). The material analyzed to determine Khatami's OC includes, but is not limited to, speech at the Italian Parliament, in 1999; speech at the World Summit on the Information Society in Geneva, in 2003; Khatami's address to Malaysian and Iranian Entrepreneurs in Kuala Lumpur in 2002; his address at the Conference of the Elite Scholars and Thinkers of Pakistan in 2002; his interview with reporters after the ceremony for Iran's cooperation with Algeria, in 2003; the News Conference in Geneva in 2003, notes on Iran's good relationship with Egypt; his speech at the parliament of the Republic of Azerbaijan in 2004, which discusses the nature of civilizations; his speech at the State University of Yerevan in 2004, about the cultural and political bond between Armenia and Iran; his speech at the 8th Summit Meeting of ECO in2004, which questions the logic of "State terrorism" who intervene in countries to stop terrorism; his speech at a ceremony in Khartoum in 2004, 
which encourages dialogue between Muslim nations and the West; a message to the 12th International Conference on Central Asia and the Caucasus in 2004, which urges regional countries to look to alternate renewable energy sources possibly from the Caspian Sea; an interview with reporters in Tehranin 2004,where he argues for Iran's right to nuclear technology; a message to the 15th International Conference of the Persian Gulf in 2005, where he states Iran will help Iraq achieve a democratic nation, stresses solidarity among Islamic nations, and condemns any military occupation; his address at the University of Zagreb in 2005, where he asserts the importance of intellectuals in today's world, and of not using knowledge ignorantly, and notes the ever presence of wars; his Press Conference in Paris in 2005, where he claims Iran will continue suspension of uranium enrichment as long as negotiations continue. More texts that I have analyzed are provided in Appendix 2.

\section{Khatami's Personality}

According to Holsti's typology, type C personality believes that the political universe is somehow harmonious, and conflict is not a permanent feature of the international system. A type C personality does not believe that conflict will be a permanent feature of world politics. Contrary to those who view conflict as a main feature of the international system, leaders with a type $\mathrm{C}$ belief system argue for the possibility of restructuring the state system in such a way that harmony of interests can be maintained and, therefore, peace can be achieved.

I will discuss Khatami's thoughts and worldview in more detail in the next chapter; however, as part of this chapter, I will examine his belief system.

Khatami believes that conflict might occur because of misunderstanding and miscommunication, but that such a situation is not permanent and could be replaced by 
peace. He also believed that through change within the international system, a harmony of states' national interests could be achieved. Khatami suggested the Dialogue Among Civilizations could overcome the conflict and pave the way for peaceful relations (Khatami, 1997, 2005).

In the realm of foreign policy, Khatami pursued the most cooperative approach in foreign policy since the Islamic Revolution in 1979. The main themes of his approach include détente, Good Neighbour relations with the Persian Gulf countries, and a Dialogue Among Civilizations within the international community (Khatami, 2005; Petito, 2007; Amuzegar, 2006). Khatami's belief system reveals that he has a type C personality, according to Holsti.

\section{Analysis of Khatami's Operational Code}

Khatami's first Philosophical belief, (P-1) is the Nature of the Political Universe. The result for this index was 0.39 , which revealed a relatively strong positive and cooperative approach to the political universe. It illustrates that Khatami has a positive worldview in the sense that he does not view world politics as conflictual, and he is inclined towards cooperative strategies. He insisted on cooperation rather than hostility.

The second Philosophical belief (P-2) measures how optimistic a decision-maker is about the possibility of being able to accomplish her/his political goal. This belief is closely related to the first philosophical belief in the sense that, according to the decision-makers, conflict is either temporary or permanent in the political universe. Therefore, one can assume that the more "optimistic the leader's diagnosis for realizing their political values, the less negative and more positive their net intensity of attributions to others in the political universe" (Walker et al., 1998, p. 179). The analysis of the P-2 value was at 0.17 , not highly 
optimistic but positive nonetheless, which can be interpreted as showing that Khatami was optimistic about his chances of achieving his goals. He believes that conflicts stem from the anarchical system and that through dialogue, peace can be achieved.

While philosophical indices reveal Khatami's fundamental beliefs about himself and the political world he lives in, the Instrumental indices measure his view on strategies and tactics in the pursuit of his political goals. The first Instrumental belief (I-1) measures what he believes is the best strategy to follow when dealing with others. Khatami's score is 0.64 , a strong positive number, which illustrates that he would strongly and undoubtedly pursue cooperation rather than conflict. Similarly, the second Instrumental belief measures the direction and intensity of the strategy, in other words, which tactic Khatami believes to be of greater utility: hostility or cooperation. In line with the scoring pattern in I-1, Khatami's I-2 is measured at 0.27 , which indicates that he views cooperation to be more useful than hostility. (Khatami's belief system will be discussed in more depth in the next chapter).

\section{Comparison Between Ahmadinejad's Operational Code and Khatami's Operational Code}

Malici and Buckner (2008), in the article Empathizing with Rogue Leaders: Mahmoud Ahmadinejad and Bashar al-Asad, examined Iranian and Syrian leaders' operational codes. Based on their studies, the indices of Ahmadinejad's philosophical beliefs (P-1), and (P-2) measured 0.07 and -0.02, respectively, compared to Khomeini's corresponding (P-1) and (P-2) indices which were 0.07 and -0.023 (Ritcher, 2016). It reveals that Ahmadinejad was very similar to late Ayatollah Khomeini. On the one hand, in Ahmadinejad's belief system, the nation-state is defined within the framework of Islamic-Shi'a ideology and worldview. His government was completely religious, as opposed to secular, and what takes priority 
in terms of Iran's identity is the Islamic revolution and the ideals and values resulting from it. In the realm of foreign policy this worldview translates into the two following beliefs: 1) The Islamic Revolution is not considered a national and limited revolution but an extranational and extraterritorial one, based on the belief that its ideology is religious and universal; 2) The goal of foreign policy is to expand the values related to the sovereignty of Islam in order to establish an international Islamic community. As a result, Iran would reject the existing international order since it is not compatible with Islamic values (Eivazi, 2008, pp. 209-219).

Moreover, Ahmadinejad, as a revolutionary affected by the Iran-Iraq War experience, believes that Iran cannot count on foreign countries, particularly the West, especially the United States. In this regard, he argued that the Iran-Iraq War clearly demonstrated that the international community not only may violate Iran's rights but also that international law and conventions, even the UN, may be manipulated to provide for the great powers' interests (Haji-Yousefi, 2010, p. 58). In short, Ahmadinejad's operational code reveals that he viewed conflict as a permanent feature of the international system, which left no room for the harmony of interests that could lead to cooperation. Furthermore, he believed that the cooperative approach of Khatami not only was not beneficial for the Islamic Republic but led to Iran being included as a part of George W. Bush's "Axis of Evil.”

Furthermore, Ahmadinejad had a very different perception of the Other compared to Khatami since he viewed others - and particularly the West—as the source of conflict, which results in a high level of distrust and fear of others. In general, Ahmadinejad's speeches reflect a conflictual worldview. These elements led to an aggressive approach, as he believed that a more assertive foreign policy was more favourable for the Islamic 
Republic. In particular, he believed in forcing the enemy into "retreat by standing firm on major and minor positions and gaining concessions while preserving the strictness of his own position or, under certain circumstances, intensifying the severity of his measures against the enemy" (Haji-Yousefi, 2010, p. 17).

\section{Conclusion}

Among the scholars who approached foreign policy analysis from an individual-level, Holsti argued that, in the context of political decision-making, leaders react not to an objective reality but to a subjective reality that is filtered through their belief system. Renshon maintained that beliefs provide essential utility for decision-makers and facilitate decision making by providing ready frameworks for analyzing situations and providing answers to fundamental questions about the way the world works and the sources of human behaviour. Schafer and Walker argue that the interactions between the world of beliefs (philosophical belief) and the world of events (instrumental belief) is significant, and this provides the foundation of Operational Code analysis. Walker, Schafer and Young introduced the quantified approach to operational code, which utilizes the software called Profiler Plus.

I have applied the software to measure Khatami's Operational Code. Comparison between him and his successor, Ahmadinejad, help us to illustrate that Khatami believed cooperation with the Other, including the West, and particularly the US, would lead to a peaceful international relation. As a result, conflict was not seen as a permanent feature of the international system, and it could be replaced by dialogue and peaceful relations. On the other hand, Ahmadinejad's belief system reveals that he believed the international 
system would be the source of conflict and struggle. This line of thought leaves no room for cooperation and coexistence. In sum, Khatami's belief system enabled him to pursue a cooperative approach in foreign policy, while Ahmadinejad's belief system led him to adopt an assertive and aggressive direction on the foreign policy front. 


\section{CHAPTER FOUR}

\section{DIALOGUE AMONG CIVILIZATIONS}

In this chapter, I will examine how Khatami's belief system resulted in bringing change in Iran's domestic politics as well as on the foreign policy front. Internally, Khatami introduced new concepts such as rule of law, civil society, freedom, and equality that had not been discussed since the 1979 revolution. Internationally, by introducing a discourse of Dialogue Among Civilizations, he aimed to have peaceful relations with the international community members. To give context to what follows, I will begin by briefly examining the early life of Khatami and the circumstances that led to his being elected president of Iran. Following this, I will explain why and how Khatami criticized power politics in international relations and proposed the Dialogue Among Civilizations as an alternative. This alternative was welcomed by the international community since the United Nations named 2001 The Year of Dialogue Among Civilizations. Thus, I will also discuss the origins of Dialogue Among Civilizations, the thoughts that shaped this discourse, and the response of international organizations such as the United Nations and UNESCO.

\section{Early Life}

Mohammad Khatami was born in 1943 to a middle-class clerical family in Ardakan, located in the province of Yazd in central Iran. Ardakan is one of Iran's oldest towns with a history of more than 1,500 years and is located on the Silk Road, the ancient trading route linking Asia with the Middle East. 
Khatami's father was Ayatollah Ruhollah Khatami, a distinguished religious scholar, known for his piety as well as his progressive views. Ruhollah Khatami was appointed leader of the Yazd Friday Prayers by Ayatollah Khomeini, where he gave regular religious lectures, but also spoke enthusiastically about a wide variety of subjects. Khatami's father was tolerant, encouraging his children to read about different subjects as well as poetry, novels, and newspapers. He also encouraged his children to be productive, and this principle played a key role in shaping his children's careers. Khatami's brother Ali, for instance, earned a masters' degree in industrial engineering while studying in New Jersey, and became a successful businessman. He later served as his brother's chief of staff during his second presidential term (Tazmini, 2009, pp. 10-11).

Mohammad Khatami completed his primary and secondary school in Ardakan, then in 1962, commenced studies at the Hawzeh Elmiye seminary in Qom (Hawzeh is a term used in Shi'i to represent Islamic academies). At the same time, Khatami found himself very interested in philosophical and sociological discourse, which led his father to send him to the University of Isfahan in 1965 where he received a bachelor's degree in Western Philosophy, "a relatively rare experience among the Shi'a clergy at the time" (Vahdat, 2005, p. 650). It was the beginning of Khatami's journey in engaging with western narratives of freedom and civil society. He also obtained a master's degree in Education from the University of Tehran.

Shortly before the outbreak of the revolution in 1978, Khatami went to Germany to replace Ayatollah Beheshti as Head of the Islamic Center in Hamburg. This center was one of the oldest and the most influential Iranian Shi'i centers in Europe, during Khomeini's exile. This position required very specific capabilities, according to decision-makers. For 
instance, the position had been held by some influential Shi'i clerics, including Ayatollah Boroujerdi, who would later become Iran's Marja-e Taqlid (the source of emulation), a role of supreme importance for Shi'i Muslims. The candidate for head of the Islamic Center in Hamburg would require the highest Shi'i credentials, an outstanding reputation in the community, strong oratory skills and, most importantly, a charismatic personality (Tazmini, 2009, pp. 13-15; Vahdat, 2005; Mirbagheri, 2007).

After the overthrow of the Shah in 1979, Khatami returned to Iran and was elected to Parliament. Between 1980 and 1982, he represented his home district, the Ardakan and Meibod constituencies. In 1981, Khomeini appointed him as the head of Keyhan newspaper-one of the most influential newspapers at the time-but eventually, conservatives forced him to resign in 1992 (www.iranchamber.com/history/mkhatami). In his resignation letter, Khatami severely criticized the conservatives, and in his Fear of The Waves (1993) and the World of the City to the City of the World (1992) called on Iranian people not only to abandon dogmatism but to retreat from Iranian isolationism and embrace integration into the world (Milani, 2013). Five years later, he was elected president of Iran.

During the Iran-Iraq war, he undertook various responsibilities, including serving as both Deputy and Head of the Joint Command of the Armed Forces, and as chairman of the War Propaganda Headquarters (Khatami, 1997, p. 5). Then from 1989 to 1992, Khatami held the post of Minister of Islamic Culture and Guidance. The main responsibility of this ministry was to make sure that all cultural productions such as books, newspapers, advertisements, music, and films should be in line with Islamic values and principles. While in this position, Khatami relaxed censorship on printed material, facilitating a rise in the number and variety of publications, he also encouraged the film industry, thereby 
winning favour among intellectuals (Nikki Keddie, 2003, p. 269). This approach led to his being known as a moderate.

After his resignation as minister of Culture and Islamic Guidance, and before being elected president, Khatami was appointed head of the National Library of Iran and cultural advisor to President Rafsanjani, a position that he held until his rise to the Presidency. Khatami notes, "without doubt, one of the most enjoyable periods of my life was the time that I spent [as head of] the National Library (Ettelaat, 6 December 1999). The atmosphere gave him the opportunity to write two books: 1) From the World of the City to the City of the World: A Study of Political Thought in the West (1992), and 2) Fear of the Waves (1993). In the latter, he compares Islamic and western thought and explores ways in which the West offers something "that is one of the basic needs of human beings: freedom." He adds, "because of this freedom, the West enjoys the strong economic, political, military, scientific, and technical power." In the former, he examines the development of western political thought from Plato and Aristotle to Cicero. He also examines the influence of Locke on the development of liberal political thought. He believes that one of the key roles of political philosophers such as Locke and Hobbes are to question the problems of their society. Khatami suggests that the same way of thinking should be applied to Islam in general, and Iran in particular. These perspectives were significant in shaping Khatami's approaches both towards domestic politics and foreign policy.

One could argue that Khatami was ahead of his time, in the sense that since the inception of the Islamic Revolution, such concepts as reform, freedom, enlightenment, and moderate had no space in decision makers' thoughts. It was Khatami who introduced these notions into Iranian political discourse. Khatami emphasized cultural openness (which 
became one of the main principles during his presidency), aiming at relaxing the obstacle of dogmatism. Moreover, it was the first time in the post-revolutionary period that a minister emphasized "tolerance" in one of the most conservative ministries.

Moreover, in his book Mardom Salari (Popular Governance), Khatami highlights the importance of political populism, emphasizing that the destiny of the Iranian people should lie in their own hands. By introducing the notion of "religious democracy," he stressed that Islamic concepts should reinforce political participation and the rule of law (Khatami, 2001, p. 16-20). One of the main differences between Khatami and other Iranian clerics rests upon his idea that religious laws are not fixed and unalterable. Indeed, Khatami maintained that religious laws should be assessed based on the needs of the people (Khatami,1998, pp. 105-8).

In what follows, I will examine the circumstances which led to Khatami's election as president.

\section{Iran's 1997 Presidential Election}

The Islamic Republic, since its inception, raised the high expectation of freedom and prosperity among the people. However, those expectations remained unfulfilled after two decades. The Iran-Iraq war in the 1980s had significant costs for the economy, which resulted in Iranian leaders' failure to establish stability and development in the aftermath of the revolution. Iranians had been patient, but in the nine years after the end of the war, no considerable improvement was achieved. Iranian youth, most of whom had not been born at the time of the revolution, faced a government that restricted civil liberties, notably

freedom of speech, and interfered in their social lives without providing answers to any of 
the socio-economic problems they faced. Dissatisfaction resulted in a series of riots in April-May 1992, August 1994 and April 1995 (Siddiqi, 2006).

The 1997 presidential election was a competition between two main groups: firstly, Islamists, and secondly, what Rajaee calls "Islamic Yuppies." The former emerged from an alliance of the traditional oligarchy and the revolting masses of the downtrodden class, whereas the latter comes from the tradition of Islamic reformism and the middle class. The Islamists' worldview stemmed from the ideological politics of the late 1960s, while the Yuppies' thought emerged from the era of globalization at play in Iran and the wider world of Islam (1999, p. 217-218). Rajaee argues that Yuppies are theosophical in their worldview, nationalist in their approach, and follow the exercise of reason. "They think the Islamic message may take different forms depending on the time and place. For them, modernity is a sophisticated philosophical achievement that cannot be dismissed outright" (Rajaee, 1999, p. 222). One of the main differences between Islamists and Yuppies was that the latter had more realistic views about politics. For instance, they attempted to adopt more pragmatic approaches towards globalization instead of rejecting it, and one of these approaches was coexistence within the international community.

The Islamist candidate was Ali Akbar Nateq-Nuri, then speaker of the parliament, and Khatami was the candidate for the Reformists. The candidacy of Khatami generated great enthusiasm among Iranians. Throughout his campaign, Khatami stressed the importance of good governance over revolutionary ideology. He advocated investment in job-generating projects and emphasized the change in the educational system. He argued that all Iranians should enjoy civil liberties, including security and freedom. He also called for increased women's rights (Khatami, 1998, p. 110-4). Furthermore, he emphasized the need for social 
justice and equal opportunities for all groups in every region of the country (Tehran TV, 14 May 1997).

Khatami openly expressed his opposition to restrictions on individual freedoms under the Islamic government. During his campaign, he said, "Iran is a society in which the government belongs to the people and is the servant of the people, not its master" (Tehran TV, 10 May 1997).

In order to illustrate the difference between Nateq-Nuri's and Khatami's worldviews, I will compare their approaches to both domestic politics and foreign policy. Khatami stressed that chanting slogans could not secure Iran's revolutionary goals. He suggested empty rhetoric — which causes more tension—should be replaced by practical solutions. Furthermore, he argued for a dialogue with the West and more flexibility in dealing with the international community. In his view, demonstrating economic and political viability, for example, would advance Iran's revolutionary values far more than impractical slogans. He also pleaded for dialogue with Western civilization and greater flexibility when dealing with the outside world (Menashri, 2001, p. 82).

Nateq-Nuri, by contrast, continued to adhere eagerly to the original dogma of the revolution, regardless of the passage of time and changing realities. His campaign regarding the West focused on the cultural onslaught. According to him, it was the West that was attacking the Iranian nation's ideology, religious thinking, national identity, and revolutionary values (Tehran TV, 18 May 1997). Nateq-Nuri blamed the West for spreading corruption and obscenity and ridiculing sacred Islamic terminology, sanctities, and divine traditions. In his view, the Islamic regime should not be measured by economic growth or construction programs, but by morals and values. Regarding Iran-U.S. relations, 
he maintained that "our struggle against America has its origin in our ideology," thus as long as the United States was domineering, Iran's struggle would continue" (quoted in Menashri, 2001, p. 84).

While Nateq-Nuri believed that in the past foreign powers had dispatched their armies to capture new territories and enslave other nations, today "they dominate other nations" by "attacking their thoughts and ideologies and promoting "the culture of corruption, decadences, and illness" (Tehran TV, 19 May 1997); Khatami maintained that "foreign policy does not mean guns and rifles, but the utilization of legitimate international means to persuade others" (Tehran TV, 20 May 1997). Iran wanted good relations with all nations which respect its independence, dignity, and interests. He added that "Iran will not interfere in the affairs of others, nor would it allow any power to interfere in its domestic affairs" (quoted in Menashri, 2001, p. 83). Therefore, Khatami and Nateq-Nuri represented two conflicting approaches. Nateq-Nuri was perceived as the symbol of establishment conservatism, while Khatami was perceived as a symbol of reformism, openness, and change. In other words, from the perspective of the belief system and operational code, one could argue that Khatami believed that by changing Iran's approach towards the international community the country would have more peaceful relations. This illustrates that Khatami accepted the international order and did not perceive the political universe as a conflictual one, while Nateq-Nuri viewed conflict as a permanent feature of the international system and according to him, Iran needed to continue to struggle and challenge the international order.

Khatami won the election with a majority of 70 percent of the votes, a clear sign of Iranians' dissatisfaction with the ruling elite. The victory of Khatami was widely known as 
a turning point for the post-1979 Islamic Republic. It was called a new phase in Iran's history, and even a second revolution. Iranians were hopeful his administration would support political and cultural openness, protect human rights, individual freedom, social justice, eliminate the Islamic socio-cultural restrictions, create increased opportunities for youth, as well as opportunities for women's employment and civic participation, liberalize the state-dominated economy, ensure the rule of law, pursue peaceful relations with the rest of the world, and seek a respectable status for Iran in the international community (Menashri 2001, Siddiqi, 2006; Tazmini 2009; Amuzagar, 2006, Rajaee, 1999).

The day of the election was such a remarkable event for Khatami's supporters that they adopted the date as the "Second of Khordad Movement". ${ }^{2}$ Khatami stated that this day had a different meaning to different people: to the youth, it corresponded with the "Day of Youngsters and the Youth"; to women, it was the "Day for the Social Activism of Women"; to politicians, it was the "Day of Peace and Independence"; and to the poets and writers, it was the "Day of Flowers and Smiles"(Khatami: 2001, p. 11). Additionally, the international community welcomed the victory of a more moderate and pragmatic candidate. In the United States, Clinton reacted favourably, calling the election “interesting" and "hopeful" (Tazmini, 2009, p. 55).

Khatami, as a moderate intellectual, advocates a moderate path. He is critical of those Iranians who regard themselves as secular intellectuals, arguing that religion belongs to the private life; he also criticizes dogmatic believers for their "parochialism and regressive visions" of religion. He argues that much of what is considered to be religion today is

\footnotetext{
2 The date of Iranian calendar that corresponds to 23 May 1997, when Khatami was first elected.
} 
nothing more than old traditions that have been given an artificial veneer of sanctity. Moreover, Khatami makes it very clear that most religious laws are open to re-evaluation in accordance with the needs of a particular civilization (Siddiqi, 2006).

In Khatami's election as president two factors were in play. Internally, dissatisfaction with the ruling government along with the quest of younger Iranians for an open society; and externally exposure to globalization. As Ramazani (1998) argued two decades before Khatam's era Iranians destroyed the Pahlavi regime and supported Khomeini's slogan: "We Must become isolated in order to become independent." The children of that revolution said they must become democratic to become part of the new world order. (p. 177). Unlike their parents, young Iranians had no memories of Iran's past marked by foreign interference, intervention, invasion, and occupation mainly by imperial powers. Neither did they remember the events that led to the Islamic revolutions. Globally, democracy had been spreading across the world; at the time of the 1997 Iranian presidential elections about half of the world's countries were considered to be democratic, twice as many as 20 years earlier, when the Iranian revolution took place (Ramazani, 1998, pp. 170180). The diffusion of democratic values and the creation of democratic institutions around the world let Iranian youth seek a freer society.

Moreover, to attract foreign investments Iran needed to assure the international community that it not only had not pursued the ideological aspirations but also would seek peaceful relations with the other state actors. At the time, Khatami convinced Iranians that he could achieve these goals. In fact, Khatami's worldview and beliefs were welcomed by the majority of Iran's populace which led to him being elected. After being elected president, to make a change on the foreign policy front, Khatami reorganized the foreign ministry 
establishment by replacing many diplomats for lack of qualifications (Rajaee, 1999, p. 228). Among those replacement, Khatami dropped Ali Akbar Velayati, Iran's foreign minister for 16 years, who had been influential in shaping Iran's hard-line stance toward the West, appointing Iran's former ambassador to the United Nations, Kamal Kharrazi instead.

\section{Khatami's Thoughts and Worldview}

One of the fundamental concepts in Khatami's worldview is freedom. He argues that freedom should not be considered merely as a political slogan. "Freedom means freedom to oppose," and the state had a responsibility to provide the conditions for opponents to express their opposition freely and peacefully (Khatami, 1999, p. 120). However, Khatami adds that freedom has certain limits and boundaries, which are defined by laws. Moreover, he argues for freedom of thought, which leads to questioning and the effort to answer the questions posed. Freedom of thought also entails the notion of pluralism, meaning that multiple sets of beliefs and practices can be legitimate simultaneously (Khatami, 1999, p. 101). This worldview allows Khatami to propose a level of tolerance toward different ideas - even unorthodox ones - that had not been tolerated by the Islamic Republic. In this regard, Khatami is one of the few officials who formally talk about the rights of nonMuslims in Iran. He states that "every citizen who lives in Iran, even though he/she may not be a Muslim [...] possesses certain rights which the Islamic Republic is obliged to realize" (Khatami, 1999, p. 280). In other words, the Islamic Republic is not only responsible for the rights of Iranian-Muslims but also for all non-Muslim Iranians as well. 
Another distinguishing feature of Khatami's thought rests upon his emphasis on social participation. He contends that the government should endeavour to guarantee people's participation in their social affairs. "The more people participate in their own affairs, the more the government's burden is reduced, allowing it to focus on essential issues such as education, health and security" (Khatami, 1999, p. 127-8). In other words, people's participation has a mutual benefit both for the government and the people. By playing their role in decision-making, people understand that their ideas are important for the government, and the government may deal with other issues that are essentials for their life. Previous presidents did not assign as much weight to social participation as Khatami did. One of the main results of this line of thought can be seen in the economic sphere. Khatami emphasized that if people desire to have real participation in economic affairs, then the government should reduce its dominant role in the state monopolies that were created after the 1979 revolution (Vahdat, 2005, p. 659). As a result, in Khatami's era, investment and productivity were considered as positive values, which led the private sector to be more active, a sharp contrast to statist policies pursued by the government since the inception of the Islamic Republic (Vahdat, 2005, p. 659).

Another key difference between Khatami and his predecessors and successors concerned the role of the Islamic Republic in the emancipation of Muslims across the world, something very important in Khomeini's worldview. Khomeini believed that one of the main characteristics of the Islamic Republic was its emancipatory role, which resulted in the Iranian government helping Muslims across the globe to liberate themselves from the tyranny of The Great Satan (the United States) or The Lesser Satan (Israel). In contrast, Khatami believed that if instead of interfering in other countries' affairs, which translates 
into terrorist behaviours, the Iranian government concentrated on domestic affairs such as rule of law, civil society, freedom of speech, human rights, and good governance, then it could be a proper model for Islamic countries (Khatami, 1998). Moreover, in the long term, these policies would encourage other international actors to have constructive and peaceful relations with Iran.

\section{How Khatami Views the West: Enemy or Counterpart?}

In another departure from the norms of the ruling clerical elites, Khatami did not view the West as a pernicious agent seeking to undermine the cohesion of Islamic civilization through its cultural intrusions. As with many Muslim reformers, Khatami had a more nuanced view of the West and stressed that its scientific achievements and democratic heritage were worthy models of emulation. "Our revolution can give rise to a new civilization if we have the ability to absorb the positive aspects of Western civilization," he declared. (Khatami,1997, p. 19).

Since the 1979 Revolution, Khomeini had argued that the West, especially the United States, has been a dangerous enemy to the Islamic Republic. However, recently released documents show that Khomeini had a secret negotiation with the U.S., wanting to be sure that the Americans would not jeopardize his plans to return to Iran from Paris (https://www.theguardian.com/world/2016/jun/10/ayatollah-khomeini-jimmy-carteradministration-iran-revolution). Among Iranian presidents, Rafsanjani was very cautious about formally talking about having a relationship with the West, even though the country was dramatically in need of foreign investment. By denying the Holocaust, Ahmadinejad worsened Iran's relations with the West. Ahmadinejad left the office in 2013, and Rouhani 
came to power. Rouhani, as a moderate leader, has tried to solve the Iran nuclear issue through diplomatic solutions - negotiations which had been severed during Ahmadinejad's presidency. However, in May 2018, when Trump withdrew from the Joint Comprehensive Plan of Action (JCPA) and reintroduced sanctions aiming at both the Iranian economy and western investors, Rouhani failed to achieve his goal, although some efforts to maintain the agreement continued.

Among these presidents, only Khatami has a different perspective on the West. He makes a clear distinction between the West's politics and Western civilization. Although he criticized Western politics because of its tendency to govern "all concerns of the world and to dominate the theory and practice of international relations," he argues that western civilizations have important strengths. He notes that the West has advocated the ideas of liberty and freedom, which are "the most cherished values for humanity in all ages" Additionally, the West has cast away the notion of authoritarian rule and "freed humans from the shackles of many oppressive traditions". He advocates borrowing "the good features of other cultures" in order to "enrich our own culture" (Khatami,199, pp. 8-9).

Although Khatami believes that the West is responsible for much of the malaise in developing countries, it does not lead him to the conclusion that the West is the enemy, and that we should therefore avoid it. In fact, he is aware of the epistemological and ontological differences between the West and the East and, upon this acknowledgement, he attempts to find a new path. That path has the object of achieving greater understanding between the West and the East with spill-over effects into other areas of cooperation. In this regard, Khatami notes that there was a time when poets who promoted colonialism, such as Rudyard Kipling, used to say that "East is East, and West is West, and never the 
twain shall meet." He argues that, because of globalization, this view does not apply anymore. Instead, he refers to Goethe, who said, "the East is God's, the West is God's." He also mentions Iqbal, who was inspired by Goethe and expressed his message of the East with the Qur'anic verse that "East and West belong to God." According to Khatami, the objective of both poets is to show a point where East and West meet. This common point of contact in both views is the divine origin of humanity. The feeling of estrangement in the East and West have towards each other will be dissolved when each side views itelf as an absolute phenomenon and see itself in relation to the Other and in relation to this common origin. This is how East and West help each other towards perfection." (Khatami, 2000, pp. 3-4). Then he continues with the comparison between Goethe and one of the most famous Iranian poets, Hafiz. He says, "we have two great German and Iranian poets Goethe and Hafiz respectively, who believed that there is no division between West and East. Goethe said:

"One who knows himself and others will find out here that East and West are no longer separable."

And Hafiz said

"Excuse the war of seventy-two sects, for they, having failed to see the truth, went astray" (Khatami, 2003, p. 5). 
Khatami maintains that "our encounter with the West has been mostly superficial. We have vacillated between the equally harmful extremes of either being taken in and entranced by the West or loathing and rejecting it" (Khatami, 1998, p. 6). He has sought to balance the anti-Western approach. In his perspective, the West has a superb civilization, which has influenced all parts of the world. He maintains that in a world of "computers, communication networks, satellites, and sound waves," nothing is wrong in "utilizing the experience of other human communications" (quoted in Menashri,186). However, he did not recommend "imitating them blindly" nor abandoning our "own identity", but he did advocate borrowing the good points of other cultures to improve our own culture (quoted in Menashri,186). Khatami argues that the West's achievements for the human being are undeniable, and the path to development and modernity certainly goes through the West. He posits that Iran would not accomplish development unless it recognized the positive and negative aspects of western civilizations (SALAM, 6 May 1997).

He highlights that modernism has been one of the main achievements of the West and adopting a meaningful and constructive approach to modernism, in particular, and to the West in general, requires a critical approach to our weakness. Again, this kind of approach was for the first time brought forth by Khatami.

Khatami suggests that there are three approaches towards modernity, especially in nonwestern countries. Firstly, the traditionalists who continue to defend their heritage against modernity, assuming that they can bring order to their lives by shutting doors to western values and civilizations, merely by relying on tradition. According to him, this ill-fated approach brings no success. In fact, western civilization's success in exporting much of its values to developing countries rests upon our "unprepared tradition-bound societies that 
have lacked the capability to understand the West." Thus, traditionalists have been left with no choice but to retreat progressively, without providing society with the tools to appraise Western civilization properly. Secondly, those who believe that this crisis can be solved by a complete and uncritical adoption of modern values. In this perspective, traditions are the biggest obstacle in the process of modernization and should be removed. However, this approach not only does not solve the problem but makes it worse (Khatami, 1998, pp. 24$5)$.

Alongside these two groups, there are reform-minded thinkers who, as a first step, criticize the weakness of their "historical-cultural identity" and then advocate a positive encounter with the achievements of the Western civilization, while being aware of the hegemonic and colonial legacy of the West (Khatami, 1998, p. 2). What is significant here is the idea of firstly criticizing the self then having a meaningful interaction with others. It is unique in the sense that Khatami was the only president who was courageous enough to speak about the Islamic Republic's weaknesses. Moreover, unlike some other Iranian officials, he did not merely speak about the problems and crises, but proposed solutions for them, which might not have been favoured by the majority of Iranian decision-makers.

\section{Self and Other in Khatami's Worldview}

One of the key components of Khatami's belief system is the relationship between self and other. In his discourse of Dialogue Among Civilizations, Khatami suggests that dialogical engagement is not only a process through which a deeper mutual understanding can emerge among different civilizations, but it is also a process of discovery of the self. In one of his speeches, he posits that one of the main goals of dialogue among cultures and 
civilizations is to recognize and understand, not only the cultures and civilizations of others, but one's own. We could know ourselves by taking a step away from ourselves and embarking a journey away from self and homeland and eventually obtaining a more profound appreciation of our true identity. It is only through engagement with another existential dimension that we can attain mediated and acquired knowledge of ourselves in addition to the immediate and direct knowledge of ourselves that we commonly possess. Through interactions with others, we attain valuable knowledge of ourselves (Khatami, 2001).

Khatami suggests that in an orientalist perspective, the East is the subject of study, not the party of a dialogue. In other words, the East is considered as other to the West. Yet, in a real dialogue, the East should be the agent of a conversation, and the West can play a key role in achieving dialogue. He maintains that civilizations do not belong to a specific kind of people. They belong to human beings, to all people. Moreover, none of these civilizations can flourish in isolation. What makes them grow and flourish is the interaction with other civilizations (address UNESCO, 1997)

Another perspective on the Self-Other relation, according to Khatami, is that human beings should help each other to solve their problems and create a better climate in which to live. In this context, Khatami argues that it seems the West merely considers its interests and benefits and is indifferent to the other countries, but the irony is that if the "West wants to maintain their security, they should help the others." (address to UNESCO, 2000). In other words, to achieve a better atmosphere for the international community in which states have meaningful and constructive relations, they ought to recognize others not as enemies 
or merely rivals, but as counterparts. In doing so, states as active players realize that despite their differences, they can cooperate.

Here, one can argue that Khatami and Louis Massignon, one of the greatest French scholars of Islam and a pioneer of Catholic-Muslim understanding of the 20th century, share a common perspective. Massignon argued that "to understand something is not to annex it, it is to transfer by decentring oneself to the heart of the other... The essence of language should be a kind of decentering. We can make ourselves understood only by entering the system of the other" (quoted in Petito, 2011, p. 18). And Khatami suggests that self would not be able to attain knowledge of itself unless it had interactions with others.

Furthermore, Petito argues that Massignon's science of compassion is related to aspirations for justice towards the other. Khatami expressed a similar viewpoint in positing that "Without the will for empathy, compassion and understanding there would be no hope for the prevalence of just order in our world" (Khatami, 2005, p. 25). Khatami maintains that "dialogue, before anything else, is a search for emotional contact and sincere trust", and that world civilizations are the products of borrowings and encounters which do not imply the lack of a fundamental originality, but the way those borrowed and exchanged elements have been ordered and organized. Such a search, according to Massignon, was an important dimension of scholarly engagement and an integral part of that journey between Self and Other (Petito 2011, p. 18-19).

Any society, culture or civilization that considers itself to be pure good and others to be absolute evil can never know others, and will even fall short of knowing itself, according to Khatami. Knowing others is dependent on knowing oneself. Wars break out when the 
image of the other is only the image of the enemy. The idea of dialogue among civilizations is contingent on the existence of a relationship of dialogue between self and other, as opposed the idea of a Clash of Civilizations, which is based on the relation between "self" and "other" in a hostile way.

To conclude, in explaining the relation between Self and Other in general, and East and West in particular, Khatami posits that West and East are not geographical regions, but different kinds of worldviews and ontologies. Through genuine dialogue, one can accept the other's capacities, values, and developments. Through this process, common human elements can be achieved between the material and the spiritual. This statement includes three related dichotomies: West and East; modernity and tradition; materialism and spirituality. Khatami believes that the path for the progress of humankind and the creation of a more just and peaceful world order goes through the border between these dichotomies. In fact, Khatami stresses, on the one hand, the imbalance suffered by the West with its over-reliance on rationality and materialism, and on the other hand, the need for the East to embark on a critique of tradition by adopting the critical approach of the West (Petito, 2007, pp. 110-12).

In the next part, some prominent alternatives for international order after the collapse of the Soviet Union and the bipolar system will be discussed. The new international environment provided the opportunity for the possible international order alternative. Among those, Huntington's Clash of Civilizations and The Remaking of World Order (1996). and Fukuyama's End of History and the Last Man (1992) received the most attention. These approaches will be briefly examined, followed by Khatami's discourse of Dialogue Among Civilizations. The comparison between those Western-oriented 
approaches and Khatami's non-Western approach illustrates that Khatami, as a nonWestern and Muslim thinker, could be a participant in the discussion on the future of the international system.

\section{Post Cold War International Order Theses}

The end of the bipolar system brought on a widespread debate on the future of the world order. In this context, two main perspectives soon became the most significant references for any discourse on the post-Cold War international order: firstly, Francis Fukuyama's End of History and The Last Man and Samuel Huntington's Clash of Civilizations and The Remaking of World Order.

After the collapse of communism, world history has reached its end, according to Fukuyama. He claims that liberalism has remained the only rational, progressive model for countries to adopt after the Cold War. From this viewpoint, the globalization of liberalism would lead to greater international homogeneity, from liberal values of the free market, human rights, and liberal democracy. In other words, liberalism led to shaping a form of global governance (Fukuyama, 1992).

Huntington, in his article "Clash of Civilizations?" states, "it is my hypothesis that the fundamental source of conflict in this new world will not be primarily ideological or primarily economic. The great divisions among mankind and the dominating source of conflict will be cultural. Nation-states will remain the most powerful actors in world affairs, but the principal conflicts of global politics will occur between nations and groups of different civilizations. The clash of civilizations will dominate global politics. The fault lines between civilizations will be the battle lines of the future" (1993, p. 22). 
Huntington categorizes civilizations into Western, Islamic, Latin American, Orthodox, African, Hindu, Buddhist, and Japanese and argues that civilizations, as cultural identities, act as the "broadest level of identifications" in the international system (1993, p. 23). He suggests that globalization has reduced the size of the world, which results in intensifying the "civilizational consciousness" of people (1993, p. 25). He calls for Europe, North America, and Latin America to "club together" as a means of countering the "threat" from non-Western civilizations intent on building up their military capabilities and the need to "exploit differences and conflicts among Islamic and Confucian states" (quoted in Seifzadeh, 2001, p. 45).

Huntington outlines his thesis that a civilizational clash between the West and the rest (basically Islam) will shape the next international order. He argues that the next world war if there is to be one, will not occur between states but civilizations as the biggest cultural groupings in humanity. The rivalry between Islam and the West as two main enemies would lead to a possible bloody clash, as Huntington suggests. The main reason behind this clash rests on the gradual weakening of the West, on the one hand, and the rising antiWestern Muslim countries, on the other hand. According to Huntington, by the year 2025, the large number of "unemployed Muslim youth will unleash their frustration on a relatively weaker West $[\ldots]$ in the name of a superior set of belief systems" (quoted in Mirbagheri, 2007, p. 307).

Both Fukuyama and Huntington hold that the Western way-whether in terms of liberal democracy or civilizations - is superior to all alternatives. However, there is a key difference between these two perspectives. Fukuyama not only finds liberal democracy to be the highest point of human progress, but he also claims that as more countries adopt it 
as their political system, the lower the probability of global conflict. Huntington agrees that the age of ideology has ended. However, he believes that after the end of the Cold War, the world is witnessing a new trend of conflict at the civilizational level. Those discourses are essentially Western-centric. As Etzioni has argued both the End of History and Clash of Civilizations arguments approach the "non-Western parts of the world as if they have little, if anything, to offer to the conception of a good society- at least to its political and economic design- or to the evolving new global architecture" (Etzioni, 2004, p. 26). Contrary to the Western orientation of these discourses, Khatami proposes an alternative that is more inclusive and calls for interaction among all nations.

\section{Huntington and Khatami: Similarities and Differences}

As Khatami's Dialogue of Civilizations is a response to Huntington's Clash of Civilizations, it would be helpful to make a comparison between those approaches, especially considering that both introduced their discourses from the civilization-level but inform it with different content. Khatami and Huntington both attempt to introduce a new paradigm in international relations. They apply a similar framework, and both argue that globalization might create a new identity not at the nation-state level, but at the civilizationlevel. Huntington's thesis is a modified version of the realist balance of power approach, while Khatami's thesis can be considered as a constructivist approach since he believes that human beings can devise or construct their own destiny, which may create a new environment for human interaction at the global level (Seifzadeh, 2001, pp. 45,59). Additionally, Khatami holds an egalitarian view of each and every individual civilization and culture, while Huntington's argument (and Fukuyama's as well) is based on the 
hierarchical nature of the international system. Huntington believes that globalization will result in conflicting interests, which increases the possibility of clashes, while Khatami assumes that civilizations can be socialized into a peaceful and cooperative political culture. Khatami suggests that the dialogue of civilizations would construct the peaceful and cooperative global village with diverse and plural cultures, while Huntington perceives plurality and self-consciousness as inherently conflictual and a serious threat to international order. Whereas Khatami assumes that the nature of human relations at the global level can be constructed by human will, wisdom, rationality, and empathy, Huntington assumes that the process of globalization determines the conflict-prone structure of human relations at the civilizational level (Seifzadeh, 2001, p. 48-50). And finally, Huntington's argument is based more on the idea of a zero-sum game, while Khatami believes in a non-zero-sum game in international relations. In sum, Khatami was critical of the Clash of Civilizations and by introducing a Dialogue among Civilizations, he proposed a new paradigm on the basis of which all nations and civilizations, regardless of their geographical and cultural difference, would be able to coexist.

Huntington's civilizational-based approach elicited different criticism from various scholars. Among these, I will examine Amartya Sen and Edward Said's, in order to illustrate why civilizational-based thinking (as Huntington describes it) is conflictgenerating, and how it widens the gap between the West and the East. With respect to those criticisms, I will explain how Khatami's approach not only aims at bridging the gap but in a more inclusive way attempts to bring peace into the international community. 


\section{Criticism of Huntington's Civilizational-Based Approach}

Both Sen and Said argue that Huntington's "clash-of-civilizations" approach deepens the gap between the West and the rest of the world. For Sen, it "overshadows the plurality of our identities and the interconnectedness of our histories" (Petito, 2011, p. 6); and for Said, it led to assigning negative values to Other as opposed to Self. Khatami was also critical of Huntington's Clash of Civilizations approach. Yet, unlike Sen and Said, he proposed an alternative for the international order from the civilization-based perspective, albeit one that is conceptually different from Huntington's.

Amartya Sen (2007), in his book Identity and Violence: The Illusion of Destiny, argued that categorizing peoples of the world according to civilization or religion leads to a solitarist approach that sees human beings as members of a single group. He warned that the unique identity is much more divisive than the universe of plural and diverse classification, which represents the world we live in.

As a result, all approaches with the aim of global peace based on a "unity of identity" can lead to counterproductive consequences and even work "against our shared humanity." Therefore, if the plurality of our identities overcomes our divisions, then there is hope for harmony in our troubled world (Sen, 2007, pp. 16-17).

Edward Said (2014) claims that Huntington's argument omits the internal dynamic and plurality of every civilization and also omits the contest over the definition or interpretation of each culture. Said posits that "a great deal of demagogy and downright ignorance is involved in presuming to speak for a whole religion or civilization.” (p. 28). Said also criticizes the description of civilizations as static and monolithic phenomena. He believes 
that civilizations are hybrid, historically constructed. According to him, civilizations are interrelated and interdependent, which makes it almost impossible to introduce any unitary description of their singularity.

Moreover, in his book, Orientalism (1978), Said warns about the dangers of essentializing civilizational differences. He explains the relationship between Self and Other in the Western concept of the Orient. He argues that the Western conception of the Orient is based on the impression that the Other is dangerous and threatening to the Western Self. According to Said, this way of thinking deepens the gap between different cultures and societies and lessens the ability to have a constructive encounter with them (pp. 4546).

Khatami's perspective is similar to that of Sen and Said. Both Khatami and Sen emphasize the pluralistic nature of human identity and warn about the use of broad criteria to categorize human beings as members of a single group. Khatami and Said share the same perspective when they explain the dangers of the dichotomy of Self and Other, which results in creating more tension. In fact, Khatami and Said believe that Self requires constructive and meaningful relations with the Other in order to flourish and develop. As mentioned above, Khatami not only criticized Huntington's civilization-based approach which results in tension and violence, he went further by proposing a new discourse of Dialogue among Civilizations. Khatami's discourse, which calls for coexistence, was influenced by the thoughts of two German philosophers, Jürgen Habermas, and HansGeorg Gadamer, as well as the Iranian philosopher Dariush Shayegan. In the next part, I briefly examine how those ideas assisted Khatami in articulating his discourse. 


\section{Khatami, Habermas, and Gadamer}

Some scholars rightly believe that Khatami was influenced by German philosophical thinkers such as Habermas and Gadamer (Moshirzadeh 2004; Ansari 2006; Lynch 2000; Khaniki, 2007; Wastnidge 2016; Paya \& Ghanneirad, 2007). The main strength of Habermas' works in particular, and the broader work of the Frankfurt School in general, was that it allowed criticism of the western hegemony. A common claim is that Khatami's Dialogue Among Civilizations closely relates to Habermas' theory of communicative action. In the latter, Habermas (1984) describes an "ideal speech situation" as one under which participants have an equal capacity for discourse, are aware of each other's social equality, and are mindful of the danger of distorting speech through ideology and misrecognition. Communicative action, a theory that recognizes the power of dialogue as a tool in solving conflicts, resembles what Khatami is seeking through a Dialogue Among Civilizations (Wastnidge, 2016, p. 60).

Habermas argues that understanding should take the form of a real or virtual dialogue between participants, employing the empathetic act of Verstehen (understanding), and not strategic success over an opponent with competing interests (Khaniki, 2007, p. 86). In a similar way, Khatami maintains that a discourse of Dialogue Among Civilizations requires that we give up the will for power and instead appeal to the will for empathy and compassion. "Without the will for empathy, compassion and understanding, there would be no hope for the prevalence of order in our world" (Khatami, 2005, p. 25). According to Khatami, the main goal of a Dialogue Among Civilizations is not dialogue for its own sake, but dialogue towards attaining empathy, compassion, and understanding. 
One of the main common themes between Habermas' and Khatami's ideas lie in the role of understanding. According to Habermas, communicative action is oriented towards understanding and not success over an opponent with competing interests, i.e., what may be achieved through strategic action, and which at the international level can be seen as the prominent form of interaction. In this regard, Risse (2000) argues that there is no need for an ideal speech situation in world politics: rather, truth-seeking behaviour leads to a consensus in international affairs and highlights that there are some examples of the process of argumentative persuasion when powerful actors change their minds and subsequently their behaviour (p. 19). Risse suggests that there is an element of social action among actors, namely, arguing about the validity claims of any communicative statement about identities, interests, and the state of the world. Arguing and truth-seeking behaviour presuppose that when the communicative interactions start, the actors no longer hold fixed interests, and become more open to the others' worldview. He also maintains that preconditions for communicative interaction, namely, a common lifeworld ${ }^{3}$ and the mutual recognition of speakers as equals in a non-hierarchical relation, are more common in international relations than is usually assumed. For instance, international institutions provide an environment and a normative framework structuring interaction (2000, p. 33).

Here, it is worth mentioning that both Habermas and Khatami have been critical of the monopolized understanding of truth. What Habermas sees as the way to truth can be seen in Khatami's arguments. Khatami states that the idea of "dialogue is far from [what is

\footnotetext{
${ }^{3}$ Common lifeworld represents common experiences with the world and its history as well as a common system of values and norms to which actors can refer in their communications (Risse, 2000, p. 15).
} 
envisaged by] either the skeptical thinkers or those who think they have the whole truth in their own hands" (quoted in Moshirzadeh, 2015, p. 32).

Khatami maintains that "dialogue, before anything else, is a search for emotional contact and sincere trust" and in this respect, the dialogue among civilizations closely resembles the model of "global conversation" articulated by Fred Dallmayr, as Petito argues. Dallmayr describes a thick conversation or thick dialogue as "a communicative exchange willing to delve into the rich fabric of different lifeworlds and cultures. The appeal in such exchange is no longer merely of their situated humanity, including their hopes, aspirations, moral and spiritual convictions, as well as their agonies and frustrations" (quoted in Petito, 2007, pp. 110-111).

Petito suggests that Gadamer's idea of new global solidarities does not mean that we require global uniformity but rather unity in diversity. Gadamer calls for tolerant pluralities, multiplicities, and cultural differences. He emphasizes unity in diversity, and not uniformity and hegemony - that is the heritage of Europe. Such unity in diversity has to be extended to the whole world to include Japan, China, India, and also Muslim cultures. "Every culture, every people have something distinctive to offer for the solidarity and welfare of humanity" (quoted in Petito, 2007, p. 115). Khatami applies Gadamer's expression "unity in diversity" to highlight that "we want a world that has commonalities, coexistence, but that also has differences and variety" (Khatami, 2001, p. 12). In this context, Khatami acknowledges the emergence of a global culture. However, he warns that "we cannot and ought not overlook the characteristics and requirements of native local cultures with the aim of imposing itself [global culture] upon them. Cultures and civilizations that have naturally evolved among various nations in the course of history are 
constituted from elements that have gradually adapted to collective souls and historical and traditional characteristics" (Khatami, 2001, p. 24-5).

For Gadamer, a dialogue has as its ultimate purpose understanding, not rational consensus. The key aim of the hermeneutic dialogue is to understand the other's point of view in the form of being able to "stand in the other's shoes" (Shapcott, 2001, p. 171). Standing in one other's shoes, according to Gadamer, is not the result of a moral hermeneutic condition but necessarily an intellectual one, since "all interpretations and understanding occur within the tradition or horizon of consciousness constituted by the linguistic and historical tradition, of the interpreter" (quoted in Shapcott, 2001, p. 136).

Gadamer uses the term fusion of horizons, which refers to the structure of the process of understanding itself rather than a dialectic synthesis. In other words, each time understanding takes place it would be in the form of a fusion of horizons, meaning that "understanding involves a fusion in the sense that it does not involve either the annihilation or assimilation of existing positions but rather their coming to inhabit a shared perspective" (Shapcott, 2001, p. 147). Therefore, what is significant is the essence of the process of understanding and, as a consequence, its transformative nature for human experience. If genuine understanding is achieved, the participants are obliged to see things from a new perspective, and to this extent, a change in the horizons and traditions that they inhabit constitutive of their identities- must have taken place (Petito, 2007, p. 16).

Like Gadamer, Khatami emphasizes the understanding of each interlocutor's logic, the avoidance of unreasonable hostility and prejudice, the acceptance of difference, a critical assessment of one's self as well as others, and the acceptance of truth. In short, he gives emphasis to the commonalities and avoidance of disparities (Khatami, 2004). It is worth 
mentioning that Khatami was critical of a monopolized understand of truth. He also was a critic of thinkers who believe that they have the whole truth (Khatami, 2001, p. 17).

Although Khatami does not use the phrase fusion of horizons, he believes that mutual understanding is promoted if the parties approach dialogue with a genuine attitude of openness to reciprocal learning. Petito (2007) argues that such mutual understanding is in great need today to avoid what Said referred to as a clash of ignorance. He goes further by arguing that dialogue of civilization includes Taylor's notion of presumption of worth, which means that every long-lived civilization has something distinctive to offer for the solidarity and welfare of humanity (pp. 20-21). In Khatami's words, every dialogue, based on the presumption of the worth of the others, provides grounds for human creativity to flourish (Khatami, 2004).

Another similarity between Gadamer and Khatami concerns the significance of the act of question and answer and talking and listening. In his book Truth and Method, Gadamer stresses the point that dialogue proceeds "by way of question and answer". According to him, to question means to bring an issue into the open, and questioning is guided by a concern shared by all dialogue partners in an open-ended search for the truth" (quoted in Dallmayr, 2001, p. 72). Like Gadamer, Khatami emphasizes that talking and listening are two main components of a dialogue, since talking and listening combine to make up a bipartite-sometimes multipartite-effort to approach the truth and reach a mutual understanding.

Furthermore, Gadamer emphasizes a non-instrumental sense of dialogue. He points out that dialogue involves not only an act of questioning but also the experience of being questioned or "calling into question." The openness means the readiness of participants to 
allow themselves to be "addressed" and challenged by others; in other words, the dialogue is based on "the plurality of familiarity and strangeness" (Dallmayr, 2001, pp, 72-3).

\section{Khatami and Shayegan}

One of the starting points when seeking to trace the origins of Dialogue Among Civilizations is the works of Dariush Shayegan, an important Iranian intellectual and philosopher who continually referred to questions of civilizations in his research. Shayegan established the Iranian Center for Studies of Civilization in 1976 (before the Islamic Revolution) and directed it until 1979. In 1977, he had organized his own symposium on Dialogue between Civilizations with the object of furthering Iranian knowledge of other civilizations (Boroujerdi, 1996, p. 148).

Shayegan is widely known among thinkers in the West and the East, especially for his analyses of the cultural situation of contemporary Muslim societies. He argues that many cultural agents (both individuals and societies) currently experience deep cultural conflicts and live in a state of "cultural schizophrenia." In Shayegan's view, the first step is to acknowledge such cultural schizophrenias, then overcome them gradually through intercultural dialogue, both at the social and individual level. He posits that in a globalized world, there are no simple and fixed cultural identities. He argues that we should not view cultural identities as having a certain value belonging to one single culture; rather, we should see them as the forum where the values of different cultures interact. We should conceive of cultural identification as the continuous process of internal cultural dialogue, a dialogue among and within societies but also among and within individual citizens" (Shayegan, 1979). Shayegan pointed to the problems caused by trying to resist Western 
influence, which he believed to be reflected in a deep-seated malaise that "results from the non-comprehension, or non-assimilation, of a major historical phenomenon: modernity in its broadest sense". In this regard, he suggests that it is essential to broaden one's horizons and accept the multicultural nature of the modern world, rather than drawing on a unitary conception of self-identity (Wastnidge, 58).

One of Shayegan's main concerns was how non-western civilizations encounter modernity. He engaged with the dichotomy of tradition and modernity, East and West, and tried to bridge the gap between Iran and the West. Shayegan discusses modernity in terms of its "traumatic impact" on the Muslim world and its traditions and is highly critical of Islamic thinkers who advocate withdrawal from modernity, cautioning against the "hysterical language of obsessional rejection" (1997, p. 2). Khatami has a similar view, as reflected in his speech at the eighth OIC conference in Tehran on December 9, 1997, when he warned against "regression and withdrawal" from the modern world and instead seeking "deep understanding" of other societies and cultures.

Shayegan insists on understanding the West. He states that "understanding Western culture is more than necessary, it is vital. Our ignorance of the West is one of the reasons for our baseless enchantment and senseless wrangling about the same" (Shayegan, 2014, p. 63). In a similar vein, Khatami, in his argument about positive encounters with modernity, suggests that instead of rejecting and denying western achievements, we need to understand western cultures. Therefore, both Shayegan and Khatami, by highlighting the positive achievements of the cross-cultural encounter between different civilizations, believe that despite differences between civilizations and cultures, meaningful and peaceful interactions can be achieved through dialogue. 
The aim of Dialogue Among Civilizations mainly focuses on dialogue among societies, states, and at the highest level, civilizations. But what about religion? Is there any possibility of dialogue between different religions?

\section{Christian-Muslim Dialogue}

Stephen Carter (2007), in his article Christopher Dawson and Ayatollah Khatami and 'The Dialogue of Civilizations': A Christian-Muslim Conversation made a comparison between English Catholic historian Christopher Dawson (1889-1970) and Mohammad Khatami. He suggested that although Dawson's thoughts dated back to over half a century before Khatami's speech to the United Nations, the commonalities between them are considerable. Firstly, they both criticized the international order and introduced an alternative for it. Secondly, regarding the issue of religion and secularism, they believed that the West, despite all its achievements, has caused malaise for the world. Dawson, like Khatami, warned about the danger that the West was creating a "common secular technological civilization which [the West] is transmitting to the rest of the world - to the old civilizations of Asia, Africa and Oceania" (quoted in Carter, 2007, p. 407). Dawson expressed his concern about the role of religion, which is controlled by technology and science. $\mathrm{He}$ argues that although those religions are alive and have an influence on human life, "all of them have lost their organic relation to society which was expressed in the traditional synthesis of religion and culture in East and West alike" (quoted in Carter, 2007, p. 410). Carter believed that Khatami's idea of global culture (when he argues that global culture should not overlook features of local culture and should not impose itself on them) would be the answer to the dilemma that Dawson posed. According to Dawson and Khatami, 
secularism poses the same challenge to cultures with different religious foundations. If spirituality were not included in a secular worldview, the result would be a global order merely based upon economic and political interests that would be culturally homogenizing and damaging to religious customs and traditions (Carter, 2007, pp. 410-11).

Secondly, regarding mysticism, Dawson believes that there is essentially no difference between the mysticism of the medieval Germans, of the early Christians of Syria and Egypt, of the Sufis of Persia, and the Ascetics of India and the Far East. Khatami expresses a similar view when he states that "mystical experience, constituted of the revelation and countenance of the sacred in the heart and soul of the mystic, opens new existential pathways on to the human spirit. A study of mystical achievement of various nations reveals to us the deepest layers of their life experience in the universal sense" (quoted in Carter, 2007, p. 413). According to Khatami, mysticism, despite various cultural, historical, and geographical backgrounds, has a unified meaning. Mysticism, from Khatami and Dawson's point of view, reveals that besides the structure of power and control, there is unity and mutual understanding which prevail over division. In other words, mysticism can have an impact on dialogue that leads to maintaining both diversity and universality.

Thirdly, Khatami emphasizes the role of the artist in international relations and argues that art is the soul of a culture and means to mutual understanding; and every artist or group of artists express themselves in their own artistic way depending on their cultural background. However, despite the difference in ways of communication, interaction is truly important. Dawson has a similar view. He believes that art is, in the broadest sense, a great bridge that crosses the gulf of mutual incomprehension that separates cultures. In 
other words, art reflects the qualitative elements of a culture in a way that science and social sciences cannot (Carter, 2007, p. 411-12).

Lastly, despite the theological differences between Christianity and Islam, Dawson and Khatami proposed a historical approach to cultural understanding, resulting in dialogue. Khatami, for instance, suggests that although human beings live within a certain historical horizon, one could argue that there could be a meta-historical discussion of eternal human questions such as the ultimate meaning of life and death, or good and evil. Similarly, Dawson believes that meta-historical discourse, not in a theological sense, but as a means to "intuitive understanding, and a universal vision," was a valuable and constructive tool. However, Dawson maintains that unity must not be artificially created but must develop organically, or as Khatami observes, through interaction and integration (Carter, 2007, p. 425).

In summary, Dawson and Khatami, coming from different religious perspectives, expressed their concerns about the global order and proposed their alternatives based on meta-historical dialogue, art as dialogue, and cultural interaction, which transcends power politics, nationalism, and material ends in order to achieve coexistence through peaceful and constructive interactions.

\section{What Is Dialogue?}

To begin analyzing Khatami's view on Dialogue Among Civilizations, one should understand what he means by dialogue and civilization. Khatami stated that "dialogue is a search for emotional contact and sincere trust"; the dialogue is about talking and listening. 
Dialogue, according to Khatami, is carried out to discover the truth and to find salvation, understanding and coexistence (Khatami, 2001, pp. 1-3).

In Khatami's words, talking and listening combine to make up a bipartite—sometimes multipartite - effort to approach the truth and to reach a mutual understanding. That is why dialogue has nothing to do with the skeptics and is not a property of those who think they are the sole proprietors of Truth. According to him, the word dialogue stands for "a discussion between people in which opinions are exchanged". Dialogue was used by the masters of Hellenic culture, like Socrates, Plato, Aristotle, and others. They base the understanding of their philosophies in the mode of dialogue, which was very helpful and compelling for the people to understand the intellectual truths in a very easy way.

Khatami posits that the Dialogue Among Civilizations means equality between people and nations and that equality has been accepted. He believes that in an atmosphere of dialogue, neither side should consider itself as being in a position of power and able to speak from a superior position. Should there be feelings of power and dominance on one side and a sense of despair and privation on the other, a dialogue would never materialize. Therefore, dialogue is based on freedom and free will. Only under this circumstance dialogue can be a preliminary step leading to peace, security, and justice (Khatami, 2004).

According to Khatami, a true and fruitful dialogue has a certain prerequisite, conditions and rules which are necessary to be understood and recognized by the parties of dialogue. Among those are understanding of each other's logic, avoidance of unreasonable hostility and prejudice, acceptance of difference, critical assessment of one's self as well as others, and acceptance of truth, and in short, emphasis on the commonalities and avoidance of disparities (Khatami, 2004). 
Effective engagement in a dialogue among civilizations and across cultures requires an understanding of essential concepts and relationships. One of these is the relationship between dialogue and knowledge. Khatami states that "Knowledge is the product of dialogue and exchange: speaking and listening. Once complemented by seeing, they constitute the most important physical, mental, and spiritual faculties and activities of human beings". He adds that seeing expands the realm of knowing, which results in strengthening and solidifying the self. However, the self needs to talk and listen to others in order to become closer to truth and achieve mutual or multi-lateral understanding. Thus, in a dialogue, listening is as important as speaking (Ahmed and Frost, 2005, p. 72) In other words, listening and speaking are the easy way to reach the truth, and the concept of Dialogue Among Civilizations is based on such a simple definition of achieving the truth, not upon the philosophical definition of truth.

Dialogue is an apolitical phenomenon since it should take place among cultures and civilizations, according to Khatami. He believes that cultures and civilizations should not be exclusively represented by politicians but should include philosophers, scientists, artists and intellectuals. Therefore, he calls on them to participate, because their worldviews are different from politicians, something which increases the possibility of having a peaceful relationship. Khatami posits that artist, for instance, "do not see, mountain, and forest as mere mines and sources of energy, oil and fuel. For the artist, the sea embodies the waving music of a heavenly dance, the mountain is not just a mass of dirt and boulders, and the forest is not merely an intimate collection of timber to cut and use" (Khatami, 2001, p. 28). Then he argues that by excluding the artists' way of understanding the world from the political and social realm, human beings fall into a merely materialistic realm without any 
spirituality. The world so thoroughly controlled by political, military and economic conditions today inevitably begets the ultimate devastation of the environment and the eradication of all spiritual, artistic and intuitive activity. This would result in a dreadful world where the human soul will find no solace or refuge (Khatami, 2001, p. 29).

In addition to a poetic and artistic experience, mysticism also provides a graceful, profound, and universal language for dialogue, as Khatami suggests. Mystical experience constituted of the revelation and countenance of the sacred in the heart and soul of the mystic, opens new existential pathways to the human spirit. A study of the mystical achievements of various nations reveals the deepest layers of their experience in the universal sense. "The unified mystical meaning and content across cultures and the linguistic parallelism among mystic, despite vast cultural, historical and geographical distance, is indeed perplexing. Promoting dialogue in the arena of culture in disparate societies should constitute one of the bedrocks of understanding between cultures and civilizations" (Khatami, 2001, p. 28).

Dialogue was designed to facilitate communicative actions, which would eventually lead to coexistence, tolerance, and a degree of cooperation in the global arena. However, Khatami stresses that dialogue could not be based on a Weltanschaunng or belief in philosophical, religious, political, or ethical systems. For dialogue to take place efficiently, Khatami maintains, "we need a set of a priori and comprehensive general axioms, without which dialogue in the precise sense of the world would be impossible" (quoted in Tazmini, 2009 , p. 82). Khatami maintained that to achieve lasting peace based on dialogue, two prerequisites are required. First, that "all states have a feeling of justice and assurance of its continuation. Second, the creation of a culture of understanding in the face of hostility, 
and kindness and friendship in the face of force and enmity." (Third\%20Meeting\%20of\%20the\%20HLG\%20-

\%20Pres.\%20Khatami\%20Message.pdf).

Khatami (2000) differentiates dialogue from political negotiations. In the latter, the dominant language is the language of diplomacy with the aim of pursuing interests, while in the former the prominent language would be empathy and attempts to understanding others, rather than defeating them.

Despite all the benefits of dialogue, Khatami, from a pragmatic perspective, argues that dialogue is not easy. It is even more difficult to prepare and open views upon one's existence to others. A belief in dialogue paves the way for hope: the hope of living in a world permeated by virtue, humanity, and love, not merely by the reign of economic indices and destructive weapons. Should the spirit of dialogue prevail, humanity, culture, and civilization will prevail (Khatami,2001, p. 29).

\section{How A Dialogue Among Civilizations Can Be Achieved}

Dialogue will not be achieved as long as the uneven normative structure of the international system relies on Western and liberal concepts, which excludes certain participants unless awareness of different cultures and civilizations across the globe is acknowledged and accepted. On the one hand, the current liberalism excludes the centrality of the cultural identity of "really existing communities", and on the other hand, the incidents of 9/11 have introduced an atmosphere of fear and war into global affairs. In this context, understanding would be a great goal that can be achieved through a Dialogue. In other words, we should 
try to find a path that is different from the current international order, to create a multicultural and peaceful international community (quoted in Petito, 2011, p. 4-5).

\section{Khatami's Discourse of Dialogue Among Civilizations}

In order to design the discourse of Dialogue Among Civilizations, Khatami explored a wide spectrum of Western thinkers' works including Husserl, Descartes, Kant, Marx, Nietzsche, Hume, Freud, Hegel and Fichte, as well as the religious traditions of Christian, Jewish and Muslim thinkers (Tazmini, 2009, p. 82). He also studied Jean Jacques Rousseau and Alexis de Tocqueville's thoughts to formulate his ideas for creating a civil society in Iran (Abdo, 2000).

Khatami was familiar with critical theories of international relations. According to him, some post-modernist ideas that were related to "criticism of modernity were convincing; however, their failure to offer an alternative was not justifiable”. It appears that it was

during his teaching of the course Comparative Political Thought in the early 1990s that the foundations of his idea of dialogue among civilizations became more articulated (Moshirzadeh, 2015, p. 32).

Khatami's critical approach to international relations is obvious. On various occasions, he has criticized what he sees as unjust manifestations of the existing international system: domination, the ever-growing gap between the rich and the poor, the heritage of the colonial era, ethnocentrism, tyranny, violence, lack of security for individuals and societies, etc. (Khatami 2000; 2001). He looks for a world in which "peace is realized" through dialogue, "justice and dialogue" are the basis of international conduct, "human 
beings and their rights are respected", and "various interactive cultures and civilizations protect their own identities and constitute a human world" (Moshirzadeh: 2015, pp. 33-34).

In his book Liberty and Development, which was published a year after his first term, Khatami maintains that the challenge facing Iran is to overcome the crisis that accompanies the birth of a "new civilization." (Khatami, 1998, p. 52). He views civilization as "an answer to the curiosity of humans who never stop questioning their world." Civilization emerges to address these questions and needs. But the needs are not constant across all times and places, and thus "civilizations change, and there is no such thing as an ultimate and eternal civilization [...]. With each question that is answered and each need that is fulfilled, humans are confronted with new questions and needs [...]" (Khatami, 1998, pp. 30-31).

Khatami's starting point is the belief that today's world is searching for a new basis for regulating human and social relations. According to him, the end of the Cold War provides a new opportunity for an alternative international order based on dialogue among civilizations rather than the clash of civilizations. Khatami's critique of the dominant realist paradigm in international relations, coupled with a commitment to the logic of dialogue, enabled him to introduce a new alternative vision of world order which is not the monopoly of any single power, but one based on pluralism. Furthermore, Khatami understands both the opportunities and the dangers of globalization. On the one hand, he acknowledges the positive effects of increasing economic, political, and cultural connectedness; on the other hand, he warns about the dangers of equating globalization with liberalism as articulated by Fukuyama. Khatami rejects any notion of a world culture, which is monolithic, 
overlooks indigenous cultures, and implies the superiority of the western liberal model (Petito, 2007, p. 107-8).

Khatami posits that "Dialogue would open the way to mutual understanding and genuine peace "based on the realization of the right of all nations" (IRNA, 9 December 1997). As humankind enters the twenty-first century, he said, "it should take inspiration from the past and build a world full of dignity, peace and honour". He added that instead of using the language of force, we should use the language of reason and logic to speak to each other (IRNA, 14 December 1997).

Khatami's discourse of Dialogue Among Civilizations, attracted the attention of the international community because it differed from the message of the other Middle East countries which had witnessed domestic violence. Moreover, it was a message from a Muslim leader. The interest in the message was increased because the initiator was the president of a country that, for approximately two decades, perceived the West and especially the United States as enemies. Maybe, it was hoped, Christianity and Islam were not "competing for the soul of mankind" after all (Mirbagheri, 2007, p. 313).

In response to his call, the UN adopted the theme of Dialogue Among Civilization and proclaimed 2001 as the United Nations Year of Dialogue Among Civilizations. On 4 November 1998, the General Assembly proclaimed the year 2001 as United Nations Year of Dialogue Among Civilizations. The General Assembly expressed its determination to facilitate and promote dialogue among civilizations and invited governments, international organizations, and non-governmental organizations to implement appropriate programmes and promote the concept of such a dialogue (A/53/L.23/Rev.1). The draft was sponsored by Afghanistan, Armenia, Austria, Azerbaijan, Bahrain, Bangladesh, Belgium, China, Côte 
D'Ivoire, Cyprus, Egypt, Fiji, Greece, India, Iran, Italy, Kuwait, Lebanon, Lesotho, Libya, Luxembourg, Malaysia, Mexico, Mongolia, Morocco, Oman, Pakistan, Qatar, Russian Federation, Saudi Arabia, Senegal, Spain, Sudan, Syria, Tajikistan, Turkey, Turkmenistan, and Yemen.

In this meeting, the representative of Austria, on behalf of the European Union, and Bulgaria, Czech Republic, Estonia, Hungary, Latvia, Lithuania, Poland, Romania, Slovakia, Slovenia, Cyprus, Iceland, Liechtenstein, and Norway said that the United Nations was the ideal place to take forward the dialogue among civilizations. However, that dialogue must occur within the framework of the United Nations Charter and other international legal norms of universal validity, to assure peace and stability in today's world. The international community must not allow such concepts as the newly popular Clash of Civilizations theory, to become self-fulfilling prophecies. The European Union, therefore, rejected the application of the Clash theory to international relations and political practice. Also referring to the clash of civilizations, the representative of Malaysia said that too often the international community had seen how misunderstandings about a nation, a culture or an individual had led to mistrust, fear, prejudice, dispute and even war. The representative of Egypt suggested that the dialogue among nations should be based on equality of civilizations, regardless of their age, achievements, level of development, or the strength of their beliefs and ideologies. The observer for the Organization of the Islamic Conference (OIC) maintained that the organization was already conducting work on the dialogue among civilizations, with a meeting of the Islamic Conference working group on that subject having been held in Jeddah the previous June. The representative of India emphasized the need for tolerance. He argued that it would be unproductive to attempt to 
prescribe universal solutions based on the preferences of a segment of the world's population.

The representative of Syria maintained that the initiative to create a world free of war and based on the peace and equality of all peoples deserved the attention of the whole world. It stemmed from the principles of the United Nations Charter and had been given broad support. The Arab civilization was a tolerant and generous one. It drew its inspiration from other civilizations. Dialogue among civilizations would open the door to prospects for everyone to contribute on equal footing for the well-being of all. He added that Syria extended a hand to other civilizations and cultures to build a society for tomorrow based on justice, equality, and cooperation. The representative of Japan stated that the international community must not resort to hostility but engage in dialogue. Encouragement of international cooperation through dialogue would prevent unnecessary violence and bloodshed in the future. Tolerance and respect for diversity were conducive to universal respect for human rights. He added that Japan expressed gratitude to Iran for having taken the initiative on the issue. Before the General Assembly took action on the draft, the Acting-President of the Assembly, announced that additional co-sponsors of the text were: Benin, Finland, France, Kazakhstan, Kyrgyzstan, Netherlands, Portugal, Romania, Slovakia, Ukraine, and United Arab Emirates. The Assembly then adopted the resolution on the dialogue among civilizations. (https://www.un.org/press/en/1998/19981104.ga9497.html). (For more details about the international meetings and conferences see Appendix 3).

One of the main achievements was communications between NGOs both in the United States and Iran with the object of pursuing mutual interests. This initiative was very 
progressive at the time. His proposal for such a dialogue was an inclusive concept that transcended Iranian/non-Iranian, Muslim/non-Muslim dichotomies. It was an appeal to all humanity in the midst of growing violence and conflict worldwide, aiming at the betterment of human life.

However, the success of Khatami's idea was dramatically influenced by violent events across the world, especially that of 11 September 2001, ironically on the year of Dialogue Among Civilizations. Moreover, violence targeting civilians in the name of religion, such as the bombing in Madrid on 11 March 2004, and in London on 7 July 2005, provided fuel to the supporters of Huntington's theory of a Clash of Civilizations. The main concern was whether these events caused more severe confrontations between the West and the rest by fundamentalist Islam.

One could argue that Khatami's address to the United Nations in September 2000 might have been a solution to this worldwide concern. He urged the United Nations to use its influence as one of the most important international organizations to introduce a new paradigm for international order, based on dialogue in which the "will for power" might be replaced by a "will for empathy and compassion" (Khatami, 2000, p. 11).

Khatami stated that force, oppression, and repression are the main features of the hegemonic paradigm in world affairs where two World Wars, the Cold War, occupation, discrimination, and repression have had destructive impacts on human life. Additionally, since the end of the $20^{\text {th }}$ century, terrorism has dramatically intensified, threatening people across the world. Under circumstances in which human relations are becoming more complex, the destiny of countries and nations is becoming more and more interdependent, and the world is turning into what is referred to as a global village. In this context, the idea 
of Dialogue Among Civilizations can provide an alternative for those who can no longer tolerate oppression, cruelty, discrimination, tension, and insecurity: it can be an alternative that stands for peace, coexistence, and justice (Khatami, 2000).

Khatami suggests that Dialogue Among Civilizations rests upon the idea that the parties to a dialogue would accept the reality of each other. This dialogue would replace monologue, which has dominated for a long time. He believes that for four centuries, only one voice has been echoed across the world: the voice saying that subordinates should accept and follow. This kind of relationship has nourished tension and conflict. Khatami criticizes the West for considering itself as the center of the universe and treating the East as a historical subject to be known, or an entity that is a historical and museum object at their disposal (Khatami, 1981, p. 97-8).

The Dialogue Among Civilizations, as a new paradigm, will highlight the significance of culture in international relations, and when such a paradigm shift occurs, it will alter many minds. Such an approach delineates how civilizations can engage in a fruitful dialogue with one another, rather than negating or being absorbed by each other.

Dialogue Among civilizations means equality between peoples and nations. The colonial relationship which has ruled over certain parts of the world over the past two or three centuries has been the result of the phenomenon of dividing peoples into first and second-class nations: that is, nations that have an inherent right to be masters and nations which are inferior and have no choice but to be followers. War arises from the phenomenon of one party giving itself a greater right because it has the power to pursue its own interests at any cost, even at the cost of war. Such war is the fruit of discrimination and injustice. However, as soon as one proposes Dialogue Among Civilizations, and it is accepted, it 
means that equality between nations has been accepted, and this is a great achievement for humanity. With an open embrace, we must benefit from the positive aspects of other civilizations and cultures. This is the sense of adopting, and adopting is a human art. This is adopting where man has understood his past and his identity, has founded his life on wisdom and reason, and puts to good use what others have already achieved. This is quite different from mere unseemly imitation. The desirability of dialogue is based on freedom and free will. In a dialogue, no idea can be imposed on the other side and his or her independent ideological and cultural integrity. Under such circumstances, dialogue can lead to peace, security, and justice (Khatami, 2001, 2004).

In February 1999, after the United Nations declared 2001 the Year of Dialogue Among Civilizations, Khatami established a center focused on building bridges between and among various cultures with the goal of promoting global interaction and dialogue, called the Center for Dialogue Among Civilizations in Tehran. The Centre sets forth its mission statement as follows:

- To promote dialogue among civilizations and cultures on an international scale as a means of advancing the interpretation of the UN Charter and of improving human well-being.

- To promote and expand the culture of dialogue at the national level.

- To promote the culture of peace to foster peaceful coexistence and prevent human rights violations.

- To help establish and broaden the international civil society through cultural interaction among nations. 
- To strengthen spiritual, moral, and religious culture.

- To conduct research on the significance and possible interpretations of Dialogue Among Civilizations and to release the findings nationally and internationally (dialoguecentre.org)

One of the activities of this center was holding the International Conference on Environment, Peace, and the Dialogue among Civilizations and Cultures in Tehran, from 9 to10 May 2005. It was organized by the Iranian Department of Environment and the United Nations Environment Programme (UNEP) and co-sponsored by the United Nations University (UNU) and the United Nations Educational, Scientific and Cultural Organization (UNESCO). Over 70 participants from more than 30 countries participated, including several ministers and other high-level representatives. The purpose of the Conference was to examine the interaction between environment, peace, and security in the context of multilateral cultural dialogue among civilizations as a means for joint action against poverty, and violence both at national and international levels (International Institute for Sustainable Development, 2005). Participants included the following: Klaus Töpfer, United Nation Environment Program (UNEP) Executive Director, who delivered a message from UN Secretary-General Kofi Annan welcoming the conference's work; Emma Nicholson, Member of the European Parliament; Geoffrey Dabelko, from the Woodrow Wilson International Center for Scholars; Barbara Janusz, from Germany Institute for International and Security Affairs; Antonio Marquina, from Complutense University; Juan Mayr Maldonado, former Colombian Minister of the Environment; Hans van Ginkel, from United Nations University; Kevin Clements, from Australian Centre for Peace and Conflict Studies, Queensland University; Lawrence Troster, from Coalition on 
the Environment and Jewish Life; Hisae Nakanishi, from Nagoya University, Japan; Nay Hun, University of Peace, U.S.; Mary Evelyn Tucker, Harvard Forum on Religion and Ecology, U.S., Hans Kochler, Leopold Franzens University, Innsbruck, Austria; and Alexandre Kiss, European Council for Environmental Law (http://www.iisd.ca/SD/SDTER)

After his second term presidency, on 29 January 2006, Khatami inaugurated the Foundation for Freedom, Growth and Development of Iran (BARAN). BARAN (literally "Rain" in Persian) had a social and cultural agenda promoting progress, sustainable development, and dialogue with the West. At its first gathering, Khatami again emphasized progress and development while maintaining the pursuit of détente with the international community. He maintained that during the reform movement, one main question guided his administration's policy both domestically and internationally, i.e., whether the Iranian government has responsibility for facilitating the development of Iran or for liberating the whole world. He argued that if the Iranian government focused on the development of Iran with a focus on humanitarian values, then Iran would affect the Islamic world in particular and the world in general (Tazmini, 2009, pp. 139-40). The Center for Dialogue Among Civilizations remained active until 30 December 2007, when Ahmadinejad proposed to integrate the center into a new National Center for Research on Globalization.

\section{General Principles of Dialogue Among Civilizations}

The general principles of dialogue among civilizations confirmed by the 23rd Session of the United Nations General Assembly are as follows: 
1) Respect for the dignity and equality of all human beings without distinctions of any kind and or any nations large and small.

2) Genuine acceptance of cultural diversity as a permanent feature of human society and as a cherished asset for the advancement and welfare of humanity at large.

3) Mutual respect and tolerance for the lives and values of different cultures and civilizations, as well as the right of members of all civilizations to preserve their cultural heritage and values, and rejection of desecration of moral, religious, or cultural values, sanctities and sanctuaries.

4) Recognition of diversified sources of knowledge throughout time and space, and the imperative of drawing upon the areas of strengths, richness, and wisdom of each civilization in a genuine process of mutual enrichment.

5) Rejection of attempts for cultural domination and imposition as well as doctrines and practices promoting confrontation and clash between civilizations.

6) Search for common ground between, and within, civilizations with the object of facing common global challenges.

7) Acceptance of cooperation of common universal values as well as the suppression of global threats.

8) Commitment to the participation of all peoples and nations, without any discrimination, in their domestic as well as global decision-making and value distribution process.

9) Compliance with principles of justice, equality, peace, and solidarity as well as fundamental principles of international law and the Charter of the United Nations; (quoted in Seifzadeh, 2001, pp. 47-48). 


\section{The United Nations and the Year of Dialogue Among Civilizations}

The UN General Assembly adopted its resolution 53/22 of 4 November 1998 proclaiming 2001 as "United Nations Year of Dialogue Among Civilizations" and its resolution 56/6 of 9 November 2001 entitled "Global Agenda for Dialogue Among Civilizations".

In these resolutions, all nations reaffirmed the purposes and principles embodied in the Charter of the United Nations, which are, among other things, to develop friendly relations among nations based on respect for the principle of equal rights and self-determination of peoples, to take other appropriate measures to strengthen universal peace, and to achieve international cooperation in solving international problems of an economic, social, cultural or humanitarian character, and promoting and encouraging respect for human rights and fundamental freedoms for all without distinction as to race, sex, language or religion.

They also emphasize that all civilizations celebrate the unity and diversity of humankind and are enriched and have evolved through dialogue with other civilizations and that, despite obstacles of intolerance and aggression, there has been constructive interaction throughout history among various civilizations $[\ldots]$ and reaffirming that the civilizational achievements constitute the collective heritage of humankind (UNGA Res.53/22)

As mentioned in resolution 53/22, dialogue among civilizations is a process between and within civilizations, founded on inclusion and a collective desire to learn, uncover and examine assumptions, unfold shared meaning and core values and integrate multiple perspectives through dialogue. Therefore, dialogue aims at the promotion of inclusion, equity, equality, justice and tolerance in human interactions, enhancement of mutual 
understanding and respect through interaction among civilizations. One of the main goals is the promotion of common ground among civilizations to address common challenges threatening shared values, universal human rights and achievements of human rights, and achievements of human society in various fields, as well as the promotion of confidencebuilding at local, national, regional, and international levels, and elaborating of common ethical standards.

Participants in the Dialogue Among Civilizations would include people from all civilizations, scholars, thinkers, intellectuals, writers, scientists, artists, representatives of culture and the media and youth, who play an international role in the initiation and sustainment of dialogue among civilizations. In order to achieve a dialogue, governments, as well as regional and international organizations should take appropriate steps and initiatives to promote, facilitate and sustain dialogue among civilizations (United Nations General Assembly Fifty-sixth session, 21 November 2001A/RES/56/6).

\section{The Role of International Organizations}

Khatami suggests that international organizations are able to play a meaningful role in order to achieve dialogue. In this regard, the United Nations Educational, Scientific and Cultural Organization (UNESCO) held a round table on Dialogue Among Civilizations on the eve of the United Nations millennium summit in 2001. In this session, Khatami talked about the role and capability of Iran in shaping such a dialogue. He began with the exceptional geographical location of Iran, which connects the culture and civilizations of Asia to Europe. This remarkable situation has placed Iran on a route of "political hurricanes" as well as "cultural exchange" and international trade. He argued that this 
strategic location has led to a certain cultural sense called "a capacity to integrate." It comprises a "reflective contemplation of the methods and achievements of various cultures and civilizations in order to augment and enrich one's own cultural repertoire." To illustrate his argument, he referred to Suhrawardy, a Persian philosopher and founder of the Iranian school of Illuminationism (an important school in Islamic philosophy that drew upon Zoroastrian and Platonic ideas), who elegantly synthesized ancient Persian religion, Greek rationalism, and intuitive Islamic knowledge as a brilliant example of the Iranian "capacity to integrate" (Khatami, 2001, pp. 22-24).

The Year of Dialogue Among Civilizations was a very fruitful year for UNESCO as it organized and co-organized a series of international colloquiums, conferences and meetings on the subject of the dialogue. In 2003, UNESCO organized a summit of Heads of State on the Dialogue Among Civilizations in Ohrid (Macedonia), which resulted in the idea for a Regional Youth Forum on the Dialogue to be held in 2006 with the aim of translating proposals and recommendations into action.

In November 2001, UNESCO member states unanimously adopted the UNESCO Universal Declaration on Cultural Diversity, which provides for the protection and development of all cultures as a source of creativity, innovation, and exchanges among people. Furthermore, the Declaration also touches upon issues related to cultural diversity, such as identity, human rights, pluralism, and international solidarity.

Between 2003 and 2005, UNESCO organized several regional and international conferences. The year 2005 was marked by the organization of the UNESCO Youth Forum during the 33rd session of the General Conference on the Theme of "Young People and the Dialogue Among Civilizations, Cultures and Peoples"-ideas for action on education, 
the sciences, culture and communication (30 September-2 October 2005). Additionally, the third edition of the White Book on Dialogue among Civilizations published in 2004 by the Islamic Educational, Scientific, and Cultural Organization (ISESCO) was published in three languages: English, Arabic, and French. This book includes a collection of documents related to dialogue among civilizations, such as resolutions, recommendations, appeals, and relevant procedural programmes, in addition to the international document on dialogue, and ISESCO's view of dialogue among civilizations, which describes its deep meanings, extensive concepts and humanitarian goals (https://1ibrary.net/document/zp2ee64ydialogue-among-civilizations-a-historical-perspective.html.)

Furthermore, then Secretary-General of the United Nations Kofi Annan, in his lecture at the Oxford Center for Islamic Studies in 1999, emphasized that dialogue must be peaceful and based on a set of shared values. He argued that "live and let live" is an insufficient norm for today's global society. "Here, I part company from Professor Huntington," Annan stated, "I do think it is vital that we preserve and cherish diversity wherever we can, but not by identifying "civilizations" with geographically distinct cultural levels". He added that dialogue among civilizations must be a dialogue within societies and between them, with the aim of enhancement of civility both at the national and international levels. He argued that the objective of a dialogue is not to eliminate differences between cultures but to preserve them as a source of strength. According to him, "we need a framework of shared values, a sense of our common humanity, within which different traditions can co-exist." Annan posited that people must be able to follow their own traditions without making war on each other. They must have sufficient freedom to exchange ideas, and they must be able to learn from each other. He believed that great 
religions and traditions overlap when it comes to the fundamental principles of human conduct: charity, justice, compassion, mutual respect, and the equality of human beings in the sight of God (Annan,1999, p. 4).

\section{Berlin International Symposium on Dialogue among Civilizations and}

\section{Cultures}

In accordance with the United Nations General Assembly resolution to proclaim 2001 as the Year of Dialogue Among Civilizations, and within the framework of cooperation between the Islamic Educational, Scientific and Cultural Organization (ISESCO) and the Muslim World League, an international symposium was held in Berlin, on 5 July 2000, on "Dialogue and Coexistence among Civilizations and Cultures."

In this symposium, participants emphasized that dialogue among cultures and civilizations must not be dominated by historical concerns. It must rather deal with topics preoccupying mankind and must seek solutions inspired by different civilizations and cultures. It is imperative to build dialogue among civilizations and cultures based on mutual respect amongst all heirs of these cultures and civilizations. In addition to safeguarding the principles of right, justice and equity, this dialogue must give impetus to the international community's endeavour to enhance and maintain peace, security, and comprehensive cultural and civilizational coexistence amongst all humankind (ISESCO, 2004, pp. 67-77).

Participants also emphasized the notion of being duty-bound towards future generations and seeking to guarantee their right to free life in dignity on this globe in accordance with the values of justice, righteousness, and peace. Furthermore, they highlighted the efforts exerted by the international community on many levels to affirm 
peace and security worldwide and spread a climate of tolerance and coexistence among peoples and nations through enhancing objective, unbiased dialogue among civilizations and cultures (ISESCO, 2004, pp. 75-76).

\section{Tunis Appeal on Dialogue Among Civilizations}

The participants in the international symposium on "Dialogue Among Civilizations: Theory and Practice" held by the ISESCO on 12-13 November 2001, in Tunis, stressed that Dialogue Among Civilizations embodies the intellectual maturity attained by humanity as an outcome of the past experience and the present events, as well as the great expectations of the future. The fight against all forms of indifference and misunderstanding requires full knowledge of the cultural specifics and aspirations of the other, a fact which renders it compulsory to promote the spirit of mutual recognition and respect. They confirmed that Dialogue Among Civilizations affirms the right to difference and to the respect of human rights as guaranteed by the international conventions.

The participants admitted that the globalization process shall consider cultural diversity and civilizational plurality as a driving force for globalization and not an impediment thereto, in such a way as to capitalize on the specificities of the peoples and nations which shall all be publicized and held in high esteem, especially in a world reduced by the information and communication revolution to a tiny global village. They also admitted that Dialogue Among Civilizations could be a principle of international law and a basis for international relations (ISESCO, 2004: 87-89). 


\section{Damascus Declaration on Dialogue Among Civilizations for Coexistence}

The Islamic Educational Scientific and Cultural Organization (ISESCO) held an international symposium in Damascus on 18-20 May 2002. The participants stressed that Dialogue Among Civilizations is a dire necessity for fulfilling the conditions required for an honourable human life under a just peace, mutual respect, and fair enforcement of international law. Dialogue reaffirms the right to difference and multiplicity within the unity of the human society, and the protection of human rights guaranteed by international law and international conventions. Dialogue Among Civilizations is an effective means of wiping out radical discrimination, ethnic superiority, and religious bigotry. It is the most powerful factor for establishing the principles of full equality between peoples and nations in terms of rights and obligations (ISESCO, 2004, p. 93-97).

\section{Tehran Declaration on Dialogue Among Civilizations}

The representatives of heads of states and Governments of the Organization of the Islamic Conference members participated in the Islamic Symposium on Dialogue Among Civilizations, held in Tehran, Islamic Republic of Iran, on 3-5 May 1999. The participants emphasized the enhancement of mutual understanding, cooperation and mutual enrichment in various fields of human endeavour and achievement: scientific, technological, cultural, social, political, economic, security, confidence-building at regional and global levels, promotion and protection of human rights and human responsibility, including the rights of minorities and migrants to maintain their cultural identity and observe their values and traditions, promotion and protection of the rights and dignity of women, safeguarding the 
institution of family, and protection of the vulnerable segments of the human population: children, youth and the elderly (ISESCO, 2004, p. 67-68).

\section{Global Culture and Global Ethics}

Alongside his Dialogue Among Civilizations, Khatami advances two other concepts: Global Culture and Global Ethics. According to him, global culture stems from exchange among cultural agents belonging to disparate geographical locations. Therefore, it is nonuniform and non-monolithic both in form and in content. However, in order to provide natural unity and harmony in form and content for global culture and to prevent anarchy and chaos, all the parties concerned should engage in a dialogue in which they can exchange knowledge, experience and understanding in diverse areas of culture and civilization. In the absence of a dialogue among thinkers, scholars, intellectuals and artists from various cultures and civilizations, the danger of cultural homelessness seems imminent. Such a state of cultural homelessness runs the risk of depriving people of solace both in their own culture and in the vast open horizon of global culture (Khatami, 2001, p. 22-25).

Regarding global ethics, Khatami maintains that we, as human beings, are responsible for building better global ethics, and this cannot be achieved by rhetoric, contractual agreements, or the law. Achievement of peace, justice, freedom, tolerance, and sustainable

development will largely depend on the insight of all men and women and their intention to lead a fair life, which adheres to global ethics that suits today's reality. According to him, rights without ethics will not materialize fully and comprehensively, and without realistic global ethics, one cannot achieve peaceful coexistence in the light of a better global 
order. However, global ethics does not imply the dominance of one global ideology over all others or even a certain religion over others. What is intended by global ethics is a major collection of essential values, irrevocable criteria, and useful individual conduct. The principles and framework of such global ethics exist in the depth of religious teachings, particularly those of the Abrahamic religions and specifically Islam. French scholar and Catholic thinker, Louis Massignon (1883-1962) stated that the phrase "Abrahamic religion" refers to all these religions come from one spiritual source. In this regard, Khatami intends to emphasize the unity of these religions. Khatami argues that the basis of consensus in global ethics can be extracted from religions, which can turn into a subject of dialogue of civilizations and cultures- and, more specifically, dialogue of religions (2001, pp. 1-7).

\section{Khatami's Post-Presidency}

Although Khatami's Dialogue among Civilizations was dramatically influenced by the event of 11 September 2001, he continued to promote his concept to the UN, stating that he was seeking to establish a coalition for peace, trying to harness what remained of the spirit of his initiative. In his message to the UNESCO Conference in November 2001, he again emphasized the need for continuing dialogue in the face of the ensuing crisis in global affairs, and also cautioned against the seeking of revenge as a result of what had recently taken place (Westnidge, 2016, p. 119).

Khatami's post-presidency has been fruitful, in the sense that he delivered numerous lectures and keynote addresses at prestigious institutions and universities. In November 2006, he completed a worldwide lecture circuit, from Harvard University in Boston to the 
University of St. Andrew in Scotland, where he inaugurated the Institute of Iranian Studies, and then on to the British think-tank Chatham House. Khatami was nominated by Kofi Annan in 2005 to serve as a member of a United Nations-sponsored high-level task force made up of about 20 eminent personalities. The group has deliberated in different international locations with the aim of fostering respect between Islamic and western societies in what became known as the Alliance of Civilizations, which was co-sponsored by Spanish Prime Minister Jose Luis Rodriguez Zapatero and the Prime Minister of Turkey, Tayyip Erdogan. Similar to the Dialogue, the Alliance of Civilizations was designed as a potential answer for those who challenged Samuel Huntington's Clash of Civilizations thesis. Zapatero first suggested the idea for the alliance in a speech before the United Nations General Assembly in September 2004, about six months after the bomb attacks in Madrid that killed more than 190 people. Turkey, where more than 60 people were killed in the November 2003 suicide bombings in Istanbul, later became a co-sponsor of the project, which was eventually backed by the United Nations and more than 20 countries (Tazmini, 2009, p. 139).

\section{Conclusion}

Khatami's beliefs expressed through his discourse of Dialogue Among Civilizations changed Iran's foreign policy. In order to explore how Dialogue Among civilizations was articulated, I started by briefly examining Khatami's life. I have argued that he grew up in an environment that influenced his worldview. His father encouraged him to become familiar with subjects other than religious texts, such as poetry, novels, and newspapers

which were uncommon among traditional and religious families. When Khatami went to 
Germany, he was even more exposed to western culture. He seized the opportunity to become more familiar with western philosophy and started to build the foundations of his discourse of Dialogue Among Civilizations.

Two main concepts that formed the foundations of his belief system, namely, freedom and equality, had significant consequences domestically and internationally. In domestic politics he relaxed censorship and, as a result, a considerable number of publications, films, and music products had been produced, something unique in the more than four decades since the Iranian revolution. At the international level, by introducing Dialogue Among Civilizations, he could assure that Iran not only would not pursue the revolutionary aspirations but would be an actor who accepted and respected international norms. In another distinguished departure from other Iranian decision-makers, he courageously criticized Iranian governments for failing to have a meaningful encounter with the West.

Khatami challenged the hegemonic structure of the international system and introduced the discourse of Dialogue Among Civilizations through which the dominant international order with the hegemony of the United States could be replaced by dialogue. His discourse partly was a response to Huntington's Clash of Civilizations. Although both approaches are civilization-based, they embodied different contents and consequences. Huntington suggested that the main source of conflict would be cultural, between the West and the rest (especially Islam). On the other hand, Khatami argued that civilizations could be socialized into a peaceful and cooperative political culture. It could be viewed as his contribution to finding a path towards initiating a dialogue between the West and the rest. Khatami's Dialogue Among Civilizations was welcomed by the international community, especially at the United Nations. I believe one of the main reasons was the common concept of 
equality in Khatami's beliefs and the United Nations' charter. The Asian, Latin American, African, Middle Eastern, and European countries supported Khatami's discourse of Dialogue; consequently, the United Nations proclaimed 2001 as the United Nations Year of Dialogue Among Civilizations.

In the next chapter, I will explain that how Dialogue Among Civilizations was reflected in Iranian foreign policy. 


\section{CHAPTER FIVE}

\section{IRANIAN FOREIGN POLICY UNDER KHATAMI PRESIDENCY}

\section{Introduction}

In this chapter, I will examine the Iranian foreign policy under the Khatami presidency. I will explore how Khatami's discourse of Dialogue Among Civilizations, which is rooted in his belief system, enabled him to start confidence-building with the Islamic World, then gradually attempt to establish cordial relations with the European countries. Moreover, he attempted to replace the long-term hostility between Iran and the United States with peace and constructive relations.

\section{Iranian Foreign Policy Under Khatami’s Presidency (1997-2005)}

This era has been described by some as the beginning of the "thermidor" of the Islamic Republic. Wells (1999) maintains that thermidor can be defined as the closing phase of a revolution, wherein hard-line revolutionaries are increasingly challenged by reformists and/or revisionists, which is usually the result of a popular backlash or revolutionary policies. Thermidorian reactions do not affect all revolutionary governments but mainly those which are "comprised of coalitions in which power is shared by diverse factions" and also "where legitimacy is derived from one over-arching charismatic figure," who is Khomeini, in our context. Because the previous regime (Pahlavi II) could not be overthrown without the cooperation of diverse groups, factions form temporal alliances, but having achieved victory, soon realize that they have little in common with one another 
except for mutual hatred of the old system. Once power has been consolidated in the hands of a central core, those factions intensely loyal to the charismatic leader, sometimes referred to as hard-liners, gain power. They then attempt to impose a political, economic and social agenda on the whole country. These efforts, however, are opposed by other factions, usually referred to as moderate, reformist or Thermidorian (pp. 27-8).

In the context of Iran, this period witnessed reformists' views challenging the revolutionary ambitions of hardliners. According to Khosrokhavar (2004), during the 1990s, new tendencies in Islamic ideologies emerged, which questioned the revolutionary tenets of the 1970s and 1980s. Since then, the main intellectual tenet in Iran has been religious reformism. These new Islamic ideas challenged the supremacy of revolutionary Islam, marked the end of the religious radicalism in mainstream intellectual life, and signalled a move towards a new kind of reformism.

Rajaee (1999) argues that Khatami's election marked two important turning points in the Islamic Revolution: first, it inaugurated the overdue Thermidorian period of the Iranian Revolution by turning the politics of revolutionary Iran into politics as usual, with its own peculiar conflict and compromise; second, it marked the emergence of a new generation in the Islamic movement in Iran who are referred to as "Islamic Yuppies" (p. 217).

The most significant change in Iran's foreign policy came with the election of Khatami in 1997. Khatami's international perspective was to put an end to Iran's isolated status and integrate it into the global community. He recognized that the main reason for Iran's isolation was less related to economic and political interests and more connected to a profound ideological distrust that had emerged through "cultural suspicions and subsequent misunderstanding." Khatami was probably the first politician since the revolution to realize 
and accept that the sphere of foreign relations could provide useful and constitutive grounds for his domestic policy. In other words, Khatami viewed foreign policy as inclusive and complementary to domestic politics, rather than as antagonistic. Thus, he argues that foreign relations are not merely an extension of revolutionary aspirations but can instead be a proper sphere of political actions that can bring positive consequences for domestic politics (Ansari, 2006, pp. 130-1). Khatami had made clear his stance on foreign relations during the election campaign when he argued that "in the field of foreign policy, we would also like to announce that we are in favour of relations with all countries and nations which respect our independence, dignity, and interests." (BBC SWB ME/2917 MED/ 13 May 1997).

Prior to his election in March 1997, Khatami talked about the notion of "culture" in foreign policy. He added that there needed to be a shift away from Rafsanjani's policy of critical dialogue with the European Union to what he described as a critical cultural discussion, which emphasized the role of cultural experts in creating a proper environment for cooperation and co-existence. To this end, Khatami stated that Iran would "extend the hand of friendship to all neighbouring countries, particularly Muslim ones" (Iran News, 25 March 1997). His emphasis on culture would become a key feature of his Dialogue Among Civilizations.

After being elected, Khatami maintained that "foreign policy does not mean guns and rifles, but the utilization of all legitimate international means to persuade others" (Tehran $T V, 10$ May 1997). He added that Iran "will not interfere in the affairs of others," nor would it allow any power to interfere in its domestic affairs (quoted in Menashri, 2001, p. 81). Khatami suggested that based on the "three strong pillars of wisdom, integrity, and 
expediency," Iran would "shake the hands of all countries and nations" who believed in "mutual respect" and who would not undermine Iran's independence and interests (Jomhuri-ye-Islami, 4 August 1997). He also emphasized dialogue as a mechanism for removing misunderstanding between nations, stating that "my government considers dialogue between civilizations...essential, and will avoid any action or behaviour causing tensions" (Iran News, 5 August 1997).

Khatami suggested that "the world needs peace and tranquillity", emphasizing that Iran "seeks neither to dominate others nor to submit to domination." He believed that dialogue would pave the way to mutual understanding and peace "based on the realization of the rights of all nations" (IRNA, 9 December 1997).

There are some signs that these policies were not simply slogans designed to win the election. In February 1998, Khatami courageously banned the Ansar-e Hizballah, the militant wing of the Islamists, and pledged to stop them from any further violent activities. Moreover, he took many measures to clean up the Iranian foreign ministry establishment. In addition to reorganizing the ministry and replacing many diplomats for lack of qualifications, important foreign policy measures were taken (Rajaee, 1999, p. 228).

One of those measures was choosing Kamal Kharrazi as foreign affairs minister. Khatami's choice reflected his seriousness about real change in Iran's foreign policy since Kharrazi was a media-savvy politician who had been Iran's Ambassador to the United Nations since 1989, and head of the Islamic Republic News Agency (IRNA). As the foreign minister, Kharrazi stated that the Islamic Republic would pursue new diplomacy and in reference to restoring relations with the European Union, that he would have no problem in meeting with EU foreign ministers (Kharrazi, Iran Daily, 28 August 1997). He added 
that Iran was "ready to cooperate with other countries to resolve misunderstandings, build confidence, remove tensions, help build regional and international peace and fight all forms of terrorism". He also emphasized Iran's desire to "elevate its status in the region and the world", stating that "Iran's key role in charting regional and global equations will be expanded" (Iran Daily, 23 August 1997). Another of Iran's important initiatives, Kharrazi suggested, would be pursuing détente on the regional and international levels. Therefore, a new foreign policy direction had been formulated, one clearly different from the previous ones.

Kharrazi, as Khatami's foreign minister, had a belief system similar to Khatami's since he emphasized building confidence and regional and international peace, which reveal that he perceived the nature of the political universe as relatively friendly. Moreover, he used the word cooperation and diplomacy which implied that his strategy was directed towards cooperation.

Khatami's government focused increasingly on maintaining the security of the borders of the Islamic Republic through a policy of détente. He believed that if the country was to be strengthened, first and foremost, a debilitating military conflict like that of the $1980 \mathrm{~s}$ had to be avoided. This was partly to be achieved through rapprochement with a number of neighbouring states including Saudi Arabia, Oman, Bahrain and Iraq. These policies began in the Rafsanjani era and were particularly strengthened following the election of Khatami in 1997, who pursued a foreign policy based on peaceful coexistence with countries in the region and beyond (Roshandel, 2002). 


\section{Dialogue with the Great Civilizations}

In chapter four, we have examined the discourse of Dialogue Among Civilizations and its key concepts. In this part, I will study how the application of this discourse would shape Iran's relations with the international community.

Khatami's emphasis on Iran as inheritor of one of the world's significant civilizations allowed him to open a dialogue with other countries which were also seen as being inheritors of great civilizations. The following case studies of Italy, Greece, Egypt, and India illustrate how this concept was applied on a practical level in Iran's foreign relations.

\section{Italy}

The interaction between Italians and Persians dates back to ancient times. Indeed, part of that interaction included the struggle between the Roman and Sassanian Empires as early as $230 \mathrm{AD}$ (Kunz, 1983; Garsoian, 1968). Then during the Safavid dynasty beginning in 1501, there is evidence of trades between the Safavid and Venetian governments (Rota, 2012).

Examining Iran-Italy relations requires consideration of the broader EU-Iran relations at the time. Rafsanjani's attempts to have constructive relations with the EU would not be achieved mainly because of the Mykonos incident (https://www.refworld.org/docid/3ae6ad824c.html).

On September 17, 1992, three leading members of the Democratic Party of Iranian Kurdistan (PDKI) and one of their supporters were assassinated in a private dining room at the Mykonos Restaurant in the Wilmersdorf district of Berlin, Germany. It is said that the attack was one of a series of assassinations sponsored by the Iranian government after 
the revolution of 1979 designed to intimidate and disrupt the activities of political opponents of the regime. The primary targets of the Mykonos operation were Dr. Mohammad Sadegh Sharafkandi, the Secretary-General of the PDKI, Fatah Abdoli, the PDKI's European representative, and Homayoun Ardalan, the PDKI's representative in Germany. The Mykonos trial lasted three and a half years, included a total of 246 sessions, heard 176 witnesses, accepted testimony from a former senior intelligence officer of Iran's Ministry of Intelligence, and considered documentary evidence varying from secret intelligence files to tapes of Iranian television broadcasts. The German authorities concluded that the Iranian government was directly involved in the Mykonos assassinations (https://iranhrdc.org/murder-at-mykonos-anatomy-of-a-political-assassination).

However, Khatami's speech at the OIC (Organization of the Islamic Conference) in December 1997 was important in the broader international context, because although it did not mention the EU specifically, it helped broadcast Khatami's message to an international audience. His message was well-received by then Prime Minister Romano Prodi, who emphasized the importance of the role of Iran and Italy for relations between Islam and Christianity (Westnidge, 2016, p. 23).

One of the positive results from the early period in Khatami's presidency was the resumption of Iran-EU ministerial ties in February 1998, and it was the Italian foreign minister Lamberto Dini who became the first European politician to visit Iran in almost a year shortly afterwards (Ettelaat International, 2 March 1998). The visit by Dini had significant economic imperatives. Relations between Iran and Germany, Iran's leading EU trade partner, were severely damaged because of the Mykonos affair. Therefore, Italy took the opportunity to promote its bilateral relations with Iran. Tehran-Rome ties were further 
improved by Khatami's visit to Italy in March 1999, the first visit by an Iranian leader to Western Europe since the revolution (Westnidge, 2016, p. 23). In his travel to Italy, Khatami described the country as the representative of western civilization, and then in line with his discourse of Dialogue Among Civilizations, he added that both nations had contributed greatly to [international] society through their ancient civilizations (Ettelaat International, 10 March 1998).

\section{Greece}

As with Italy, relations between Iran and Greece have a long history dating back to ancient times. However, it appeared that the enmity between the Athenian empire (and Greek citystates more broadly) and the Achaemenian Empire had been exaggerated. Some scholars believe that this enmity was the key element in a great cultural exchange between these two ancient civilizations. This relation continued during the Seleucid period, following Alexander the Great's defeat of the Achaemenians and in the continuous function of boundaries between the culturally Greek Eastern Roman/Byzantine Empires and the Parthian and Sassanian Empires, until the Islamic conquest of Persia (Wastnidge, 2016).

In the context of our discussion, following the Islamic Revolution, Greece was an active trade partner with Iran, and the only EU member not to withdraw its ambassador in protest following the Mykonos trial—a Greek government spokesman claiming at the time that isolating the country "was not the best way to bring Iran into the international community" (Reuters, 11 April 1997).

One of the significant applications of Khatami's Dialogue Among Civilizations in IranGreece relations was the gathering of representatives of four of the world's ancient civilizations in Delphi, entitled The Heritage of Ancient Civilizations: Implications for the 
Modern World. The meeting took place at the invitation of the Greek government, on 11 November 1998, with the aim of recognizing the interactions that had taken place between these civilizations and how these could serve as a model for furthering peace and mutual understanding in the modern era (Wastnidge, 2016, pp. 77-78). One of the primary outcomes was the Athens Declaration (For the full text of the Declaration of Athens see United Nations website- http://www.un.org/documents/s54-60.pdf).

\section{Egypt}

The Egyptian-Iranian rivalry goes back several decades, with implications not only for bilateral relations but also for regional and international security. Iran-Egypt relations had improved following the short-lived marriage in 1939 of Mohammad Reza Shah and Princess Fauzieh of Egypt. However, following the rise of Kemal Abdul Nasser in Egypt, circumstances changed. Nasser, inspired by the idea of Arab nationalism, joined the Soviet Union's bloc, while the Pahlavi regime of Iran, with strong ties to the U.S. and Israel, pursued an opposite strategy. Diplomatic relations between Cairo and Tehran were severed in 1960 and restored in August 1970, one month before Nasser's death.

Events following the 1979 Revolution affected Iran-Egypt relations, especially when Sadat gave refuge to the Shah and his family. The relations worsened with Egypt's support of Iraq during the Iran-Iraq war (https://mepc.org/journal/egypt-and-iran-30-year-

\section{estrangement).}

Based on his discourse of Dialogue Among Civilizations, Khatami attempted to normalize Iran's relations with Egypt. To this end, when Iran hosted the Organization of Islamic Conference (OIC) summit in December 1997, Khatami took the opportunity to meet with the then foreign minister of Egypt, Amr Moussa. In their meeting, despite their 
differing stances on the Arab-Israel peace process, Khatami stated that "Tehran has a special respect for Cairo, so differences of political opinions, which are natural, must not undermine these countries' axes and historical and cultural commonalities" (Ettelaat international, 12 December 1997). He added that "two great and civilized countries such as Iran and Egypt were more than capable of settling their differences through renewed dialogue with one another". Khatami described Iran-Egypt ties as "two great wings of Islamic civilizations" (Ettelaat international,15 December 1997). Through this approach, Khatami expressed his willingness to remove the tension between these two countries. With Egypt being the largest Arab state and an active participant in Middle East diplomacy, the normalization of relations could have been positive for Iran, particularly in terms of greater acceptance in the region and also regarding the difficult issue of Iran-U.S. relations.

\section{India}

Iran and India have more cultural and ethnolinguistic links than the ones previously examined. The Indo-European family of language-which has its common root in the Aryan tribes of southern Siberia and Central Asia that subsequently migrated to northern India and Iran —as well as geographical proximity provided a basis for such links. These are evident in the concurrent development of Zoroastrian and early Vedic religions, whose respective languages of Avastin and Sanskrit bear a close resemblance to one another. Later, parts of western India and present-day Pakistan formed part of the Achaemenid Empire, after which Buddhism spread from India into parts of Iran during the Seleucid period. Trade relations were maintained throughout the Parthian and Sassanian eras, and during the Islamic conquest of Persia the well-documented flight of Zoroastrians to India, where they became the present-day Parsees, took place (Wastnidge,2016, p. 78). 
During the Safavid period, diplomatic relations between the Safavids and the Mughal Empire were established and remained friendly. However, following Nader Shah's invasion of India in 1739, those friendly relations declined. Then during the Cold War, India's close relationship with the Soviet Union, despite its declared non-alignment, worsened relations. Not surprisingly, in the post-revolutionary period relations declined even more as a result of Iran's approach on issues sensitive to India, such as Kashmir and its own large Muslim population (Pant, 2004, p. 90).

Under Rafsanjani's presidency, economic connections were established. Khatami pursued Rafsanjani's policy to improve economic relations. Yet, he took the opportunity to stress commonalities between the two nations by stating that "solidarity between the Iranian and Indian nations is not based on temporary political and material interests but has roots in the Eastern outlooks of the two countries towards the universe and humanity" (BBC, 18 October 1997).

\section{Organization of Islamic Conference (OIC)}

It was crucial for Khatami to consider the full range of orientations and to adopt a gradual and peaceful approach to lessening Iran's isolation. Khatami focused on assuring the world that Iran would not pursue regional dominance, rather it would seek coexistence with the rest of the world. Within six months of taking office, in 1997, he hosted a summit of the Organization of the Islamic Conference in Tehran. This was the first effort to end Iran's regional and international isolation and to help improve relations with the Arab world. Khatami spoke about his foreign policy agendas to one of the largest gatherings of Muslim leaders who met to discuss political, economic, and social issues. The idea of Dialogue 
Among Civilizations was first articulated to the wider international public at this summit. The summit was followed by his famous interview with Christiane Amanpour on CNN (in January 1998), where he called for American-Iranian cultural exchange among scholars, artists, athletes and tourists (Tazmini, 2009, pp. 84-85). Then, the concept went on to be ratified as an Iranian-sponsored UN resolution, culminating in the designation of 2001 as the Year of Dialogue Among Civilizations.

Before discussing the role of Dialogue Among Civilizations in Iran's relations with the OIC members, it is helpful to provide some background on Iran's relations with these countries, to gain a better understanding of Iranian foreign policy before Khatami's presidency. Ramazani has discussed how Iran's relations with OIC states were particularly strained following the Revolution and during the subsequent Iran-Iraq war. He argues that the rhetoric following the Islamic Revolution caused neighbouring states to view Iran as a threat to the internal stability of their own countries (Ramazani, 1992, p. 1-2).

A further source of conflict was Iran's relations with Saudi Arabia, particularly in the light of problems surrounding Iranian pilgrims participating in the Hajj. In July 1987, there was a clash between Shi'a demonstrators and Saudi Arabian security forces. Since 1981, Iranian pilgrims have held an annual demonstration against Israel and the United States, but in 1987 the Saudi Arabian National Guard closed part of the planned demonstration route, resulting in a violent clash between the two sides. The clash cost about 400 lives, out of which two-thirds had Iranian nationality. Following this incident, in 1988, Saudi Arabia cut its diplomatic relations with Iran and banned Iranians from obtaining a Saudi travel visa for performing the Hajj. Tensions between Iran and Saudi Arabia continued until Khatami's approach eased them and paved the way for a cordial relationship. During this 
period, trade relations between the two countries expanded. Additionally, Iran tried to assure its neighbours that it would not seek to export its revolution, hoping that the new approach would enhance the possibility of rapprochement with the regional states and the West. Iraq's invasion of Kuwait led Saudi Arabia to realize that the real threat came from Iraq, not Iran. They also realized that Iran was the only other country in the region that could contain Saddam's regional ambitions (Monshipour and Dorraj, 2013, p. 142). It is worth noting that despite cordial relations between Iran and Saudi Arabia, the latter remains resolutely opposed to any deal between Tehran and Washington, partly because they are worried that any improvements in US-Iran relations may lead to Iran's playing a larger role in regional affairs (Monshipour and Dorraj, 2013, p. 142).

Since the theoretical framework of this research is based on operational code, which examines the significance of the belief system of decision-makers, it would be useful to make a comparison between Khatami's approach and Velayati's (foreign minister of Rafsanjani’s administration).

In his speech to the $4^{\text {th }}$ meeting of OIC Foreign Ministers in Dhaka, in 1983, Velayati began with calls for solidarity with the Palestinians and criticizing the lack of unity over the issue. He then focused on issues facing the organization, such as the conflicts in Lebanon and Afghanistan. In reference to Afghanistan, Velayati was forceful in his conviction that the Islamic Republic "could not be impartial to stay silent [on the issue]" (Velayati,1983, p. 60).

In the following year, when addressing the OIC Foreign Ministers in Sanaa, Velayati again took a confrontational tone, criticizing the member states for their re-admission of Egypt, despite its peace treaty with Israel, declaring it a "green light for collaboration with 
the enemy" (Velayati, 1984). In his speech, Velayati specifically refers to OIC resolutions 18/10-P and 3/11-P, the former dealing with Egypt's suspension from the OIC and the latter reaffirming that all member states should sever relations with her. Egypt was re-admitted to the OIC in 1984. Syria and Libya also raised objections to Egypt's re-admittance to the organization at the Sanaa meeting. Velayati emphasized that continued suspension of Egypt was a necessity, warning of grave consequences for the future of the OIC and its ideals. The tone and the content of Velayati's speeches show that Iran's relations with the OIC were somewhat strained, and how during the 1980s, it was used by the Iranian government as a platform from which to air its grievances about key issues such as the Arab-Israel peace process and the war with Iraq (Wastnidge, 2011, p. 130)

The eighth summit of the ICO entitled Session of Dignity, Dialogue and Participation was held in Tehran in December 1997 and brought an opportunity for Iran to present a new face of the Iranian government that sought to coexist with its neighbours. In his address to the OIC, Khatami began that "We should know that between the Islamic Civilization—or more correctly, the civilization of the Muslims - and our lives today, there stands a phenomenon known as Western civilizations. The civilizations whose effective achievements are not few, and its negative effects are also manifold, especially for nonWesterners. Our age is one of the dominations of Western civilizations and culture. Understanding it is necessary. An effective understanding goes beyond the frills of that civilization and reaches the roots and foundations of its values and principle" (Salaam, 11 Dec. 1997). Then he argued for the necessity of developing Islamic civil society, which was different from the civil society based on Greek philosophical thinking, in the sense that the concept of secularism has not been accepted by Iranian culture and that religion 
has been one of the most important factors in Iranian history. With this in mind, Khatami suggested that secularism "lacks deep roots in Iran's culture" therefore it "had not much effect" (2003, p. 110). Khatami also emphasized the importance of dialogue within the context of a greater understanding of the West based on an Islamic concept of civil society. He, however, maintained that a common Islamic home should not take the form of regression and withdrawal from the modern world but should rather focus on developing a deep understanding of other societies and cultures, and crucially, engage in dialogue with them. He then argued that, through the dialogue, the relationship between the Islamic world and others would overcome the mistrust that has prevailed in their relationships. In his closing note, Khatami stated that "Muslim countries [...] desire Islamic dignity and greatness and effective participation in global issues and international decision making, based on dialogue among civilizations and refraining from conflict and hostility. Constructive and well-intended dialogue among different nations and societies in the world is the best available solution for reducing the atrocities of the international system" (CNN, Dec. 1997).

As the conclusion of the summit, the OIC instituted the concept of Dialogue Among Civilizations with the support of the heads of member states, which resulted in the Tehran Declaration. In short, the Tehran Declaration pronounced that Islamic civilization has been rooted in peaceful coexistence, cooperation, mutual understanding, as well as constructive dialogue with other civilizations, beliefs, and ideologies.

Following the Tehran summit, the first concrete steps were made in officially instituting the idea of dialogue among civilizations and formalizing its application within the OIC. Khatami (1997) suggested forming a group of experts in conjunction with the Ministry of 
Foreign Affairs to practically implement the Dialogue Among Civilizations. The outcome was one of the central themes of the $25^{\text {th }}$ Foreign Ministers meeting in Doha, Qatar a few months later. During this gathering, Kharrazi mentioned that, in line with a Dialogue Among Civilizations, "we must renounce all causes of differences in light of our Islamic norms. There is a need for holding dialogue between the Islamic countries and other civilizations to encourage mutual understanding and advance co-operations" (Kharrazi, 1998).

\section{The Issue of Palestine}

Khatami and his administration recognized that Iran's rhetoric and some of its policies resulted in the country's international isolation. One of those issues was the country's aid to Palestinian groups designed, not only to help in "wiping Israel off the map," but also to increase economic sanctions against Iran. Since the inception of the revolution, opposition to Israel has been an indication of ideological reliability and of a revolutionary spirit. Consequently, no one has been willing to pay the political price for a fundamental revision of these aspects of Khomeini's vision. However, for Khatami and his administration, Iran's policy towards Israel was not as important as domestic political reform and changing the direction of foreign policy. As a result, Khatami adopted a more pragmatic and very different approach towards the Israel-Palestine conflict: he changed the tone of the regime's rhetoric. Based on the discourse of Dialogue Among Civilizations, he left the door open to communication with Jewish scholars. Khatami rejected anti-Semitism as a Western phenomenon and posited that "In the East, we have had despotism and dictatorship, but never fascism and Nazism," (IRNA, September 21, 1998). 
Moreover, Khatami, in an interview with $\mathrm{CNN}$ regarding Arab-Israeli peace, maintained that "we do not intend to impose our views on others or stand in their way" (IRNA, January 8, 1998). Foreign minister spokesman, Hamid Asefi, reiterated this position, noting that Iran "will in no way interfere with the decisions of the Palestinian groups. We respect all decisions taken by the majority of the Palestinians" (AFP, October 17, 2002).

\section{Relations with Persian Gulf Arab States}

The new direction in Iranian foreign policy offered by Khatami was well received by both the regional and international community. At the regional level, Khatami highlighted Iran's commitment to improving ties with Middle Eastern states by meeting with Sultan Qaboos of Oman (Ettelaat, 7 August 1997) and Qatar's foreign minister, Sheikh Hammad bin Jassem (Ettelaat, 14 September 1998) soon after his inauguration. Bahraini Emir Sheikh Isa also expressed his willingness to pursue bilateral relations, stating that "we are optimistic that [good relations] will happen during the new era based on the policy principles declared by Khatami (Iran Daily, 28 August 1997). However, the Persian Gulf Arab countries' relations with the U.S. had been one of the issues that led to the failure of Iran's reconciliation with those countries. Khatami was willing to normalize relations with the Persian Gulf states despite their attachment to the United States. Khatami's Good Neighbor policy finally managed to reconcile Iran's relations with the regional regimes. As a consequence, an entire range of trade, diplomatic, and security arrangements was signed between Iran and the Arab sheikhdoms. One of the main achievements of Khatami's new policy was improving Iran-Saudi Arabia relations. After two decades of animosity, 
Khatami met Crown Prince Abdullah in Saudi Arabia in 2001. The two parties signed a historical security pact for combating crime, terrorism, money laundering and surveillance of borders and territorial waters (htpp://gulfnews.com). One can argue that under Khatami's Presidency, Iran's Persian Gulf policy underwent a fundamental shift.

Marschall (2003) argues that Iran's new direction in foreign affairs came out at an appropriate time because, at the time, the Persian Gulf Arab states were facing increasing popular pressures and an Islamic challenge due to the deterioration of the Arab-Israel peace process and the Israeli-Turkish military alliance. These states thus turned to a new stage in their relations with Iran as a counterbalance to the Israeli-Turkish alliance as well as Iraq (p. 143).

\section{Approach to the United States}

\section{Background}

During much of the 1990s, American foreign policy was guided by the Democratic administration of Bill Clinton. Although the Clinton administration criticized various aspects of its Republican predecessor's international policies, its approach to Iran remained almost the same. Secretary of State Warren Christopher-who had served in the Carter administration and was the chief negotiator in the final months of the hostage crisisdenounced Iran as an "international outlaw" and a "dangerous country" (quoted in Lake, 2004). Similarly, Anthony Lake, the national security advisor, argued that Iran, as one of the "reactionary backlash states", "seeks to advance their agenda through terror, intolerance and coercion." (New York Times, 5 July 1994). 
The disintegration of the Soviet Union was perceived by the Clinton administration as an ideal opportunity to resolve the Arab-Israeli conflict and promote the plan of the New Middle East. The main goals of the plan would be stability and integration into global economics. However, by introducing dual containment, the U.S. sought to "prevent the potential resurgence of Iraq and to prolong the policy of isolating and coercing Iran" (Cause, 1994). Trade prohibitions that resulted in limiting Iran's access to the world economy and even the imposition of secondary sanctions on European investors made Iran's circumstance even worse. Moreover, Iran still maintained a sponsorship of terrorism in the region, in America's eyes.

The U.S. position became clearer when its ambassador Richard Holbrooke said, "if the Iranian government responds positively to the American position on issues of state sponsorship of terrorism and cooperating in solving regional problems and sources of instability in which Iran plays a big role, then the road will be open for a major development in the relationship." (Takeyh, 2006, p. 114). This American approach, according to Takeyh, instead of devising a negotiation process that could resolve such disputes, put the responsibility and obligation on Iran, without any improvement of relations between Iran and the U.S. (2006, p. 114).

The most significant steps towards smoothing relations between Iran and the U.S. have been made under Khatami's presidency. Although the climate both within Iran and the U.S. would not lead to formal and diplomatic relations, signals of willingness to improve conditions were apparent. On the Iranian side, for instance, it was evident that the majority of the society was tired of the old slogans such as "Death to the U.S." and hoped for change. On the American side too, there were encouraging signals. However, the results expected 
by both parties were not achieved. In the following paragraphs, I will explain why, despite the willingness of both countries, diplomatic relations did not improve.

Khatami presented Iran's willingness to open a new chapter in its relations with the U.S. most explicitly and specifically in his interview with CNN television in January 1998. In his interview with Christiane Amanpour, Khatami declared "an intellectual affinity with the essence of the American civilization" as based on "religiosity, liberty, and justice," and proposed an exchange of "professors, writers, scholars, artists, journalists, and tourists" to remove the "wall of mistrust between us and the U.S. administration".

Regarding the main issues of concern such as hostage-taking, the slogan "Death to America", and the burning of the American flag, Khatami maintained that those actions had to be analyzed within their own context. He argued that the revolutionary atmosphere and the pressures to which the Iranians were subjected led them to express their anxieties and concerns. Khatami explained that those slogans indicated a desire to put an end to the relations which existed between Iran and the United States. He, for instance, referred to the former U.S. defence secretary who said that the "Iranian nation must be rooted out". He also argued that those slogans were a response to the downing of the Iranian airliner that killed approximately 300 innocent people, mostly women and children. "Even if we accept that the shooting down was accidental, the decoration of the commander of the American naval vessel responsible for the tragedy was indeed adding insult to injury" Khatami said. He also referred to House Speaker Newt Gingrich's initiative to allocate $\$ 20$ million for overthrowing the Iranian government.

It was this sort of relationship, according to Khatami, that Iranians sought to end. $\mathrm{He}$ went further by explaining that "no one has the intention of insulting the American nation 
and we even consider the U.S. government as the legitimate and lawful representative of American flag, which represents its nationhood". Additionally, Khatami posited that there is a wall of mistrust between Iran and the U.S. which stemmed from the policies of American governments. He said "when we say that there exists a high wall of mistrust between us and the U.S., it is not a mere slogan. The Iranian people feel that Americans have dominated their destiny, at least from the 1953 coup until now. Doesn't this nation have a right to blame all the losses, the lives lost, the damages endured, and the humiliation and insults the nation has been subjected, on this incorrect U.S. policy?... since the coup, U.S. policies have weighed heavily on the life of the Iranian people. The Iranian nation has been inflicted with heavy human, financial and social costs. A lot of people suffered as a result of the unpopular (Pahlavi) regime. We were left behind by the rest of the world. It is not just that something was done, and an apology is now made [...] an apology must be accompanied by a series of practical measures showing a change of manner and behaviour" (http://www.cnn.com/WORLD/9801/07/iran/interview.html).

However, Khatami suggested that nothing should prevent a dialogue between two nations. In general, Khatami's overall tone was conciliatory. It can be argued that people around the world remembered the main aspects of Khatami's invitation to the American people to a Dialogue Among Civilizations. He knew that the time for diplomatic exchanges had not come yet, but it might be a proper time for the exchange of professors, writers, scholars, artists, journalists, and tourists. Another issue that observers might remember was that Khatami rejected any form of terrorism and that he expressed regret for the seizure of the US embassy in 1979 (Malici and Walker, 2017, p. 155). 
According to Khatami, the Iranian government is looking for a world in which misunderstandings can be overcome, nations can understand one another, and mutual respect and logic govern relations among states. Khatami's attitude was distinctly more conciliatory when he extended an olive branch to the American people in his CNN interview. Following the interview, the United States softened its tone slightly towards Iran. In May 1998, it announced that it would waive the provisions of the 1996 Iran-Libya sanction Act (ILSA) against a consortium of French, Russian and Malaysian companies, in return for Europe agreeing to press Iran about terrorism and weapons of mass destruction (Alikhani, 2000, p. 320-33).

Additionally, the United States removed Iran from the list of state sponsors of terrorism, and small changes were adopted to make American visas easier to obtain for Iranians. In 1999, sanctions aiming to prevent the sale of food and medicine to Iran were removed. More importantly, at the higher level, Clinton in his statements recognized positive changes in Iran's policies. He acknowledged that "Iran had legitimate grievances because of the past involvement of external powers in its domestic affairs" (quoted in Tazmini, 2009, p. 90). These advances represented an important shift in American foreign policy during Khatami's first two years in office.

In March 2000, Madeline Albright, Secretary of State in the Clinton administration, had delivered a sympathetic speech on the past, present, and future of U.S.-Iran relations. Although she criticized some aspects of Iranian policy, she admitted the cultural contributions of Iranian civilization. More importantly, she apologized for U.S. involvement in the 1953 coup against Mohammad Mosaddeq and U.S. support for Saddam Hussein during the Iran-Iraq war (Pollack, 2004, p. 25). Albright added that the time had 
come "for America and Iran to enter a new season in which mutual trust may grow and quality of warmth supplant the long, cold winter of our mutual discontent" (quoted in Tazmini, 2009, p. 90). However, the tone of the speech changed when Albright declared, "despite the trend toward democracy, control over the military, judiciary courts, police remain in unelected hands, and the elements of its foreign policy, about which we are most concerned, have not improved." The speech that began by apologizing for intervention in Iran's internal affairs ended up interfering in Iran's domestic conflicts (quoted in Takeyh, 2006, p. 115).

The Islamic Republic's reaction was predictable; it declared the speech an intervention in domestic politics. In fact, the reformist government appreciated the historical significance of the speech and was inclined to respond positively, but the phrase "unelected hands" offered the hard-liners sufficient reasons to prevent reformists from any initiative. Takeyh (2006) maintains that America's gesture was too little and, more importantly, too late since the crucial time would have been after Khatami's election, especially after his CNN interview. More sanctions relief, including U.S. investment in Iran's energy industry, might have improved the balance in favour of reformers, and might have allowed Khatami to breach the "wall of mistrust." In a relationship that has witnessed many missed opportunities, the inability of the Clinton administration to adopt a timely and constructive policy stands as one of its most tragic failures (p. 115-116).

Khatami's second term was overshadowed by the tragic event of 9/11. Little more than three months after his successful re-election, the international environment was dramatically altered by the devasting terrorist attacks on the World Trade Center and the Pentagon by members of an Islamic group known as Al-Qaeda. From that time on, the 
foreign policy dimension would increasingly take center stage within Iranian politics as rival groups sought to deal with the reality of U.S. power in the region, and while in many ways the internal dynamic of reform and reaction continued, it was dramatically affected by an event that happened beyond Iran's borders (Ansari, 2006, p. 229).

\section{Under the Shadow of September 11}

When Iran-U.S. relations seemed to be settling into normalcy, the events of $9 / 11$ took place. Some American journalists and politicians tried to link the attacks to Iran, and Khatami was determined that Iran should not fall victim to American revenge. He immediately expressed his condolences, as did the mayor of Tehran and the fire chief. Foreign Minister, Kharrazi reportedly informed his American counterpart Colin Powell that, "The U.S. should know that the Iranian people and the Iranian government stand with the U.S. in its time of need and absolutely condemn these vicious terrorist attacks" (quoted in Slavin, 2007, p. 193). In addition to these formal positions, groups of young Iranians had organized candle-lit vigils for the victims.

The first rapprochement towards the United States was regarding Afghanistan. In October 2001, after unproductive negotiations with the Afghan leadership, the U.S. launched a military invasion aiming at removing the Taliban. For Iran, this provided an opportunity, since there was tension between Iran and the militant Sunni regime of the Taliban and its Wahhabi terrorist allies. During the 1990s, Iran actively assisted opposition groups such as the Northern Alliance. Once U.S. military operations commenced, indirect signs were sent to Washington. Foreign minister Kamal Kharrazi publicly declared, "We

have some common points with the US over Afghanistan." (Al-Sharq al-Awsat, October 
29, 2001). Additionally, Khatami noted that "Afghanistan provides the two countries [Iran and the U.S.] with a perfect opportunity to improve relations." (quoted in Abrahamian, 2004, p. 96). The circumstances of 9/11 and Iran's devastating economic conditions led to the shaping of a new consensus around a foreign policy of New Thinking. A coalition of reformers and pragmatic conservatives came to the conclusion that in the new map of the Middle East, Iran must cooperate with the U.S. on issues of common concern. Iran cooperated with the West in the removal of the Taliban regime from Afghanistan and did what it could to assist the U.S. in the rebuilding of its impoverished eastern neighbour.

It is argued that America's war on terrorism could not have succeeded as easily as it did without Iranian support. The fact is that by 2001 “America's link with the Northern Alliance was fragmentary, and its long years of neglect had led many Afghan oppositions groups to be suspicious of the U.S." (Takeyh, 200, p. 122). Tehran's mediation proved essential as Iran actively pressed the Northern Alliance and other opposition groups to cooperate with American forces. Iran also provided intelligence to the Northern Alliance, agreed to rescue American pilots in distress, and allowed some 165,000 tons of U.S. food aid to traverse its territory into Afghanistan. The speedy collapse of the Taliban acclaimed by the Bush administration had in fact, been the result of substantial Iranian assistance (Takeyh, 2006, pp. 122-123). The Taliban was defeated after a rather short military campaign, and Iranian help had proved very important.

Parsi (2012) believes that for the Iranian side, it was a moment of triumph. Not only was the Taliban defeated, but Iran proved that it could help stabilize the region, and the United States could benefit from a better relationship with Iran (40). Throughout this collaborative period, Khatami and his team expressed a desire to expand cooperation on 
other issues as well. On the American side, Secretary of State Colin Powell tried to respond with a more proactive policy toward Iran. The neo-conservatives in the Bush administration, however, prevented any initiatives. Their opposition caused the Bush administration to miss the "perfect opportunity" to re-define the relationship (Slavin 2007; Hunter 2010, p. 59). Indeed, in his 2002 State of the Union address, George W. Bush effectively blocked the possibility of a new chapter in U.S.-Iran relations, denouncing the Islamic Republic as a member of an "Axis of Evil”, along with Saddam Hussein's Iraq and Kim Jong-un's North Korea. Bush described Iran as a major sponsor of terrorism, and a threat to Israel and its neighbours in its pursuit of weapons of mass destruction. He stated "Iran aggressively pursues these weapons and exports terror [...] states like these, and their terrorist allies, constitute an axis of evil, arming to threaten the people of the world. By seeking weapons of mass destruction, these regimes pose a grave and growing danger. They could provide these arms to terrorists, giving them the means to match their hatred. They could attack our allies or attempt to blackmail the U.S. Given this situation, the price of indifference would be catastrophic." (https://georgebushwhitehouse.archives.gov/news/release/2002/01/20020129-11.html). Khatami found that there was no chance for negotiation. He rejected Bush's speech as "bellicose, insulting and anti-Iranian," pointing out that "such mentality is what brought terrorism into existence in the first place and is now the policy ruling in today's world" (quoted in Shakibi, 2017, p. 214).

The Bush speech constituted a strong setback in U.S.-Iran relations. It "underscored the inflexibility, dogmatism, and lack of imagination and strategic thinking at the base of U.S. foreign policy" in dealing with Iran (Shakibi, 2017, p. 214). On 20 September 2002, the 
U.S. position became more aggressive, as it published its new national security doctrine in which one could read that the most dangerous and urgent threats facing the country were the "crossroads of radicalization and ideology" (http://www.state.gov/documents/organization/63562.pdf). As a result, traditional means of American statecraft such as deterrence and containment were replaced by the "rights of self-defence by acting pre-emptively." Short of such action was the goal of regime change, but it was clear that the most prominent target for pre-emption remained Iran and Iraq. Thus, the hopeful years following Khatami's initiatives aiming at a peaceful relationship failed (Malici and Walker, 2017, pp. 147-149).

Bush's proposal for dealing with Iran included a range of possibilities, including preemptive war, actions aiming at destabilizing the Islamic regime, assistance to internal and external opposition groups, and financial aid for foreign-based Iranian media (Amuzegar, 2000, p. 44-45; Ansari, 2006). Takeyh (2006) argues that 9/11 made the U.S. re-evaluate the traditional concepts of American politics. He maintains that the U.S. not only sought to contain rogue states but also to actively "alter the political culture of the region by ushering in democratic dawn." Regime change, pre-emptive war, and coerced democratization, according to him, were the new concepts of American policy. In this regard, the Bush administration perceived $9 / 11$ as a unique opportunity to "reformulate the dysfunctional political topography of the region and finally ensure that stability that all empires crave. In this context, Iran was no longer a problem to manage, but a radical, unsavoury regime to topple" (p. 118). Moreover, under this framework, Iraq and Iran were threats not just because of their nuclear ambitions but because they oppressed their citizens. Such "recalcitrant regimes could be neither contained nor deterred, leaving regime change as the 
only

viable

option"

(https://www.pbs.org/wgbh/pages/frontline/shows/iraq/interviews/gaddis.html).

The call for regime change in Iran was routinely repeated in 2003 after the Iraqi invasion. George W. Bush's justification of the invasion of Iraq based on the threat posed by Saddam Hussein's nonexistent weapons of mass destruction had at least one disastrous consequence. Iranian officials came to the conclusion that the United States invaded Iraq because it knew Saddam did not have any weapons of mass destruction, and therefore seemed an easy target. Therefore, for its own preservation, Iran had to have a nuclear bomb (Amir-Arjomand,2009, p. 197).

Some scholars hold that categorizing Iran along with Iraq and North Korea illustrated the U.S. administration's failure to differentiate between Khatami and Saddam Hussein (Amuzegar, 2006; Ramazani 2013, Ehteshami, 2008, p. 2014). Saddam Hussein overtly challenged the U.S., but while he disagreed with Washington's policies in the Middle East, Khatami attempted to find common grounds to cooperate. One of those issues was both sides' interests in removing the Taliban. To this end, Iran actively supported U.S. military action against the Taliban. Iran also participated in the post-war Bonn Conference of December 2001, where the transitional governing authority for Afghanistan was established. After the collapse of the Taliban, Khatami supported the new government under Hamed Karzai and encouraged cooperation between Iran and Afghanistan (Malici and Walker,2017, p. 148).

The classification of Iran as part of the Axis of Evil gave an opportunity to both Iranian radicals and reformers. The reformers attempted to create an atmosphere under which negotiation can happen. However, the American administration disappointed the 
reformers, which led to an increasingly anti-American approach that gave the radicals leverage over reformers. It is argued that Washington failed to capitalize on the opportunity to negotiate with a moderate president in power in Iran (Pollack and Takeyh, 2005, p. 22). In fact, the United States failed to understand that Khatami was a pragmatic and peaceseeking politician with whom they could have engaged in meaningful and constructive dialogue. Khatami represented an opportunity that the American government might have converted to its own interests, but instead turned its back on it (Amuzegar, 2006, p. 91-2).

From the Iranian perspective, Iran has had sufficient reasons to feel strategically uncomfortable. Since 2003, it has been surrounded by the U.S. military: U.S. combat troops are stationed in Iraq and Afghanistan, the U.S. navy's presence in the waters of the Persian Gulf, Turkey is a NATO member, the U.S. military support of non-NATO ally Pakistan, and even Azerbaijan's engagement in military cooperation with the U.S., as well as with Israel. Furthermore, Iran finds itself between two nuclear-armed states, Pakistan, and Israel: the former is a direct neighbour and a fragile state with strong Sunni fundamentalist currents that sometimes give rise to anti-Shi'a violence, the latter is an enemy (Mojtahedzadeh, 2005; Perthes, 2010, p. 96-7).

Despite Khatami's attempt to improve coexistence between Iran and the world, Bush's categorizing Iran as part of an Axis of Evil made Khatami's second term much more diplomatically tense. Furthermore, the nuclear debate fuelled a power struggle among different Iranian political factions, enabling the neoconservatives to come to power with a confrontational approach in foreign policy, especially concerning the country's nuclear programme and its security dimensions. 
Amir-Arjomand (2009) argues that more than any other international event, America's response to the September 11 attacks revealed the fault lines among Iranian hard-liners and reformers. For the hard-liners, the Islamic Revolution remained a model worthy of export, and the necessity of resisting America and the regional states it backed had never been greater. Moreover, a confrontational foreign policy had the advantage of strengthening a revolution whose popularity had decreased. By contrast, reformers stressed that despite American presence, Iran had to act carefully and cultivate cooperative relations with its neighbours. They also argued that given Iran's economic pressures, dogmatism would prevent the attraction of foreign investment. Such debates were once again polarizing Iran's clerical rulers into competing factions of hard-liners or ideologists and realists or reformers (pp. 118-119). In this battle, the hard-liners came to power with Ahmadinejad as the president.

\section{Missed Opportunities}

In the summer of 2003, Iran requested that the Swiss ambassador to Tehran, Tim Guldimann, deliver a document to the U.S. State Department. The document known as The Roadmap was an agenda aiming at rapprochement between Iran and the United States which was prepared by Khatami and his foreign minister, Kharrazi (Leverett and Leverett, 2013; Mousavian, 2012).

The outline of the roadmap was simple. It identified U.S. and Iranian aims. Iranian leaders promised to the U.S. "full transparency for security" and "no Iranian endeavours to develop or possess WMD." Toward this end, the regime would make its nuclear program transparent by voluntarily placing its nuclear facilities under the supervision of monitors from the International Atomic Energy Agency (IAEA). It also promised "decisive action 
against any terrorists - above all Al-Qaida on Iranian territory." Regarding Iraq, Iran committed to the coordination of Iranian influence for actively supporting political stabilization and the establishment of democratic institutions and a democratic government. Finally, with regard to the decades-long Israel-Palestine conflict, it promised to accept the two-state solution and "action on Hezbollah to become an exclusively political and social organization within Lebanon." Regarding Iran itself, Tehran requested that the U.S. refrain from supporting a change of the political system. It also demanded the removal of all sanctions, simultaneous access to peaceful nuclear technology, and recognition of Iran's legitimate security interests in the region (Malici and Walker, 2017, pp. 168-200)

In Washington, the Roadmap received no serious consideration. While some senior officials such as Secretary of State Colin Powell and his deputy Richard Armitage favoured a positive response, Vice President Dick Cheney and Secretary of Defense Donald Rumsfeld blocked them from responding to the Iranian communication. "We don't speak to evil" was their response (Porter 2006, p. 170). Meanwhile, three European countries France, Germany, and Britain (known as EU3) welcomed the Iranian proposal. The negotiation between Iran and the EU3 resulted in the Tehran Declaration of October 2003. Based on this document, Iran reaffirmed that it would not pursue the acquisition of nuclear weapons, and its nuclear program and activities would be exclusively for peaceful purposes. To demonstrate its commitment to the nuclear non-proliferation regime, it agreed to sign the Additional Protocol to the NPT aiming at enhancing confidence for peaceful cooperation in the nuclear field. This would allow the IAEA to conduct more extensive inspections and, to suspend all enrichment-related activities. The EU3, in turn, agreed to have a "dialogue as the basis of longer-term cooperation," encompassing economic, 
technological, and security concerns (Bahramitash 2014, p. 10. Also see http://news.bbc.co.uk/2/hi/middle_east/3211036.stm.).

Iranian leaders expected their European counterparts to bring the U.S. to the negotiation table. However, this would not happen for two main reasons. Firstly, the Bush administration was "riding high at the moment": Saddam Hussein's regime had collapsed, but the difficulties of the occupation had not yet been revealed. The anticipated American victory in the situation let the American leaders dictate the terms of any agreement to their Iranian counterparts rather than negotiate them. Secondly, as the months passed, it turned out that the EU3 lacked political will and resolve to work from mutual promises toward actual concrete steps (Mousavian, 2008; Leverett and Leverett, 2013).

Two years later, in March 2005, Iran offered another deal by then-Secretary of Iran's Supreme National Security Council Hassan Rouhani. This time the offer was to implement the Additional Protocol, to limit the number of centrifuges Iran would deploy, restrict the production of low-enriched uranium, convert enriched uranium into proliferation-resistant fuel rods, and allow the continuous on-site presence of IAEA inspectors at their fuel cycle facilities. The EU3, in turn, would guarantee Iran's access to EU markets and financial and public and private investment resources, to advanced and nuclear technology, and to fuel for Iranian nuclear power reactors to complement Iran's domestic production. The EU3 would also work with Iran to build new nuclear power plants there, and they would accept Iran's basic right to enrich uranium. Due to American pressure, however, the European position had been tough and severe when they emphasized that fuel cycle activities had to be suspended indefinitely. This, obviously, was not acceptable to Iran (Malici and Walker, 2017, pp. 170-171). 
Despite the American pressure on the EU3, the Bush administration considered the possibility of war with Iran. In his State of the Union address on January 31, 2006, Bush described Iran as a "nation now held by a small clerical elite that is isolating and repressing its people". He went further by stressing that the "Iranian government is defying the world with its nuclear ambition, and the nations of the world must not permit the Iranian regime to gain nuclear weapons." (www.washingtonpost.com/wpdyn/content/article/2006/01/31/AR2006013101468.html) Not surprisingly, the reaction from Tehran came immediately. The new president Mahmoud Ahmadinejad who came to be known for his provocative rhetoric denounced Bush as the one "whose arms are smeared up to the elbow in the blood of other nations" and pledged that "God willing, we shall drag you to trial in the near future at the courts set up by the nations" (quoted in Takeyh, 2006, p. 1).

\section{Relations with the European Union}

By introducing a détente in foreign policy, Khatami pursued three main goals: firstly, a continuation of the policy of not exporting the revolution; secondly, promoting rapprochement with Arab states, particularly those neighbouring Iran; and finally, promoting normalization of relations with the EU states (Ahmadi, 2005, p. 21). The last point was affected by two incidents that hindered Iran's relations with the EU. First, the assassination of Iranian-Kurdish opposition leaders at the Mykonos restaurant in Berlin in 1992. During the trial, German courts implicated key Iranian figures in the assassination of Kurdish dissidents (https://fas.org/irp/news/1997/970416-mr.htm). Subsequently, the EU recalled its ambassadors from Iran. The second incident was Khomeini's fatwa calling 
for the death of Salman Rushdie, author of The Satanic Verses in February 1989, which resulted in the withdrawal of European ambassadors from Iran. The Rushdie affair complicated relations between Iran and European countries even after the death of Khomeini. In 1998, Khatami announced that the ten-year fatwa ordering the death of Salman Rushdie was revoked, insisting that his government would not carry out the fatwa, and after extensive negotiation with Khamenei, Khatami managed to secure the return of European ambassadors to Tehran, which was a significant shift in Iranian foreign policy (Tazmini, 2009, p. 85).

Following Khatami's new approach in foreign policy, European Union members expressed their willingness to have a comprehensive dialogue with Iran. In February 1998, European Union foreign ministers reached a consensus to lift the ban on top-level contracts with Iran in response to encouraging developments in the country. Agreements between Iran and $15 \mathrm{EU}$ states were made, after pressure from Italy and Greece, which had strong commercial ties with Iran. However, Germany and Britain continued with a more cautious approach (Tazmini, 2009, pp. 85-86).

Khatami's trip to Paris at the invitation of the French president, Jacques Chirac, in October 1999 was the first visit to France by an Iranian head of state since the revolution. During his trip to France, Khatami visited the tomb of Jean Jacques Rousseau. In the same year, Pope John Paul II gave a private audience to Khatami, the first papal encounter with an Iranian head of state since the days of the Shah. In his speech at the University of Florence, Khatami referred to some European philosophers to explain his idea of Dialogue Among Civilizations. (Ansari, 2006, p. 139). During this time, Kharrazi and his Italian counterpart, Lamberto Dini, signed an agreement for bilateral cooperation in an anti-drug 
campaign, as well as agreements for cooperation in academia and technology (http://iccim.org/iran-commerce/no2-1999). On his trip to Germany in 2000, he specifically requested a visit to Weimar so that he could open a memorial to the Persian poet Hafez and the German poet Goethe (Ansari, 2006, p. 139).

Prime Minister Jose Maria Aznar visited Iran in 2000: the first visit by a Spanish government leader since the revolution. In 2002, Spanish King Juan Carlos officially welcomed Khatami at his royal palace (Iran News, 29 Oct. 2002). In 2004, prince Charles travelled to Iran to visit the earthquake-destroyed city of Bam. This was the first visit to the country by a member of the British royal family since the revolution (RFE/RL, 11 February 2004). Khatami also met with Home Secretary Jack Straw and visited Vienna on a trip intended to bolster ties with the European Union.

The European Union also signed energy deals with Iran, defying Washington's pressure. In fact, several international companies (Total-Fina-Elf, Shell and Repsol) became involved in oil and gas exploration projects in Iranian oilfields. Moreover, in October 2004, the World Bank approved Iran's request for new infrastructure loans amounting to $\$ 220$ million, despite Washington’s continued opposition (Amuzegar, 2000, p. 99). After repeated applications to the World Trade Organization, Iran succeeded in achieving observer status in 2005 , allowing the Iranians to participate in meetings but not in the decision-making process (Tazmini, 2009, p. 87).

Additionally, Khatami made journeys to Central Asia, the Caucasus, and the Far East. He was warmly received in Japan, where he was the first Iranian head of state to visit in 40 years. Khatami met with the emperor, the prime minister and his cabinet, and numerous businessmen and industrialists, and offered a general framework for economic, 
technological and scientific cooperation between the two countries. In his travel to China, Khatami also emphasized the importance of cooperation and asked China to play a more prominent role in the Iranian economy. During that visit, the two countries signed several agreements regarding economics, energy, industry, culture, and science (Cornell, 2001).

At the end of his first term, and preparing for the second term, Khatami presented the 175-page Report of the President of the People, including his administration's foreign policy achievements, focussing mainly on diplomatic initiatives that resulted in improving relationships with Persian Gulf Arab states, Europe, Southeast Asia, and Russia, as well with the Central Asian republics. These improvements included attempts to finalize the legal status of the Caspian Sea, fighting anti-Iranian propaganda, participating in regional and international strategic decisions (for example, OPEC's price stabilization efforts), participating in 50 international organizations dealing with weapons of mass destruction and environmental protection, signing international treaties against chemical and biological weapons, and winning worldwide praise for the fight against drug trafficking (Amuzegar, 2006, p. 87-88).

Khatami's second presidential term was basically devoted to relieving the international community of its fear of Iran's nuclear program.

\section{Iran's Nuclear Program}

On 18 December 2003, Iran made an overture of sustained transparency by volunteering to sign the Additional Protocol to the Nuclear Non-Proliferation Treaty (NPT). Iran's ambassador, Ali Salehi, signed an Additional Protocol to Iran's Non-Proliferation Treaty (NPT) safeguards agreement, granting the International Atomic Energy Agency (IAEA) 
inspectors greater authority in verifying the country's nuclear programme. The Additional Protocol requires states to provide an expanded declaration of their nuclear activities and grants the IAEA broader rights of access to the country's sites (IAEA.org, Iran Signs $\begin{array}{lllll}\text { Additional } & \text { Protocol } & \text { on }\end{array}$ (http://www.iaea.org/NewsCenter/News/2003). Another initiative was Iran's temporary suspension of its nuclear fuel cycle, deemed a "voluntary" and "temporary confidencebuilding" measure under the Paris agreement of November 2004 (International Herald Tribune, 12 August 2005).

These initiatives aimed at preventing Iran's nuclear dossier from being sent to the UN Security Council. Moreover, Iran wanted to prove that it would pursue the international norms, and its nuclear program would follow peaceful purposes. However, Ahmadinejad dramatically shifted Iran's approach towards its nuclear program, resulting in increased tension between Iran and almost all members of the international community.

\section{The 2003 invasion of Iraq and Iran's Approach}

This crisis was an opportunity for Khatami's government to enhance its standing in the international community and the region. Throughout the crisis, Iran did not side with Iraq, but in its role as the chair of the Organization of Islamic Conference (OIC), assisted in finding a diplomatic solution. Kharrazi stressed that Iran was against the use of force by the U.S. and Britain. He tried to mediate with the Iraqi foreign minister, emphasizing the necessity of Iraqi compliance with UN resolutions. He also was in contact with Kofi Annan. Khatami himself called on Iraq to abide by international resolutions but strongly condemned any aggression against Iran's neighbour. He declared, "I call on all countries 
and international organizations to make every effort to prevent a great human tragedy in Iraq and called on the countries of the region to work together to ensure the security of the Persian Gulf without foreign interference.” (Quoted in Marschall, 2003, p. 146)

It showed that Iran stood firmly on the side of the international community and would not ally itself with Saddam Hussein. Throughout the crisis, Tehran was in constant touch with the UN Secretary-General, the Secretary-General of the ICO and the Saudi government and demonstrated its willingness to co-operate and play a constructive role in solving this regional conflict.

It is worth mentioning that a change in the balance of power in the region occurred prior to Khatami’s presidency Iraq invaded Kuwait in August 1990. This crisis provided Iran with an opportunity to prove its commitment to improve its relations with the Persian Gulf States. Iran denounced Iraq's invasion and the subsequent annexation of Kuwait. In fact, Iran was the first Gulf country to condemn Iraq and to demand its total and unconditional withdrawal from Kuwait. Iran remained neutral during this crisis, and what is more, attempted to mediate an end to the crisis. Indeed, Iran's Foreign Minister went to Oman, Qatar, the UAE, and Syria, where he declared that Iran would not accept any change in Kuwaiti borders. In addition to its diplomatic efforts, Iran also gave humanitarian help to the victims of the conflict. It provided shelter to thousands of Kuwaiti refugees. Iran's policy resulted in calls from some of the GCC leaders to include Iran into a regional security arrangement. Less than a week after the Iraqi invasion of Kuwait, Sultan Qaboos of Oman called for regional cooperation, including with Iran, to establish security in the region. The most tangible sign of the GCC States' changing perception towards Iran came during the GCC Summit at Doha on December 22-24, 1990, when the GCC decided to 
seek closer ties with Iran in order to counter the military threat from Iraq. The Summit also discussed the inclusion of Iran in a wider regional security framework (Mumtaz, 2005, p. 15-17).

\section{Conclusion}

Khatami's conciliatory foreign policy was based on the two principles of Dialogue Among Civilizations and détente, which aimed at cooperation and coexistence rather than confrontation. The foundation of these changes rests on Khatami's belief system which viewed the other not only as enemy or rival but as friend or counterpart with whom he could have a dialogue. Khatami's belief system enabled him to redefine and redirect Iran's image from that of a revolutionary actor to that of a proactive player who accepts and respects the international norms which let Iran have peaceful relations with the international community. In this regard, Khatami's Iran was able to assure the Persian Gulf Arab states that Iran not only would not export the Revolution but that it would attempt to establish constructive relations with its neighbouring countries. Moreover, he succeeded in creating peaceful relations of Iran with the European Union. In addition, he reached out to an open a dialogue with the United States. However, the U.S. labelling Iran as part of an Axis of Evil prevented Khatami from achieving all his goals. I would not dismiss the significance of the external circumstances in shaping Iran's foreign policy direction, but I argue that between 1997 and 2005, Iran ended its isolation and became part of the international community. It was able to establish relationships with almost all countries compared to Rafsanjan's period and Ahmadinajad's during which Iran's key allies were mainly Syria and some African countries. During Khatami's presidency, Iran was an active 
player in the international community, something which I believe is better explained by Khatami's worldview than by the external environment. 


\section{CHAPTER SIX}

\section{CONCLUSIONS}

In this study, I argued that Iran's foreign policy under Khatami's presidency has gone through a paradigm shift, and the main reason for this change was Khatami's belief system. I suggested that Khatami's beliefs changed Iran's foreign policy through his discourse of Dialogue Among Civilizations.

Before highlighting the difference between Khatami's period and that of his predecessors' and successors', I explained the relationship between the Supreme Leader and the president in order to question the common idea that the Supreme Leader has the ultimate authority and the most power to make decisions on the foreign policy front, and to suggest that there should be cooperation between the Supreme Leader and the president in order to maintain the country's stability.

Iranian post-revolutionary foreign policy has gone through five phases. By the emergence of the 1979 revolution, Iran's foreign relations underwent a fundamental shift from "positive equilibrium" to "neither East nor West" based on Khomeini's belief system, which viewed the world as divided into two camps, oppressors and oppressed. Oppressors include those countries that are powerful and use their power to dominate and exploit others, while the oppressed include those who lack power and are exploited and under domination. Based on these beliefs, Islamic issues became dominant in Iranian foreign policy, and Iran supported Islamic organizations in different countries. Consequently, relations between Iran and the international community worsened to the point of being 
severed. Moreover, Khomeini believed that since the Islamic Revolution had an emancipatory dimension, other states - especially the Arab monarchs - had to follow it. This approach threatened the Persian Gulf Arab states' integrity and established the Gulf Cooperation Council (GCC) to contain Iranian influence. Additionally, the Gulf states increased their security ties to the United States and generously supported Saddam Hussein during the Iran-Iraq war.

As a result of the weighty lessons learned from the war and the realization that Iran could not afford to antagonize the rest of the world, a slow shift away from ideology and towards more pragmatism occurred during the Rafsanjani presidency. Rafsanjani's administration realized that Iran's economy depended on the safe passage of oil through the Persian Gulf and that further crisis had to be avoided. It also required Saudi support in the Organization of the Petroleum Exporting Countries (OPEC) and investment in the Iranian economy. To this end, Iran sent an increasing number of envoys to the Persian Gulf states and even invited the Saudi Foreign Minister, Prince Saud, to visit Tehran. However, this rapprochement suffered a setback due to the Hajj incident in 1987 when around 400 Iranian pilgrims were killed in Mecca. As a result, policy towards Saudi Arabia reverted to one which was more openly hostile. This incident made it difficult for policymakers to conduct a high-level, pragmatic policy towards Saudi Arabia for years to come. It was only after Khatami's election as president in 1997 and a generally more favourable political and economic climate in the region that both countries were willing to overcome their problems.

Another incident that prevented Iran from rapprochement with regional states was the Iraqi invasion of Kuwait in 1991. Iran remained militarily neutral and called for the 
withdrawal of Iraq from Kuwait, and it played a diplomatic role in bringing an end to the crisis. The regional states, however, afraid of Iraqi military capabilities, made bilateral defence agreements with foreign powers, especially the U.S. The presence of the U.S. in the region limited the chance of reconciliation between Iran and the Arab states. Iran received nothing for its cooperative behaviour, and to some extent shifted its attention away from the Persian Gulf to the new republics on its northern borders and the East, including China, Japan, India, Pakistan, and Afghanistan.

Although Rafsanjani hoped to establish cordial relations with the European Union countries, two key incidents dramatically undermined his attempts: Khomeini's Fatwa against Salman Rushdie and the assassination of Kurdish dissidents at the Mykonos restaurant in Berlin by suspected agents of the Iranian government.

The 1997 presidential election was a competition between two main groups: Islamists and reformists. The Islamists' worldview stemmed from the ideological politics of the late 1960s, and the reformists' worldview reflected the era of globalization. The reformists with Khatami as their representative, consequently had a more realistic understanding of world politics.

The impact of Khatami's beliefs on the foreign policy front occurred through his discourse of Dialogue Among Civilizations. In order to articulate his discourse, Khatami explored a wide spectrum of Western thinkers including Husserl, Descartes, Kant, Marx, Nietzsche, Hume, Freud, Hegel and Fichte, as well as the religious traditions of Christian, Jewish and Muslim thinkers. He also studied Jean Jacques Rousseau and Alexis de Tocqueville's thoughts, as well as Habermas and Gadamer's works, which means that Khatami believed in the conversation between different ideas. 
Khatami stressed that such Dialogue was designed to facilitate communicative actions, which would eventually lead to coexistence, tolerance, and a degree of cooperation in the global arena. Khatami suggested that dialogue would open the way to mutual understanding and genuine peace based on the realization of the rights of all nations. This dialogue, according to him, could replace monologues, which had been dominant for a long time. He believed that for almost four centuries, only one (Western) voice has echoed across the world, that is, the voice that subordinates, which others should accept and follow. This kind of relationship has brought tension and conflict among nations.

Khatami's discourse of Dialogue Among Civilizations had two main components: 1) freedom and equality; 2) Self-Other relations. Regarding freedom and equality, he maintained that in an atmosphere of dialogue, neither side should consider themselves as being in a position of power that entitle them to speak from a superior position. Should there be feelings of power and dominance on one side and a sense of despair and privation on the other, a dialogue can never materialize. Therefore, a dialogue must be based on freedom and equality. Only under such circumstances can dialogue be a preliminary step leading to peace, security, and justice.

With Self-Other relations, Khatami suggested that the dichotomy of Self-Other, which has attributed negative value to the Other should be replaced by constructive and dialogical relations. He believed that through interactions with others, we attain a valuable knowledge of ourselves. In other words, one of the main goals of dialogue among cultures and civilizations is to recognize and understand not only the cultures and civilizations of others but one's own as well. This worldview has been distinguished since the inception of the Islamic Republic where the West, especially the United States, has been viewed as an 
enemy to the Iranian revolution, and having relations with the Great Satan has been taboo. Khatami was the only Iranian president who passed this red line by suggesting that the West brought about scientific achievements and democracy for human beings.

Khatami's Dialogue Among Civilizations and the United Nations charter share common themes. First, both emphasize equality and freedom. Second, both aim at preventing conflicts among nations. For this reason, the United Nations declared 2001 as The Year of Dialogue Among Civilizations. For the first time, an Iranian initiative was supported by the most representative governmental institution in the world, the United Nations.

Since the main point of this study was to examine the main reason for the change in Iran's foreign policy under Khatami's presidency, and I argued that his beliefs led to this change, I have chosen the Operational Code approach as the theoretical framework.

It is worth mentioning the difference between a decision-making process approach and an outcome-oriented approach. As Carlsnaes (2012) points out, studies focusing on explaining the choice of specific policies rather than decision-making processes view policies as resulting from such processes rather being part of them. The focus of an outcome-centred approach is the purposive nature of foreign policy actions, and the centrality of policy. He also maintains that by distinguishing a foreign policy action from the decision-making process, the authors are not foreclosing any particular approach to answering "why" questions. According to Carlsnaes, contrary to a process-oriented approach, the outcome-oriented approach does not, a priori, view either actors or structures in any particular way, since the focus here is on policy undertaking, not the behaviour of any particular entity within a specific structural environment such as decision making (p. 
118). Based on this definition, the Operational Code analysis is categorized as an outcomeoriented approach.

The Operational Code approach examines the role of a belief system in decisionmaking outcomes. In other words, it examines how a decision-maker perceives the nature of the political world, and then what strategies she/he would adopt to pursue the goals. However, one could argue that the automated coding of Operational Code which is based on the analysis of verbal statements of decision-makers and has remained focused on English-language texts, reduces both the quality and quantity of available data since most people do not speak English as their first language. The problem for Operational Code Analysis is that many texts are not available in English, and neither machine translation, such as Google Translate, nor human translation provides an acceptable solution. This is because machine translations are problematic and the cost of high-quality human translation (Brummer, et. al., 2020, pp. 3-4). Regarding the text quality, leaders whose first language is not English are more comfortable with their native language than with English. This means that leaders' statements in their native language should lead to a more accurate understanding of his or her beliefs.

Brummer, et.al., (2020) argued for the added value of non-English coding schemes. They suggested that non-English coding schemes increase the volume of source text on which leadership profiles can be structured. Additionally, those texts provide more accurate profiles since they are based on leaders' statements in their native tongue. Finally, it broadens the scope of leadership profiling beyond the English-speaking leaders (pp. 4-5). They have recently provided coding schemes for Arabic, German, Spanish, Turkish, and 
Persian, which means that subsequent studies on non-English-leaders will be more accurate.

In order to calculate Khatami's Operational Code, I examined his speech at different international organizations such as United Nations, UNESCO, as well as international conferences, in addition to his interviews with internal and external media. Moreover, I examined his books and articles in Persian.

His Operational Code suggests that he believes that even under conditions of anarchy there is harmony under which state actors could cooperate, and unlike his predecessors and successors he perceived the others not as the enemy but as interlocutors and partners with whom Iran could have a dialogue. Furthermore, he believed that the best strategy is cooperation rather than hostility and an aggressive approach. He argued that cooperation enabled states to pursue and achieve their goals.

Khatami's belief system through his discourse of Dialogue Among Civilizations translated into foreign policy. In this regard, he adopted a gradual and peaceful approach to lessening Iran's isolation. Khatami focused on assuring the world that Iran would not pursue regional dominance, rather it would seek coexistence with the rest of the world. Within six months of taking office, in 1997, he hosted a summit of the Organization of the Islamic Conference (OIC) in Tehran. This was the first effort to end Iran's regional and international isolation and to help improve relations with the Arab world. Khatami spoke about his foreign policy agendas to one of the largest gatherings of Muslim leaders who met to discuss political, economic, and social issues. The positive results of this summit were considerable. 
One of the main concrete steps taken in order to reconcile with the Arab regional countries concerned the Palestine-Israel conflict. In this case, too, the role of Khatami's beliefs can be traced. Since he did not view international politics as conflictual, and because he favoured cooperative strategies, Khatami adopted a more pragmatic and very different approach towards the Israel-Palestine conflict. He changed the tone of the regime's rhetoric. Based on the discourse of Dialogue Among Civilizations, he left the door open to exchanges with Jewish scholars while hard-liners were criticizing Arab states who entered peace treaties with Israel. Furthermore, in his famous interview with $\mathrm{CNN}$ with regard to Arab-Israeli peace, Khatami maintained that Iran would respect the decisions made by the majority of Palestinians.

Khatami's Good Neighbour policy, finally managed to reconcile Iran's relations with Oman, Qatar, Bahrain and, above all, Saudi Arabia. As a result, an entire range of trade, diplomatic, and security arrangements was signed between Iran and the Arab sheikhdoms.

Khatami's discourse of Dialogue Among Civilizations also help him to establish meaningful and constructive relations with the successor states of great world civilizations such as Greece, Italy, India, and Egypt. Relations between Iran and Greece, Italy, and India dated back centuries. However, relations between Iran and Egypt had deteriorated since the Islamic Revolution. Khatami expressed his willingness to remove the tension between these two countries. The normalization of relations was significant for Iran since Egypt, as the largest Arab state, has been an active participant in Middle East diplomacy.

Regarding the relationship with European Union, Khatami insisted that his government would not carry out the Rushdie Fatwa, and after extensive negotiation with Khamenei, Khatami managed to secure the return of European ambassadors to Tehran, which was an 
important shift in Iranian foreign policy. Khatami's new directions in foreign policy was welcomed by European countries, and in February 1998 European Union foreign ministers reached a consensus to lift the ban on top-level contacts with Iran in response to encouraging developments in the country. As a result, agreements between Iran and fifteen states of the EU were concluded after pressure from Italy and Greece, which had strong commercial ties with Iran.

The European Union also signed energy deals with Iran, defying Washington's pressure. Several international companies (Total-Fina-Elf, Shell and Repsol) became involved in oil and gas exploration projects in Iranian oilfields. Moreover, in October 2004, the World Bank approved Iran's request for new infrastructure loans amounting to $\$ 220$ million, despite Washington's continued opposition. After repeated applications to the World Trade Organization, Iran succeeded in achieving observer status in 2005, allowing the Iranians to participate in meetings but not in the decision-making process.

The most significant steps towards releasing the tension and smoothing the atmosphere between Iran and the U.S. since the 1979 revolution were made under Khatami's presidency. Khatami presented Iran's willingness to open a new chapter in its relations with the U.S. in his interview with CNN television in January 1998, where he proposed an exchange of professors, writers, scholars, artists, journalists, and tourists to remove the wall of mistrust between Iran and the U.S.

Following the interview, the United States to some extent softened its tone towards Iran. In May 1998, it announced that it would waive the provisions of the 1996 Iran-Libya Sanctions Act (ILSA) against a consortium of French, Russian and Malaysian companies. Additionally, the United States removed Iran from the list of state sponsors of terrorism, 
and small changes were adopted to make American visas easier to obtain for Iranians. In 1999, sanctions aiming to prevent the sale of food and medicine to Iran were removed. More importantly, at the higher level, President Clinton's statements recognized positive changes in Iran's policies. These advances represented changes in American-Iranian relations during Khatami’s first two years in office.

It seemed that approximately two decades of hostility was being replaced, gradually but cautiously, by normalcy until the events of 9/11 happened. It was argued that the new international circumstances provided an opportunity to both Iran and the U.S. to cooperate in achieving a common goal: removing the Taliban. America's fragile link with the Northern Alliance had led many Afghan's opposition groups to be suspicious of the U.S. In these circumstances, Iran, as an active actor, pressed the Northern Alliance and other opposition groups to cooperate with American forces. Iran also provided intelligence to the Northern Alliance, agreed to rescue American pilots in distress, and allowed some 165,000 tons of U.S. food aid to traverse its territory into Afghanistan. The speedy collapse of the Taliban acclaimed by the Bush administration had, in fact, been facilitated by substantial Iranian assistance. The Taliban was defeated after a rather short military campaign, and Iranian help had proved very important.

However, in his 2002 State of the Union address, George W. Bush effectively blocked the possibility of a new chapter in US-Iran relations by denouncing the Islamic Republic as a member of an Axis of Evil along with Iraq and North Korea. Bush described Iran as a major sponsor of terrorism, and a threat to Israel and its neighbours for its pursuit of weapons of mass destruction. Bush's proposals for dealing with Iran included the possibility of pre-emptive war, actions aiming at destabilizing the Islamic regime, and 
assistance to internal and external opposition groups. Call for regime change in Iran was also routinely repeated in 2003 after the invasion of Iraq. Bush's justification for the invasion of Iraq, the threat posed by Saddam Hussein's nonexistent weapons of mass destruction, had one disastrous consequence in particular. Iranian officials concluded that the United States invaded Iraq precisely because it knew Saddam did not have any weapons of mass destruction and therefore seemed an easy target. Therefore, for its own preservation, Iran had to have the nuclear bomb. The classification of Iran as part of the Axis of Evil led to an increasingly anti-American approach and gave the hard-liners leverage over reformers.

Despite all the struggles and difficulties that Khatami faced during his presidency, both domestically and internationally, his foreign policy direction was positive compared to his predecessors and successors. For instance, when Khatami was elected president, the Islamic Republic had only one ally, which was Syria. Pakistan officially represented Iran's diplomatic interests in Washington but maintained a tenuous relationship with Iran. Israel and the United States were only declared enemies. The E.U. was the largest beneficiary of Iran's trade, and while acting as an occasional diplomatic critic, it was still Tehran's only refuge against Washington's attacks. Russia and China were also "fair-weather bedfellows." And the rest of the world appeared to be suspicious and fearful or indifferent. By the time Khatami left office, Cuba, North Korea, and Venezuela had joined Russia and China as Iran's supporters against Washington (Amuzegar, 2006, pp. 69-71). Iraq and Afghanistan had far better relations with Iran, despite the presence of U.S. troops. Moreover, most members of the 115-nation Non-Aligned Movement, dissatisfied with Washington's approach over many global issues, became somewhat sympathetic to 
Tehran's position, even occasionally on the nuclear energy issue. Therefore, Khatami succeeded in redirecting Iran's relations from West to East and North to South, thereby changing Iran's image from reactive actor to proactive player in the international system.

It should be noted that Khatami's initiative continued at the international level even after his presidency. It first resulted in the establishment of the Foundation for Dialogue Among Civilizations (FDC) in 2007, in Geneva to encourage dialogue between cultures, civilizations and religions, and to promote peace, justice and tolerance. Strategic objectives of the Foundation for Dialogue Among Civilisations include: 1) Promoting and facilitating the peaceful resolution of conflicts and/disputes, 2) Reconciling tensions between cultures, countries and religions, 3) Promoting and facilitating dialogue between Muslim societies and other societies around the world, and 4) Contributing to academic research and enriching the wider debate around peace in the world (http://dialoguefoundation.org/en/page/20/about-fdc).

The Foundation for Dialogue Among Civilizations has been active through a series of meetings and cultural, artistic, and scientific activities, involving NGOs and international organizations such as United Nations Economic and Social Council (ECOSOC) to promote mutual understanding, tolerance, peaceful coexistence and international cooperation and security (Zaccara, 2016, p. 68).

Another result was the creation of the Alliance of Civilizations. The proposal was first presented by the Prime Minister of Spain, Jose Luis Rodriguez Zapatero, in the United Nations General Assembly in September 2004. It was supported by the Turkish Prime Minister, Recep Tayyip Erdogan, and then Secretary-General of the General Assembly, Kofi Annan. On July 14, 2005, Kofi Annan formally proclaimed the launch of the Alliance 
of Civilizations at the United Nations Headquarters in New York. The role of the Alliance of Civilizations is to maintain a global network of partners including states, international and regional organizations, civil society groups, and the private sector to improve crosscultural relations between diverse nations and communities (https://www.unaoc.org/whowe-are/). The proposal also included the creation of a High-Level Group (HLG) of 20 representatives of governmental and non-governmental organizations. Khatami was among those representatives. The HLG worked on two different fields: political/security and cultural issues. During the inaugural year three meetings were held: the first at Palma de Mallorca, Spain (26 to 29 November 2005); the second at Doha, Qatar (25 to 28 February 2006); and the third at Dakar, Senegal (28 to 30 May 2006), (for more details on the meetings, see Appendix 3). In all these meetings, Khatami participated mainly because the Alliance of Civilizations was recognized as the continuation of Khatami's discourse of Dialogue Among Civilizations (Zaccara, 2016, p. 69). The High-Level Group's mandate is to explore the roots of polarization between societies and cultures and provide analysis with practical recommendations which formed the basis for the implementation plan of the United Nations Alliance of Civilizations (https://www.unaoc.org/who-we-are/).

Furthermore, the Alliance benefits from the support of the Group of Friends, a community of countries and international organizations which actively promote the Alliance's objectives. Group of Friends plays a key role in the Alliance of Civilizations' strategic planning and implementation process, through a broad dialogue-based and consensus-building approach. The Group of Friends currently includes 156 members of which are $127 \mathrm{UN}$ member states, and 28 international organizations (https://www.unaoc.org/who-we-are/group-of-friends/). 
To sum up, words are taken seriously since they indicate a leader's belief system, which affects conduct in international relations. Thus, in Iran's case, the change in tone can be seen as having had a major effect on the way it was perceived, therefore highlighting the role that beliefs play in shaping relations. The positive response that the application of Dialogue Among Civilizations received at the international level certainly helped Khatami to gain recognition for his ideas, with numerous conferences and workshops that resulted in helping to shape and develop the concept further. Khatami's belief system through his discourse of Dialogue Among Civilisations fundamentally improved Iran's international image, casting Iran in a more positive light as a proactive actor rather than the revisionist one of previous years.

Khatami followed a new direction in Iranian foreign policy which originated from his belief system, one that rejected the belief that conflict was a permanent feature of international politics and advanced the notion that states by pursuing a cooperative approach towards others, could play a significant role in creating a more peaceful international system. His discourse of Dialogue Among Civilization aimed at understanding, cooperation, and constructive relations as means towards peace. With Dialogue Among Civilizations, Khatami believed that international actors could be friendly and converse with one another. The exchange of views is essential as it allows the development of one's own culture through giving, taking, and adapting, rather than clashing.

Through his initiative, Khatami sought to create a new legacy for generations to come. To replace force, violence, and hostility by understanding and cooperation was Khatami's 
image of a better world. His belief was "the final victory of the word over the sword." (Khatami, 2000:55).

In this dissertation I have analysed Khatami's intellectual worldview and its implications. One could argue that the change Khatami brought into Iran's both domestic and international arenas did not last, and it dramatically shifted towards a more aggressive approach when his successor came to power. The analysis of reasons behind Khatami's failure is beyond the scope of this dissertation. However, I argue that Khatami introduced new horizons and alternative paradigms in foreign policy realm which led Iran to have more peaceful relations with international community. It has been unique since 1979 Revolution. Khatami offered dialogue in three arenas: 1) personal, 2) collective and 3) in general. In other words, Khatami's intellectual world was not subjunctive but rather had concrete consequences in Iran's foreign policy. 


\section{REFERENCES}

Abdo, Genevie (2000). “The Fragility of Khatami’s Revolution", Washington Quarterly. Vol. 23 No.1

Adib-Moghadam, A. (2005). "Islamic Utopian Romanticism and Foreign Policy Culture of Iran", Critique: Critical Middle East Studies, Vol.14, No.3

Adler, E. (1997). "Seizing the Middle Ground: Constructivism in World Politics" European Journal of International Relations, Vol.3

Afrasiabi, Kaveh (1994). After Khomeini: New Directions in Iran's Foreign Policy. Boulder: Westview Press

Aghazadeh, Mahdieh (2013). "A Historical Overview of Sanctions on Iran and Iran's Nuclear Program", Akademik Araştırmalar Dergisi.

Ahmadi, Koroush(2005). "Iran and the United Nations During Khatami's Presidency", Iranian Journal of International Affairs, Vol. 28. No.2

Albright, M. (1998). Speech at the 1998 Asia Society Dinner, June 17, New York

Alam, Shah (2000). "The Changing Paradigm of Iranian Foreign Policy Under Khatami”, Strategic Analysis, Vol.9, No.24

Al-Hoseyni, Seyyed Hasan. (2008). "The Global Mission and a Few Points" in Iran Paper Criticizes Ahmadinejad's Efforts to Change World Management. BBC Monitoring, April 19,2008

Alison, Graham (1971). Essence of Decision: Explaining the Cuban Missile Crisis. Boston, MA: Little, Brown

Amirahmadi, Hooshang (1993). The United States and the New Middle East. New York: SUNY Press 
Amir-Arjomand, Said (2009). After Khomeini: Iran Under His Successors. Oxford University Press

Amuzegar, Jahangir (2006). "Khatami’s Legacy: Dashed Hopes”, Middles East Journal, Vol.60, No.1

. (2000). “Iran's Visual Democracy at a Turning Point”, SAIS Review, Vol.20, No.2

. (1998). “Iran's Crumbling Revolution”, Foreign Affairs, Vol.82, No.1

. (1997). “Adjusting to Sanctions”, Foreign Affairs, Vol. 76, No. 3.

Annan, Kofi (1999). Dialogue of Civilizations and Need for a World Ethic. Oxford: Oxford Center for Islamic Studies

Ansai, Ali (2006). Islam, Iran and Democracy: The Politics of Managing Change. London: Royal Institute of International Affairs.

. (2006). The Failure of American Foreign Policy and the Next Great Crisis in The Middle East. New York: Basic books

Arghavani Pirsalami, Fariborz (2013). "Third Worldism and Ahmadinejad's Foreign Policy”, Iranian Review of Foreign Affairs, Vol. 4, No. 2.

Badian, E. "Alexander in Iran" in The Cambridge History of Iran. Cambridge: Cambridge University Press Vol.2

Bahramitash, R. (2014). “It's All About Timing: Iran and the U.S. Negotiations”, Turkish Review. Vol.4. No.1

Baldwin, D. (1978). "Power and Social Exchange", Political Science Review, Vol. 72, No

Barnekow Rasmussen, Katrine (2009). "Ideology and Pragmatism in the Islamic Republic", Defence and Security Studies, Danish Ministry of Defence.

Barzegar, Kayhan (2010). “Iran’s Foreign Policy Strategy after Saddam”, Washington Quarterly, Vol.33, No.1 
Boroujerdi, Mehrzad (1996). Iranian Intellectuals and the West: The Tormented Triumph of Nativism. New York: Syracuse University Press

Brummer Klaus and Valerie M. Hudson (2017). "The Boundedness of Foreign Policy Analysis Theory?", Global Society, Vol.31, No.2

Brummer, Klaus, Michael D. Young, Ozgur Ozdamar, Sercan Canbolat, Consuelo Thiers, Christian Rabini, Katharina Dimmroth, Mischa Hansel, and Ameneh Mehvar (2020). "Forum: Coding in Tongues: Developing Non-English Coding Schemes for Leadership Profiling”, International Studies Review. Volume 22, Issue 4

Bowden, M. (2006). "Guests of the Ayatollah: The First Battle in America's War with Militant Islam", New York: Atlantic Monthly Press

Bull. Hedley (1997). The Anarchical Society. New York: Columbia University Press

Burn, R. (1995). "Persia and the Greeks" in Ilya Gershevitch (ed.,) The Cambridge History of Iran, Vol.2 The Median and Achaemenian Periods. Cambridge: Cambridge University Press

Byman, Daniel L.; Kenneth, Pollack (2001). "Let Us Now Praise Great Man: Bringing the Stateman Back”, International Security, Vol.25, No. 4

Carlsnaes, Walter (2012). "Actors, Structures, and Foreign Policy Analysis" in Steve Smith, Amelia Hadfield, and Tim Dunne (eds.), Foreign Policy, Theories, Actors, Cases. Oxford University Press

Carter, G. (2007). "Christopher Dawson and Ayatollah Khatami and Dialogue of Civilizations: A Christian-Muslim Conversation”, Islam and Christian-Muslim Relations. (www.tandfonline.com)

Cause, George (1994). “The Illogic of Dual Containment”, Foreign Affairs. March-April

Chubin, Shahram (2006). Iran's Nuclear Ambitions. Washington: Carnegie Endowment for International Peace. 
Cornell, Svante, E. (2001). "Iran and the Caucasus: The Triumph of Pragmatism Over Ideology”, Global Dialogue, Spring-summer

Cottam, R. (1988). Iran and the United States: A Cold War Case Study. Pittsburgh: University of Pittsburgh Press

Dadandish, Parvin (2012). "Iran-Europe Relations: A Diagnostic Analysis", Iranian Review of Foreign Affairs, Vol. 3, No 1.

Dahl, R. (1957). “The Concept of Power”, Behavioral Science, Vol. 2, Issue 3.

Dallmayr, Fred (2001). "A Gadamerian Perspective on Civilizational Dialogue", Global Dialogue, Vol.3 No.1

Dehghani Firouzabadi, Seyed Jalal (2005). A Discursive Change in the Islamic Republic's Foreign Policy. Tehran: Samt Publications.

. (2007). "The Discourse of Justice-Oriented Principles in Ahmadinejad Government”, Political Knowledge (in Persian). Vol. 3, No. 1.

Dehshiri, M.R. (2001). "The Cycle of Idealism and Realism in the Foreign Policy of the Islamic Republic of Iran”, The Iranian Journal of International Affairs, Vol.12, No.2

De Mesquita, B. B. (1992). War and Reason: Domestic and International Imperatives. New Haven: Yale University Press.

Doty, Roxanne L., (1993) "Foreign Policy as Social Construction: A Post-Positivists Analysis of U.S. Counterinsurgency Policy in the Philippines", International Studies Quarterly, Vol. 37, No.3

Doyle, Michal. W. (1997). Ways of War and Peace. New York: Norton \& Company, Inc

Ebtekar, M. (2001). Takeover in Tehran: The Inside Story of the 1979 U.S. Embassy Capture. Vancouver: Talonbooks 
Edgar, Tracy (1998). Operational Code Beliefs of Ronald Reagan, The Nature of the International Environment, and Image of the Soviet Union. The University of British Columbia

Ehteshami, Anoushirvan (1995). After Khomeini, The Iranian Second Republic. London: Routledge

. (2014). "The Foreign Policy of Iran", in Raymond A. Hinnesburg and A.Ehteshami, (eds). The Foreign Policies of Middle East States. London: Lynne Rienner Publishers

Ehteshami, Anoushirvan and Mahjoob Zweiri(2007). Iran and the Rise of its Neoconservatives, The Politics of Tehran's Silent Revolution. London: I.B. Tauris \& Co Ltd

Eivazi, Mohammad Rahim (2008). “An Analysis of Dr. Ahmadinejad's Foreign Policy”. Rahbord Yas.

Ejazee, Ehsan and Seyed Amir Niakooee (2014). "Foreign Policy and Economic Development: Iran Under Rafsanjani”. Iranian Review of Foreign Affairs, Vol. 5, No. 3

Etzioni, Amitai (2004). From Empire to Community: A New Approach to International Relations. New York: Palgrave

Farhang, M., (1993). "U.S. Policy Toward the Islamic Republic of Iran", in Hooshang Amirahmadi (ed) The United States and the Middle East. New York: SUNY Press

Feng, Huiyun (2005). "The Operational Code of Mao Zedong, Defensive or offensive Realist?”. Security Studies, Vol. 14, No.4

Finnemore, M., and K. Sikkink (2001). "Taking Stock: The Constructivist Research Program in International Relations and Comparative Politics". Annual Review of Political Science. Vol. 4 (https://doi.org/10.1146/annurev.polisci.4.1.391).

Fukuyama, Francis (1992). The End of History and The Last Man. New York: Free Press

Fuller, G. (1991). The Center of the Universe: The Geopolitics of Iran. Boulder: Westview Press. 
Gaddis, John (2002). “Bush's Security Strategy,” Foreign Policy. November-December

Garsoian. Nina (1968). "Byzantium and Sassanians", in the Cambridge History of Iran. Vol.3, No.1

George, Alexander.L. (1969). "The 'Operational Code': A Neglected Approach to the Study of Political Leaders and Decision-Making”, International Studies Quarterly, Vol.13, No.2

George, William. (2014). Explaining State Crisis Behaviour Using the Operational Code. University of Central Florida

Gilpin, R. (1981). War and Change in World Politics. Cambridge University Press.

Golan, Galia (1998). Russia and Iran: A Strategic Partnership. Royal Institute of International Affairs

Griffiths, Martin, Terry O'Callaghan and Steven C. Roach (2008). International Relations: The Key Concepts, 2nd ed. New York: Routledge

Habermas, Jurgen (1981). The Theory of Communicative Action. Tran. T. McCarthy. New York: penguin

Haji-Yousefi, Amir Mohammad (2018). "Political Culture and Iran's Foreign Policy: A Comparative Study of Iran's Foreign Policy During Ahmadinejad and Rouhani”, Journal of World Sociopolitical Studies. Vol. 2, No. 2

. (2010). "Iran's Foreign Policy During Ahmadinejad: From Confrontation to Accommodation", Alternatives: The Turkish Journal of International Affairs. Vol. 9, No. 2

. (2009). "Whose Agenda is Served by the Idea of a Shia Crescent?", Alternatives: The Turkish Journal of International Affairs, Vol.8, No.1.

Halliday, Fred (2001). "Iran and the Middle East, Foreign Policy and Domestic Change", Middle East Report. 
Hashim, Wahid (2008). comments at "Iran on the Horizon, Panel II: Iran and the Gulf," Middle East Institute Conference Series, Middle East Institute, Washington, D.C., February 1, 2008.

Hermann, Margaret (1980). "Explaining Foreign Policy Behavior Using the Personal Characteristics of Political Leaders", International Studies Quarterly. Vol. 24, No. 1

Hermann, M. G., and Charles, Hermann (1989). "Who Makes Foreign Policy Decisions and How: An Empirical Inquiry”. International Studies Quarterly, Vol. 33. No. 4

Hermann, Charles (1990). "Changing Course: When Governments Choose to Redirect Foreign Policy”. International Studies Quarterly, Vol 34, No.1

Hermann, Margaret G., et.al., (2001). "Who Leads Matters: The Effects of Powerful Individuals". International Studies Review, Vol 3. No.2

Hill, Christopher (2003). The Changing Politics of Foreign Policy. Basingstoke: Palgrave Macmillan

Hoffmann, M.J. (2010). "Norms and Social Constructivism in International Relations", in R.A Denmark (ed.), The International Studies Encyclopedia. Oxford: Blackwell

Holsti, O.R. (1970). "The 'Operational Code's Approach to the Study of Political Leaders: John Foster Dulles' Philosophical and Instrumental Beliefs". Canadian Journal of Political Science. Vol.3, No.1 . (1977). The "Operational Code" as an Approach to the Analysis of Belief Systems. Duke University.

Hudson, Valerie, M. and Christopher S. Vore (1995). "Foreign Policy Analysis, Yesterday, Today, and Tomorrow". International Studies Review. Vol.39, No.2

Hudson, Valerie, M. (2005). "Foreign Policy Analysis: Actor-Specific Theory and the Ground of International Relations”. Foreign Policy Analysis, Vol.1, No.1 . (2007). Foreign Policy Analysis: Classic and Contemporary Theory. Lanham, MD: Rowman \& Littlefield 
Hunter, Shireen T. (2010). Iran's Foreign Policy in the Post-Soviet Era. Santa Barbara: Praeger.

. (1990). Iran and the World: Continuity in a Revolutionary Decade. Bloomington: Indian university press.

. (1986). "Iranian Foreign Policy Since 1979: Internationalism and Nationalism in the Islamic Revolution”, in J.R.I. Cole and N.R. Keddie (eds), Shi' ism and Social Protest. New Haven: Yale University Press

Huntington, Samuel P. (1993). “The Clash of Civilizations?”, Foreign Affairs, Vol. 72, No. 3

. (1996). The Clash of Civilizations and the Remaking of World Order. New York: Simon \& Schuster

James, Patrick (2007). "Behavioural IR: Practical Suggestions". International Studies Review, Vol.9, No.1

Jervis, Robert (1978). "Cooperation under the Security Dilemma". World politics, Vol.30, No.2

- (1994). "Leadership, Post-Cold War Politics, and Psychology", Political Psychology. Vol. 15, No. 4 . (2003). "Understanding the Bush Doctrine", Political Science Quarterly

Jones, Stephen (2009). The Islamic Republic of Iran: An Introduction. Research Paper. UK house of commons library

Juneau, Thomas (2015). Squandered Opportunity: Neoclassical Realism and Iran's Foreign Policy. Stanford: Stanford University Press

Juneau, Thomas and Sam Razavi (eds). (2013). Iranian Foreign policy since 2001, Alone in the World. New York: Routledge 
Kaarbo, Juliet, Lantis, Jeffrey and Beasley, Ryan (2012). Foreign Policy in Comparative Perspective: Domestic and International Influences on State behaviour. 2nd Edition. Washington Press.

Katzenstein, P. (ed) (1996). The Culture of National Security: Norms and Identity in World Politics. New York: Columbia University Press

. (2010). Civilizations in World Politics: Plural and Pluralist Perspectives. New York: Routledge

Kazemzadeh, M. (2007). “Ahmadinejad's Foreign Policy”, Comparative Studies of South Asia, Africa and the Middle East, Vol. 27, Issue 2

Keddie, Nikkie(2006). Modern Iran: Roots and Results of Revolution. Yale University Press

.(1980). Iran: Religion, Politics and Society: Collected Essays. Frank Cass and Company Unlimited.

Keddie, N., and Rudi Matthee, (eds.). (2002). Iran and the Surrounding World. Seattle: University of Washington Press.

Kharrazi, Kamal (1998). "Speech to the 25th OIC Foreign Ministers Summit", Doha, Qatar . (1997). Iran Daily, 28 August

Khatami, Mohammad (2009). Dialogue: The Way to Peace, Center for Arab and Islamic Studies, the Middle East, and Central Asia. Vol.16 No.1

. (2001). Remarks at the Symposium on Islam, Iran and the Dialogue of Civilizations, Palace of Weimar, Berlin, 12 July 2000; an edited transcript of the discussion can be found in Mohammad Khatami, Josef van Ess, and Hans Kung, 'Symposium: Islam, Iran and the Dialogue of Civilizations', Global Dialogue. Vol. 3. No.1

. (1997). Statement at the Eighth Session of the Islamic Summit Conference, Tehran, 9 December 1997. www.persia.org 
. (2005) "The Role of Religion in the Dialogue Among Civilizations" in Achim D. Kodderman (ed.), Dialogue Among Civilizations: A Collection of Presentation from the General Assembly of the United Nations. Vol.2. New York: Global Scholarly Publications.

. (2004). "Dialogue among Civilizations and Cultures", in Akbar Ahmed and Brian Frost (eds), After Terror: Promoting Dialogue Among Civilizations.

. (1998). Islam, Liberty, and Development. New York: Institute of Global Cultural Studies, Binghamton University, State University of New York Press

. (1997). Hope and Challenge. New York: Institute of Global Cultural Studies, Binghamton University

. (1998). Speech at the UN General Assembly. New York, 21 September 1998, available at: www.parstimes.com/history/khatami_speech_un.html

. (2001). Speech at the United Nations General Assembly

. (1997). Statement at the Eighth Session of the Islamic Summit Conference, Tehran, 9 December 1997 (www.persia.org)

- (1998). Interview with Christiane Amanpour, CNN, 7 January 1998 www.persia.org/khatami/s_khatami06.html.

. (2001). Address at the Dialogue among Civilizations Conference at the United Nations, New, 5 September 2000 [http://www.un.int/iran/dialog05.html] (20 September 2001).

. (1999). Speech at the European University Institute, Fiesole, Florence, 15 March 1999

. (2001). Dialogue Among Civilizations, the Round Table on the Eve of the United Nations Millennium Summit, by United Nations Educational, Scientific and Cultural Organization. Paris

Khosrokhavar, Farhad (2004). "The New Intellectuals in Iran”. Social Compass, Vol. 51, No.2 
Keohane, R.O. (1993). "Institutional Theory and the Realist Challenge After the Cold War", in Baldwin (ed.), Neorealism and Neoliberalism: The Contemporary Debate. New York: Columbia University Press

Kurtz, Stanley (2002). "The Future of History", Policy Review (https://www.hoover.org/research/future-history)

Kunz, Otto (1998). "Cultural Relations Between Parthia and Rome", in Ehsan Yarshater (ed.,) The Cambridge History of Iran, Vol. III. The Seleucid Parthian and Sassanian Periods Cambridge: Cambridge University press

Lake. Anthony (2004). “Confronting Backlash States”, Foreign Affairs. March-April

Larsen, Henrik (1997). Foreign Policy and Discursive Analysis: France, Britain, and Europe. London: Routledge . (1999). "British and Danish European Policies in the 1990s: A Discourse Approach", European Journal of International Relations, Vol.5 No.4

Larson, Deborah, W. (1994). "The Role of Belief Systems and Schemas in Foreign Policy Decision-Making”, Political Psychology, Vol.15, No.1

Lavikainen, Jyri Joonas (2016). "The Operational Code of Vladimir Putin in the Ukrainian Crisis in 2016", University of Helsinki

Leites, Nathan (1953). A Study of Bolshevism. New York: Free Press . (1951). The Operational Code of the Politburo. New York: McGraw-Hill.

Leverett, F., and H.M. Leverett (2013). "Going to Tehran: Why the United States Must Come to Terms with The Islamic Republic of Iran”. New York: Metropolitan Book

Levy, J. S. (1994). "Learning and Foreign Policy: Sweeping a Conceptual Minefield", International Organization. Vol. 48, No.2

. (2003). "Political Psychology and Foreign Policy". Oxford Handbook of Political Psychology 
Lynch, Marc (2000). "The Dialogue of Civilizations and International Public Sphere", Millennium: Journal of International Studies, Vol. 29, No. 2

Malici, Akan and Stephen G. Walker (2017). Role Theory and Role Conflicts in U.S.- Iran Relations, Enemies of Our Own Making. New York and London: Routledge

Marschall, Christin (2003). Iran's Persian Gulf Policy from Khomeini to Khatami. London: Routledge Curzon

Mearsheimer, J (1995). "Back to the Future: Instability in Europe After the Cold War", in Brown et.al (eds), The Perlis of Anarchy: Contemporary Realism and International Security. Cambridge: MIT Press

. (2001). The Tragedy of Great Power Politics. New York: Norton

Menashri, David (2001). Post-Revolutionary Politics in Iran, Religion, Society and Power. London: Frank Cass

Milani, Abbas (2013). Foreign Policy. http://foreignpolicy.com/2013/06/12/theayatollahspoint-man/ (accessed March 4, 2015).

Milani, M. (1994). The Making of Iran's Islamic Revolution: From Monarchy to Islamic Republic. Boulder: Westview press

Miliken, J (1999). "The Study of Discourse in International Relations: A Critique of Research and Methods", European Journal of International Relations. Vol.5, No.2

Miller, Margaret C. (1997). Athens and Persia in the Fifth Century B.C: A Study in Cultural Receptivity. Cambridge: Cambridge University press

Mintz, A (2007). “Why Behavioral IR?”, International Studies Review. Vol.9, Issue 1. . (2004). "How Do Leaders Make Decisions? A Poli-Heuristic Perspective", Conflict Resolution, Vol.48, No.1

Mohammad Nia, Mahdi (2011). "A Holistic Constructivist Approach to Iran's Foreign Policy”, International Journal of Business and Social Science, Vol.2 No.4 

. (2012). "Discourse and Identity in Iran's Foreign Policy", Iranian Review of Foreign Affairs, Vol. 3, No. 3.

Moin, B. (2000). Khomeini: Life of the Ayatollah. New York: Thomas Dunne Books.

Mojtahedjadeh, Pirouz (2001). "Geopolitics and Reform Under Khatami", Global Dialogue. Spring-Summer

Mohammadi, M. (2009), "The 9th Government and International System" in Rational Foundations and Practical Policy of the 9th Government and International Relations (in Persian), Tehran: The Presidential Documentary Research Center

Molana, Hamid and Manoucher Mohammadi (2009). Iranian Foreign policy in Ahmadinejad Government. Tehran: Dadgostar.

Molana, Hamid (2008), "The Fundamental Elements in Foreign Policy of the 9th Government" in Rational Foundations and Practical Policy of the 9th Government and International Relations (in Persian). Tehran: The Presidential Documentary Research Center

Monshipour, Mohammad and Manouchehr Dorraj (2013). "Iran's Foreign policy: A Shifting Strategic Landscape”, Middle East Policy.

Moravcsik, A. (1997). "Taking Preferences Seriously: A Liberal Theory of International Politics”, International Organization. Vol. 51, No.4

Morgenthau, Hans J. (2005). Politics Among Nations. New York: McGraw-Hill

Moslem, Mehdi (2002). Factional Politics in Post-Khomeini Iran. Syracuse: Syracuse University Press.

Moshirzadeh, Homeira (2007), "Discursive Foundation of Iran's Nuclear Policy”, Security Dialogue, Vol.38. No.4

. (2015). "International Relations in Iran and its Discursive Dynamics". Iranian Review of Foreign Affairs, Vol.5, No.4 
. (2004). "Dialogue of Civilizations and International Theory", Iranian journal of International Affairs. Vol. 16, No.1

Mousavian, H. (2008). Iran-Europe relations: Challenges and Opportunities. Oxford: Routledge

. (2012). The Iranian Nuclear Crisis. Washington: Carnegie Endowment for International Peace

. (2014). "The Solution to the Iranian Nuclear Crisis and Its Consequences for the Middle East”, Global Governance. Vol. 20

Mumtaz, Kashif (2005). "Changing Patterns of Iran-GCC Relations". Strategic Studies. Vol.25, No. 4

Nahavandian, M. (2008). quoted in "E'temad-e Melli" (Tehran) Website, in "Nahavandian: Moderation in Foreign Policy is the Only Way Towards Development," Dialogue, World News

Neack, Laura (2003). The New Foreign Policy: U.S. and Comparative Foreign Policy in the 21st Century. Lanham: Rowman \& Littlefield Publishers, Inc . (2008). The Foreign Policy: Power Seeking in a Globalized Era. Lanham: Rowman $\&$ Littlefield Publishers, Inc.

Obama, Barack, H. (2009). "Message to the Iranian People", 20 March 2009, https:// obamawhitehouse.archives.gov/blog/2012/03/20/nowruz-president-obama- speaksIranian-people

Onuf, Nicholas, G. (1989). World of Our Making. Columbia: University of South California Press

Orlov, Vladimir, and Alexander Vinnikov, "The Great Guessing Game: Russia and the Iranian nuclear Issues”, Washington Quarterly, Vol.28. No.2

Panah, Maryam (2007). The Islamic Republic and the World: Global Dimensions of The Iranian Revolution. London: Pluto Press 
Pantham, Thomas (1992). "Some Dimensions of Universality of Philosophical Hermeneutics: A Conversation with Hans-Georg Gadamer", Journal of Indian Council of Philosophical Research. Vol. 9, No.1

Rakel, Eva, P. (2008). "The Iranian Political Elite, State and Society Relations, and Foreign Relations Since the Islamic Revolution". PhD Dissertation. Faculty of Social and Behavioural Science. Amsterdam Institute for Social Science Research

Pant, Harsh V. (2004). "India and Iran: An Axis in the Making?", Asian Survey. Vol.44, No. 3

Parekh, A. (2000). Rethinking Multiculturalism: Cultural Diversity and Political Theory. London: Macmillan

Parsi, Trita (2007). Treacherous Alliance: The Secret Dealings of Israel, Iran, and the United States. Princeton: Yale University Press

. (2012). A single Role of the Dice. New Haven: Yale University Press

Perthes, Volker (2010). “Ambition and Fear: Iran's Foreign Policy and Nuclear Programme”. Survival. Vol. 52, Issue. 3

Petito, Fabio (2011). "In Defence of Dialogue of Civilizations: With a Brief Illustration of The Diverging Agreement Between Edward Said and Louis Massignon". Millennium: Journal of International Studies, Vol.39, Issue 3

. (2007). "The Global Political Discourse of Dialogue among Civilizations: Mohammad Khatami and Vaclav Havel", Global Change, Peace, and Security. Vol.19. No.2

. (2004). "Khatami's Dialogue Among Civilizations as International Political Theory", Journal of Humanities, Vol.11, No. 3

Pollack, Kenneth (2010). "Containing Iran”, in R. Wright (ed.), The Iran Primer, United States. Institute of Peace (USIP) 
. (2013). Unthinkable, Iran, the Bomb, and American Strategy. New York: Simon \&Schuster.

. (2004). The Persian Puzzle: The Conflict Between Iran and America. New York: Random House,

Pollack, K. and Ray Takeyh (2005). “Taking on Tehran”, Foreign Affairs, March-April

Porter, G. (2006). “Cheney-led 'Cabal' Blocked 2003 Nuclear Talks with Iran. IPS, May 28.

Rajabi, F. (2006). "Ahmadinejad: The Miracle of the 21st Century" (in Persian) Tehran: Daneshamooz . (2007). The White House's Guest (in Persian), Tehran: Daneshamooz

Rajaee, Farhang (1999). “A Thermidor of 'Islamic Yuppies'? Conflict and Compromise in Iran's Politics”. Middle East Journal.Vol.53, No.2

. (2013). "Why Alone?" in Thomas Juneau and Sam Razavi (eds), Iranian Foreign policy since 2001, Alone in the World. New York: Routledge

Ramazani, R. (1992). "Iran's Foreign Policy: Both North and South", Middle East Journal, Vol.46, No.3

. (1986). Revolutionary Iran: Challenge and Response in the Middle East. Baltimore: John Hopkins University Press

. (1966). The Foreign Policy of Iran, 1500-1941. Charlottesville: University Press of Virginia

. (2004). "Ideology and Pragmatism in Iran's Foreign Policy", The Middle East Journal, Vol. 58, No.4

. (2009), "Understanding Iran's Foreign Policy", Journal of Foreign Relations, (in Persian), No. 1 
Renshon, Jonathan (2008). "Stability and Change in Belief System, The Operational Code of George W. Bush", Conflict Resolution. Vol.52. No.6

. (2011). "Stability and Change in Belief Systems: The Operational Code of George W. Bush from Governor to Second-Term President”, in Walker, S. G., Malici, A., and Schafer, M. (eds.). Rethinking Foreign Policy Analysis: States, Leaders, and The MicroFoundations of Behavioral International Relations. New York: Routledge.

Reus-Smit, Christian (2013). "Constructivism" in Scott Burchill and Andrew Linklater (eds). Theories of International Relations, UK: Palgrave Macmillan

Ripsman, Norrin, M. (2017). "Neoclassical Realism", International Studies. https://doi.org/10.1093/acrefore/9780190846626.013.36

Risse Thomas (2000). “'Let's Argue!':Communicative Action in World Politics”, International Organizations. Vol.54, No.1

Ritter, Scott (2006). Target Iran: The Truth about the White House's Plans for Regime Change. New York: Nation Books

Rosenberg, Philipp J. (1986). "Presidential Beliefs and Foreign Policy Decision-Making: Continuity during the Cold War Era", Political Psychology, Vol.7, No.4

. (2009). "When Public Statements Reveal Private Beliefs: Assessing Operational Codes at a Distance", Political Psychology, Vol. 30, No. 4

Rigter, Tom (2017). Belief (in)stability and the Operational Code of Mark Rutte. Leiden University

Ritcher, Elizabet (2016). Operational Code Analysis of Iran's Supreme LeadershipAyatolah Khomeini and Khamenei. Master Dissertation, Department of International Relations. Ankara: Ihsan Dogramaci Bilkent University

Rivera, William, A. (2016). "Discursive Practices of Honor: Rethinking Iran's Nuclear Program”, Foreign Policy Analysis, Vol. 12, No. 3 
Rose, G. (1998). "Neoclassical Realism and Theories of Foreign Policy", World Politics. Vol. 51, No.1

Rota, Giorgio (2012). "Safavid Persia and Its Diplomatic Relations with Venice", in Willem Foor and Edmund Herzig (eds), Iran and the Words in the Safavid Age. London: I.B Tauris

Rouhani, Hassan (2007). Interview with Tehran-e Emrooz (Tehran), December 13, 2007, in BBC Monitoring .(2007). "20 Years Perspectives and a Progressive Foreign Policy," in Persian

Reus-Smit, Christian (2005). "Constructivism" in Scot Burchill, et.al., (eds), Theories of International Relations. UK: Palgrave

Said, Edward (2014). "The Clash of Ignorance", in Jason Dittmer and Joanne Sharp (eds), Geopolitics, An Introductory Reader. New York: Routledge . (1978). Orientalism. New York: Pantheon Books

Sabet-Saeidi, Shahriar (2008). "Iranian-European Relations: A Strategic Partnership?" in Anoushiravan Ehteshami and Mahjoob Zweiri. Iran's Foreign Policy from Khatami to Ahmadinejad. Lebanon: Ithaca.

Salehi, Mokhtar (2014). "Economic Diplomacy of Iran during Construction Era". Journal of Political Science, Vol. 9, No. 3.

Salimi, Hossein (2012). "Foreign Policy as Social Construction", in A. Ehteshami and R. Molavi (eds), Iran and the International System, London: Routledge

Samoudi, Alireza, and Aziz Hatamzadeh (2012). "Iran in Transatlantic Interactions", Iranian Review of Foreign Affairs, Vol. 3, No. 3.

Sarmadi, Hamid and Morteza Badri (2017). "The Effect of Hashemi Rafsanjani's Technocrat Government and changing of Foreign Policy of Iran from Power to Pragmatism". Academia Journal of Educational Research, Vol.5, No.2 
Schafer, Mark, and Stephen G. Walker (2006). "Operational Code Analysis at a Distance: The Verbs in Context System of Content Analysis." in M. Schafer and S. G. Walker, (eds). Beliefs and Leadership in World Politics: Methods and Applications of Operational Code Analysis. New York: Palgrave Macmillan

Schafer, M., and Walker, S. (eds.). (2006). Beliefs and Leadership in World Politics: Methods and Applications of Operational Code Analysis. New York: Palgrave Macmillan.

Schmidt, Brian C., and Tim Dunne, (2005). "Realism" in John Baylis and Steve Smith, The Globalization of World Politics. Oxford: Oxford University Press

Seifzadeh, Hossein (2001). "Cooperation Within Global Civilizations and Coexistence of Diverse Cultures”. Discourse: An Iranian Quarterly. Vol.3, No.1

Sen, Amartya (2007). Identity and Violence: The Illusion of Destiny. London: Penguin

Siddiqi, Ahmad (2006). "Khatami and the Search for Reform in Iran". Stanford Journal of International Relations

Shakibi, Z. (2010). Khomeini and Gorbachev: Politics of Change in The Islamic Republic of Iran and the USSR. New York: I.B. Tauris

Shannon Vaughn P. and Paul A. Kowert (eds). (2012). Psychology and constructivism in International Relations. An Ideational Alliance. University of Michigan Press

Shapcott, Richard (2001). Justice, Community and Dialogue in International Relations Cambridge: Cambridge University Press

Shayegan, Dariush (1997). Cultural Schizophrenia: Islamic Societies Confronting the West. Syracuse University Press.

Slavin, B. (2007). Bitter Friends, Bosom Enemies: Iran, the US, and the Twisted Path to Confrontation. New York: St. Martin's press.

Sprout, Harold and Margaret Sprout (1956). Man-Milieu Relationship Hypotheses in the Context of International Politics. Princeton: Princeton University Press. 
.(1965). The Ecological Perspective in Human Affairs. Princeton: Princeton University Press.

Snyder, R. C., Bruck, H. W., and Sapin, B. (1954). The Decision-Making Approach to the Study of International Politics. New York: Free Press of Glencoe

Struwe, V. Matthias (1998). The Policy of Critical Dialogue: An Analysis of European Human Rights Policy Towards Iran from 1992 to 1997. Durham: University of Durham, Centre for Middle Eastern and Islamic Studies.

Tabatabai M., and Annie Tracy S. (2017). "What the Iran-Iraq War Tells Us About the Future of the Iran Nuclear Deal?", International Security, Vol.42, No.1

Takeyh, Ray (2009). Guardians of the Revolution: Iran and the World in the Age of the Ayatollahs. Oxford: Oxford University Press.

. (2006). Hidden Iran, Paradox and Power in The Islamic Republic. New York: Keddie Times Books

. (2003). "Iran at the Crossroad", Middle East Journal, Vol. 57, No.1

Tarock, Adam (1999). Iran's Foreign Policy Since 1990: Pragmatism Supersedes Islamic Ideology. New York: Nova Science Publishers

Tazmini, Goncheh (2009). Khatami's Iran: The Islamic Republic and the Turbulent Path to Reform. New York. London: Tauris Publishers

Tetlock, Philip (2005). Expert Political Judgement. How Good Is It? How Can We Know?, Princeton: Princeton University Press

. (1998). "Social Psychology and World Polities", in Daniel Gilbert, Susan Fiske \& Gardner Lindzey, (eds.), The Handbook of Social Psychology, Volume II, 4th edit. New York: McGraw-Hill

. (1991). "Learning in U.S. and Soviet Foreign Policy". in George W. Breslauer and Philip Tetlock (eds), Learning in U.S. and Soviet Foreign Policy, Boulder, CO: Westview. 
Thaler, Davis, Alireza Nader, Shahram Chubin, Jerrold D. Green, Charlotte Lynch and Frederic Wehrey (2010). Mullahs, Guards, and Bonyads: An Exploration of Iranian Leadership Dynamics. RAND Corporation

Vahdat, Farzin (2005). "Religious Modernity in Iran: Dilemmas of Islamic Democracy in the Discourse of Mohammad Khatami". Comparative Studies of South Asia, Africa and the Middle East, Vol.25, No. 3

Vakil, Sanam (2006). "Iran: Balancing East against West”, Washington Quarterly, Vol. 29, No.4

Velayati, Ali Akbar (1983). "Speech at the 4th meeting of OIC Foreign Ministers". Dhaka . (1984). Speech at the 15th meeting of Foreign Ministers of Islamic Conference Member. Sana'a

Walker, Stephan G., Akan Malici, and Mark Schafer (eds).(2011). Rethinking Foreign Policy Analysis, States, Leaders and The Micro Foundations of Behavioural International Relations. New York and London: Routledge

Walker, S. G, Mark Schafer, and Michael D. Young. (1998). "Systematic Procedures for Operational Code Analysis: Measuring and Modeling Jimmy Carter's Operational Code." International Studies Quarterly. Vol. 42, No.1

Walker, Stephen G. (1997). "The Interface Between Beliefs and Behavior: Henry Kissinger's Operational Code and the Vietnam War". The Journal of Conflict Resolution. Vol.21, No.1

. (1983). "The Motivational Foundations of Political Belief Systems: A Re-Analysis of the Operational Code Construct." International Studies Quarterly. Vol.27, No.2

. (1990). "The Evolution of Operational Code Analysis.", Political Psychology. Vol. 11. No.2

- (1977). "The Interface Between Beliefs and Behavior, Henry Kissinger's Operational Code and Vietnam War", Journal of Conflict Resolution, Vol. 21, No.1 
Walt, S.M (1991). “The Renaissance of Security Studies”, International Studies Quarterly. Vol.35, No.2

. (2002). "The Enduring Relevance of the Realist Tradition", in Katznelson and Miller (eds), Political Science: The State of the Discipline. New York: Norton

Wastnidge, Edward (2016). Diplomacy and Reform in Iran, Foreign Policy Under Khatami. London, New York: I.B Tauris \& Co. Ltd

. (2011). "Détente and Dialogue: Iran and the OIC during the Khatami Era (19972005)", Politics, Religion \& Ideology, Vol. 12, No. 4

. (2014). "Pragmatic Politics: Iran, Central Asia and Cultural Foreign Policy". Politics, Religion \& Ideology, Vol. 15, No. 4

Waltz, Kenneth (1979). Theory of International Politics. New York: Random House

Wells. Mathew C. (1999). "Thermidor in the Islamic Republic of Iran: The Rise of Muhammad Khatami”. British Journal of Middle Eastern Studies. Vol.26, No.1

Wendt, A. (2013). Social Theory of International Politics. Cambridge: Cambridge University Press

. (1998). "On Constitution and Causation in International Relations". International Studies, Vol. 24, December

(1992). "Anarchy Is What States Make of It: The Social Construction of Power Politics”, International Organization, Vol.46, No. 2

White Book on Dialogue Among Civilizations/ Third Edition/ publications of the Islamic Educational, Scientific and Cultural Organization ISESC/ Morocco/2004

Yektafar, Babak (2008). "Under the Thinking Cap: A Conversation with Karim Sadjadpour on U.S.-Iran Relations", Washington Prism, February 13, 2008; in BBC Monitoring, January 8, 2008 
Zarif, Mohammad Javad (2014). "What Iran Really Wants: Iranian Foreign Policy in the Rouhani Era", Foreign Affairs. (May/June). http://www.foreignaffairs.com/articles/141209/mohammad-javad-zarif/what-iran-reallywants.

\section{References in Persian (Farsi) Language}

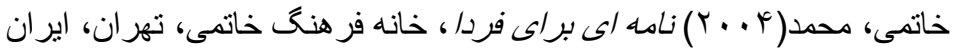

$$
\begin{aligned}
& \text { خاتمى، محمد (99V (1) )ز دنباى شهر تا شهر دنبا ، نشر نى، تهران، ايران } \\
& \text { خاتمى، محمد (999 ( ) آبين و انديثه در دام خودكامكى، انتشار ات طرح نو، تهران، ايران }
\end{aligned}
$$

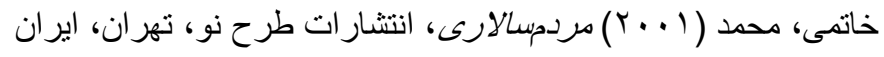

$$
\begin{aligned}
& \text { خاتمى، محمد (999 (1996تكوى تمدن ها، انتشار ات طرح نو، تهران، ايران }
\end{aligned}
$$

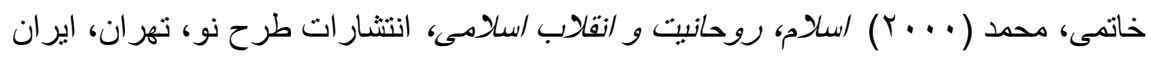

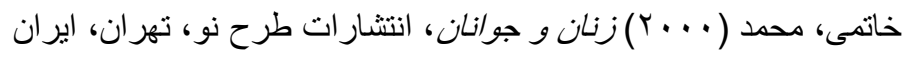

\section{Online Resources}

http://apps.whashingtonpost.com/g/documents/world/full-text-of-the-iran-nucleardeal $/ 1651 /$.

http://babel.hathitrust.org/cgi/pt?id=mdp.39015003460568;view=1up;seq=8

Www.whitehouse.gov/the-press-office/2013/06/15/statement -press-secretary-electionIran

http://gadebate.un.org/sites/default/files/gastatements/68/IR_en.pdf

http://www.un.org/documents/dialogue.htm., the UNESCO (UN Educational, Scientific, and Cultural Organization) actions for dialogue among civilizations. http://www.unesco. 
org/dialogue2001., the ISESCO (Islamic Organization for Education, Science, and Culture) conferences on dialogue of civilizations. www.isesco.org.ma., and the World Public Forum 'Dialogue of Civilizations' (a Russian-led initiative) meetings.

http://www.dialogueofcivilizations.org

www.socialsciencesautomation.com

www.iranchamber.com/history/mkhatami

https://www.theguardian.com/world/2016/jun/10/ayatollah-khomeini-jimmy-carteradministration-iran-revolution

http://www.un.org/documents/s54-60.pdf).

https://enb.iisd.org/crs/sdter/ymbvol108numle.html,

https://unesdoc.unesco.org/ark:/48223/pf0000123890,

https://www.akdn.org/gallery/international-conference-dialogue-among-civilisationscultures-and-peoples-unesco,

https://www.un.org/press/en/2000/20000905.ga9748.doc.html

htpp://gulfnews.com

http://www.presstv.com/detail/2014/02/24/352108/iran-keen-to-expand-ties-with-africa/

http://gadebate.un.org/sites/default/files/gastatements/68/IR_en.pdf

http://www.parstimes.com/history/khatami_speech_un.html

http://www.cnn.com/WORLD/9801/07/iran/interview.html).

http://www.iaea.org/NewsCenter/News/2003). 
https://georgebush-whitehouse.archives.gov/news/release/2002/01/20020129-11.html

http://www.state.gov/documents/organization/63562.pdf

www.washingtonpost.com/wp-dyn/content/article/2006/01/31/AR2006013101468.htmlF

http://news.bbc.co.uk/2/hi/middle_east/3211036.stm

http://www.foreignaffairs.com/articles/141209/mohammad-javad-zarif/what-iran-reallywants.

http://iccim.org/iran-commerce/no2-1999

Afkar News, 24 September 2005

Al-Sharq al-Awsat, October 29, 2001

AFP, October 17, 2002

BBC SWB ME/2917 MED/ 13 May 1997

BBC, 18 October 1997

CNN, Dec.1997

Ettelaat International, 2 March 1998

Ettelaat International, 10 March 1998

Ettelaat international, 12 December 1997

Ettelaat international,15 December 1997

Ettelaat, 7August 1997

Ettelaat,14 September 1998 
Jomhuri-ye-Islami, 4 August 1997

Hamshahri, February 17, 1996

Keyhan Havai 13 December 1989

Iran Daily, 23 August 1997

Iran Daily, 28 August 1997

Iranian Diplomacy, August 12, 2013

International Herald Tribune, 12 August 2005

Iran News, 29 Oct. 2002

Iran News, 25 March 1997

Iran News, 5 August 1997

RFE/RL, 11 February 2004

IRNA 9 December 1997

IRNA, 14 December 1997

IRNA, September 21, 1998

IRNA, January 8, 1998

Mardom Salary, 28 Novenmber, 2007

New York Times, 5 July 1994

Reuters, 5 September 2000 
Reuters, 11 April 1997

Reuters, February 29, 2001

Reuters, 10 April 1997

Salam Newspaper, 6 May 1997

Salam Newspaper/11 Dec. 1997

Tehran TV, 10 May 1997

Tehran TV, 14 May 1997

Tehran TV, 18 May 1997

Tehran TV, 19 May 1997

Tehran TV, 20 May 1997 
Appendix 1

Khatami's Operational Code Analysis 


\section{Appendix 1 - Khatami's Operational Code Analysis}

\begin{tabular}{|c|c|c|c|c|c|c|c|c|c|c|c|c|c|c|c|c|c|}
\hline filename & $\begin{array}{l}\text { word } \\
\text { count }\end{array}$ & $\begin{array}{c}\text { self } \\
\text { punish }\end{array}$ & \begin{tabular}{|c|} 
self \\
threaten
\end{tabular} & \begin{tabular}{|c|} 
self \\
oppose
\end{tabular} \mid & \begin{tabular}{|c|} 
self \\
appeal
\end{tabular} & \begin{tabular}{|c|} 
self \\
promise
\end{tabular} & \begin{tabular}{|c} 
self \\
reward
\end{tabular} & $\begin{array}{c}\text { other } \\
\text { punish }\end{array}$ & \begin{tabular}{|c|} 
other \\
threaten
\end{tabular} & $\begin{array}{c}\text { other } \\
\text { oppose }\end{array}$ & $\begin{array}{c}\text { other } \\
\text { appeal }\end{array}$ & \begin{tabular}{|c|} 
other \\
promise
\end{tabular} & $\begin{array}{c}\text { other } \\
\text { reward }\end{array}$ & I1 & I2 & P1 & P2 \\
\hline $\begin{array}{l}\text { C:ISSA-Collections- } \\
\text { Master|Iran\Khatami_Mohammed } \backslash \text { Standard } \backslash \text { Khatami } \\
\text { 20000101.pro }\end{array}$ & 1616 & 0 & 0 & 0 & 7 & 0 & 1 & 10 & 1 & 6 & 12 & 0 & 10 & $\begin{array}{c}1.0 \\
0\end{array}$ & $\begin{array}{c}0.4 \\
2\end{array}$ & $\begin{array}{c}0.1 \\
3\end{array}$ & $\begin{array}{c}0.0 \\
3\end{array}$ \\
\hline $\begin{array}{l}\text { C:ISSA-Collections- } \\
\text { MasterIIran\Khatami_Mohammed } \backslash \text { Standard } \backslash \text { Khatami } \\
\text { 20001102.pro }\end{array}$ & 2013 & 0 & 0 & 0 & 0 & 0 & 2 & 3 & 3 & 4 & 14 & 0 & 9 & $\begin{array}{c}1.0 \\
0\end{array}$ & $\begin{array}{c}1.0 \\
0\end{array}$ & $\begin{array}{c}0.3 \\
9\end{array}$ & $\begin{array}{c}0.2 \\
2\end{array}$ \\
\hline $\begin{array}{l}\text { C:ISSA-Collections- } \\
\text { Master|Iran\Khatami_Mohammed } \backslash \text { Standard } \backslash \text { Khatami } \\
\text { 20001113.pro }\end{array}$ & 549 & 0 & 0 & 0 & 0 & 0 & 0 & 6 & 0 & 2 & 5 & 0 & 4 & $\begin{array}{c}\mathrm{NI} \\
\mathrm{L}\end{array}$ & $\begin{array}{c}\mathrm{NI} \\
\mathrm{L}\end{array}$ & $\begin{array}{c}0.0 \\
6\end{array}$ & $\begin{array}{c}- \\
0.0 \\
6\end{array}$ \\
\hline $\begin{array}{l}\text { C:ISSA-Collections- } \\
\text { Master|Iran } \backslash \text { Khatami_Mohammed } \backslash \text { Standard } \backslash \text { Khatami } \\
\text { 20001113a.pro }\end{array}$ & 1104 & 0 & 0 & 0 & 1 & 0 & 0 & 12 & 1 & 3 & 12 & 0 & 9 & $\begin{array}{c}1.0 \\
0\end{array}$ & $\begin{array}{c}0.3 \\
3\end{array}$ & $\begin{array}{c}0.1 \\
4\end{array}$ & $\begin{array}{c}- \\
0.0 \\
2\end{array}$ \\
\hline $\begin{array}{l}\text { C:ISSA-Collections- } \\
\text { Master|Iran } \backslash \text { Khatami_Mohammed } \backslash \text { Standard } \backslash \text { Khatami } \\
\text { 20010213.pro }\end{array}$ & 150 & 0 & 0 & 0 & 3 & 0 & 1 & 0 & 0 & 1 & 0 & 1 & 0 & $\begin{array}{c}1.0 \\
0\end{array}$ & $\begin{array}{c}0.5 \\
0\end{array}$ & $\begin{array}{c}0.0 \\
0\end{array}$ & $\begin{array}{c}0.1 \\
7\end{array}$ \\
\hline $\begin{array}{l}\text { C:ISSA-Collections- } \\
\text { Master|Iran\Khatami_Mohammed } \backslash \text { Standard } \backslash \text { Khatami } \\
\text { 20010217.pro }\end{array}$ & 1901 & 0 & 0 & 2 & 15 & 1 & 3 & 8 & 0 & 4 & 16 & 1 & 17 & $\begin{array}{c}0.8 \\
1\end{array}$ & $\begin{array}{c}0.3 \\
8\end{array}$ & $\begin{array}{c}0.4 \\
8\end{array}$ & $\begin{array}{c}0.3 \\
0\end{array}$ \\
\hline $\begin{array}{l}\text { C:ISSA-Collections- } \\
\text { Master|Iran } \backslash \text { Khatami_Mohammed } \backslash \text { Standard } \backslash \text { Khatami } \\
\text { 20010219.pro }\end{array}$ & 1016 & 0 & 0 & 1 & 3 & 0 & 1 & 0 & 0 & 3 & 12 & 2 & 9 & $\begin{array}{c}0.6 \\
0\end{array}$ & $\begin{array}{c}0.3 \\
3\end{array}$ & $\begin{array}{c}0.7 \\
7\end{array}$ & $\begin{array}{c}0.5 \\
1\end{array}$ \\
\hline $\begin{array}{l}\text { C:ISSA-Collections- } \\
\text { Master|Iran\Khatami_Mohammed } \backslash \text { Standard } \backslash \text { Khatami } \\
\text { 20010316.pro }\end{array}$ & 1162 & 1 & 0 & 1 & 13 & 4 & 4 & 3 & 0 & 1 & 9 & 0 & 6 & $\begin{array}{c}0.8 \\
3\end{array}$ & $\begin{array}{c}0.4 \\
2\end{array}$ & $\begin{array}{c}0.5 \\
8\end{array}$ & $\begin{array}{c}0.3 \\
0\end{array}$ \\
\hline $\begin{array}{l}\text { C:ISSA-Collections- } \\
\text { Master|Iran\Khatami_Mohammed } \backslash \text { Standard } \backslash \text { Khatami } \\
\text { 20010320.pro }\end{array}$ & 875 & 0 & 0 & 0 & 1 & 0 & 2 & 2 & 0 & 2 & 9 & 1 & 2 & $\begin{array}{c}1.0 \\
0\end{array}$ & $\begin{array}{c}0.7 \\
8\end{array}$ & $\begin{array}{c}0.5 \\
0\end{array}$ & $\begin{array}{c}0.1 \\
9\end{array}$ \\
\hline $\begin{array}{l}\text { C:ISSA-Collections- } \\
\text { Master|Iran } \backslash \text { Khatami_Mohammed } \backslash \text { Standard } \backslash \text { Khatami } \\
\text { 20010610.pro }\end{array}$ & 283 & 0 & 0 & 1 & 2 & 0 & 0 & 0 & 0 & 0 & 2 & 0 & 0 & $\begin{array}{c}0.3 \\
3\end{array}$ & $\begin{array}{c}0.1 \\
1\end{array}$ & $\begin{array}{c}1.0 \\
0\end{array}$ & $\begin{array}{c}0.3 \\
3\end{array}$ \\
\hline $\begin{array}{l}\text { C:ISSA-Collections- } \\
\text { Master|Iran\Khatami_Mohammed } \backslash \text { Standard } \backslash \text { Khatami } \\
\text { 20010827.pro }\end{array}$ & 1712 & 0 & 1 & 2 & 20 & 1 & 4 & 7 & 0 & 1 & 16 & 3 & 9 & $\begin{array}{c}0.7 \\
9\end{array}$ & $\begin{array}{c}0.3 \\
6\end{array}$ & $\begin{array}{c}0.5 \\
6\end{array}$ & $\begin{array}{c}0.2 \\
5\end{array}$ \\
\hline $\begin{array}{l}\text { C:ISSA-Collections- } \\
\text { Master|Iran\Khatami_Mohammed } \backslash \text { Standard } \backslash \text { Khatami } \\
\text { 20010922.pro }\end{array}$ & 1439 & 0 & 1 & 2 & 7 & 0 & 0 & 6 & 2 & 7 & 11 & 1 & 10 & $\begin{array}{c}0.4 \\
0\end{array}$ & \begin{tabular}{c|}
0.1 \\
0
\end{tabular} & $\begin{array}{c}0.1 \\
9\end{array}$ & $\begin{array}{c}0.1 \\
3\end{array}$ \\
\hline $\begin{array}{l}\text { C:ISSA-Collections- } \\
\text { Master|Iran\Khatami_Mohammed } \backslash \text { Standard } \backslash \text { Khatami } \\
\text { 20011109.pro }\end{array}$ & 984 & 0 & 1 & 2 & 5 & 1 & 2 & 7 & 1 & 1 & 16 & 1 & 0 & $\begin{array}{c}0.4 \\
5\end{array}$ & $\begin{array}{c}0.2 \\
7\end{array}$ & $\begin{array}{c}0.3 \\
1\end{array}$ & $\begin{array}{c}- \\
0.0 \\
8\end{array}$ \\
\hline $\begin{array}{l}\text { C:ISSA-Collections- } \\
\text { Master|Iran\Khatami_Mohammed } \backslash \text { Standard } \backslash \text { Khatami } \\
\text { 20020701.pro }\end{array}$ & 1802 & 0 & 1 & 2 & 4 & 0 & 0 & 10 & 1 & 5 & 18 & 2 & 10 & $\begin{array}{c}0.1 \\
4\end{array}$ & $\begin{array}{c}0.0 \\
0\end{array}$ & $\begin{array}{c}0.3 \\
0\end{array}$ & $\begin{array}{c}0.1 \\
1\end{array}$ \\
\hline $\begin{array}{l}\text { C:ISSA-Collections- } \\
\text { Master|Iran\Khatami_Mohammed } \backslash \text { Standard } \backslash \text { Khatami } \\
\text { 20020701a.pro }\end{array}$ & 1580 & 0 & 0 & 0 & 5 & 1 & 1 & 2 & 0 & 2 & 13 & 1 & 11 & $\begin{array}{c}1.0 \\
0\end{array}$ & $\begin{array}{c}0.4 \\
8\end{array}$ & $\begin{array}{c}0.7 \\
2\end{array}$ & $\begin{array}{c}0.4 \\
6\end{array}$ \\
\hline
\end{tabular}




\section{Appendix 1 - Khatami's Operational Code Analysis}

C:ISSA-Collections-

Master|Iran\Khatami Mohammed\Standard\Khatami 20021204.pro

C:ISSA-Collections-

Master Iran $\backslash$ Khatami_Mohammed $\backslash$ Standard $\backslash$ Khatami 20021225.pro

C: ISSA-Collections-

Master Iran\Khatami Mohammed $\backslash$ Standard $\backslash$ Khatami 20030224.pro

C: ISSA-Collections-

Master|Iran\Khatami_Mohammed $\backslash$ Standard $\backslash$ Khatam 20030514a.pro

C:ISSA-Collections-

Master Iran $\backslash$ Khatami Mohammed $\backslash$ Standard $\backslash$ Khatami 20031019.pro

C:ISSA-Collections-

Master Iran\Khatami_Mohammed $\backslash$ Standard $\backslash$ Khatami 20031217.pro

C: ISSA-Collections-

Master Iran $\backslash$ Khatami Mohammed $\backslash$ Standard $\backslash K h a t a m i$ 20031223.pro

C:ISSA-Collections-

Master|Iran\Khatami_Mohammed $\backslash$ Standard $\backslash$ Khatami 20031230.pro

C:ISSA-Collections-

Master Iran $\backslash$ Khatami_Mohammed $\backslash$ Standard $\backslash$ Khatami

20040107.pro

C:ISSA-Collections-

Master Iran\Khatami_Mohammed $\backslash$ Standard\Khatami 20040427.pro

C:ISSA-Collections-

Master|Iran\Khatami_Mohammed $\backslash$ Standard $\backslash$ Khatami

20040521.pro

C:ISSA-Collections-

Master Iran\Khatami_Mohammed $\backslash$ Standard\Khatami 20040606.pro

C:ISSA-Collections-

Master $\backslash$ Iran $\backslash$ Khatami Mohammed $\backslash$ Standard $\backslash$ Khatami

20040610.pro

C:ISSA-Collections-

Master Iran\Khatami_Mohammed $\backslash$ Standard\Khatami 20040806.pro

C:ISSA-Collections-

Master|Iran\Khatami_Mohammed $\backslash$ Standard $\backslash$ Khatami

20040807.pro

C:ISSA-Collections-

Master|Iran $\backslash$ Khatami_Mohammed $\backslash$ Standard $\backslash$ Khatami 20040908.pro

\begin{tabular}{|c|c|c|c|c|c|c|c|c|c|c|c|c|c|c|c|c|}
\hline 2226 & 1 & 0 & 2 & 0 & 0 & 0 & 6 & 3 & 3 & 21 & 1 & 11 & $\begin{array}{c}1.0 \\
0 \\
\end{array}$ & $\begin{array}{c}0.5 \\
6 \\
\end{array}$ & $\begin{array}{c}0.4 \\
7\end{array}$ & $\begin{array}{c}0.2 \\
1\end{array}$ \\
\hline 1580 & 0 & 0 & 0 & 4 & 0 & 1 & 3 & 0 & 3 & 4 & 5 & 5 & $\begin{array}{c}1.0 \\
0\end{array}$ & $\begin{array}{c}0.4 \\
7\end{array}$ & $\begin{array}{c}0.4 \\
0\end{array}$ & $\begin{array}{c}0.2 \\
8\end{array}$ \\
\hline 1679 & 1 & 0 & 1 & 6 & 0 & 0 & 6 & 3 & 5 & 16 & 0 & 11 & $\begin{array}{c}0.5 \\
0\end{array}$ & $\begin{array}{c}0.0 \\
8\end{array}$ & $\begin{array}{c}0.3 \\
2\end{array}$ & $\begin{array}{c}0.1 \\
6\end{array}$ \\
\hline 1939 & 0 & 0 & 1 & 0 & 0 & 1 & 2 & 0 & 4 & 22 & 0 & 7 & $\begin{array}{c}0.0 \\
0\end{array}$ & $\begin{array}{c}0.3 \\
3\end{array}$ & $\begin{array}{c}0.6 \\
6\end{array}$ & $\begin{array}{c}0.3 \\
1\end{array}$ \\
\hline 127 & 0 & 1 & 0 & 3 & 0 & 1 & 0 & 0 & 0 & 3 & 0 & 1 & $\begin{array}{c}0.6 \\
0\end{array}$ & $\begin{array}{c}0.2 \\
7\end{array}$ & $\begin{array}{c}1.0 \\
0\end{array}$ & $\begin{array}{c}0.5 \\
0\end{array}$ \\
\hline 176 & 0 & 0 & 1 & 2 & 0 & 0 & 1 & 3 & 1 & 3 & 0 & 0 & $\begin{array}{c}0.3 \\
3\end{array}$ & $\begin{array}{c}0.1 \\
1\end{array}$ & $\begin{array}{c}- \\
0.2 \\
5\end{array}$ & $\begin{array}{c}- \\
0.2 \\
9\end{array}$ \\
\hline 211 & 0 & 0 & 0 & 5 & 0 & 0 & 1 & 0 & 0 & 3 & 0 & 1 & $\begin{array}{c}1.0 \\
0\end{array}$ & $\begin{array}{c}0.3 \\
3\end{array}$ & $\begin{array}{c}0.6 \\
0\end{array}$ & $\begin{array}{c}0.2 \\
0\end{array}$ \\
\hline 625 & 1 & 1 & 0 & 5 & 0 & 1 & 2 & 0 & 0 & 7 & 0 & 6 & $\begin{array}{c}0.5 \\
0\end{array}$ & $\begin{array}{c}0.1 \\
3\end{array}$ & $\begin{array}{c}0.7 \\
3\end{array}$ & $\begin{array}{c}0.4 \\
2\end{array}$ \\
\hline 1671 & 0 & 0 & 0 & 2 & 0 & 0 & 6 & 0 & 2 & 16 & 2 & 4 & $\begin{array}{c}1.0 \\
0\end{array}$ & $\begin{array}{c}0.3 \\
3\end{array}$ & $\begin{array}{c}0.4 \\
7\end{array}$ & $\begin{array}{c}0.1 \\
3\end{array}$ \\
\hline 874 & 0 & 0 & 0 & 3 & 0 & 0 & 0 & 0 & 3 & 4 & 1 & 1 & $\begin{array}{c}1.0 \\
0\end{array}$ & $\begin{array}{c}0.3 \\
3\end{array}$ & $\begin{array}{c}0.3 \\
3\end{array}$ & $\begin{array}{c}0.2 \\
2\end{array}$ \\
\hline 2158 & 1 & 0 & 1 & 2 & 0 & 0 & 8 & 0 & 1 & 13 & 0 & 12 & $\begin{array}{c}0.0 \\
0\end{array}$ & \begin{tabular}{|c} 
\\
0.1 \\
7
\end{tabular} & $\begin{array}{c}0.4 \\
7\end{array}$ & $\begin{array}{c}0.2 \\
4\end{array}$ \\
\hline 1140 & 0 & 0 & 0 & 3 & 0 & 3 & 6 & 0 & 1 & 4 & 0 & 7 & $\begin{array}{c}1.0 \\
0\end{array}$ & $\begin{array}{c}0.6 \\
7\end{array}$ & $\begin{array}{c}0.2 \\
2\end{array}$ & $\begin{array}{c}0.1 \\
1\end{array}$ \\
\hline 1201 & 0 & 0 & 1 & 2 & 0 & 0 & 1 & 0 & 1 & 3 & 1 & 7 & $\begin{array}{c}0.3 \\
3\end{array}$ & $\begin{array}{c}0.1 \\
1\end{array}$ & $\begin{array}{c}0.6 \\
9\end{array}$ & $\begin{array}{c}0.5 \\
6\end{array}$ \\
\hline 1871 & 0 & 0 & 0 & 4 & 0 & 0 & 4 & 1 & 4 & 15 & 1 & 9 & $\begin{array}{c}1.0 \\
0\end{array}$ & $\begin{array}{c}0.3 \\
3\end{array}$ & $\begin{array}{c}0.4 \\
7\end{array}$ & $\begin{array}{c}0.2 \\
5\end{array}$ \\
\hline 1852 & 0 & 0 & 1 & 7 & 0 & 2 & 4 & 1 & 2 & 21 & 1 & 14 & $\begin{array}{c}0.8 \\
0\end{array}$ & $\begin{array}{c}0.4 \\
0\end{array}$ & $\begin{array}{c}0.6 \\
7\end{array}$ & $\begin{array}{c}0.3 \\
8\end{array}$ \\
\hline 1933 & 1 & 0 & 2 & 3 & 0 & 2 & 7 & 0 & 5 & 7 & 0 & 5 & $\begin{array}{c}0.2 \\
5\end{array}$ & $\begin{array}{c}0.1 \\
7\end{array}$ & $\begin{array}{c}0.0 \\
0\end{array}$ & $\begin{array}{c}- \\
0.0 \\
6\end{array}$ \\
\hline
\end{tabular}

Appendix 1-2 


\section{Appendix 1 - Khatami's Operational Code Analysis}

C:ISSA-Collections-

Master VIran\Khatami_Mohammed $\backslash$ Standard $\backslash$ Khatami 20040909.pro

C:ISSA-Collections-

Master Iran \Khatami_Mohammed $\backslash$ Standard $\backslash$ Khatami 20040912.pro

C:ISSA-Collections-

Master|Iran\Khatami_Mohammed $\backslash$ Standard\Khatami 20040914.pro

C:ISSA-Collections-

Master|Iran\Khatami_Mohammed $\backslash$ Standard $\backslash$ Khatam 20040921.pro

C:ISSA-Collections-

Master Iran $\backslash$ Khatami Mohammed $\backslash$ Standard $\backslash$ Khatami 20040922.pro

C:ISSA-Collections-

Master Iran\Khatami_Mohammed $\backslash$ Standard $\backslash$ Khatami 20041002.pro

C:ISSA-Collections-

Master Iran $\backslash$ Khatami Mohammed $\backslash$ Standard $\backslash$ Khatami 20041002a.pro

C:ISSA-Collections-

Master Iran\Khatami_Mohammed $\backslash$ Standard $\backslash$ Khatami 20041005.pro

C:ISSA-Collections-

Master Iran $\backslash$ Khatami_Mohammed $\backslash$ Standard $\backslash$ Khatami

20041006 pro

C:ISSA-Collections-

Master Iran\Khatami_Mohammed $\backslash$ Standard\Khatami 20041008.pro

C:ISSA-Collections-

Master|Iran\Khatami_Mohammed $\backslash$ Standard $\backslash$ Khatami

20041012.pro

C:ISSA-Collections-

Master Iran\Khatami_Mohammed $\backslash$ Standard $\backslash$ Khatami 20041020.pro

C:ISSA-Collections-

Master|Iran $\backslash$ Khatami_Mohammed $\backslash$ Standard $\backslash$ Khatami

20041020a.pro

C:ISSA-Collections-

Master Iran\Khatami_Mohammed \Standard $\backslash$ Khatam 20041021.pro

C:ISSA-Collections-

Master|Iran\Khatami_Mohammed $\backslash$ Standard $\backslash K h a t a m i$ 20041021a.pro

C:ISSA-Collections-

Master|Iran $\backslash$ Khatami_Mohammed $\backslash$ Standard $\backslash$ Khatami 20041102.pro

\begin{tabular}{|c|c|c|c|c|c|c|c|c|c|c|c|c|c|c|c|c|}
\hline 1497 & 0 & 0 & 1 & 3 & 0 & 1 & 7 & 0 & 3 & 2 & 1 & 5 & $\begin{array}{c}0.6 \\
0\end{array}$ & $\begin{array}{c}0.3 \\
3\end{array}$ & $\begin{array}{c}0.1 \\
1\end{array}$ & $\begin{array}{c}0.0 \\
9\end{array}$ \\
\hline 359 & 0 & 0 & 0 & 3 & 2 & 4 & 1 & 0 & 0 & 2 & 0 & 7 & $\begin{array}{c}1.0 \\
0\end{array}$ & $\begin{array}{c}0.7 \\
0\end{array}$ & $\begin{array}{c}0.8 \\
0\end{array}$ & $\begin{array}{c}0.6 \\
7\end{array}$ \\
\hline 1659 & 1 & 0 & 0 & 6 & 0 & 1 & 6 & 2 & 4 & 15 & 3 & 14 & $\begin{array}{c}0.7 \\
5\end{array}$ & $\begin{array}{c}0.2 \\
5\end{array}$ & $\begin{array}{c}0.4 \\
5\end{array}$ & $\begin{array}{c}0.2 \\
8\end{array}$ \\
\hline 2121 & 2 & 1 & 4 & 10 & 1 & 3 & 19 & 0 & 2 & 16 & 0 & 13 & $\begin{array}{c}0.3 \\
3\end{array}$ & $\begin{array}{c}0.1 \\
4\end{array}$ & $\begin{array}{c}0.1 \\
6\end{array}$ & $\begin{array}{c}0.0 \\
3\end{array}$ \\
\hline 1143 & 0 & 0 & 0 & 9 & 0 & 1 & 5 & 2 & 1 & 12 & 4 & 15 & $\begin{array}{c}1.0 \\
0\end{array}$ & $\begin{array}{c}0.4 \\
0\end{array}$ & $\begin{array}{c}0.5 \\
9\end{array}$ & $\begin{array}{c}0.3 \\
8\end{array}$ \\
\hline 250 & 0 & 0 & 0 & 1 & 0 & 0 & 1 & 1 & 2 & 0 & 0 & 1 & $\begin{array}{c}1.0 \\
0\end{array}$ & $\begin{array}{c}0.3 \\
3\end{array}$ & \begin{tabular}{|c}
- \\
0.6 \\
0
\end{tabular} & $\begin{array}{c}- \\
0.2 \\
7\end{array}$ \\
\hline 90 & 0 & 0 & 0 & 0 & 0 & 0 & 0 & 0 & 0 & 4 & 0 & 0 & $\begin{array}{c}\text { NI } \\
\text { L }\end{array}$ & $\begin{array}{c}\text { NI } \\
\text { L }\end{array}$ & $\begin{array}{c}1.0 \\
0\end{array}$ & $\begin{array}{c}0.3 \\
3\end{array}$ \\
\hline 202 & 0 & 0 & 0 & 2 & 0 & 0 & 2 & 0 & 1 & 3 & 0 & 2 & $\begin{array}{c}1.0 \\
0\end{array}$ & $\begin{array}{c}0.3 \\
3\end{array}$ & $\begin{array}{c}0.2 \\
5\end{array}$ & $\begin{array}{c}0.0 \\
8\end{array}$ \\
\hline 168 & 0 & 0 & 1 & 1 & 2 & 0 & 2 & 0 & 3 & 1 & 0 & 0 & $\begin{array}{c}0.5 \\
0\end{array}$ & $\begin{array}{c}0.3 \\
3\end{array}$ & $\overline{0}$ & $\begin{array}{c}- \\
0.4 \\
4\end{array}$ \\
\hline 579 & 0 & 0 & 1 & 1 & 0 & 1 & 4 & 0 & 1 & 10 & 0 & 7 & $\begin{array}{c}0.3 \\
3\end{array}$ & $\begin{array}{c}0.3 \\
3\end{array}$ & $\begin{array}{c}0.5 \\
5\end{array}$ & $\begin{array}{c}0.2 \\
7\end{array}$ \\
\hline 141 & 0 & 0 & 0 & 0 & 0 & 0 & 0 & 0 & 1 & 0 & 0 & 1 & $\begin{array}{c}\text { NI } \\
\text { L }\end{array}$ & $\begin{array}{c}\text { NI } \\
\text { L }\end{array}$ & $\begin{array}{c}0.0 \\
0\end{array}$ & $\begin{array}{c}0.3 \\
3\end{array}$ \\
\hline 261 & 0 & 0 & 0 & 1 & 0 & 0 & 0 & 1 & 0 & 6 & 1 & 2 & $\begin{array}{c}1.0 \\
0\end{array}$ & $\begin{array}{c}0.3 \\
3\end{array}$ & \begin{tabular}{|c}
0.8 \\
0
\end{tabular} & $\begin{array}{c}0.4 \\
0\end{array}$ \\
\hline 146 & 0 & 0 & 0 & 0 & 0 & 0 & 1 & 0 & 0 & 1 & 0 & 0 & $\begin{array}{c}\text { NI } \\
\text { L }\end{array}$ & $\begin{array}{c}\text { NI } \\
\text { L }\end{array}$ & $\begin{array}{c}0.0 \\
0\end{array}$ & 0.3 \\
\hline 145 & 0 & 0 & 0 & 0 & 0 & 2 & 1 & 0 & 0 & 3 & 0 & 2 & $\begin{array}{c}1.0 \\
0\end{array}$ & $\begin{array}{c}1.0 \\
0\end{array}$ & $\begin{array}{c}0.6 \\
7\end{array}$ & $\begin{array}{c}0.3 \\
3\end{array}$ \\
\hline 197 & 0 & 0 & 0 & 0 & 0 & 0 & 1 & 0 & 1 & 5 & 0 & 1 & $\begin{array}{c}\text { NI } \\
\text { L }\end{array}$ & $\begin{array}{c}\mathrm{NI} \\
\mathrm{L}\end{array}$ & $\begin{array}{c}0.5 \\
0\end{array}$ & $\begin{array}{c}0.1 \\
7\end{array}$ \\
\hline 310 & 0 & 0 & 0 & 0 & 0 & 0 & 3 & 0 & 1 & 1 & 1 & 3 & $\begin{array}{c}\text { NI } \\
\text { L }\end{array}$ & $\begin{array}{c}\text { NI } \\
\text { L }\end{array}$ & $\begin{array}{c}0.1 \\
1\end{array}$ & $\begin{array}{c}0.0 \\
7\end{array}$ \\
\hline
\end{tabular}

Appendix 1-3 


\section{Appendix 1 - Khatami's Operational Code Analysis}

C:ISSA-Collections-

Master Iran\Khatami_Mohammed\Standard\Khatami 20041102a.pro

C:ISSA-Collections-

Master|Iran\Khatami_Mohammed $\backslash$ Standard\Khatam

20041104.pro

C:ISSA-Collections-

Master Iran\Khatami_Mohammed $\backslash$ Standard $\backslash$ Khatami

20041114.pro

C:ISSA-Collections-

Master Iran\Khatami_Mohammed $\backslash$ Standard $\backslash$ Khatami 20041117.pro

C:ISSA-Collections-

Master $\backslash$ Iran $\backslash$ Khatami_Mohammed $\backslash$ Standard $\backslash$ Khatami

20041117a.pro

C:ISSA-Collections-

Master Iran\Khatami_Mohammed $\backslash$ Standard $\backslash$ Khatami 20041117b.pro

C:ISSA-Collections-

Master Iran $\backslash$ Khatami Mohammed $\backslash$ Standard $\backslash K h a t a m i$

20041117c.pro

C:ISSA-Collections-

Master\Iran\Khatami_Mohammed $\backslash$ Standard\Khatami 20041117d.pro

C:ISSA-Collections-

Master Iran $\backslash$ Khatami_Mohammed $\backslash$ Standard $\backslash$ Khatami

20041129 pro

C:ISSA-Collections-

Master Iran\Khatami_Mohammed $\backslash$ Standard\Khatami 20041202.pro

C:ISSA-Collections-

Master Iran $\backslash$ Khatami_Mohammed $\backslash$ Standard $\backslash$ Khatami

20041207.pro

C:ISSA-Collections-

Master Iran\Khatami_Mohammed $\backslash$ Standard $\backslash$ Khatami 20041212.pro

C:ISSA-Collections-

Master Iran\Khatami Mohammed $\backslash$ Standard\Khatami

20041213.pro

C:ISSA-Collections-

Master|Iran\Khatami_Mohammed $\backslash$ Standard\Khatam 20041213a.pro

C:ISSA-Collections-

Master|Iran\Khatami_Mohammed \Standard\Khatam

20050111.pro

C:ISSA-Collections-

Master|Iran \Khatami_Mohammed $\backslash$ Standard $\backslash$ Khatami

20050111a.pro

\begin{tabular}{|c|c|c|c|c|c|c|c|c|c|c|c|c|c|c|c|c|}
\hline 268 & 0 & 0 & 2 & 2 & 2 & 0 & 1 & 1 & 0 & 5 & 1 & 0 & $\begin{array}{c}0.3 \\
3\end{array}$ & $\begin{array}{c}0.2 \\
2\end{array}$ & $\begin{array}{c}0.5 \\
0\end{array}$ & $\begin{array}{c}0.0 \\
8\end{array}$ \\
\hline 407 & 0 & 0 & 0 & 5 & 0 & 0 & 8 & 0 & 3 & 5 & 0 & 2 & $\begin{array}{c}1.0 \\
0\end{array}$ & $\begin{array}{c}0.3 \\
3\end{array}$ & $\begin{array}{c}- \\
0.2 \\
2\end{array}$ & $\begin{array}{c}- \\
0.3 \\
0\end{array}$ \\
\hline 547 & 0 & 0 & 0 & 4 & 0 & 0 & 4 & 0 & 3 & 2 & 0 & 6 & $\begin{array}{c}1.0 \\
0\end{array}$ & $\begin{array}{c}0.3 \\
3\end{array}$ & $\begin{array}{c}0.0 \\
7\end{array}$ & $\begin{array}{c}0.1 \\
1\end{array}$ \\
\hline 743 & 0 & 0 & 0 & 0 & 0 & 0 & 2 & 0 & 0 & 9 & 0 & 2 & $\begin{array}{c}\text { NI } \\
\text { L }\end{array}$ & $\begin{array}{c}\text { NI } \\
\text { L }\end{array}$ & $\begin{array}{c}0.6 \\
9\end{array}$ & $\begin{array}{c}0.2 \\
3\end{array}$ \\
\hline 611 & 0 & 0 & 1 & 5 & 1 & 2 & 2 & 0 & 0 & 5 & 3 & 2 & $\begin{array}{c}0.7 \\
8\end{array}$ & $\begin{array}{c}0.4 \\
4\end{array}$ & $\begin{array}{c}0.6 \\
7\end{array}$ & $\begin{array}{c}0.3 \\
1\end{array}$ \\
\hline 162 & 0 & 0 & 0 & 1 & 0 & 0 & 0 & 0 & 1 & 0 & 0 & 4 & $\begin{array}{c}1.0 \\
0\end{array}$ & $\begin{array}{c}0.3 \\
3\end{array}$ & $\begin{array}{c}0.6 \\
0\end{array}$ & $\begin{array}{c}0.7 \\
3\end{array}$ \\
\hline 534 & 2 & 0 & 0 & 6 & 0 & 1 & 3 & 0 & 3 & 10 & 3 & 3 & $\begin{array}{c}0.5 \\
6\end{array}$ & $\begin{array}{c}0.1 \\
1\end{array}$ & $\begin{array}{c}0.4 \\
5\end{array}$ & $\begin{array}{c}0.2 \\
0\end{array}$ \\
\hline 221 & 1 & 0 & 0 & 6 & 1 & 1 & 5 & 0 & 2 & 1 & 0 & 1 & $\begin{array}{c}0.7 \\
8\end{array}$ & $\begin{array}{c}0.3 \\
0\end{array}$ & $\begin{array}{c}- \\
0.5 \\
6\end{array}$ & $\begin{array}{c}- \\
0.4\end{array}$ \\
\hline 178 & 1 & 0 & 0 & 2 & 1 & 0 & 0 & 0 & 1 & 2 & 3 & 0 & $\begin{array}{c}0.5 \\
0\end{array}$ & $\begin{array}{c}0.0 \\
8\end{array}$ & $\begin{array}{c}0.6 \\
7\end{array}$ & $\begin{array}{c}0.3 \\
9\end{array}$ \\
\hline 155 & 1 & 0 & 0 & 1 & 0 & 0 & 0 & 0 & 0 & 4 & 0 & 0 & $\begin{array}{c}0.0 \\
0\end{array}$ & $\begin{array}{c}- \\
0.3\end{array}$ & $\begin{array}{c}1.0 \\
0\end{array}$ & $\begin{array}{c}0.3 \\
3\end{array}$ \\
\hline 99 & 0 & 0 & 0 & 0 & 0 & 0 & 0 & 0 & 0 & 1 & 0 & 0 & $\begin{array}{c}\mathrm{NI} \\
\mathrm{L}\end{array}$ & NI & $\begin{array}{c}1.0 \\
0\end{array}$ & $\begin{array}{c}0.3 \\
3\end{array}$ \\
\hline 116 & 0 & 0 & 1 & 0 & 0 & 0 & 0 & 0 & 1 & 0 & 0 & 2 & $\begin{array}{c}- \\
1.0 \\
0\end{array}$ & $\begin{array}{c}- \\
0.3 \\
3\end{array}$ & $\begin{array}{c}0.3 \\
3\end{array}$ & $\begin{array}{c}0.5 \\
6\end{array}$ \\
\hline 146 & 0 & 0 & 0 & 0 & 0 & 0 & 0 & 0 & 0 & 2 & 0 & 2 & $\begin{array}{c}\mathrm{NI} \\
\mathrm{L}\end{array}$ & $\begin{array}{c}\text { NI } \\
\text { L }\end{array}$ & $\begin{array}{c}1.0 \\
0\end{array}$ & $\begin{array}{c}0.6 \\
7\end{array}$ \\
\hline 112 & 0 & 0 & 0 & 0 & 0 & 0 & 0 & 0 & 0 & 1 & 0 & 0 & $\begin{array}{c}\mathrm{NI} \\
\mathrm{L}\end{array}$ & $\begin{array}{c}\text { NI } \\
\text { L }\end{array}$ & $\begin{array}{c}1.0 \\
0\end{array}$ & $\begin{array}{c}0.3 \\
3\end{array}$ \\
\hline 208 & 0 & 0 & 0 & 0 & 1 & 0 & 0 & 0 & 0 & 2 & 1 & 3 & $\begin{array}{c}1.0 \\
0\end{array}$ & $\begin{array}{c}0.6 \\
7\end{array}$ & $\begin{array}{c}1.0 \\
0\end{array}$ & $\begin{array}{c}0.7 \\
2\end{array}$ \\
\hline 133 & 0 & 0 & 0 & 1 & 0 & 0 & 1 & 0 & 0 & 1 & 0 & 2 & $\begin{array}{c}1.0 \\
0\end{array}$ & $\begin{array}{c}0.3 \\
3\end{array}$ & $\begin{array}{c}0.5 \\
0\end{array}$ & $\begin{array}{c}0.3 \\
3\end{array}$ \\
\hline
\end{tabular}




\section{Appendix 1 - Khatami's Operational Code Analysis}

C:ISSA-Collections-

Master Iran $\backslash$ Khatami_Mohammed $\backslash$ Standard $\backslash$ Khatami 20050112.pro

C:ISSA-Collections-

Master $\backslash$ Iran $\backslash$ Khatami_Mohammed $\backslash$ Standard $\backslash$ Khatami 20050112a.pro

C:ISSA-Collections-

Master Iran\Khatami Mohammed $\backslash$ Standard $\backslash$ Khatami 20050115.pro

C:ISSA-Collections-

Master Iran\Khatami_Mohammed $\backslash$ Standard $\backslash$ Khatami 20050115a.pro

C:ISSA-Collections-

Master|Iran\Khatami_Mohammed\Standard\Khatami 20050116.pro

C:ISSA-Collections-

Master Iran\Khatami_Mohammed $\backslash$ Standard $\backslash$ Khatami 20050116a.pro

C:ISSA-Collections-

Master Iran $\backslash$ Khatami Mohammed $\backslash$ Standard $\backslash K h a t a m i$ 20050124.pro

C:ISSA-Collections-

Master Iran\Khatami_Mohammed $\backslash$ Standard $\backslash$ Khatami 20050125.pro

C:ISSA-Collections-

Master Iran $\backslash$ Khatami_Mohammed $\backslash$ Standard $\backslash$ Khatami

20050209 pro

C:ISSA-Collections-

Master Iran $\backslash$ Khatami_Mohammed $\backslash$ Standard $\backslash$ Khatami 20050210.pro

C:ISSA-Collections-

Master|Iran\Khatami_Mohammed $\backslash$ Standard $\backslash$ Khatami

20050226.pro

C:ISSA-Collections-

Master Iran\Khatami_Mohammed $\backslash$ Standard $\backslash$ Khatami 20050301.pro

C:ISSA-Collections-

Master|Iran\Khatami_Mohammed $\backslash$ Standard\Khatami

20050307.pro

C:ISSA-Collections-

Master Iran\Khatami_Mohammed $\backslash$ Standard $\backslash$ Khatami 20050307a.pro

C:ISSA-Collections-

Master|Iran \Khatami_Mohammed $\backslash$ Standard $\backslash$ Khatami

20050309.pro

C:ISSA-Collections-

Master|Iran $\backslash$ Khatami_Mohammed $\backslash$ Standard $\backslash$ Khatami 20050309a.pro

\begin{tabular}{|c|c|c|c|c|c|c|c|c|c|c|c|c|c|c|c|c|}
\hline 566 & 0 & 0 & 2 & 2 & 0 & 0 & 0 & 0 & 4 & 9 & 1 & 3 & $\begin{array}{c}0.0 \\
0\end{array}$ & $\begin{array}{c}0.0 \\
0\end{array}$ & $\begin{array}{c}0.5 \\
3\end{array}$ & $\begin{array}{c}0.3 \\
1\end{array}$ \\
\hline 217 & 0 & 0 & 0 & 1 & 0 & 0 & 1 & 0 & 1 & 2 & 0 & 2 & $\begin{array}{c}1.0 \\
0\end{array}$ & $\begin{array}{c}0.3 \\
3\end{array}$ & $\begin{array}{c}0.3 \\
3\end{array}$ & $\begin{array}{c}0.2 \\
2\end{array}$ \\
\hline 512 & 0 & 0 & 0 & 2 & 0 & 0 & 0 & 0 & 0 & 5 & 0 & 1 & $\begin{array}{c}1.0 \\
0\end{array}$ & $\begin{array}{c}0.3 \\
3\end{array}$ & $\begin{array}{c}1.0 \\
0\end{array}$ & $\begin{array}{c}0.4 \\
4\end{array}$ \\
\hline 178 & 0 & 0 & 0 & 2 & 0 & 0 & 1 & 0 & 0 & 5 & 0 & 0 & $\begin{array}{c}1.0 \\
0\end{array}$ & $\begin{array}{c}0.3 \\
3\end{array}$ & $\begin{array}{c}0.6 \\
7\end{array}$ & $\begin{array}{c}0.1 \\
1\end{array}$ \\
\hline 377 & 0 & 0 & 0 & 3 & 0 & 0 & 1 & 0 & 2 & 2 & 0 & 0 & $\begin{array}{c}1.0 \\
0\end{array}$ & $\begin{array}{c}0.3 \\
3\end{array}$ & $\begin{array}{c}- \\
0.2 \\
0\end{array}$ & $\begin{array}{c}- \\
0.2 \\
0\end{array}$ \\
\hline 190 & 0 & 0 & 0 & 0 & 0 & 0 & 0 & 0 & 0 & 2 & 1 & 1 & $\begin{array}{c}\text { NI } \\
\text { L }\end{array}$ & $\begin{array}{c}\mathrm{NI} \\
\mathrm{L}\end{array}$ & $\begin{array}{c}1.0 \\
0\end{array}$ & $\begin{array}{c}0.5 \\
8\end{array}$ \\
\hline 88 & 0 & 0 & 0 & 0 & 0 & 0 & 1 & 0 & 1 & 3 & 0 & 0 & $\begin{array}{c}\text { NI } \\
\text { L }\end{array}$ & $\begin{array}{c}\mathrm{NI} \\
\mathrm{L}\end{array}$ & $\begin{array}{c}0.2 \\
0\end{array}$ & 0.0 \\
\hline 78 & 0 & 0 & 0 & 0 & 0 & 0 & 0 & 0 & 0 & 2 & 0 & 0 & $\begin{array}{c}\text { NI } \\
\text { L }\end{array}$ & $\begin{array}{c}\mathrm{NI} \\
\mathrm{L}\end{array}$ & $\begin{array}{c}1.0 \\
0\end{array}$ & $\begin{array}{c}0.3 \\
3\end{array}$ \\
\hline 420 & 1 & 0 & 1 & 5 & 0 & 1 & 2 & 1 & 3 & 6 & 1 & 4 & $\begin{array}{c}0.5 \\
0\end{array}$ & $\begin{array}{c}0.1 \\
7\end{array}$ & $\begin{array}{c}0.2 \\
9\end{array}$ & $\begin{array}{c}0.1 \\
8\end{array}$ \\
\hline 93 & 0 & 0 & 0 & 0 & 0 & 0 & 0 & 0 & 2 & 0 & 0 & 0 & $\begin{array}{c}\text { NI } \\
\text { L }\end{array}$ & $\begin{array}{c}\text { NI } \\
\text { L }\end{array}$ & - & $\begin{array}{c}- \\
0.3\end{array}$ \\
\hline 135 & 0 & 0 & 0 & 0 & 0 & 0 & 1 & 0 & 0 & 0 & 0 & 1 & $\begin{array}{c}\text { NI } \\
\text { L }\end{array}$ & $\begin{array}{c}\text { NI } \\
\text { L }\end{array}$ & $\begin{array}{c}0.0 \\
0\end{array}$ & $\begin{array}{c}0.0 \\
0\end{array}$ \\
\hline 138 & 0 & 0 & 0 & 0 & 0 & 0 & 0 & 0 & 2 & 1 & 0 & 2 & $\begin{array}{c}\text { NI } \\
\text { L }\end{array}$ & $\begin{array}{c}\text { NI } \\
\text { L }\end{array}$ & $\begin{array}{c}0.2 \\
0\end{array}$ & $\begin{array}{c}0.3 \\
3\end{array}$ \\
\hline 489 & 0 & 0 & 0 & 0 & 0 & 0 & 3 & 0 & 6 & 7 & 0 & 7 & $\begin{array}{c}\text { NI } \\
\text { L }\end{array}$ & $\begin{array}{c}\text { NI } \\
\text { L }\end{array}$ & $\begin{array}{c}0.2 \\
2\end{array}$ & $\begin{array}{c}0.1 \\
9\end{array}$ \\
\hline 87 & 0 & 0 & 0 & 1 & 0 & 0 & 0 & 1 & 0 & 0 & 0 & 0 & $\begin{array}{c}1.0 \\
0\end{array}$ & $\begin{array}{c}0.3 \\
3\end{array}$ & $\begin{array}{c}- \\
1.0 \\
0\end{array}$ & $\begin{array}{c}- \\
0.6\end{array}$ \\
\hline 566 & 0 & 1 & 0 & 2 & 0 & 2 & 8 & 0 & 1 & 11 & 0 & 8 & $\begin{array}{c}0.6 \\
0\end{array}$ & $\begin{array}{c}0.4 \\
0\end{array}$ & $\begin{array}{c}0.3 \\
6\end{array}$ & $\begin{array}{c}0.1 \\
2\end{array}$ \\
\hline 136 & 0 & 0 & 0 & 0 & 0 & 0 & 0 & 0 & 0 & 2 & 0 & 0 & $\begin{array}{c}\text { NI } \\
\text { L }\end{array}$ & $\begin{array}{c}\text { NI } \\
\text { L }\end{array}$ & $\begin{array}{c}1.0 \\
0\end{array}$ & $\begin{array}{c}0.3 \\
3\end{array}$ \\
\hline
\end{tabular}




\section{Appendix 1 - Khatami's Operational Code Analysis}

C:ISSA-Collections-

Master Iran $\backslash$ Khatami Mohammed $\backslash$ Standard $\backslash$ Khatami 20050314.pro

C:ISSA-Collections-

Master $\backslash$ Iran $\backslash$ Khatami_Mohammed $\backslash$ Standard $\backslash$ Khatami 20050316.pro

C:ISSA-Collections-

Master Iran $\backslash$ Khatami_Mohammed $\backslash$ Standard $\backslash$ Khatam 20050320.pro

C:ISSA-Collections-

Master|Iran\Khatami_Mohammed $\backslash$ Standard $\backslash$ Khatam 20050326.pro

C:ISSA-Collections-

Master Iran $\backslash$ Khatami Mohammed $\backslash$ Standard $\backslash$ Khatami 20050330.pro

C:ISSA-Collections-

Master|Iran\Khatami_Mohammed $\backslash$ Standard $\backslash$ Khatami 20050330a.pro

C:ISSA-Collections-

Master Iran $\backslash$ Khatami Mohammed $\backslash$ Standard $\backslash K h a t a m i$ 20050331.pro

C:ISSA-Collections-

Master Iran\Khatami_Mohammed $\backslash$ Standard $\backslash$ Khatami 20050402.pro

C:ISSA-Collections-

Master Iran $\backslash$ Khatami_Mohammed $\backslash$ Standard $\backslash$ Khatami

20050404 pro

C:ISSA-Collections-

Master Iran\Khatami_Mohammed $\backslash$ Standard\Khatami 20050404a.pro

C:ISSA-Collections-

Master Iran $\backslash$ Khatami Mohammed $\backslash$ Standard $\backslash$ Khatami

20050405.pro

C:ISSA-Collections-

Master Iran\Khatami_Mohammed $\backslash$ Standard $\backslash$ Khatami 20050407.pro

C:ISSA-Collections-

Master Iran\Khatami Mohammed $\backslash$ Standard $\backslash$ Khatami

20050409.pro

C:ISSA-Collections-

Master|Iran\Khatami_Mohammed $\backslash$ Standard\Khatami 20050409a.pro

C:ISSA-Collections-

Master|Iran\Khatami_Mohammed $\backslash$ Standard $\backslash K h a t a m i$ 20050409b.pro

C:ISSA-Collections-

Master Iran $\backslash$ Khatami_Mohammed $\backslash$ Standard $\backslash$ Khatami 20050412.pro

\begin{tabular}{|c|c|c|c|c|c|c|c|c|c|c|c|c|c|c|c|c|}
\hline 179 & 0 & 2 & 0 & 1 & 1 & 1 & 1 & 2 & 2 & 2 & 0 & 0 & $\begin{array}{c}0.2 \\
0\end{array}$ & $\begin{array}{c}0.1 \\
3\end{array}$ & $\begin{array}{c}0.4 \\
3\end{array}$ & $\begin{array}{c}0.3 \\
3\end{array}$ \\
\hline 215 & 1 & 0 & 0 & 0 & 0 & 1 & 1 & 0 & 4 & 2 & 0 & 1 & $\begin{array}{c}0.0 \\
0\end{array}$ & $\begin{array}{c}0.0 \\
0\end{array}$ & $\begin{array}{c}- \\
0.2 \\
5\end{array}$ & $\begin{array}{c}- \\
0.0 \\
8\end{array}$ \\
\hline 1130 & 0 & 0 & 0 & 6 & 0 & 0 & 3 & 0 & 3 & 13 & 1 & 9 & $\begin{array}{c}1.0 \\
0\end{array}$ & $\begin{array}{c}0.3 \\
3\end{array}$ & $\begin{array}{c}0.5 \\
9\end{array}$ & $\begin{array}{c}0.3 \\
4\end{array}$ \\
\hline 110 & 0 & 0 & 1 & 0 & 0 & 0 & 4 & 0 & 0 & 3 & 3 & 0 & \begin{tabular}{|c}
- \\
1.0 \\
0
\end{tabular} & \begin{tabular}{|c}
- \\
0.3 \\
3 \\
\end{tabular} & $\begin{array}{c}0.2 \\
0\end{array}$ & $\begin{array}{c}- \\
0.1 \\
0\end{array}$ \\
\hline 159 & 0 & 0 & 0 & 2 & 0 & 0 & 3 & 0 & 0 & 3 & 0 & 2 & $\begin{array}{c}1.0 \\
0\end{array}$ & $\begin{array}{c}0.3 \\
3\end{array}$ & $\begin{array}{c}0.2 \\
5\end{array}$ & $\begin{array}{c}0.0 \\
0\end{array}$ \\
\hline 159 & 0 & 0 & 0 & 3 & 1 & 0 & 1 & 0 & 0 & 1 & 0 & 0 & $\begin{array}{c}1.0 \\
0\end{array}$ & $\begin{array}{c}0.4 \\
2\end{array}$ & $\begin{array}{c}0.0 \\
0\end{array}$ & $\begin{array}{c}- \\
0.3\end{array}$ \\
\hline 490 & 0 & 0 & 0 & 5 & 1 & 0 & 2 & 1 & 0 & 6 & 1 & 2 & $\begin{array}{c}1.0 \\
0\end{array}$ & $\begin{array}{c}0.3 \\
9\end{array}$ & $\begin{array}{c}0.5 \\
0\end{array}$ & $\begin{array}{c}0.1 \\
7\end{array}$ \\
\hline 149 & 0 & 0 & 0 & 0 & 0 & 0 & 0 & 0 & 0 & 2 & 1 & 0 & $\begin{array}{c}\text { NI } \\
\text { L }\end{array}$ & $\begin{array}{c}\text { NI } \\
\text { L }\end{array}$ & $\begin{array}{c}1.0 \\
0\end{array}$ & $\begin{array}{c}0.4 \\
4\end{array}$ \\
\hline 122 & 0 & 0 & 0 & 1 & 0 & 0 & 0 & 0 & 0 & 6 & 0 & 2 & $\begin{array}{c}1.0 \\
0\end{array}$ & $\begin{array}{c}0.3 \\
3\end{array}$ & $\begin{array}{c}1.0 \\
0\end{array}$ & $\begin{array}{c}0.5 \\
0\end{array}$ \\
\hline 111 & 0 & 0 & 0 & 0 & 0 & 0 & 0 & 0 & 1 & 2 & 1 & 1 & $\begin{array}{c}\text { NI } \\
\text { L }\end{array}$ & $\begin{array}{c}\text { NI } \\
\text { L }\end{array}$ & $\begin{array}{c}0.6 \\
0\end{array}$ & $\begin{array}{c}0.4 \\
0\end{array}$ \\
\hline 125 & 0 & 0 & 0 & 1 & 0 & 0 & 0 & 0 & 0 & 6 & 1 & 0 & $\begin{array}{c}1.0 \\
0\end{array}$ & $\begin{array}{c}0.3 \\
3\end{array}$ & $\begin{array}{c}1.0 \\
0\end{array}$ & $\begin{array}{c}0.3 \\
8\end{array}$ \\
\hline 99 & 0 & 0 & 0 & 0 & 0 & 0 & 0 & 0 & 1 & 2 & 0 & 0 & $\begin{array}{c}\mathrm{NI} \\
\mathrm{L}\end{array}$ & $\begin{array}{c}\mathrm{NI} \\
\mathrm{L}\end{array}$ & $\begin{array}{c}0.3 \\
3\end{array}$ & $\begin{array}{c}0.1 \\
1\end{array}$ \\
\hline 294 & 0 & 0 & 1 & 3 & 0 & 0 & 1 & 0 & 0 & 4 & 2 & 1 & $\begin{array}{c}0.5 \\
0\end{array}$ & $\begin{array}{c}0.1 \\
7\end{array}$ & $\begin{array}{c}0.7 \\
5\end{array}$ & $\begin{array}{c}0.3 \\
3\end{array}$ \\
\hline 418 & 0 & 0 & 1 & 2 & 2 & 0 & 0 & 0 & 1 & 3 & 0 & 1 & $\begin{array}{c}0.6 \\
0\end{array}$ & $\begin{array}{c}0.3 \\
3\end{array}$ & $\begin{array}{c}0.6 \\
0\end{array}$ & $\begin{array}{c}0.3 \\
3\end{array}$ \\
\hline 74 & 0 & 0 & 0 & 0 & 0 & 0 & 1 & 0 & 0 & 0 & 0 & 0 & $\begin{array}{c}\mathrm{NI} \\
\mathrm{L}\end{array}$ & $\begin{array}{c}\text { NI } \\
\text { L }\end{array}$ & $\begin{array}{c}- \\
1.0 \\
0\end{array}$ & $\begin{array}{c}- \\
1.0 \\
0\end{array}$ \\
\hline 745 & 1 & 0 & 1 & 4 & 1 & 2 & 2 & 2 & 2 & 10 & 1 & 8 & $\begin{array}{c}0.5 \\
6\end{array}$ & $\begin{array}{c}0.3 \\
0\end{array}$ & $\begin{array}{c}0.5 \\
2\end{array}$ & $\begin{array}{c}0.3 \\
2\end{array}$ \\
\hline
\end{tabular}




\section{Appendix 1 - Khatami's Operational Code Analysis}

\begin{tabular}{|c|c|c|c|c|c|c|c|c|c|c|c|c|c|c|c|c|c|}
\hline $\begin{array}{l}\text { C:ISSA-Collections- } \\
\text { Master|Iran\Khatami_Mohammed } \backslash \text { Standard } \backslash \text { Khatami } \\
\text { 20050412a.pro }\end{array}$ & 117 & 0 & 0 & 1 & 1 & 0 & 0 & 0 & 1 & 0 & 6 & 0 & 1 & $\begin{array}{c}0.0 \\
0\end{array}$ & $\begin{array}{c}0.0 \\
0\end{array}$ & $\begin{array}{c}0.7 \\
5\end{array}$ & $\begin{array}{c}0.2 \\
9\end{array}$ \\
\hline $\begin{array}{l}\text { C:ISSA-Collections- } \\
\text { Master|Iran } \backslash \text { Khatami_Mohammed } \backslash \text { Standard } \backslash \text { Khatami } \\
\text { 20050417.pro }\end{array}$ & 98 & 1 & 0 & 0 & 0 & 0 & 0 & 0 & 1 & 0 & 2 & 0 & 1 & \begin{tabular}{|c|}
- \\
1.0 \\
0 \\
\end{tabular} & \begin{tabular}{|c|}
- \\
1.0 \\
0 \\
\end{tabular} & $\begin{array}{c}0.5 \\
0\end{array}$ & $\begin{array}{c}0.2 \\
5\end{array}$ \\
\hline $\begin{array}{l}\text { C:ISSA-Collections- } \\
\text { Master|Iran\Khatami_Mohammed } \backslash \text { Standard } \backslash \text { Khatami } \\
\text { 20050418.pro }\end{array}$ & 967 & 1 & 0 & 0 & 3 & 0 & 1 & 2 & 0 & 2 & 7 & 0 & 7 & $\begin{array}{c}0.6 \\
0\end{array}$ & $\begin{array}{c}0.2 \\
0\end{array}$ & $\begin{array}{c}0.5 \\
6\end{array}$ & $\begin{array}{c}0.3 \\
7\end{array}$ \\
\hline $\begin{array}{l}\text { C:ISSA-Collections- } \\
\text { Master|Iran } \backslash \text { Khatami_Mohammed } \backslash \text { Standard } \backslash \text { Khatami } \\
\text { 20050422.pro }\end{array}$ & 122 & 0 & 0 & 0 & 1 & 0 & 0 & 0 & 0 & 0 & 3 & 1 & 1 & $\begin{array}{c}1.0 \\
0\end{array}$ & $\begin{array}{c}0.3 \\
3\end{array}$ & $\begin{array}{c}1.0 \\
0\end{array}$ & $\begin{array}{c}0.5 \\
3\end{array}$ \\
\hline $\begin{array}{l}\text { C:ISSA-Collections- } \\
\text { Master|Iran } \backslash \text { Khatami_Mohammed } \backslash \text { Standard } \backslash \text { Khatami } \\
\text { 20050424.pro }\end{array}$ & 115 & 0 & 0 & 0 & 0 & 0 & 0 & 3 & 0 & 2 & 2 & 0 & 0 & $\begin{array}{c}\mathrm{NI} \\
\mathrm{L}\end{array}$ & $\begin{array}{c}\text { NI } \\
\text { L }\end{array}$ & \begin{tabular}{|c|}
0.4 \\
3 \\
\end{tabular} & \begin{tabular}{|c|}
0.4 \\
3 \\
\end{tabular} \\
\hline $\begin{array}{l}\text { C:ISSA-Collections- } \\
\text { Master|Iran } \backslash \text { Khatami_Mohammed } \backslash \text { Standard } \backslash \text { Khatami } \\
\text { 20050501.pro }\end{array}$ & 115 & 0 & 0 & 0 & 2 & 0 & 0 & 1 & 0 & 0 & 1 & 0 & 0 & $\begin{array}{c}1.0 \\
0\end{array}$ & $\begin{array}{c}0.3 \\
3\end{array}$ & $\begin{array}{c}0.0 \\
0\end{array}$ & \begin{tabular}{|c|}
- \\
0.3 \\
3 \\
\end{tabular} \\
\hline $\begin{array}{l}\text { C:ISSA-Collections- } \\
\text { Master|Iran } \backslash \text { Khatami_Mohammed } \backslash \text { Standard } \backslash \text { Khatami } \\
\text { 20050502.pro }\end{array}$ & 125 & 0 & 0 & 0 & 1 & 0 & 1 & 0 & 0 & 0 & 2 & 0 & 0 & $\begin{array}{c}1.0 \\
0\end{array}$ & $\begin{array}{c}0.6 \\
7\end{array}$ & $\begin{array}{c}1.0 \\
0\end{array}$ & $\begin{array}{c}0.3 \\
3\end{array}$ \\
\hline $\begin{array}{l}\text { C:ISSA-Collections- } \\
\text { Master|Iran } \backslash \text { Khatami_Mohammed } \backslash \text { Standard } \backslash \text { Khatami } \\
\text { 20050504.pro }\end{array}$ & 1430 & 0 & 0 & 0 & 1 & 0 & 0 & 6 & 4 & 11 & 11 & 1 & 2 & $\begin{array}{c}1.0 \\
0\end{array}$ & $\begin{array}{c}0.3 \\
3\end{array}$ & \begin{tabular}{|c|}
- \\
0.2 \\
0 \\
\end{tabular} & \begin{tabular}{|c|}
- \\
0.1 \\
7 \\
\end{tabular} \\
\hline $\begin{array}{l}\text { C:ISSA-Collections- } \\
\text { Master|Iran } \backslash \text { Khatami_Mohammed } \backslash \text { Standard } \backslash \text { Khatami } \\
\text { unknown.pro }\end{array}$ & 692 & 0 & 0 & 0 & 3 & 0 & 1 & 2 & 1 & 0 & 7 & 1 & 1 & $\begin{array}{c}1.0 \\
0\end{array}$ & $\begin{array}{c}0.5 \\
0\end{array}$ & $\begin{array}{c}0.5 \\
0\end{array}$ & $\begin{array}{c}0.1 \\
1\end{array}$ \\
\hline & & & & & & & & & & & & & & & & & \\
\hline & & & & & & & & & & & & & $\begin{array}{c}\text { Averag } \\
\mathrm{e}\end{array}$ & $\begin{array}{c}0.6 \\
4\end{array}$ & $\begin{array}{c}0.2 \\
7\end{array}$ & $\begin{array}{c}0.3 \\
9\end{array}$ & $\begin{array}{c}0.1 \\
7 \\
\end{array}$ \\
\hline
\end{tabular}


Appendix 2

Text Analysis 


\begin{tabular}{|c|c|}
\hline Date & Text \\
\hline 19990310 & $\begin{array}{l}\text { Speech at Italian Parliament, emphasizes on genuine peace, through justice, tolerance, } \\
\text { exchange of views, and act accordingly; argues that tolerance leads to dialogue, and } \\
\text { intolerance culminates in war, criticizes the application of double standards in } \\
\text { relationship between "themselves" and "others". }\end{array}$ \\
\hline 20031210 & $\begin{array}{l}\text { World Summit on the Information Society, Geneva, emphasizes cultural diversity as } \\
\text { the foundation for the common existence of human society, commitment to ethical } \\
\text { values, human rights and principles of democracy and instruments of "good } \\
\text { governance". }\end{array}$ \\
\hline 20020701 & $\begin{array}{l}\text { Address to the Institute for Strategic and International Studies, argues for a "dialogue } \\
\text { of civilizations" as necessary for diplomatic peace as opposed to the traditional idea } \\
\text { that countries must be prepared for war; scholars, intellectuals, citizens, and } \\
\text { government at forefront of movement. }\end{array}$ \\
\hline 20020701 & $\begin{array}{l}\text { Address to Malaysian and Iranian Entrepreneurs Kuala Lumpur, current world one of } \\
\text { increased international communication, greater access to knowledge; changes in the } \\
\text { nature of 'national security' and 'national development'; countries need to cooperate } \\
\text { with alliances and dialogues; encourages economic relations with Iran. }\end{array}$ \\
\hline 20021204 & $\begin{array}{l}\text { Address to Conference of the Elite Scholars and Thinkers of Pakistan, discusses the } \\
\text { religious philosophical works of Allameh Mohammad Eghbal including Islamic } \\
\text { heritage and culture; criticizes the West and Muslims who give into their values the } \\
\text { idea of war. }\end{array}$ \\
\hline 20021225 & $\begin{array}{l}\text { Address to the Conference of The Iranian and Pakistani Businessmen, encourages } \\
\text { economic cooperation between Pakistan and Iran; encourages regional cooperation as } \\
\text { well. }\end{array}$ \\
\hline 20030224 & $\begin{array}{l}\text { Statements delivered at the XIII Summit of the Non-Aligned Movement Kuala } \\
\text { Lumpur, encourages the Non-Aligned Movement to counter the super powers. }\end{array}$ \\
\hline
\end{tabular}




\begin{tabular}{|c|c|}
\hline 20030513 & $\begin{array}{l}\text { Address at the Gathering of the People of Beirut, praises Lebanon for its solidarity in } \\
\text { spite of suppression and war; underlines the conflict in Iraq and other Middle Eastern } \\
\text { countries and expresses dismay at U.S. tactics to intervene. }\end{array}$ \\
\hline 20030514 & $\begin{array}{l}\text { Address at the Parliament of Lebanon, praises Lebanon's resistance and democracy; } \\
\text { attributes success of resistance to institution of democracies and change in world } \\
\text { economy; criticizes United State's military dominance citing increased global } \\
\text { division; encourages further development of common goals. }\end{array}$ \\
\hline $20030514 a$ & $\begin{array}{l}\text { Address at the University of Beirut, addresses the importance of universities to further } \\
\text { scientific and political thought; highlights current and past ties between } \\
\text { philosophy,science and society; stresses importance of spirituality and ethics. }\end{array}$ \\
\hline 20031009 & $\begin{array}{l}\text { Interview with reporters in Tehran, talks about death of prisoner Zahra Kazemi; } \\
\text { conflicts with the Majles and the Supreme National Security Council; talks about } \\
\text { current situations with upcoming elections, the Cultural Revolution Council and } \\
\text { treatment of political prisoners; on dispute with U.S. over nuclear development. }\end{array}$ \\
\hline 20031017 & $\begin{array}{l}\text { News Conference at OIC Summit, states that he hopes conference will strengthen } \\
\text { bonds between Islamic nations; affirms Iran's good relationship with Russia; verifies } \\
\text { Iran's commitment to non-proliferation, but states Iran will continue peaceful nuclear } \\
\text { technology. }\end{array}$ \\
\hline 20031019 & $\begin{array}{l}\text { Interview with reporters after ceremony for cooperation with Algeria, says Iran not } \\
\text { threatened by imminent visits by European Ministers; will try to comply with them; } \\
\text { hopes they will recognize Iran's right to nuclear technology. }\end{array}$ \\
\hline 20031211 & $\begin{array}{l}\text { News Conference in Geneva, notes good relationship with Egypt; says Iran and Egypt } \\
\text { have similar political goals; in response to questions mentions the fact that Iran wants } \\
\text { peace in the Balkans and is willing to help them with IT systems; notes vast } \\
\text { communications system and denies censorship of American and British media; } \\
\text { stresses importance of freedom of speech and the release of wrongly accused } \\
\text { prisoners; stresses good relationship with Algeria. }\end{array}$ \\
\hline
\end{tabular}




\begin{tabular}{|c|c|}
\hline 20031217 & $\begin{array}{l}\text { Interview with the Iranian Student News Agency, condones death penalty, says } \\
\text { nobody will neglect the upcoming elections. }\end{array}$ \\
\hline 20031223 & $\begin{array}{l}\text { Press conference in Tehran, discusses the situation of political prisoners; hopes Majles } \\
\text { keep national interests in mind. }\end{array}$ \\
\hline 20031230 & $\begin{array}{l}\text { Interview with Iran Student News Agency, offers condolences to survivors of the Bam } \\
\text { disaster; criticizes the U.S. for trying not cooperating with Iran and for putting pressure } \\
\text { to stop developing nuclear fuel; wants to ensure U.S. respects Iranian territorial } \\
\text { integrity. }\end{array}$ \\
\hline 20040107 & $\begin{array}{l}\text { Discusses the Bam earthquake, how it has brought people together; use intercultural } \\
\text { dialogue to ease human suffering; encourages international dialogue through centers } \\
\text { and universities and teachings between nations. }\end{array}$ \\
\hline 20040131 & $\begin{array}{l}\text { Speaking to reporters, says Iran will make its own decisions and act in its own interest; } \\
\text { acknowledges other countries who have helped and protected Iran; Islamic Republic } \\
\text { must be protected by anyone who believes in it. }\end{array}$ \\
\hline 20040427 & $\begin{array}{l}\text { Speech to intellectuals at Tehran University, encourages successful upcoming } \\
\text { election; encourages the merging of culture and politics to gain world sympathy and } \\
\text { promote peace; wants cultural dialogue between nations and states that this was } \\
\text { apparent at a recent meeting of UNESCO; is grateful to scientists, philosophers who } \\
\text { have made cultural dialogue possible. }\end{array}$ \\
\hline 200040521 & $\begin{array}{l}\text { Speech at the commemoration conference Mulla Sadra, discusses Islamic } \\
\text { philosophers, their philosophies and their importance to society. }\end{array}$ \\
\hline 20040606 & $\begin{array}{l}\text { Speech at e-Commerce Conference in Tehran, technological advances is indispensable } \\
\text { in today's world and necessary for survival; Iran has adjust its Macro National Plan to } \\
\text { accommodate the growth of ICT; notes that the commerce ministry has taken on e- } \\
\text { Commerce, and advancements must be applied to private sector; encourages further } \\
\text { usage of e-commerce and ICT. }\end{array}$ \\
\hline
\end{tabular}




\begin{tabular}{|c|c|}
\hline 20040610 & $\begin{array}{l}\text { Video message to Euro-Asia Conference on dialogue, states "dialogue between } \\
\text { cultures and civilizations" is a necessary step to establishing world peace; to make this } \\
\text { successful it must be applied also to economics; can be used to curb terrorism. }\end{array}$ \\
\hline 20040806 & $\begin{array}{l}\text { Speech at the parliament of the Republic of Azerbaijan, discusses the nature of } \\
\text { civilizations; notes today's tendency towards democracy; stresses the importance of } \\
\text { cultural dialogue to help transition to democracy and use states' potential. }\end{array}$ \\
\hline 20040807 & $\begin{array}{l}\text { Speech to Academy of Science in Azerbaijan, encourages the use of dialogue between } \\
\text { nations, stressing the importance this has towards global understanding and preventing } \\
\text { wars and terrorism. }\end{array}$ \\
\hline 20040908 & $\begin{array}{l}\text { Acknowledges the rise of democracy and stresses the need to re-examine the nature } \\
\text { of democracy and how it interacts with world society. }\end{array}$ \\
\hline 20040909 & $\begin{array}{l}\text { Speech at the State University of Yerevan, talks about the cultural and political bond } \\
\text { between Armenia and Iran; stresses the importance of cultural dialogue for good } \\
\text { international relations; encourages continued cooperation between Armenia and Iran. }\end{array}$ \\
\hline 20040912 & $\begin{array}{l}\text { News Conference in Dushanbe, discusses the importance of Russian cooperation with } \\
\text { Iran; praises Russia and Tajikistan for supporting Iran and nuclear developments. }\end{array}$ \\
\hline 20040914 & $\begin{array}{l}\text { Speech at the 8th Summit meeting of ECO, questions the logic of "State terrorism" } \\
\text { who intervene in countries to stop terrorism; calls for aid from ECO to help rebuilding } \\
\text { of Afghanistan; encourages the integration of new programs in ECO specifically } \\
\text { economic related ones. }\end{array}$ \\
\hline 20040921 & $\begin{array}{l}\text { Speech at annual army parade, reflects on the nature of the Iranian revolution and } \\
\text { subsequent 8-year war; attributes Iran's success to its military forces. }\end{array}$ \\
\hline 20040922 & $\begin{array}{l}\text { Speech on radio Iran, discusses the current educational system and reassures public } \\
\text { that steps are being taken to correct problems; reflects on Iranian nationalism and the } \\
\text { role of religion in Iran. }\end{array}$ \\
\hline
\end{tabular}




\begin{tabular}{|c|c|}
\hline $20041002 \mathrm{a}$ & $\begin{array}{l}\text { Speech at economic delegation in Algeria, shares Iran's strategies to dealing with } \\
\text { sanctions by the West; encourages dialogue between states; says that Islamic and } \\
\text { Arabic states have a special place in Iran's foreign policy; promotes cooperation and } \\
\text { expansion in Africa and the Middle East; describes Iran's goal of global peace and } \\
\text { security. }\end{array}$ \\
\hline 20041005 & $\begin{array}{l}\text { Speech at ceremony in Khartoum, encourages dialogue between Muslim nations and } \\
\text { the West. }\end{array}$ \\
\hline 20041006 & $\begin{array}{l}\text { Speaking to reporters in Khartoum, maintains Iran's commitment to the Non- } \\
\text { Proliferation Treaty and its willingness to host inspectors; stresses that Iran plans to } \\
\text { continue its development of nuclear technology; criticizes Iraqi occupation. }\end{array}$ \\
\hline 20041008 & $\begin{array}{l}\text { Press conference in Tehran, states that visits to Syria, Oman, Sudan, and Algeria were } \\
\text { successful; visits aimed at boosting harmony and solidarity; proposes increased } \\
\text { economic ties with Algeria and technological assistance to Sudan; criticizes Iraqi } \\
\text { occupation; criticizes the way in which the West has dealt with the crisis in Darfur. }\end{array}$ \\
\hline 20041012 & $\begin{array}{l}\text { Message to the } 12 \text { th International Conference on Central Asia and the Caucasus, urges } \\
\text { regional countries to look to alternate renewable energy sources possibly from the } \\
\text { Caspian Sea. }\end{array}$ \\
\hline 20041016 & $\begin{array}{l}\text { Speech at 10th OIE Summit, states the uniting factor in the OIC is Islam; religious } \\
\text { democracy cannot survive through coercion and violence; criticizes Israeli terrorism; } \\
\text { urges Islamic nations to adopt stance for peace and urge the withdrawal of forces from } \\
\text { Iraq and Palestinian sovereignty; Iran reaffirms its commitment to peace and justice } \\
\text { and non-proliferation. }\end{array}$ \\
\hline 20041021 & $\begin{array}{l}\text { Speech at National Export Day Ceremony, cites growing technical exports as a result } \\
\text { of Iran's improved global status; urges this trend to continue, committed government } \\
\text { funds and training new workers. }\end{array}$ \\
\hline $20041102 \mathrm{a}$ & Briefing reporters, defends Iran's right to develop peaceful nuclear technology. \\
\hline
\end{tabular}




\begin{tabular}{|c|c|}
\hline 20041104 & $\begin{array}{l}\text { Speech marking the martyrdom of the first Shiite Iman, criticizes current state of } \\
\text { violence and terrorism in the world citing specifically apartheid in Africa and the } \\
\text { liberation of Palestine. }\end{array}$ \\
\hline 20041117 & $\begin{array}{l}\text { Speech at the opening of the Research Academy of Iran's Philosophy Institute, } \\
\text { discusses the nature of philosophy particularly in relation to its importance in politics; } \\
\text { discusses the nature of Islam and its historical relationship to politics. }\end{array}$ \\
\hline 20041117 & $\begin{array}{l}\text { Speech on Islamic Republic of Iran Network, defends Iran's right to develop nuclear } \\
\text { technology; maintains that Iran does not want confrontation and is in agreements with } \\
\text { the International Atomic Energy Agency and is open to further negotiation with } \\
\text { Europe. }\end{array}$ \\
\hline 20041117 & $\begin{array}{l}\text { Speech at National Council for Globalisation, stresses that government and population } \\
\text { should be open to changes but choose policies that underpin ethnic values and national } \\
\text { interests. }\end{array}$ \\
\hline 20041117 & $\begin{array}{l}\text { Speaking with reporters after cabinet meeting, emphasizes on Iran's peaceful nuclear } \\
\text { technology; discusses the problems of Iraqi occupation; states Iran will help Iraq in } \\
\text { establishing security. }\end{array}$ \\
\hline 20041129 & $\begin{array}{l}\text { Interview with reporters in Tehran, argues for Iran's right to nuclear technology; } \\
\text { speaks about planned dialogues with European states; maintains good relationship } \\
\text { with Venezuela. }\end{array}$ \\
\hline 20041207 & $\begin{array}{l}\text { Speech marking International Anti-Corruption Day, affirms government's } \\
\text { commitment to limiting corruption given democracy's guarantee of human rights; } \\
\text { states that government has taken steps towards development, reducing its role in } \\
\text { economics. }\end{array}$ \\
\hline 20041212 & $\begin{array}{l}\text { Meeting with Sergei Mironov, expresses interest in regional security; expresses Iran's } \\
\text { and Russia's opposition to terrorism; wants a regional regime of five states bordering } \\
\text { the Caspian Sea; stresses commitment of bilateral trade with Russia. }\end{array}$ \\
\hline 20041213 & $\begin{array}{l}\text { Address to a gathering titled 'Rule of the Constitution', stresses the importance of } \\
\text { Constitution in maintaining rights and stability; stresses there is no conflict between } \\
\text { Islam and democracy. }\end{array}$ \\
\hline
\end{tabular}




\begin{tabular}{|c|c|}
\hline 20050109 & $\begin{array}{l}\text { Speech at open Majles session, submits government bill for } 2005 \text { and the fourth } \\
\text { development plan; Iran moving toward a national privatized economy; goes in detail } \\
\text { over the effects of the third development plan and plans for the fourth citing } \\
\text { specifically the implementation of welfare and the use of oil for revenue; hopes this } \\
\text { will better foreign trade, unemployment, increase decentralization of economy. }\end{array}$ \\
\hline 20050111 & $\begin{array}{l}\text { Speech at dinner banquet in Abuja, confirms policy of cooperation with Nigeria; } \\
\text { commits to support development and industrialization there; urges bilateral } \\
\text { cooperation between both countries; expresses satisfaction with recent visit to Nigeria; } \\
\text { criticizes situation in Iraq; maintains good relations with African nations. }\end{array}$ \\
\hline 20050112 & $\begin{array}{l}\text { Speaking to Nigerian elite-Iran against occupation of Iraq and Afghanistan; criticizes } \\
\text { the situation between Israel and Palestine saying Palestine should choose its own fate; } \\
\text { criticizes the use of force instead of looking for peaceful solutions; criticizes West's } \\
\text { approach of dealing with Middle East; stresses need for dialogue with West; notes } \\
\text { Iran's success in manufacturing experimental AIDS drugs. }\end{array}$ \\
\hline $20050116 a$ & $\begin{array}{l}\text { Addressing intellectuals in Iran Culture House, urges young Muslims to go out and } \\
\text { acquire skills; advocates solidarity among Islamic nations; acknowledges strong ties } \\
\text { with Africa. }\end{array}$ \\
\hline 20050124 & $\begin{array}{l}\text { Interview with reporters in Azerbaijan, says Karabakh conflict will be resolved } \\
\text { through negotiation; stresses Iran's good relationship with Azerbaijan and Armenia, } \\
\text { willing to mediate conflict; condemns occupation of any country. }\end{array}$ \\
\hline 20050209 & $\begin{array}{l}\text { Speech to gathering of ambassadors for international organizations-Affirms Iran's } \\
\text { right to peaceful nuclear technology; Iran has suspended uranium enrichment to show } \\
\text { its goodwill. }\end{array}$ \\
\hline 20050301 & $\begin{array}{l}\text { Message to the } 15 \text { th International Conference of the Persian Gulf, says Iran will help } \\
\text { Iraq achieve a democratic nation; stresses solidarity among Islamic nations; condemns } \\
\text { any military occupation. }\end{array}$ \\
\hline 20050307 & $\begin{array}{l}\text { Address at University of Zagreb, asserts the importance of intellectuals in today's } \\
\text { world, and not using knowledge ignorantly; notes the ever presence of wars. }\end{array}$ \\
\hline
\end{tabular}




\begin{tabular}{|c|c|}
\hline 20050307 & $\begin{array}{l}\text { Lecture at Croatian Science Academy, Stresses the importance of dialogue between } \\
\text { countries in order to eradicate violence. }\end{array}$ \\
\hline 20050309 & $\begin{array}{l}\text { Speech in Sarajevo, calls for world peace among nations with the cooperation of } \\
\text { Islamic ones; expresses admiration for Bosnian people and their struggle; advocates } \\
\text { global support for the reconstruction of Bosnia-Herzegovina; stresses importance of } \\
\text { Bosnian Muslims representing peaceful coexistence. }\end{array}$ \\
\hline 20050314 & $\begin{array}{l}\text { Speech at the Iran Nuclear Energy Council, explains that the development of nuclear } \\
\text { energy is key to development; criticizes unreasonable pressure put on Iran by western } \\
\text { countries; maintains Iran's commitment to non-proliferation and its accordance to } \\
\text { standards of NPT; states that five proposals have been sent to European nations. }\end{array}$ \\
\hline 20050316 & $\begin{array}{l}\text { Speaking to reporters in Esfahan, blames large part of current crises in the Middle East } \\
\text { is due to U.S. policies; maintains Iran's position for nuclear technology; talks of } \\
\text { cooperation with the UN and European nations vis a vis the Paris talks to begin } \\
\text { peaceful development of nuclear technology; refuses to negotiate with the U.S. }\end{array}$ \\
\hline 20050330 & $\begin{array}{l}\text { Speaking with reporter after visits to Esfahan and Natanz, states commitment to } \\
\text { peaceful development of nuclear energy; criticizes U.S. policies regarding Iran's } \\
\text { nuclear technology. }\end{array}$ \\
\hline 20040530 & $\begin{array}{l}\text { Press conference in Iran, wishes to continue talk with Europe; Iran's commitment to } \\
\text { a nuclear free Middle East; states that nuclear armament is destructive and undermines } \\
\text { development; encourages Europe to stick to its agreements. }\end{array}$ \\
\hline 20050404 & $\begin{array}{l}\text { Joint press conference with Austrian President Heins Fischer, maintains right to } \\
\text { peaceful nuclear technology; sites cooperation with additional protocol of the NPT; } \\
\text { IAEA acknowledges Iran's following of protocol; Iran ready to sign contracts with } \\
\text { Europe and US to produce } 8,000 \text { megawatts of electricity. }\end{array}$ \\
\hline 20050405 & $\begin{array}{l}\text { Press conference in Paris, Iran will continue suspension of uranium enrichment as long } \\
\text { as negotiations continue; talks with Chirac cover nuclear issues and bilateral relations. }\end{array}$ \\
\hline
\end{tabular}




\begin{tabular}{|l|l|}
\hline 20050409 & $\begin{array}{l}\text { Comments to Swiss newspaper, discusses nuclear development and other } \\
\text { achievements; says it's time for European nations to recognize Iran's right to nuclear } \\
\text { technology; does not wish to open discussion with the U.S. }\end{array}$ \\
\hline 20050409 & $\begin{array}{l}\text { Interview with Iran Network, says Iran does not trust U.S. as broker of peace plans as } \\
\text { it is not trustworthy; wants Europe involved in peace talks. }\end{array}$ \\
\hline 20050409 & $\begin{array}{l}\text { Interview with Iran Radio, speaks about meetings with Austria, France, and Italy over } \\
\text { nuclear negotiation; mentions their support; prepared to open discussions to provide } \\
\text { frameworks and regulations for development of nuclear technology. }\end{array}$ \\
\hline 20050412 & $\begin{array}{l}\text { Meeting with Saparmyrat Nyyazow, shows solidarity between Turks and Iranians; } \\
\text { suggests making people more satisfied with system by improving development and } \\
\text { economy; discusses bilateral relations with Turkey, citing the Caspian Sea legal } \\
\text { regime and joint projects. }\end{array}$ \\
\hline 20050422 & \begin{tabular}{l} 
Message to Pope Benedict XVI, congratulations regarding his election as Pope. \\
\hline 20050502
\end{tabular} \\
$\begin{array}{l}\text { Meeting with new Australian Ambassador Gregory Lawrence, Iran welcomes } \\
\text { economic and political ties with Australia; Iran wants stability and spread of } \\
\text { democracy in Middle East; maintains importance of reconstruction in Iraq; maintains } \\
\text { right to nuclear technology, leaves door open to future negotiations. }\end{array}$ \\
\hline
\end{tabular}


Appendix 3

Documents on International Meetings and Conferences 
Appendix 3 - Documents on International Meetings and Conferences

\begin{tabular}{|c|c|c|}
\hline Document & Date & Summary \\
\hline $\mathrm{A} / \mathrm{RES} / 56 / 6$ & $\begin{array}{l}21 / 11 / 200 \\
1\end{array}$ & Global Agenda for Dialogue among Civilizations. \\
\hline $\mathrm{A} / \mathrm{RES} / 56 / 3$ & $11 / 5 / 2001$ & $\begin{array}{l}\text { Decides to convene the plenary meetings devoted to "United } \\
\text { Nations Year } \quad \text { of Dialogue } \\
\text { Civilizations" on } 8 \text { and } 9 \text { November } 2001 .\end{array}$ \\
\hline $\mathrm{A} / \mathrm{RES} / 55 / 23$ & $\begin{array}{l}13 / 11 / 200 \\
0\end{array}$ & $\begin{array}{l}\text { Decides to include the provisional agenda of its fifty-sixth } \\
\text { session of "United Nations Year of } \\
\text { Dialogue among Civilizations". }\end{array}$ \\
\hline $\begin{array}{l}\text { A/55/492/Rev. } \\
1\end{array}$ & $9 / 11 / 2000$ & $\begin{array}{l}\text { United Nations Year of Dialogue among Civilizations: } \\
\text { Report of the Secretary-General }\end{array}$ \\
\hline A/RES/54/113 & $\begin{array}{l}10 / 12 / 199 \\
9\end{array}$ & $\begin{array}{l}\text { Decides to include the provisional agenda of the } \\
\text { fifty-third session of the General Assembly on } \\
\text { "The United Nations Year of Dialogue among } \\
\text { Civilizations". }\end{array}$ \\
\hline $\mathrm{A} / \mathrm{RES} / 53 / 22$ & $\begin{array}{l}16 / 11 / 199 \\
8\end{array}$ & $\begin{array}{l}\text { Proclaims the year } 2001 \text { as the United Nations Year of } \\
\text { Dialogue among Civilizations. }\end{array}$ \\
\hline
\end{tabular}

\begin{tabular}{|l|l|l|}
\hline \multicolumn{3}{|l|}{ Table 2: UNESCO Decisions/Resolutions/Declarations } \\
\hline Document & Date & Summary \\
\hline Resolution 25 & $02 / 11 / 2001$ & $\begin{array}{l}31 \text { C/Resolution 25 adopted by the UNESCO General } \\
\text { Conference: UNESCO Universal Declaration on Cultural } \\
\text { Diversity }\end{array}$ \\
\hline Resolution 39 & $20 / 10 / 2001$ & $\begin{array}{l}31 \text { C/Resolution 39 adopted by the UNESCO General } \\
\text { Conference: Call for international co-operation to prevent and } \\
\text { eradicate acts of terrorism. }\end{array}$ \\
\hline 161 EXIINF.14 & $21 / 05 / 2001$ & $\begin{array}{l}\text { Report of the Director-General of UNESCO on the Execution } \\
\text { of the Programme adopted by the General Conference: United } \\
\text { Nations Year of Dialogue among Civilizations - UNESCO } \\
\text { Framework for Action }\end{array}$ \\
\hline Resolution 31 & $17 / 11 / 1999$ & $\begin{array}{l}\text { 30 C/Resolution 31 adopted by the UNESCO General } \\
\text { Conference: Preparation by UNESCO of the United Nations } \\
\text { Year of Dialogue among Civilizations }\end{array}$ \\
\hline Source: (Zaccara, 2016:67)
\end{tabular}


Appendix 3 - Documents on International Meetings and Conferences

\begin{tabular}{|c|c|c|}
\hline Date & Title & Location \\
\hline $\begin{array}{l}20-21 \\
\text { June } 2006\end{array}$ & $\begin{array}{l}\text { African Regional Conference on the Dialogue among } \\
\text { Civilizations, Cultures and Peoples }\end{array}$ & Abuja, Nigeria \\
\hline $\begin{array}{l}1-2 \\
\text { June } 2006\end{array}$ & $\begin{array}{l}\text { Communication of Heritage: A New Vision of } \\
\text { Southeast Europe }\end{array}$ & Opatija, Croatia \\
\hline $\begin{array}{l}\text { 14-16 } \\
\text { June } 2005\end{array}$ & $\begin{array}{l}\text { Conference on Fostering Dialogue among Cultures } \\
\text { and Civilizations through Concrete and Sustained } \\
\text { Action }\end{array}$ & $\begin{array}{l}\text { Rabat, Kingdom of } \\
\text { Morocco }\end{array}$ \\
\hline $\begin{array}{l}6 \text { to } 8 \\
\text { May } 2005\end{array}$ & Dialogue Among Civilizations: Islam and the West & $\begin{array}{l}\text { Laval University, Sainte- } \\
\text { Foy, Quebec, Canada }\end{array}$ \\
\hline $\begin{array}{l}20-22 \\
\text { December } \\
2004\end{array}$ & $\begin{array}{l}\text { Asia-Pacific Regional Conference on "Dialogue } \\
\text { Among Cultures and Civilizations for Peace and } \\
\text { Sustainable Development" }\end{array}$ & Hanoi, Vietnam \\
\hline $\begin{array}{l}9-10 \\
\text { December } \\
2004\end{array}$ & $\begin{array}{l}\text { Regional Summit on Inter-religious and Inter-ethnic } \\
\text { Dialogue }\end{array}$ & Tirana, Albania \\
\hline $\begin{array}{l}4-6 \\
\text { October } \\
2004\end{array}$ & $\begin{array}{l}\text { Second International Conference on Turkic } \\
\text { Civilization: The Role and Place of the Turkic } \\
\text { Civilization amongst World Civilizations }\end{array}$ & Bishkek, Kyrgyzstan \\
\hline $\begin{array}{l}\text { 6-8 } \\
\text { September } \\
2004\end{array}$ & $\begin{array}{l}\text { "New Ignorance, New Literacies - } \\
\text { Learning to Live Together in a Globalizing World" }\end{array}$ & Barcelona, Spain \\
\hline $\begin{array}{l}10-11 \\
\text { June } 2004\end{array}$ & $\begin{array}{l}\text { High Level Conference Eurasia in the } 21^{\text {st }} \text { Century - } \\
\text { Dialogue of Cultures or Conflict of Civilizations? }\end{array}$ & Issyk Kul, Kyrgyzstan \\
\hline $\begin{array}{l}10 \quad-11 \\
\text { February } \\
2004\end{array}$ & $\begin{array}{l}\text { Colloquium on the Dialogue among Civilizations and } \\
\text { Cultures }\end{array}$ & Sana' a, Yemen \\
\hline $\begin{array}{ll}17 & -19 \\
\text { January } & \\
2004 & \\
\end{array}$ & $\begin{array}{l}\text { Euro Mediterranean Forum for Science, } \\
\text { Development \& Peace: The "Clash of Civilizations" } \\
\text { will not take place }\end{array}$ & $\begin{array}{l}\text { UNESCO HQ, Paris, } \\
\text { France }\end{array}$ \\
\hline $\begin{array}{l}15-1 \\
\text { December } \\
2003\end{array}$ & $\begin{array}{l}\text { International Congress on Dialogue of Civilization, } \\
\text { Religion and Cultures in West Africa }\end{array}$ & Abuja, Nigeria \\
\hline $\begin{array}{l}17-21 \\
\text { November } \\
2003\end{array}$ & $\begin{array}{l}\text { International Conference on Intercultural Dialogue } \\
\text { and a Culture of Peace in Central Africa and the Great } \\
\text { Lakes Region }\end{array}$ & Libreville, Gabon \\
\hline $\begin{array}{l}9-11 \\
\text { November } \\
2003\end{array}$ & $\begin{array}{l}\text { International Experts' Symposium on A Culture of } \\
\text { Innovation and the Building of Knowledge Societies }\end{array}$ & Moscow, Russia \\
\hline $\begin{array}{l}29 \& 30 \\
\text { August } 2003\end{array}$ & Regional Forum on Dialogue among Civilizations & Ohrid, Macedonia \\
\hline $\begin{array}{l}30 \& 31 \\
\text { July } 2003\end{array}$ & Globalization with a Human Face - Benefiting All & Tokyo, Japan \\
\hline
\end{tabular}


Appendix 3 - Documents on International Meetings and Conferences

\begin{tabular}{|l|l|l|}
\hline $\begin{array}{l}9 \& 10 \\
\text { July } 2003\end{array}$ & $\begin{array}{l}\text { International Ministerial Conference on the Dialogue } \\
\text { among Civilizations Quest for New Perspectives }\end{array}$ & New Delhi, India \\
\hline
\end{tabular}

Source: (Zaccara, 2016: 67-68)

\begin{tabular}{|c|c|c|}
\hline Date & Title & Location \\
\hline $\begin{array}{l}26-29 \\
\text { November } \\
2005\end{array}$ & First meeting of the Alliance of Civilizations High-level Group & $\begin{array}{l}\text { Palma. de } \\
\text { Mallorca, } \\
\text { Spain }\end{array}$ \\
\hline $\begin{array}{l}25-28 \\
\text { February } \\
2006\end{array}$ & Second meeting of the Alliance of Civilizations High-level Group & Doha, Qatar \\
\hline $\begin{array}{l}28-30 \quad \text { May } \\
2006\end{array}$ & Third meeting of the Alliance of Civilizations High-level Group & $\begin{array}{l}\text { Dakar, } \\
\text { Senegal }\end{array}$ \\
\hline $\begin{array}{l}05-06 \\
\text { September } \\
2006\end{array}$ & Working meeting of the Alliance of Civilizations High-level Group & New York \\
\hline $\begin{array}{l}22 \\
\text { September } \\
2006\end{array}$ & $\begin{array}{l}\text { First Ministerial Meeting of the Alliance of Civilizations Group of } \\
\text { Friends at United Nations Headquarters }\end{array}$ & New York \\
\hline $\begin{array}{l}12-13 \\
\text { November } \\
2006\end{array}$ & $\begin{array}{l}\text { Fourth and Final Meeting of the Alliance of Civilizations High-level } \\
\text { Group Presentation of the High-level Group Report to UN-SG Kofi } \\
\text { Annan }\end{array}$ & $\begin{array}{l}\text { Istanbul, } \\
\text { Turkey }\end{array}$ \\
\hline $\begin{array}{l}26 \\
\text { September } \\
2007\end{array}$ & $\begin{array}{l}\text { Second Ministerial Meeting of the Alliance of Civilizations Group } \\
\text { of Friends at the United Nations Headquarters }\end{array}$ & New York \\
\hline $\begin{array}{l}15-16 \\
\text { January } \\
2008\end{array}$ & $\begin{array}{l}\text { First Alliance of Civilizations Forum and the Third Ministerial } \\
\text { Meeting of the Alliance of Civilizations Group of Friends }\end{array}$ & $\begin{array}{l}\text { Madrid, } \\
\text { Spain }\end{array}$ \\
\hline $\begin{array}{l}24 \\
\text { September } \\
2008 \\
\end{array}$ & $\begin{array}{l}\text { Fourth Ministerial Meeting of the Alliance of Civilizations Group of } \\
\text { Friends at United Nations Headquarters }\end{array}$ & New York \\
\hline $\begin{array}{l}2-3 \text { October } \\
2008\end{array}$ & $\begin{array}{l}\text { First Meeting of the Focal Points of the Alliance of Civilizations } \\
\text { Group of Friends. }\end{array}$ & $\begin{array}{l}\text { Paris, } \\
\text { France }\end{array}$ \\
\hline $\begin{array}{ll}6-7 & \text { April } \\
2009 & \\
\end{array}$ & $\begin{array}{l}\text { Second Alliance of Civilizations Forum and the Fifth Ministerial } \\
\text { Meeting of the Alliance of Civilizations' Group of Friends }\end{array}$ & $\begin{array}{l}\text { Istanbul, } \\
\text { Turkey }\end{array}$ \\
\hline 8 April 2009 & $\begin{array}{l}\text { Second Meeting of the Focal Points of the Alliance of Civilizations' } \\
\text { Group of Friends. }\end{array}$ & $\begin{array}{l}\text { Istanbul, } \\
\text { Turkey }\end{array}$ \\
\hline $\begin{array}{l}26 \\
\text { September } \\
09\end{array}$ & $\begin{array}{l}\text { Sixth Ministerial Meeting of the Alliance of Civilizations Group of } \\
\text { Friends at United Nations Headquarters }\end{array}$ & New York \\
\hline
\end{tabular}


Appendix 3 - Documents on International Meetings and Conferences

\begin{tabular}{|c|c|c|}
\hline $\begin{array}{l}10-11 \\
\text { November } \\
2009\end{array}$ & $\begin{array}{l}\text { Third Meeting of the Focal Points of the Alliance of Civilizations' } \\
\text { Group of Friends. }\end{array}$ & $\begin{array}{l}\text { Rabat, } \\
\text { Kingdom of } \\
\text { Morocco }\end{array}$ \\
\hline 27 May 2010 & $\begin{array}{l}\text { Fifth Meeting of the Focal Points of the Alliance of Civilizations' } \\
\text { Group of Friends }\end{array}$ & $\begin{array}{l}\text { Rio de } \\
\text { Janeiro, } \\
\text { Brazil }\end{array}$ \\
\hline $\begin{array}{ll}27-29 & \text { May } \\
2010 & \end{array}$ & $\begin{array}{l}\text { Third Alliance of Civilizations. Forum and the Seventh Ministerial } \\
\text { Meeting of the Alliance of Civilizations Group of Friends at the } \\
\text { Third UNAOC Forum }\end{array}$ & $\begin{array}{l}\text { Rio de } \\
\text { Janeiro, } \\
\text { Brazil }\end{array}$ \\
\hline $\begin{array}{l}24 \\
\text { September } \\
2010\end{array}$ & $\begin{array}{l}\text { Seventh Ministerial Meeting of the Alliance of Civilizations Group } \\
\text { of Friends at United Nations Headquarters. }\end{array}$ & New York \\
\hline $\begin{array}{l}25-27 \\
\text { October } \\
2010\end{array}$ & $\begin{array}{l}\text { Fifth Meeting of the Focal Points of the Alliance of Civilizations' } \\
\text { Group of Friends }\end{array}$ & $\begin{array}{l}\text { Berlin, } \\
\text { Germany }\end{array}$ \\
\hline $\begin{array}{l}23 \\
\text { September } \\
2011\end{array}$ & $\begin{array}{l}\text { Eighth Ministerial Meeting of the Alliance of Civilizations' Group } \\
\text { of Friends at United Nations Headquarters }\end{array}$ & New York \\
\hline $\begin{array}{l}2 \text { November } \\
2011\end{array}$ & $\begin{array}{l}\text { Sixth meeting of the Focal Points of the Alliance of Civilizations' } \\
\text { Group of Friends }\end{array}$ & $\begin{array}{l}\text { Lisbon, } \\
\text { Portugal }\end{array}$ \\
\hline $\begin{array}{l}11-13 \\
\text { December } \\
2011\end{array}$ & $\begin{array}{l}\text { Fourth Alliance of Civilizations Forum and the Ninth Ministerial } \\
\text { Meeting of the Alliance of Civilizations Group of Friends }\end{array}$ & Doha, Qatar \\
\hline $\begin{array}{l}31 \quad \text { May-1 } \\
\text { June } 2012\end{array}$ & First Partners Forum for the Alliance of Civilizations & $\begin{array}{l}\text { Istanbul, } \\
\text { Turkey }\end{array}$ \\
\hline
\end{tabular}

